\title{
PESQUISA EM ONTOPSICOLOGIA NO BRASIL
}

\section{FACULDADE ANTONIO MENEGHETTI (AMF) \\ FUNDAÇÃO ANTONIO MENEGHETTI PESQUISA CIENTÍFICA HUMANISTA CULTURAL EDUCACIONAL}

Este levantamento de Estado da Arte apresenta as pesquisas científicas realizadas em âmbito brasileiro nas instâncias Stricto Sensu em Cursos de Doutorado (Teses de Doutorado) e Cursos de Mestrado (Dissertações de Mestrado), Lato Sensu em Cursos de Especialização e MBA's (Trabalhos de Conclusão de Curso - TCC), em nível de Graduação (Trabalhos de Conclusão de Curso - TCC). Na sequência também apresenta Artigos Científicos publicados em Periódicos Científicos, Trabalhos apresentados em Congressos na área e/ou áreas afins (em nível nacional e internacional), Capítulos de Livros e Livros Publicados. São apresentados ainda textos de pesquisas provenientes de trabalhos de Iniciação Científica na área, em nível de Cursos de Graduação (por exemplo, as Pequenas Teses no Curso de Bacharelado em Ontopsicologia).

A todos os autores que são pesquisadores científicos e atuam também na docência no ensino superior em instituições de ensino superior (IES) no Brasil, que possuem Currículo Lattes cadastrado na Plataforma Lattes (http://lattes.cnpq.br/) do CNPq (Conselho Nacional de Desenvolvimento Científico e Tecnológico), foi inserido o endereço eletrônico do respectivo Currículo Lattes abaixo o nome do autor nas planilhas do levantamento realizado.

Período alcançado: início no ano de 1973 à hoje.

Elaborado por: Curso de Bacharelado em Ontopsicologia e Núcleo Interdisciplinar de Pesquisa da Faculdade Antonio Meneghetti (NIP), maio a novembro de 2019. 


\section{Sumário}

TESES DE DOUTORADO

DISSERTAÇÕES DE MESTRADO

TRABALHOS DE CONCLUSÃO DE CURSO (TCC) DE CURSO DE ESPECIALIZAÇÃO LATO SENSU

TRABALHOS DE CONCLUSÃO DE CURSO (TCC) DE CURSO DE

MBA LATO SENSU

LIVROS PUBLICADOS COM FUNDAMENTAÇÃO TEÓRICA NA CIÊNCIA ONTOPSICOLÓGICA NO BRASIL

CAPÍTULOS DE LIVROS PUBLICADOS COM FUNDAMENTAÇÃO TEÓRICA E RELATOS DE PESQUISAS EXPERIMENTAIS NA CIÊNCIA ONTOPSICOLÓGICA NO BRASIL..96 ARTIGOS CIENTÍFICOS COM FUNDAMENTAÇÃO NA CIÊNCIA ONTOPSICOLÓGICA PUBLICADOS NO BRASIL (PESQUISA TEÓRICA E PESQUISA EXPERIMENTAL).....110 TRABALHOS APRESENTADOS E PUBLICADOS EM ANAIS DE CONGRESSOS NACIONAIS E INTERNACIONAIS

TRABALHOS DE INICIAÇÃO CIENTÍFICA FINALIZADOS E AINDA NÃO PUBLICADOS

MOSTRAS DE INICIAÇÃO CIENTÍFICA DO CURSO DE BACHARELADO EM ONTOPSICOLOGIA.

\section{TESES DE DOUTORADO}


Saber Humano, ISSN 2446-6298, V. 9, n. 15, p. 186-423, jul./dez. 2019.

\begin{tabular}{|c|c|c|c|c|c|c|}
\hline № & Autor & Curso/Programa & Universidade & Título & Orientador & Ano \\
\hline 1 & $\begin{array}{l}\text { Ângelo Accorsi Moreira } \\
\text { http://buscatextual.cnpq.br/buscatextual/ } \\
\text { visualizacv.do?id=K4771598A2 }\end{array}$ & $\begin{array}{l}\text { Doutorado em } \\
\text { Psicologia Clínica, } \\
\text { Programa de } \\
\text { PósGraduação em } \\
\text { Psicologia da Pontifícia } \\
\text { Universidade Católica de } \\
\text { São Paulo (PUC-SP). }\end{array}$ & $\begin{array}{l}\text { Universidade } \\
\text { Católica de São } \\
\text { Paulo (PUC-SP). }\end{array}$ & $\begin{array}{l}\text { Psicoterapia } \\
\text { Ontopsicológica: a } \\
\text { formação do } \\
\text { Ontoterapeuta }\end{array}$ & $\begin{array}{l}\text { Profa Drạ } \\
\text { Marlise } \\
\text { Bassani }\end{array}$ & 2019 \\
\hline 2 & $\begin{array}{l}\text { Ricardo Schaefer } \\
\text { http://buscatextual.cnpq.br/buscatextual/ } \\
\text { visualizacv.do?metodo=apresentar\&id=K4 } \\
764272 Z 0\end{array}$ & $\begin{array}{l}\text { Doutorado em } \\
\text { Administração } \\
\text { Programa de } \\
\text { PósGraduação em } \\
\text { Administração da UFSM }\end{array}$ & $\begin{array}{l}\text { Universidade } \\
\text { Federal de Santa } \\
\text { Maria (UFSM) }\end{array}$ & $\begin{array}{l}\text { Empreender } \\
\text { como uma forma } \\
\text { de ser, saber e } \\
\text { fazer: o } \\
\text { desenvolvimento } \\
\text { da mentalidade e } \\
\text { do } \\
\text { comportamento } \\
\text { empreendedores } \\
\text { por meio da } \\
\text { educação } \\
\text { empreendedora }\end{array}$ & $\begin{array}{l}\text { Prof. Dr. Ítalo } \\
\text { Fernando } \\
\text { Minello }\end{array}$ & 2018 \\
\hline 3 & $\begin{array}{l}\text { Érico de Lima Azevedo } \\
\text { http://buscatextual.cnpq.br/buscatextual/ } \\
\text { visualizacv.do?metodo=apresentar\&id=K4 } \\
\text { 795585H8 }\end{array}$ & $\begin{array}{l}\text { Doutorado em } \\
\text { Engenharia Elétrica } \\
\text { Programa de } \\
\text { PósGraduação em } \\
\text { Engenharia Elétrica da }\end{array}$ & $\begin{array}{l}\text { Universidade } \\
\text { Estadual de } \\
\text { Campinas } \\
\text { (UNICAMP) }\end{array}$ & $\begin{array}{l}\text { Campos } \\
\text { Semânticos: } \\
\text { experimentação e } \\
\text { síntese teórica }\end{array}$ & $\begin{array}{l}\text { Prof. Dr. José } \\
\text { Pissolato } \\
\text { Filho }\end{array}$ & $\begin{array}{l}\text { Doutorado } \\
\quad \text { em } \\
\text { andamen } \\
\text { to desde } \\
2014\end{array}$ \\
\hline & & UNICAMP & & & & \\
\hline
\end{tabular}




\begin{tabular}{|c|c|c|c|c|c|c|}
\hline 4 & $\begin{array}{l}\text { Claudiane Weber } \\
\text { http://buscatextual.cnpq.br/buscatextual/ } \\
\text { visualizacv.do?metodo=apresentar\&id=K4 } \\
\text { 258687A7 }\end{array}$ & $\begin{array}{l}\text { Doutorado em Ciências } \\
\text { da } \\
\text { Informação/Programa } \\
\text { de Pós-Graduação em } \\
\text { Ciências da Informação } \\
\text { da USP com período } \\
\text { sanduíche na Abo } \\
\text { Akademi University na } \\
\text { Finlândia }\end{array}$ & $\begin{array}{l}\text { Universidade de } \\
\text { São Paulo (USP) } \\
\text { com período } \\
\text { sanduíche na Abo } \\
\text { Akademi } \\
\text { University na } \\
\text { Finlândia }\end{array}$ & $\begin{array}{l}\text { A imagem } \\
\text { fotográfica e seus } \\
\text { usos: } \\
\text { aproximações da } \\
\text { Ontopsicologia } \\
\text { com a Ciência da } \\
\text { Informação }\end{array}$ & $\begin{array}{l}\text { Profa Drạ } \\
\text { Sueli Mara } \\
\text { Soares Pinto } \\
\text { Ferreira e } \\
\text { coorientação } \\
\text { da } \\
\text { Profa Drạ } \\
\text { Jannica } \\
\text { Heinström } \\
\text { (na } \\
\text { universidade } \\
\text { na Finlândia) }\end{array}$ & 2018 \\
\hline 5 & $\begin{array}{l}\text { Érico de Lima Azevedo } \\
\text { http://buscatextual.cnpq.br/buscatextual/ } \\
\text { visualizacv.do?metodo=apresentar\&id=K4 } \\
\text { 795585H8 }\end{array}$ & $\begin{array}{l}\text { Doutorado em } \\
\text { Psicologia } \\
\text { Programa de Pós- } \\
\text { Graduação em } \\
\text { Psicologia da PUC-SP }\end{array}$ & $\begin{array}{l}\text { Pontifícia } \\
\text { Universidade } \\
\text { Católica de São } \\
\text { Paulo (PUC-SP) }\end{array}$ & $\begin{array}{l}\text { O método } \\
\text { ontopsicológico } \\
\text { na clínica } \\
\text { psicológica } \\
\text { contemporânea }\end{array}$ & $\begin{array}{l}\text { Profa Dra } \\
\text { Marlise } \\
\text { Aparecida } \\
\text { Bassani }\end{array}$ & 2017 \\
\hline 6 & $\begin{array}{l}\text { Maria Alice Castilho Schuch } \\
\text { http://buscatextual.cnpq.br/buscatextual/ } \\
\text { visualizacv.do?id=K4381719H4 }\end{array}$ & $\begin{array}{l}\text { Doutorado em Ciências } \\
\text { da Educação. } \\
\text { Departamento de } \\
\text { Educação Universidad } \\
\text { Del Mar, UDELMAR, } \\
\text { Chile. }\end{array}$ & $\begin{array}{l}\text { Universidad Del } \\
\text { Mar, UDELMAR, } \\
\text { Chile. }\end{array}$ & $\begin{array}{l}\text { Educação e } \\
\text { gênero: uma } \\
\text { abordagem } \\
\text { pedagógica } \\
\text { ontopsicológica } \\
\text { das relações entre } \\
\text { emocionalidade, }\end{array}$ & $\begin{array}{l}\text { Prof. Dr. } \\
\text { Leopoldo } \\
\text { Briones } \\
\text { Salazar }\end{array}$ & 2017 \\
\hline
\end{tabular}




\begin{tabular}{|c|c|c|c|c|c|c|}
\hline & & & & $\begin{array}{l}\text { prática docente e } \\
\text { grau de satisfação } \\
\text { pessoal e } \\
\text { profissional dos } \\
\text { municípios de } \\
\text { Restinga Seca e } \\
\text { São João do } \\
\text { Polêsine na região } \\
\text { central do } \\
\text { Rio Grande do } \\
\text { Sul }\end{array}$ & & \\
\hline 7 & $\begin{array}{l}\text { Helena Biasotto } \\
\text { http://buscatextual.cnpq.br/buscatextual/ } \\
\text { visualizacv.do?metodo=apresentar\&id=K4 } \\
\text { 776562E0 }\end{array}$ & $\begin{array}{l}\text { Doutorado em } \\
\text { Educação } \\
\text { Programa de } \\
\text { PósGraduação em } \\
\text { Educação da } \\
\text { Universidade SEK }\end{array}$ & $\begin{array}{l}\text { Universidade SEK } \\
\text { de Santiago do } \\
\text { Chile, Chile }\end{array}$ & $\begin{array}{l}\text { Impactos da } \\
\text { formação } \\
\text { ontopsicológica } \\
\text { nos egressos da } \\
\text { educação superior } \\
\text { da Antonio } \\
\text { Meneghetti } \\
\text { Faculdade }\end{array}$ & $\begin{array}{l}\text { Prof. Dr. } \\
\text { Enrique } \\
\text { Sepúlveda } \\
\text { Donoso }\end{array}$ & 2016 \\
\hline 8 & $\begin{array}{l}\text { Rafael Padilha dos Santos } \\
\text { http://buscatextual.cnpq.br/buscatextual/ } \\
\text { visualizacv.do?metodo=apresentar\&id=K4 } \\
\text { 737412D6 }\end{array}$ & $\begin{array}{l}\text { Doutorado em Ciência } \\
\text { Jurídica } \\
\text { Programa de } \\
\text { PósGraduação em } \\
\text { Ciência } \\
\text { Jurídica da }\end{array}$ & $\begin{array}{l}\text { Universidade do } \\
\text { Vale do Itajaí } \\
\text { (UNIVALI) com } \\
\text { período sanduíche } \\
\text { na } \\
\text { Università degli } \\
\text { Studi di Perugia }\end{array}$ & $\begin{array}{l}\text { O princípio da } \\
\text { dignidade da } \\
\text { pessoa humana } \\
\text { como regulador } \\
\text { da economia no } \\
\text { espaço }\end{array}$ & $\begin{array}{l}\text { Prof. Dr. Liton } \\
\text { Lanes Pilau } \\
\text { Sobrinho e co- } \\
\text { orientação do } \\
\text { Prof. D. } \\
\text { Maurizio } \\
\text { Oliviero (na }\end{array}$ & 2015 \\
\hline
\end{tabular}


Saber Humano, ISSN 2446-6298, V. 9, n. 15, p. 186-423, jul./dez. 2019.

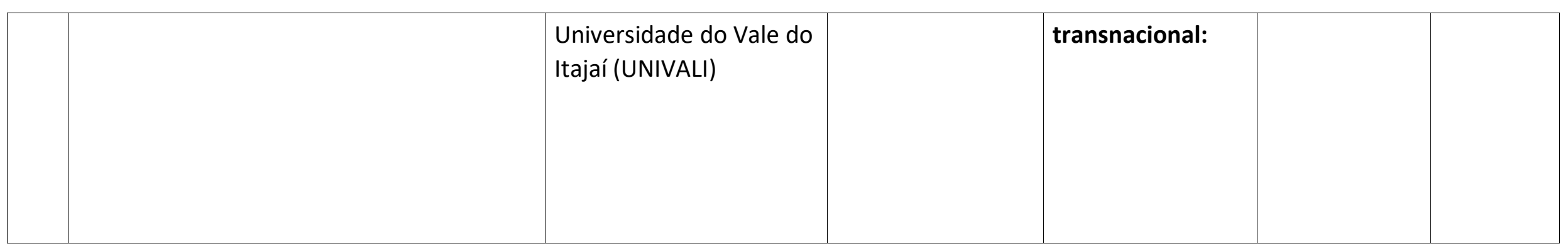

\begin{tabular}{|c|c|c|c|c|c|c|}
\hline & & & $\begin{array}{l}\text { (em Perugia, } \\
\text { Itália) }\end{array}$ & $\begin{array}{l}\text { uma proposta de } \\
\text { economia } \\
\text { humanista }\end{array}$ & $\begin{array}{l}\text { universidade } \\
\text { da Itália) }\end{array}$ & \\
\hline
\end{tabular}


Saber Humano, ISSN 2446-6298, V. 9, n. 15, p. 186-423, jul./dez. 2019.

\begin{tabular}{|c|c|c|c|c|c|c|}
\hline 10 & $\begin{array}{l}\text { Annalisa Cangelosi } \\
\text { http://buscatextual.cnpq.br/buscatextual/ } \\
\text { visualizacv.do?id=K8049758H1 }\end{array}$ & $\begin{array}{l}\text { Doutorado em } \\
\text { Pedagogia Experimental } \\
\text { pela Università degli } \\
\text { Studi di Roma "La } \\
\text { Sapienza", UNIROMA. }\end{array}$ & $\begin{array}{l}\text { Università degli } \\
\text { Studi di Roma "La } \\
\text { Sapienza", } \\
\text { UNIROMA }\end{array}$ & $\begin{array}{l}\text { La lezione } \\
\text { universitaria. } \\
\text { Insegnamento } \\
\text { efficace e percorsi } \\
\text { di formazione dei } \\
\text { docenti }\end{array}$ & $\begin{array}{l}\text { Prof. Dr. Pietro } \\
\text { Lucisano }\end{array}$ & 2012 \\
\hline \multirow[t]{2}{*}{11} & $\begin{array}{l}\text { Josemar Sidinei Soares } \\
\text { http://buscatextual.cnpq.br/buscatextual/ } \\
\text { visualizacv.do?id=K4706660P7 }\end{array}$ & $\begin{array}{l}\text { Doutorado em Filosofia } \\
\text { Programa de } \\
\text { PósGraduação em } \\
\text { Filosofia da Universidade } \\
\text { Federal do Rio Grande } \\
\text { do Sul } \\
\text { (UFRGS) }\end{array}$ & $\begin{array}{l}\text { Universidade } \\
\text { Federal do Rio } \\
\text { Grande do Sul } \\
\text { (UFRGS) }\end{array}$ & $\begin{array}{l}\text { Consciência-de-si } \\
\text { e } \\
\text { reconhecimento } \\
\text { na } \\
\text { Fenomenologia } \\
\text { do Espírito e suas } \\
\text { implicações na } \\
\end{array}$ & $\begin{array}{l}\text { Prof. Dr. } \\
\text { Denis Lerrer } \\
\text { Rosenfield }\end{array}$ & 2009 \\
\hline & & & & $\begin{array}{l}\text { Filosofia do } \\
\text { Direito }\end{array}$ & & \\
\hline 12 & $\begin{array}{l}\text { Adriane Maria Moro Mendes } \\
\text { http://buscatextual.cnpq.br/buscatextual/ } \\
\text { visualizacv.do?metodo=apresentar\&id=K4 } \\
\text { 705318A6 }\end{array}$ & $\begin{array}{l}\text { Doutorado em } \\
\text { Engenharia e Gestão do } \\
\text { Conhecimento } \\
\text { Programa de } \\
\text { PósGraduação em } \\
\text { Engenharia e Gestão do } \\
\text { Conhecimento da UFSC }\end{array}$ & $\begin{array}{l}\text { Universidade } \\
\text { Federal de Santa } \\
\text { Catarina (UFSC) }\end{array}$ & $\begin{array}{l}\text { Método para a } \\
\text { Gestão do } \\
\text { Conhecimento em } \\
\text { Iniciação } \\
\text { Científica segundo } \\
\text { os pressupostos } \\
\text { da Ontopsicologia }\end{array}$ & $\begin{array}{l}\text { Prof. Dr. Prof. } \\
\text { Dr. Silvio } \\
\text { Serafim da } \\
\text { Luz Filho }\end{array}$ & 2009 \\
\hline
\end{tabular}


Saber Humano, ISSN 2446-6298, V. 9, n. 15, p. 186-423, jul./dez. 2019.

\begin{tabular}{|l|l|l|l|l|l|}
\hline 13 & Estela Maris Giordani & $\begin{array}{l}\text { Doutorado em } \\
\text { Educação } \\
\text { Departamento de } \\
\text { Educação da } \\
\text { Universidade Estadual } \\
\text { de Campinas, UNICAMP }\end{array}$ & $\begin{array}{l}\text { Universidade } \\
\text { Estadual de } \\
\text { Campinas, } \\
\text { UNICAMP } \\
\text { visualizacv.do?id=K4727982D6 }\end{array}$ & $\begin{array}{l}\text { Relaçães } \\
\text { Interdisciplinares } \\
\text { na Pedagogia: } \\
\text { Piaget e } \\
\text { Montessori }\end{array}$ & $\begin{array}{l}\text { Profa. Dra. } \\
\text { Carmem } \\
\text { Maria } \\
\text { Andrade }\end{array}$ \\
\hline 14 & Alécio Vidor & $\begin{array}{l}\text { Doutorado em Filosofia } \\
\text { Departamento de } \\
\text { Filosofia, Pontifícia } \\
\text { Universidade Santo } \\
\text { Tomás de Aquino de } \\
\text { Roma (PUCST) }\end{array}$ & $\begin{array}{l}\text { Pontifícia } \\
\text { Universidade } \\
\text { Santo Tomás de } \\
\text { Aquino, Roma } \\
\text { (PUCST) }\end{array}$ & $\begin{array}{l}\text { Rogers e a } \\
\text { Educação Não } \\
\text { Diretiva }\end{array}$ & $\begin{array}{l}\text { Prof. Dr. } \\
\text { Antonio } \\
\text { visualizacv.do?id=K4780240A3 }\end{array}$ \\
\hline
\end{tabular}

\section{DISSERTAÇÕES DE MESTRADO}


Saber Humano, ISSN 2446-6298, V. 9, n. 15, p. 186-423, jul./dez. 2019.

\begin{tabular}{|c|c|c|c|c|c|c|}
\hline 1 & $\begin{array}{l}\text { Eloy Demarchi Teixeira } \\
\text { http://buscatextual.cnpq.br/buscatextual/ } \\
\text { visualizacv.do?id=K8461039H7 }\end{array}$ & $\begin{array}{l}\text { Mestrado em } \\
\text { Administração } \\
\text { Programa de Pós- } \\
\text { Graduação em } \\
\text { Administração da } \\
\text { Universidade de Passo } \\
\text { Fundo (UPF) }\end{array}$ & $\begin{array}{l}\text { Universidade de } \\
\text { Passo Fundo } \\
\text { (UPF) }\end{array}$ & $\begin{array}{l}\text { A aplicação da } \\
\text { Formação } \\
\text { Ontopsicológica } \\
\text { Interdisciplinar } \\
\text { Liderística na } \\
\text { formação do } \\
\text { profissional de } \\
\text { Administração }\end{array}$ & $\begin{array}{l}\text { Profa Dra } \\
\text { Anelise } \\
\text { Rebelato } \\
\text { Mozzato }\end{array}$ & $\begin{array}{l}\text { Em } \\
\text { anda } \\
\text { ment } \\
\text { o }\end{array}$ \\
\hline 2 & $\begin{array}{l}\text { Nathália Thomazini Perin } \\
\text { http://buscatextual.cnpq.br/buscatextual/ } \\
\text { visualizacv.do?id=K4806155J3 }\end{array}$ & $\begin{array}{l}\text { Mestrado em } \\
\text { Psicologia } \\
\text { Programa de Pós- } \\
\text { Graduação em } \\
\text { Psicologia da } \\
\text { Pontifícia } \\
\text { Universidade Católica } \\
\text { de São Paulo (PUC-SP) }\end{array}$ & $\begin{array}{l}\text { Pontifícia } \\
\text { Universidade } \\
\text { Católica de São } \\
\text { Paulo (PUC-SP) }\end{array}$ & $\begin{array}{l}\text { A Psicoterapia } \\
\text { Ontopsicológica: um } \\
\text { mapeamento } \\
\text { bibliográfico do } \\
\text { período de } 2007 \text { a } \\
2018\end{array}$ & $\begin{array}{l}\text { Profa. Dra. Ida } \\
\text { Elizabeth } \\
\text { Cardinalli }\end{array}$ & 2018 \\
\hline 3 & $\begin{array}{l}\text { Ricardo Schaefer } \\
\text { http://buscatextual.cnpq.br/buscatextual/ } \\
\text { visualizacv.do?metodo=apresentar\&id=K4 } \\
764272 Z 0\end{array}$ & $\begin{array}{l}\text { Mestrado em } \\
\text { Comunicação } \\
\text { Programa de } \\
\text { PósGraduação em } \\
\text { Ciências da } \\
\text { Comunicação } \\
\text { Universidade Federal } \\
\text { de Santa Maria }\end{array}$ & $\begin{array}{l}\text { Universidade } \\
\text { Federal de Santa } \\
\text { Maria (UFSM) }\end{array}$ & $\begin{array}{l}\text { O líder em Exame: o } \\
\text { enquadramento da } \\
\text { liderança na mídia de } \\
\text { negócios }\end{array}$ & $\begin{array}{l}\text { Prof. a Dra. } \\
\text { Rejane de } \\
\text { Oliveira } \\
\text { Pozobon }\end{array}$ & 2014 \\
\hline
\end{tabular}


Saber Humano, ISSN 2446-6298, V. 9, n. 15, p. 186-423, jul./dez. 2019.

\begin{tabular}{|c|c|c|c|c|c|c|}
\hline & & (UFSM) & & & & \\
\hline 4 & $\begin{array}{l}\text { Viviane Elias Portela } \\
\text { http://buscatextual.cnpq.br/buscatextual/ } \\
\text { visualizacv.do?id=K4440459A4 }\end{array}$ & $\begin{array}{l}\text { Mestrado em } \\
\text { Educação } \\
\text { Programa de } \\
\text { PósGraduação em } \\
\text { Educação } \\
\text { Universidade Federal } \\
\text { de Santa Maria } \\
\text { (UFSM) }\end{array}$ & $\begin{array}{l}\text { Universidade } \\
\text { Federal de Santa } \\
\text { Maria (UFSM) }\end{array}$ & $\begin{array}{l}\text { Projeto Flauta na } \\
\text { Educação Musical: } \\
\text { um estudo com } \\
\text { entrevistas em São } \\
\text { João do Polêsine-RS }\end{array}$ & $\begin{array}{l}\text { Profa. Drạ. } \\
\text { Cláudia Ribeiro } \\
\text { Bellochio }\end{array}$ & 2014 \\
\hline 5 & $\begin{array}{l}\text { Maria Alice Castilho Schuch } \\
\text { http://lattes.cnpq.br/5768202542112018 }\end{array}$ & $\begin{array}{l}\text { Mestrado em } \\
\text { Educação } \\
\text { Departamento de } \\
\text { Educação } \\
\text { Universidad Del Mar, } \\
\text { UDELMAR, Chile }\end{array}$ & $\begin{array}{l}\text { Universidad Del } \\
\text { Mar, UDELMAR, } \\
\text { Chile }\end{array}$ & $\begin{array}{l}\text { A relação } \\
\text { pedagógica: } \\
\text { Abordagem } \\
\text { Ontopsicológica. } \\
\text { Dificuldade dos } \\
\text { professores da } \\
\text { Educação Básica em } \\
\text { duas escolas com alto } \\
\text { índice de repetência, } \\
\text { evasão ou frequência } \\
\text { ocasional da Região } \\
\text { Central do Rio } \\
\text { Grande do Sul, } \\
\text { Brasil. }\end{array}$ & $\begin{array}{l}\text { Prof. Dr. } \\
\text { Fernando Paste } \\
\text { Cordovez }\end{array}$ & 2013 \\
\hline
\end{tabular}


Saber Humano, ISSN 2446-6298, V. 9, n. 15, p. 186-423, jul./dez. 2019.

\begin{tabular}{|c|c|c|c|c|c|c|}
\hline 6 & $\begin{array}{l}\text { Maria Tereza Andreola } \\
\text { http://buscatextual.cnpq.br/buscatextual/ } \\
\text { visualizacv.do?id=K4292658H4 }\end{array}$ & $\begin{array}{l}\text { Mestrado em Ciências } \\
\text { da Saúde Programa de } \\
\text { Pós- } \\
\text { Graduação em } \\
\text { Ciências da Saúde } \\
\text { Universidade do Sul de } \\
\text { Santa Catarina } \\
\text { (UNISUL) }\end{array}$ & $\begin{array}{l}\text { Universidade do } \\
\text { Sul de Santa } \\
\text { Catarina (UNISUL) }\end{array}$ & $\begin{array}{l}\text { Qualidade de vida e } \\
\text { características de } \\
\text { personalidade de } \\
\text { pessoas que vivem } \\
\text { com Aids }\end{array}$ & $\begin{array}{l}\text { Profa. Dra } \\
\text { Rosemeri } \\
\text { Maurici da Silva }\end{array}$ & 2013 \\
\hline 7 & $\begin{array}{l}\text { Ana Claudia Valentini Montenegro } \\
\text { http://buscatextual.cnpq.br/buscatextual/ } \\
\text { visualizacv.do?id=K4737094Z0 }\end{array}$ & $\begin{array}{l}\text { Mestrado em } \\
\text { Administração de } \\
\text { Empresas } \\
\text { Programa de Pós- } \\
\text { Graduação em } \\
\text { Administração de } \\
\text { Empresas } \\
\text { Universidade } \\
\text { Presbiteriana } \\
\text { Makenzie, São Paulo } \\
\text { (MAKENZIE) }\end{array}$ & $\begin{array}{l}\text { Universidade } \\
\text { Presbiteriana } \\
\text { Makenzie, São } \\
\text { Paulo } \\
\text { (MAKENZIE) }\end{array}$ & $\begin{array}{l}\text { A Formação de } \\
\text { Líderes segundo a } \\
\text { Ontopsicologia }\end{array}$ & $\begin{array}{l}\text { Prof. Dr. } \\
\text { Diógenes de } \\
\text { Souza Bido }\end{array}$ & 2012 \\
\hline
\end{tabular}


Saber Humano, ISSN 2446-6298, V. 9, n. 15, p. 186-423, jul./dez. 2019.

\begin{tabular}{|c|c|c|c|c|c|c|}
\hline 8 & $\begin{array}{l}\text { Carolina Schuskel Miranda } \\
\text { http://buscatextual.cnpq.br/buscatextual/ } \\
\text { visualizacv.do?id=K4467858A3 }\end{array}$ & $\begin{array}{l}\text { Mestrado em } \\
\text { Educação, Arte e } \\
\text { História da Cultura } \\
\text { Programa de Pós- } \\
\text { Graduação em } \\
\text { Educação, Arte e } \\
\text { História da Cultura } \\
\text { Universidade } \\
\text { Presbiteriana }\end{array}$ & $\begin{array}{l}\text { Universidade } \\
\text { Presbiteriana } \\
\text { Mackenzie, São } \\
\text { Paulo } \\
\text { (MACKENZIE) }\end{array}$ & $\begin{array}{l}\text { O processo criativo de } \\
\text { uma agência } \\
\text { publicitária a partir } \\
\text { dos princípios da } \\
\text { Ontopsicologia e da } \\
\text { OntoArte }\end{array}$ & $\begin{array}{l}\text { Profa. Dra. } \\
\text { Mirian Celeste } \\
\text { Ferreira Dias } \\
\text { Martins }\end{array}$ & 2012 \\
\hline & & $\begin{array}{l}\text { Mackenzie, São Paulo } \\
\text { (MACKENZIE) }\end{array}$ & & & & \\
\hline 9 & $\begin{array}{l}\text { Cláudio Correa Carrara } \\
\text { http://buscatextual.cnpq.br/buscatextual/ } \\
\text { visualizacv.do?id=K4329101U5 }\end{array}$ & $\begin{array}{l}\text { Mestrado em } \\
\text { Administração } \\
\text { Programa de Pós- } \\
\text { Graduação em } \\
\text { Administração } \\
\text { Universidade do Vale } \\
\text { do Rio dos Sinos, São } \\
\text { Leopoldo-RS } \\
\text { (UNISINOS) }\end{array}$ & $\begin{array}{l}\text { Universidade do } \\
\text { Vale do Rio dos } \\
\text { Sinos (UNISINOS) }\end{array}$ & $\begin{array}{l}\text { Uma análise sobre } \\
\text { capacidades em } \\
\text { outsourcing de } \\
\text { tecnologia da } \\
\text { informação: um } \\
\text { estudo no contexto } \\
\text { de manutenção de } \\
\text { aplicações }\end{array}$ & $\begin{array}{l}\text { Profa. Dra. Yeda } \\
\text { Swirski de } \\
\text { Souza }\end{array}$ & 2012 \\
\hline
\end{tabular}


Saber Humano, ISSN 2446-6298, V. 9, n. 15, p. 186-423, jul./dez. 2019.

\begin{tabular}{|c|c|c|c|c|c|c|}
\hline 10 & $\begin{array}{l}\text { Vera Lúcia Rodegheri } \\
\text { http://buscatextual.cnpq.br/buscatextual/ } \\
\text { visualizacv.do?id=K4485711J5 }\end{array}$ & $\begin{array}{l}\text { Mestrado em } \\
\text { Psicologia } \\
\text { Programa de } \\
\text { PósGraduação em } \\
\text { Psicologia } \\
\text { Pontifícia } \\
\text { Universidade Católica } \\
\text { de São Paulo (PUC-SP) }\end{array}$ & $\begin{array}{l}\text { Pontifícia } \\
\text { Universidade } \\
\text { Católica de São } \\
\text { Paulo (PUC-SP) }\end{array}$ & $\begin{array}{l}\text { A Psicoterapia em } 23 \\
\text { Periódicos Nacionais: } \\
\text { uma contribuição à } \\
\text { história da } \\
\text { Psicologia no Brasil }\end{array}$ & $\begin{array}{l}\text { Profa. Dra. } \\
\text { Maria do } \\
\text { Carmo Guedes }\end{array}$ & 2011 \\
\hline & $\begin{array}{l}\text { http://buscatextual.cnpq.br/buscatextual/ } \\
\text { visualizacv.do?metodo=apresentar\&id=K4 } \\
294106 \text { A3 }\end{array}$ & $\begin{array}{l}\text { Programa de } \\
\text { PósGraduação em } \\
\text { Filosofia } \\
\text { Pontifícia } \\
\text { Universidade Católica } \\
\text { de São Paulo (PUC-SP) }\end{array}$ & $\begin{array}{l}\text { Universidade } \\
\text { Católica de São } \\
\text { Paulo (PUC-SP) }\end{array}$ & $\begin{array}{l}\text { Fenomenologia e } \\
\text { Psicologia a partir da } \\
\text { obra } \\
\text { 'Fenomenologia e } \\
\text { Psicologia' (1917) de } \\
\text { Edmund Husserl }\end{array}$ & $\begin{array}{l}\text { Ariel Gonzalez } \\
\text { Porta }\end{array}$ & \\
\hline
\end{tabular}


Saber Humano, ISSN 2446-6298, V. 9, n. 15, p. 186-423, jul./dez. 2019.

\begin{tabular}{|c|c|c|c|c|c|c|}
\hline 13 & $\begin{array}{l}\text { Ângelo Accorsi Moreira } \\
\text { http://buscatextual.cnpq.br/buscatextual/ } \\
\text { visualizacv.do?id=K4771598A2 }\end{array}$ & $\begin{array}{l}\text { Mestrado em } \\
\text { Psicologia } \\
\text { Programa de } \\
\text { PósGraduação em } \\
\text { Psicologia } \\
\text { Pontifícia } \\
\text { Universidade Católica } \\
\text { do Rio Grande do Sul } \\
\text { (PUCRS) }\end{array}$ & $\begin{array}{l}\text { Pontifícia } \\
\text { Universidade } \\
\text { Católica do Rio } \\
\text { Grande do Sul } \\
\text { (PUCRS) }\end{array}$ & $\begin{array}{l}\text { Aprendizagem nas } \\
\text { Organizações: a } \\
\text { relação entre líder } \\
\text { gestor e } \\
\text { colaboradores } \\
\text { estratégicos }\end{array}$ & $\begin{array}{l}\text { Prof. Dr. Nedio } \\
\text { Seminotti }\end{array}$ & 2011 \\
\hline 14 & $\begin{array}{l}\text { Érico de Lima Azevedo } \\
\text { http://buscatextual.cnpq.br/buscatextual/ } \\
\text { visualizacv.do?metodo=apresentar\&id=K4 } \\
\text { 795585H8 }\end{array}$ & $\begin{array}{l}\text { Mestrado em Filosofia } \\
\text { Programa de } \\
\text { PósGraduação em } \\
\text { Filosofia } \\
\text { Pontifícia } \\
\text { Universidade Católica } \\
\text { de São Paulo (PUC-SP) }\end{array}$ & $\begin{array}{l}\text { Pontifícia } \\
\text { Universidade } \\
\text { Católica de São } \\
\text { Paulo (PUC-SP) }\end{array}$ & $\begin{array}{l}\text { A crise das ciências } \\
\text { europeias e a } \\
\text { fenomenologia } \\
\text { transcendental de } \\
\text { Edmund Husserl: } \\
\text { uma apresentação }\end{array}$ & $\begin{array}{l}\text { Prof. Dr. Mário } \\
\text { Ariel Gonzalez } \\
\text { Porta }\end{array}$ & 2011 \\
\hline 15 & $\begin{array}{l}\text { Claudiane Weber } \\
\text { http://buscatextual.cnpq.br/buscatextual/ } \\
\text { visualizacv.do?metodo=apresentar\&id=K4 } \\
\text { 258687A7 }\end{array}$ & $\begin{array}{l}\text { Mestrado em } \\
\text { Engenharia de } \\
\text { Produção } \\
\text { Programa de Pós- } \\
\text { Graduação em } \\
\text { Engenharia de }\end{array}$ & $\begin{array}{l}\text { Universidade } \\
\text { Federal de Santa } \\
\text { Maria (UFSM) }\end{array}$ & $\begin{array}{l}\text { Portal Corporativo } \\
\text { para Gestão do } \\
\text { Conhecimento: } \\
\text { alinhando pessoas, } \\
\text { informação e } \\
\text { estratégia }\end{array}$ & $\begin{array}{l}\text { Prof. Dr. } \\
\text { Rolando J. Soliz } \\
\text { Estrada }\end{array}$ & 2010 \\
\hline & & $\begin{array}{l}\text { Produção da } \\
\text { Universidade Federal } \\
\text { de Santa Maria (UFSM) }\end{array}$ & & $\begin{array}{l}\text { organizacional em } \\
\text { uma Instituição de } \\
\text { Ensino Superior } \\
\text { Privada }\end{array}$ & & \\
\hline
\end{tabular}


Saber Humano, ISSN 2446-6298, V. 9, n. 15, p. 186-423, jul./dez. 2019.

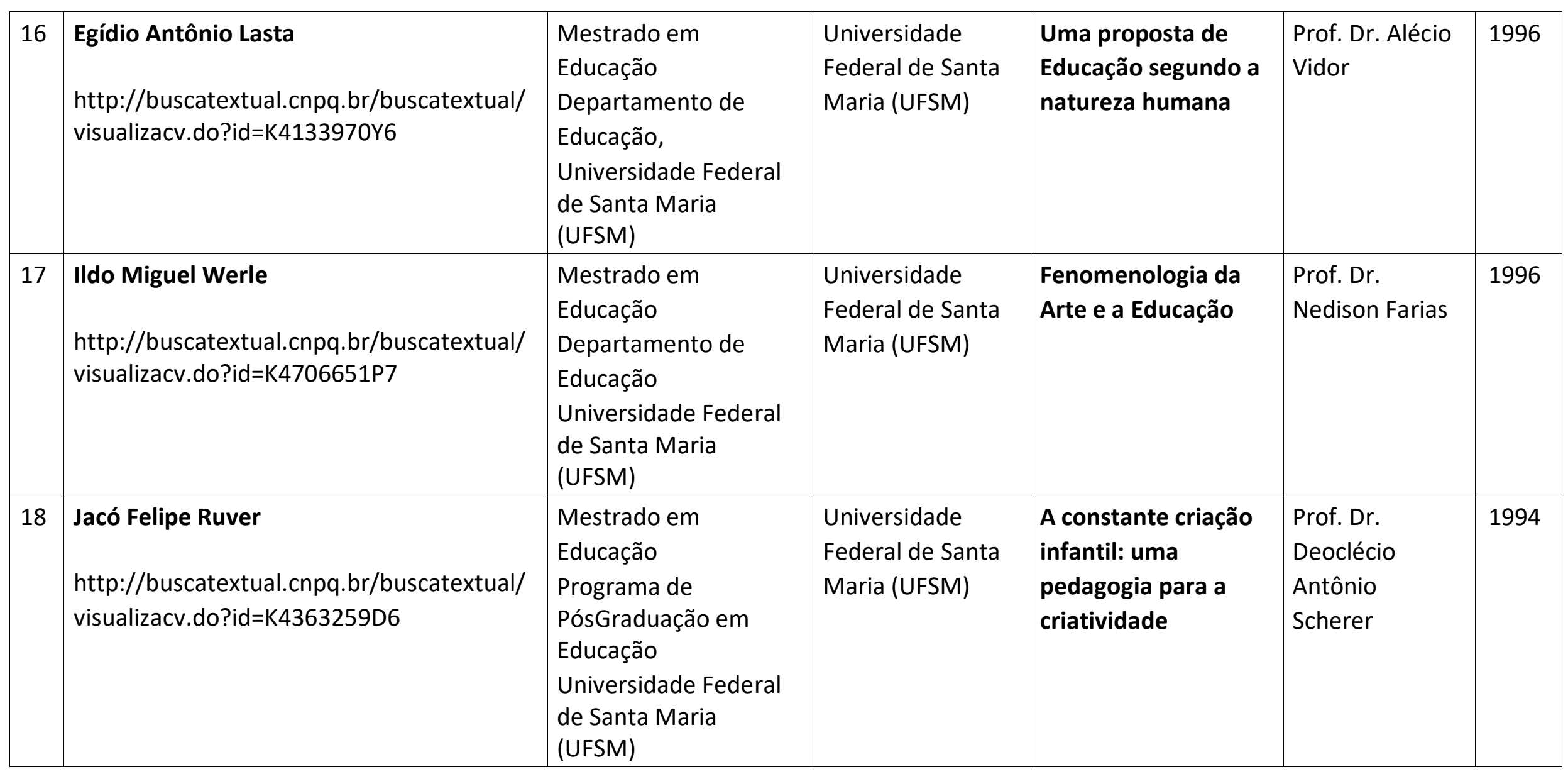


Saber Humano, ISSN 2446-6298, V. 9, n. 15, p. 186-423, jul./dez. 2019.

\begin{tabular}{|c|c|c|c|c|c|c|}
\hline 19 & Denise Bee & $\begin{array}{l}\text { Mestrado em Filosofia } \\
\text { Programa de } \\
\text { PósGraduação em } \\
\text { Filosofia } \\
\text { Universidade Federal } \\
\text { de Santa Maria } \\
\text { (UFSM) }\end{array}$ & $\begin{array}{l}\text { Universidade } \\
\text { Federal de Santa } \\
\text { Maria (UFSM) }\end{array}$ & $\begin{array}{l}\text { Intencionalidade e } \\
\text { subjetividade }\end{array}$ & $\begin{array}{l}\text { Prof. Dr. } \\
\text { Miguel Spinelli }\end{array}$ & 1992 \\
\hline
\end{tabular}




\section{TRABALHOS DE CONCLUSÃO DE CURSO (TCC) DE CURSO DE ESPECIALIZAÇÃO LATO SENSU}

\begin{tabular}{|c|c|c|c|c|c|c|}
\hline № & Autor & Curso/Programa & Universidade & Título & Orientador & Ano \\
\hline 1 & $\begin{array}{l}\text { Vinícius Foletto Montagner } \\
\text { http://buscatextual.cnpq.br/bus } \\
\text { catextual/visualizacv.do?id=K47 } \\
99235 Z 9\end{array}$ & $\begin{array}{l}\text { Especialização em } \\
\text { Ontopsicologia } \\
\text { Faculdade Antonio } \\
\text { Meneghetti (AMF) }\end{array}$ & $\begin{array}{l}\text { Faculdade Antonio } \\
\text { Meneghetti (AMF) }\end{array}$ & $\begin{array}{l}\text { Elementos do processo de } \\
\text { ensino-aprendizagem em } \\
\text { uma perspectiva } \\
\text { ontopsicológica }\end{array}$ & $\begin{array}{l}\text { Profa. Dra } \\
\text { Estela Maris } \\
\text { Giordani }\end{array}$ & 2019 \\
\hline 2 & $\begin{array}{l}\text { Mateus Renard Machado } \\
\text { http://lattes.cnpq.br/077727148 } \\
3931142\end{array}$ & $\begin{array}{l}\text { Especialização em } \\
\text { Ontopsicologia } \\
\text { Faculdade Antonio } \\
\text { Meneghetti (AMF) }\end{array}$ & $\begin{array}{l}\text { Faculdade Antonio } \\
\text { Meneghetti (AMF) }\end{array}$ & $\begin{array}{l}\text { Os estereótipos como } \\
\text { barreira no processo de } \\
\text { ensino-aprendizagem de } \\
\text { conceitos de Filosofia } \\
\text { moral no nível superior }\end{array}$ & $\begin{array}{l}\text { Prof. Dr. } \\
\text { Ricardo } \\
\text { Schaefer }\end{array}$ & 2019 \\
\hline 3 & Anita Brandt & $\begin{array}{l}\text { Especialização em } \\
\text { Ontopsicologia } \\
\text { Faculdade Antonio } \\
\text { Meneghetti (AMF) }\end{array}$ & $\begin{array}{l}\text { Faculdade Antonio } \\
\text { Meneghetti (AMF) }\end{array}$ & $\begin{array}{l}\text { Pedagogia Empresarial: } \\
\text { reflexões sobre a } \\
\text { aplicação da Pedagogia } \\
\text { Ontopsicológica pela } \\
\text { liderança, no contexto } \\
\text { organizacional }\end{array}$ & $\begin{array}{l}\text { Profa. Ms. } \\
\text { Josiane } \\
\text { Beatriz } \\
\text { Piccin } \\
\text { Barbieri }\end{array}$ & 2019 \\
\hline
\end{tabular}


Saber Humano, ISSN 2446-6298, V. 9, n. 15, p. 186-423, jul./dez. 2019.

\begin{tabular}{|c|c|c|c|c|c|c|}
\hline 4 & Jhosué Carlesso & $\begin{array}{l}\text { Especialização em } \\
\text { Ontopsicologia } \\
\text { Faculdade Antonio } \\
\text { Meneghetti (AMF) }\end{array}$ & $\begin{array}{l}\text { Faculdade Antonio } \\
\text { Meneghetti (AMF) }\end{array}$ & $\begin{array}{l}\text { Fisionômica da pessoa, } \\
\text { estética do sorriso e } \\
\text { reconstituição dos valores } \\
\text { do humanismo }\end{array}$ & $\begin{array}{l}\text { Profa. Ms. } \\
\text { Vera Lúcia } \\
\text { Rodegheri }\end{array}$ & 2019 \\
\hline & & & & perene & & \\
\hline 5 & André de Carvalho Fraga & $\begin{array}{l}\text { Especialização em } \\
\text { Ontopsicologia } \\
\text { Faculdade Antonio } \\
\text { Meneghetti (AMF) }\end{array}$ & $\begin{array}{l}\text { Faculdade Antonio } \\
\text { Meneghetti (AMF) }\end{array}$ & $\begin{array}{l}\text { Consultoria } \\
\text { ontopsicológica, o } \\
\text { processo de metanoia do } \\
\text { líder, do âmbito individual } \\
\text { ao âmbito empresarial }\end{array}$ & $\begin{array}{l}\text { Profa. Ms. } \\
\text { Vera Lúcia } \\
\text { Rodegheri }\end{array}$ & 2019 \\
\hline 6 & Gilberto de Souza & $\begin{array}{l}\text { Especialização em } \\
\text { Ontopsicologia } \\
\text { Faculdade Antonio } \\
\text { Meneghetti (AMF) }\end{array}$ & $\begin{array}{l}\text { Faculdade Antonio } \\
\text { Meneghetti (AMF) }\end{array}$ & $\begin{array}{l}\text { Processo de } \\
\text { autossabotagem e } \\
\text { indicações resolutivas no } \\
\text { contexto empresarial }\end{array}$ & $\begin{array}{l}\text { Profa. Ms. } \\
\text { Maria } \\
\text { Tereza } \\
\text { Andreola }\end{array}$ & 2019 \\
\hline 7 & $\begin{array}{l}\text { Claudio Roberto Esteves de } \\
\text { Carvalho }\end{array}$ & $\begin{array}{l}\text { Especialização em } \\
\text { Ontopsicologia } \\
\text { Faculdade Antonio } \\
\text { Meneghetti (AMF) }\end{array}$ & $\begin{array}{l}\text { Faculdade Antonio } \\
\text { Meneghetti (AMF) }\end{array}$ & $\begin{array}{l}\text { A psicologia masculina } \\
\text { negativa punta verme: } \\
\text { suas manifestacões } \\
\text { dinâmicas e efeitos }\end{array}$ & $\begin{array}{l}\text { Profa. Ms. } \\
\text { Maria } \\
\text { Tereza } \\
\text { Andreola }\end{array}$ & 2019 \\
\hline 8 & $\begin{array}{l}\text { Bruna de Franceschi Schirmer } \\
\text { Gindri } \\
\text { http://lattes.cnpq.br/804079316 } \\
9006962\end{array}$ & $\begin{array}{l}\text { Especialização em } \\
\text { Ontopsicologia } \\
\text { Faculdade Antonio } \\
\text { Meneghetti (AMF) }\end{array}$ & $\begin{array}{l}\text { Faculdade Antonio } \\
\text { Meneghetti (AMF) }\end{array}$ & $\begin{array}{l}\text { Estudo exploratório sobre } \\
\text { a causalidade psíquica em } \\
\text { paciene com queixa de } \\
\text { zumbido crônico }\end{array}$ & $\begin{array}{l}\text { Profá. Drạ. } \\
\text { Adriane } \\
\text { Maria Moro } \\
\text { Mendes }\end{array}$ & 2019 \\
\hline
\end{tabular}


Saber Humano, ISSN 2446-6298, V. 9, n. 15, p. 186-423, jul./dez. 2019.

\begin{tabular}{|c|c|c|c|c|c|c|}
\hline 9 & Alaor José Cerolini & $\begin{array}{l}\text { Especialização em } \\
\text { Ontopsicologia } \\
\text { Faculdade Antonio } \\
\text { Meneghetti (AMF) }\end{array}$ & $\begin{array}{l}\text { Faculdade Antonio } \\
\text { Meneghetti (AMF) }\end{array}$ & $\begin{array}{l}\text { Alta performance e } \\
\text { miricismo cotidiano do } \\
\text { líder }\end{array}$ & $\begin{array}{l}\text { Profa. Dra } \\
\text { Estela Maris } \\
\text { Giordani }\end{array}$ & 2019 \\
\hline \multirow[t]{2}{*}{10} & $\begin{array}{l}\text { Djovani Pozzobon } \\
\text { http://lattes.cnpq.br/625465026 } \\
7524583\end{array}$ & $\begin{array}{l}\text { Especialização em } \\
\text { Ontopsicologia } \\
\text { Faculdade Antonio } \\
\text { Meneghetti (AMF) }\end{array}$ & $\begin{array}{l}\text { Faculdade Antonio } \\
\text { Meneghetti (AMF) }\end{array}$ & $\begin{array}{l}\text { Ciência Jurídica e o critério } \\
\text { de refundação epistêmico } \\
\text { segundo a autopoiese } \\
\text { ôntico- }\end{array}$ & $\begin{array}{l}\text { Prof. Dr. } \\
\text { Josemar } \\
\text { Sidinei } \\
\text { Soares }\end{array}$ & 2019 \\
\hline & & & & humanista & & \\
\hline 11 & $\begin{array}{l}\text { Ana Marli Bulegon } \\
\text { http://buscatextual.cnpq.br/bus } \\
\text { catextual/visualizacv.do?id=K45 } \\
\text { 59963D2 }\end{array}$ & $\begin{array}{l}\text { Especialização em } \\
\text { Psicologia com abordagem } \\
\text { em Ontopsicologia } \\
\text { Universidade Estatal de } \\
\text { São Petersburgo, Rússia } \\
\text { (SPbU) }\end{array}$ & $\begin{array}{l}\text { Universidade Estatal } \\
\text { de São Petersburgo, } \\
\text { Rússia (SPbU) }\end{array}$ & $\begin{array}{l}\text { Influência da participação } \\
\text { no jogo de papéis, } \\
\text { segundo o método } \\
\text { “Psicotea", sobre a } \\
\text { aquisição dos } \\
\text { conhecimentos de } \\
\text { Matemática Financeira } \\
\text { pelos estudantes }\end{array}$ & $\begin{array}{l}\text { Profa. Dra } \\
\text { Natalia } \\
\text { Gortchakova }\end{array}$ & 2016 \\
\hline 12 & $\begin{array}{l}\text { Ana Paula Mariano Pregardier } \\
\text { http://lattes.cnpq.br/871035219 } \\
8434928\end{array}$ & $\begin{array}{l}\text { Especialização em } \\
\text { Psicologia com abordagem } \\
\text { em Ontopsicologia } \\
\text { Universidade Estatal de } \\
\text { São Petersburgo, Rússia } \\
\text { (SPbU) }\end{array}$ & $\begin{array}{l}\text { Universidade Estatal } \\
\text { de São Petersburgo, } \\
\text { Rússia (SPbU) }\end{array}$ & $\begin{array}{l}\text { Potencial do jogo de } \\
\text { enredo e papeis na } \\
\text { formação de atitude das } \\
\text { crenças e adolescentes ao } \\
\text { dinheiro }\end{array}$ & $\begin{array}{l}\text { Profa. Dra. } \\
\text { Elena } \\
\text { Volkova }\end{array}$ & 2016 \\
\hline
\end{tabular}


Saber Humano, ISSN 2446-6298, V. 9, n. 15, p. 186-423, jul./dez. 2019.

\begin{tabular}{|c|c|c|c|c|c|c|}
\hline 13 & Joana de Jesus & $\begin{array}{l}\text { Especialização em } \\
\text { Psicologia com abordagem } \\
\text { em Ontopsicologia } \\
\text { Universidade Estatal de } \\
\text { São Petersburgo, Rússia } \\
\text { (SPbU) }\end{array}$ & $\begin{array}{l}\text { Universidade Estatal } \\
\text { de São Petersburgo, } \\
\text { Rússia (SPbU) }\end{array}$ & $\begin{array}{l}\text { Particularidades } \\
\text { sociaispsicológicas das } \\
\text { mulheres líderes no Brasil }\end{array}$ & $\begin{array}{l}\text { Profa. Dra. } \\
\text { Veronica } \\
\text { Odintsova }\end{array}$ & 2016 \\
\hline 14 & $\begin{array}{l}\text { Viviane Elias Portela } \\
\text { http://buscatextual.cnpq.br/bus } \\
\text { catextual/visualizacv.do?id=K44 } \\
\text { 40459A4 }\end{array}$ & $\begin{array}{l}\text { Especialização em } \\
\text { Psicologia com abordagem } \\
\text { em Ontopsicologia } \\
\text { Universidade Estatal de } \\
\text { São Petersburgo, Rússia } \\
\text { (SPbU) }\end{array}$ & $\begin{array}{l}\text { Universidade Estatal } \\
\text { de São Petersburgo, } \\
\text { Rússia (SPbU) }\end{array}$ & $\begin{array}{l}\text { Particularidades } \\
\text { individuais-psicológicas e } \\
\text { atitude ao trabalho dos } \\
\text { vendedores com } \\
\text { diferentes níveis de } \\
\text { eficácia }\end{array}$ & $\begin{array}{l}\text { Profa. Dra. } \\
\text { Elena } \\
\text { Volkova }\end{array}$ & 2016 \\
\hline \multirow[t]{2}{*}{15} & José Luiz Richetti & Especialização em & Universidade Estatal & Peculiaridades pessoais & Profa. Dra. & 2016 \\
\hline & & $\begin{array}{l}\text { Psicologia com abordagem } \\
\text { em Ontopsicologia } \\
\text { Universidade Estatal de } \\
\text { São Petersburgo, Rússia } \\
\text { (SPbU) }\end{array}$ & $\begin{array}{l}\text { de São Petersburgo, } \\
\text { Rússia (SPbU) }\end{array}$ & $\begin{array}{l}\text { dos que se dirigem ao } \\
\text { tribunal para pedir a } \\
\text { indenização moral }\end{array}$ & $\begin{array}{l}\text { Marina } \\
\text { Salitova }\end{array}$ & \\
\hline 16 & Simone Ferri & $\begin{array}{l}\text { Especialização em } \\
\text { Psicologia com abordagem } \\
\text { em Ontopsicologia } \\
\text { Universidade Estatal de } \\
\text { São Petersburgo, Rússia } \\
\text { (SPbU) }\end{array}$ & $\begin{array}{l}\text { Universidade Estatal } \\
\text { de São Petersburgo, } \\
\text { Rússia (SPbU) }\end{array}$ & $\begin{array}{l}\text { Correlações psicológicas } \\
\text { de escolha das imagens } \\
\text { nas pessoas com } \\
\text { diferentes níveis de } \\
\text { bemestar psiológico }\end{array}$ & $\begin{array}{l}\text { Profa. Dra. } \\
\text { Veronica } \\
\text { Odintsova }\end{array}$ & 2016 \\
\hline
\end{tabular}


Saber Humano, ISSN 2446-6298, V. 9, n. 15, p. 186-423, jul./dez. 2019.

\begin{tabular}{|c|c|c|c|c|c|c|}
\hline 17 & Adriana Tomazi & $\begin{array}{l}\text { Especialização em } \\
\text { Psicologia com abordagem } \\
\text { em Ontopsicologia } \\
\text { Universidade Estatal de } \\
\text { São Petersburgo, Rússia } \\
\text { (SPbU) }\end{array}$ & $\begin{array}{l}\text { Universidade Estatal } \\
\text { de São Petersburgo, } \\
\text { Rússia (SPbU) }\end{array}$ & $\begin{array}{l}\text { Dinâmica de } \\
\text { autoavaliação de eficácia } \\
\text { pessoal no resultado do } \\
\text { treinamento de } \\
\text { crescimento pessoal }\end{array}$ & $\begin{array}{l}\text { Profa. Dra. } \\
\text { Marina } \\
\text { Salitova }\end{array}$ & 2016 \\
\hline 18 & Adriana Tomazi & $\begin{array}{l}\text { Especialização em Gestão } \\
\text { do Conhecimento e o } \\
\text { Paradigma } \\
\text { Ontopsicológico } \\
\text { Faculdade Antonio } \\
\text { Meneghetti (AMF) }\end{array}$ & $\begin{array}{l}\text { Faculdade Antonio } \\
\text { Meneghetti (AMF) }\end{array}$ & $\begin{array}{l}\text { A resistência como fator } \\
\text { de impedimento ao } \\
\text { crescimento e à realização }\end{array}$ & $\begin{array}{l}\text { Profa. Ms. } \\
\text { Josiane } \\
\text { Beatriz } \\
\text { Piccin } \\
\text { Barbieri }\end{array}$ & 2016 \\
\hline 19 & Ágatha Cristine Depiné & $\begin{array}{l}\text { Especialização em Gestão } \\
\text { do Conhecimento e o } \\
\text { Paradigma } \\
\text { Ontopsicológico } \\
\text { Faculdade Antonio }\end{array}$ & $\begin{array}{l}\text { Faculdade Antonio } \\
\text { Meneghetti (AMF) }\end{array}$ & $\begin{array}{l}\text { Princípios do sucesso da } \\
\text { Consultoria } \\
\text { Ontopsicológica } \\
\text { Empresarial }\end{array}$ & $\begin{array}{l}\text { Prof. Dr. } \\
\text { Érico de } \\
\text { Lima } \\
\text { Azevedo }\end{array}$ & 2016 \\
\hline & & Meneghetti (AMF) & & & & \\
\hline 20 & Alessandra Heinz & $\begin{array}{l}\text { Especialização em Gestão } \\
\text { do Conhecimento e o } \\
\text { Paradigma } \\
\text { Ontopsicológico } \\
\text { Faculdade Antonio } \\
\text { Meneghetti (AMF) }\end{array}$ & $\begin{array}{l}\text { Faculdade Antonio } \\
\text { Meneghetti (AMF) }\end{array}$ & $\begin{array}{l}\text { O jovem e o sentido } \\
\text { fundamental da vida }\end{array}$ & $\begin{array}{l}\text { Profa. Dra. } \\
\text { Carmen } \\
\text { Ivanete } \\
\text { D'Agostini } \\
\text { Spanhol }\end{array}$ & 2016 \\
\hline
\end{tabular}


Saber Humano, ISSN 2446-6298, V. 9, n. 15, p. 186-423, jul./dez. 2019.

\begin{tabular}{|c|c|c|c|c|c|c|}
\hline 21 & $\begin{array}{l}\text { Ana Paula Mariano Pregardier } \\
\text { http://lattes.cnpq.br/871035219 } \\
8434928\end{array}$ & $\begin{array}{l}\text { Especialização em Gestão } \\
\text { do Conhecimento e o } \\
\text { Paradigma } \\
\text { Ontopsicológico } \\
\text { Faculdade Antonio } \\
\text { Meneghetti (AMF) }\end{array}$ & $\begin{array}{l}\text { Faculdade Antonio } \\
\text { Meneghetti (AMF) }\end{array}$ & $\begin{array}{l}\text { Método lúdico-vivencial } \\
\text { de formação de hábitos } \\
\text { financeiros e a } \\
\text { abordagem da Pedagogia } \\
\text { Ontopsicológica }\end{array}$ & $\begin{array}{l}\text { Profa. Dra. } \\
\text { Estela Maris } \\
\text { Giordani }\end{array}$ & 2016 \\
\hline 22 & Ana Valéria Silva Gonçalves & $\begin{array}{l}\text { Especialização em Gestão } \\
\text { do Conhecimento e o } \\
\text { Paradigma } \\
\text { Ontopsicológico } \\
\text { Faculdade Antonio } \\
\text { Meneghetti (AMF) }\end{array}$ & $\begin{array}{l}\text { Faculdade Antonio } \\
\text { Meneghetti (AMF) }\end{array}$ & $\begin{array}{l}\text { A Pedagogia } \\
\text { Ontopsicológica na } \\
\text { mediação de processos } \\
\text { de divórcio }\end{array}$ & $\begin{array}{l}\text { Profa. Dra. } \\
\text { Estela Maris } \\
\text { Giordani }\end{array}$ & 2016 \\
\hline 23 & Artur Lorentz & $\begin{array}{l}\text { Especialização em Gestão } \\
\text { do Conhecimento e o } \\
\text { Paradigma } \\
\text { Ontopsicológico } \\
\text { Faculdade Antonio } \\
\text { Meneghetti (AMF) }\end{array}$ & $\begin{array}{l}\text { Faculdade Antonio } \\
\text { Meneghetti (AMF) }\end{array}$ & $\begin{array}{l}\text { Sucessão em empresas } \\
\text { familiares: a visão } \\
\text { ontopsicológica }\end{array}$ & $\begin{array}{l}\text { Profa. Ms. } \\
\text { Ana Maris } \\
\text { Petry }\end{array}$ & 2016 \\
\hline 24 & $\begin{array}{l}\text { Cleoci Werle Rockenbach } \\
\text { http://lattes.cnpq.br/050489033 }\end{array}$ & $\begin{array}{l}\text { Especialização em Gestão } \\
\text { do Conhecimento e o } \\
\text { Paradigma }\end{array}$ & $\begin{array}{l}\text { Faculdade Antonio } \\
\text { Meneghetti (AMF) }\end{array}$ & Psicologia e Ontologia & $\begin{array}{l}\text { Prof. Dr. } \\
\text { Alécio Vidor }\end{array}$ & 2016 \\
\hline & 1870011 & $\begin{array}{l}\text { Ontopsicológico } \\
\text { Faculdade Antonio } \\
\text { Meneghetti (AMF) }\end{array}$ & & & & \\
\hline
\end{tabular}


Saber Humano, ISSN 2446-6298, V. 9, n. 15, p. 186-423, jul./dez. 2019.

\begin{tabular}{|c|c|c|c|c|c|c|}
\hline 25 & Clóvis Peruzzolo & $\begin{array}{l}\text { Especialização em Gestão } \\
\text { do Conhecimento e o } \\
\text { Paradigma } \\
\text { Ontopsicológico } \\
\text { Faculdade Antonio } \\
\text { Meneghetti (AMF) }\end{array}$ & $\begin{array}{l}\text { Faculdade Antonio } \\
\text { Meneghetti (AMF) }\end{array}$ & $\begin{array}{l}\text { Estudo de caso: gestão de } \\
\text { uma média empresa } \\
\text { Gallus Avícola Ltda. }\end{array}$ & $\begin{array}{l}\text { Prof. Ms. } \\
\text { Wesley } \\
\text { Lacerda e } \\
\text { Silva }\end{array}$ & 2016 \\
\hline 25 & Cristiano Romagna & $\begin{array}{l}\text { Especialização em Gestão } \\
\text { do Conhecimento e o } \\
\text { Paradigma } \\
\text { Ontopsicológico } \\
\text { Faculdade Antonio } \\
\text { Meneghetti (AMF) }\end{array}$ & $\begin{array}{l}\text { Faculdade Antonio } \\
\text { Meneghetti (AMF) }\end{array}$ & $\begin{array}{l}\text { Do cuidado aplicado ao } \\
\text { estilo de vida à } \\
\text { emergência da potência } \\
\text { criativa: um estudo } \\
\text { autobiográfico }\end{array}$ & $\begin{array}{l}\text { Profa. Ms. } \\
\text { Fernanda } \\
\text { Goulart } \\
\text { Martins }\end{array}$ & 2016 \\
\hline 27 & Edson Ceratti & $\begin{array}{l}\text { Especialização em Gestão } \\
\text { do Conhecimento e o } \\
\text { Paradigma } \\
\text { Ontopsicológico } \\
\text { Faculdade Antonio } \\
\text { Meneghetti (AMF) }\end{array}$ & $\begin{array}{l}\text { Faculdade Antonio } \\
\text { Meneghetti (AMF) }\end{array}$ & $\begin{array}{l}\text { A formação do líder e a } \\
\text { Consultoria } \\
\text { Ontopsicológica: um } \\
\text { estudo autobiográfico }\end{array}$ & $\begin{array}{l}\text { Profa. Ms. } \\
\text { Vera Lúcia } \\
\text { Rodegheri }\end{array}$ & 2016 \\
\hline 28 & Élcio Marques Pereira Brazão & $\begin{array}{l}\text { Especialização em Gestão } \\
\text { do Conhecimento e o } \\
\text { Paradigma } \\
\text { Ontopsicológico }\end{array}$ & $\begin{array}{l}\text { Faculdade Antonio } \\
\text { Meneghetti (AMF) }\end{array}$ & $\begin{array}{l}\text { O tempo livre do líder } \\
\text { empreendedor: riscos e } \\
\text { oportunidades de } \\
\text { investimento para o }\end{array}$ & $\begin{array}{l}\text { Profa. Ms. } \\
\text { Josiane } \\
\text { Beatriz } \\
\text { Piccin }\end{array}$ & 2016 \\
\hline
\end{tabular}


Saber Humano, ISSN 2446-6298, V. 9, n. 15, p. 186-423, jul./dez. 2019.

\begin{tabular}{|c|c|c|c|c|c|c|}
\hline & & $\begin{array}{l}\text { Faculdade Antonio } \\
\text { Meneghetti (AMF) }\end{array}$ & & crescimento existencial & Barbieri & \\
\hline 29 & $\begin{array}{l}\text { Gabrielle Viegas Foletto } \\
\text { http://lattes.cnpq.br/799636910 } \\
9974689\end{array}$ & $\begin{array}{l}\text { Especialização em Gestão } \\
\text { do Conhecimento e o } \\
\text { Paradigma } \\
\text { Ontopsicológico } \\
\text { Faculdade Antonio } \\
\text { Meneghetti (AMF) }\end{array}$ & $\begin{array}{l}\text { Faculdade Antonio } \\
\text { Meneghetti (AMF) }\end{array}$ & $\begin{array}{l}\text { Proposta de um guia para } \\
\text { a escolha dos } \\
\text { colaboradores do líder } \\
\text { baseado nos oito critérios } \\
\text { para escolha dos } \\
\text { colaboradores } \\
\text { explicitados pela FOIL }\end{array}$ & $\begin{array}{l}\text { Profa. Drạ. } \\
\text { Adriane } \\
\text { Maria Moro } \\
\text { Mendes }\end{array}$ & 2016 \\
\hline 30 & $\begin{array}{l}\text { Glauber Benetti Carvalho } \\
\text { http://lattes.cnpq.br/244671083 } \\
7435488\end{array}$ & $\begin{array}{l}\text { Especialização em Gestão } \\
\text { do Conhecimento e o } \\
\text { Paradigma } \\
\text { Ontopsicológico } \\
\text { Faculdade Antonio } \\
\text { Meneghetti (AMF) }\end{array}$ & $\begin{array}{l}\text { Faculdade Antonio } \\
\text { Meneghetti (AMF) }\end{array}$ & $\begin{array}{l}\text { IMPARE e o Projeto } \\
\text { Musicalizando a Rede } \\
\text { como perspectiva } \\
\text { metodológica na } \\
\text { formação da musicalidade } \\
\text { de professores não } \\
\text { especialistas }\end{array}$ & $\begin{array}{l}\text { Profa. Dráa. } \\
\text { Estela Maris } \\
\text { Giordani }\end{array}$ & 2016 \\
\hline 31 & Helena Maria Camacho & $\begin{array}{l}\text { Especialização em Gestão } \\
\text { do Conhecimento e o } \\
\text { Paradigma } \\
\text { Ontopsicológico } \\
\text { Faculdade Antonio } \\
\text { Meneghetti (AMF) }\end{array}$ & $\begin{array}{l}\text { Faculdade Antonio } \\
\text { Meneghetti (AMF) }\end{array}$ & $\begin{array}{l}\text { Escolha profissional e } \\
\text { satisfação pessoal: um } \\
\text { estudo com jovens } \\
\text { profissionais egressos de } \\
\text { uma universidade em São } \\
\text { Paulo }\end{array}$ & $\begin{array}{l}\text { Profa. Dra. } \\
\text { Noemi Boer }\end{array}$ & 2016 \\
\hline 32 & Jorge Luiz Palma Freire & Especialização em Gestão & Faculdade Antonio & Promoção da saúde e o & Prof. Esp. & 2016 \\
\hline
\end{tabular}


Saber Humano, ISSN 2446-6298, V. 9, n. 15, p. 186-423, jul./dez. 2019.

\begin{tabular}{|c|c|c|c|c|c|c|}
\hline & $\begin{array}{l}\text { http://lattes.cnpq.br/635316777 } \\
3331135\end{array}$ & $\begin{array}{l}\text { do Conhecimento e o } \\
\text { Paradigma } \\
\text { Ontopsicológico } \\
\text { Faculdade Antonio } \\
\text { Meneghetti (AMF) }\end{array}$ & Meneghetti (AMF) & $\begin{array}{l}\text { Paradigma } \\
\text { Ontopsicológico }\end{array}$ & $\begin{array}{l}\text { Horácio } \\
\text { Chikota }\end{array}$ & \\
\hline 33 & José Luiz Richetti & $\begin{array}{l}\text { Especialização em Gestão } \\
\text { do Conhecimento e o } \\
\text { Paradigma } \\
\text { Ontopsicológico } \\
\text { Faculdade Antonio } \\
\text { Meneghetti (AMF) }\end{array}$ & $\begin{array}{l}\text { Faculdade Antonio } \\
\text { Meneghetti (AMF) }\end{array}$ & $\begin{array}{l}\text { A Fenomenologia do dano } \\
\text { moral }\end{array}$ & $\begin{array}{l}\text { Prof. Dr. } \\
\text { Josemar } \\
\text { Sidinei } \\
\text { Soares }\end{array}$ & 2016 \\
\hline 34 & Juliane Neumann & $\begin{array}{l}\text { Especialização em Gestão } \\
\text { do Conhecimento e o } \\
\text { Paradigma } \\
\text { Ontopsicológico } \\
\text { Faculdade Antonio } \\
\text { Meneghetti (AMF) }\end{array}$ & $\begin{array}{l}\text { Faculdade Antonio } \\
\text { Meneghetti (AMF) }\end{array}$ & $\begin{array}{l}\text { Campo etérico: um } \\
\text { estudo relativo à saúde }\end{array}$ & $\begin{array}{l}\text { Prof. Dr. } \\
\text { Érico de } \\
\text { Lima } \\
\text { Azevedo }\end{array}$ & 2016 \\
\hline 35 & Luiz Ignácio de Azevedo & $\begin{array}{l}\text { Especialização em Gestão } \\
\text { do Conhecimento e o } \\
\text { Paradigma } \\
\text { Ontopsicológico } \\
\text { Faculdade Antonio } \\
\text { Meneghetti (AMF) }\end{array}$ & $\begin{array}{l}\text { Faculdade Antonio } \\
\text { Meneghetti (AMF) }\end{array}$ & $\begin{array}{l}\text { Pedagogia Empresarial: a } \\
\text { retenção do jovem } \\
\text { colaborador nas } \\
\text { organizações }\end{array}$ & $\begin{array}{l}\text { Profa. Ms. } \\
\text { Ana Maris } \\
\text { Petry }\end{array}$ & 2016 \\
\hline
\end{tabular}


Saber Humano, ISSN 2446-6298, V. 9, n. 15, p. 186-423, jul./dez. 2019.

\begin{tabular}{|c|c|c|c|c|c|c|}
\hline 36 & Márcio Jibrin & Especialização em Gestão & Faculdade Antonio & Reflexões sobre a relação & Profa. Ms. & 2016 \\
\hline & & $\begin{array}{l}\text { do Conhecimento e o } \\
\text { Paradigma } \\
\text { Ontopsicológico } \\
\text { Faculdade Antonio } \\
\text { Meneghetti (AMF) }\end{array}$ & Meneghetti (AMF) & $\begin{array}{l}\text { psicoterapêutica e as } \\
\text { contribuições do } \\
\text { Paradigma } \\
\text { Ontopsicológico }\end{array}$ & $\begin{array}{l}\text { Maria } \\
\text { Tereza } \\
\text { Andreola }\end{array}$ & \\
\hline 37 & Márcio Sudati Rodrigues & $\begin{array}{l}\text { Especialização em Gestão } \\
\text { do Conhecimento e o } \\
\text { Paradigma } \\
\text { Ontopsicológico } \\
\text { Faculdade Antonio } \\
\text { Meneghetti (AMF) }\end{array}$ & $\begin{array}{l}\text { Faculdade Antonio } \\
\text { Meneghetti (AMF) }\end{array}$ & $\begin{array}{l}\text { Importância do processo } \\
\text { sucessório em empresas } \\
\text { familiares do } \\
\text { Agronegócio: um estudo } \\
\text { de revisão teórica }\end{array}$ & $\begin{array}{l}\text { Profa. Ms. } \\
\text { Josiane } \\
\text { Beatriz } \\
\text { Piccin } \\
\text { Barbieri }\end{array}$ & 2016 \\
\hline
\end{tabular}


Saber Humano, ISSN 2446-6298, V. 9, n. 15, p. 186-423, jul./dez. 2019.

\begin{tabular}{|c|c|c|c|c|c|c|}
\hline 38 & Silvana Guerra & $\begin{array}{l}\text { Especialização em Gestão } \\
\text { do Conhecimento e o } \\
\text { Paradigma } \\
\text { Ontopsicológico } \\
\text { Faculdade Antonio } \\
\text { Meneghetti (AMF) }\end{array}$ & $\begin{array}{l}\text { Faculdade Antonio } \\
\text { Meneghetti (AMF) }\end{array}$ & $\begin{array}{l}\text { Estudo comparativo sobre } \\
\text { a forma mentis de um } \\
\text { time comercial que atinge } \\
\text { a meta para encontrar } \\
\text { fatores de sucesso }\end{array}$ & $\begin{array}{l}\text { Profa. Ms. } \\
\text { Fernanda } \\
\text { Goulart } \\
\text { Martins }\end{array}$ & 2016 \\
\hline 39 & Simone Ferri & $\begin{array}{l}\text { Especialização em Gestão } \\
\text { do Conhecimento e o } \\
\text { Paradigma } \\
\text { Ontopsicológico } \\
\text { Faculdade Antonio } \\
\text { Meneghetti (AMF) }\end{array}$ & $\begin{array}{l}\text { Faculdade Antonio } \\
\text { Meneghetti (AMF) }\end{array}$ & $\begin{array}{l}\text { A imagem como } \\
\text { constructo determinante } \\
\text { da dinâmica existencial do } \\
\text { ser humano }\end{array}$ & $\begin{array}{l}\text { Prof. Dr. } \\
\text { Josemar } \\
\text { Sidinei } \\
\text { Soares }\end{array}$ & 2016 \\
\hline \multirow[t]{2}{*}{40} & Taline Souza Mendes & Especialização em Gestão & Faculdade Antonio & A identidade como & Prof. Dr. & 2016 \\
\hline & & $\begin{array}{l}\text { do Conhecimento e o } \\
\text { Paradigma } \\
\text { Ontopsicológico } \\
\text { Faculdade Antonio } \\
\text { Meneghetti (AMF) }\end{array}$ & Meneghetti (AMF) & $\begin{array}{l}\text { critério de resultado: um } \\
\text { estudo de casos múltiplos } \\
\text { sobre liderança e práticas } \\
\text { de integração de } \\
\text { colaboradores em redes } \\
\text { de empresas do Setor da } \\
\text { Gastronomia no Rio } \\
\text { Grande do Sul }\end{array}$ & $\begin{array}{l}\text { Ricardo } \\
\text { Schaefer }\end{array}$ & \\
\hline
\end{tabular}


Saber Humano, ISSN 2446-6298, V. 9, n. 15, p. 186-423, jul./dez. 2019.

\begin{tabular}{|c|c|c|c|c|c|c|}
\hline 41 & $\begin{array}{l}\text { Juliane Neves Fiorezi } \\
\text { http://buscatextual.cnpq.br/bus } \\
\text { catextual/visualizacv.do?id=K42 } \\
\text { 13233J5 }\end{array}$ & $\begin{array}{l}\text { Especialização em } \\
\text { Psicologia com abordagem } \\
\text { em Ontopsicologia } \\
\text { Universidade Estatal de } \\
\text { São Petersburgo, Rússia } \\
\text { (SPbU) }\end{array}$ & $\begin{array}{l}\text { Universidade Estatal } \\
\text { de São Petersburgo, } \\
\text { Rússia (SPbU) }\end{array}$ & $\begin{array}{l}\text { Avaliação da experiência } \\
\text { corporal subjetiva e } \\
\text { modificações } \\
\text { psicofisiológicas no } \\
\text { decorrer das práticas da } \\
\text { Melolística }\end{array}$ & $\begin{array}{l}\text { Profa. Dra. } \\
\text { Natalia } \\
\text { Gortchakova }\end{array}$ & 2016 \\
\hline 42 & $\begin{array}{l}\text { Juliane Neves Fiorezi } \\
\text { http://buscatextual.cnpq.br/bus } \\
\text { catextual/visualizacv.do?id=K42 } \\
\text { 13233J5 }\end{array}$ & $\begin{array}{l}\text { Especialização em Gestão } \\
\text { do Conhecimento e o } \\
\text { Paradigma } \\
\text { Ontopsicológico } \\
\text { Faculdade Antonio } \\
\text { Meneghetti (AMF) }\end{array}$ & $\begin{array}{l}\text { Faculdade Antonio } \\
\text { Meneghetti (AMF) }\end{array}$ & $\begin{array}{l}\text { Aferição dos efeitos em } \\
\text { nível físico-biológico } \\
\text { mediante aplicação da } \\
\text { Melolística em jovens de } \\
18 \text { a } 25 \text { anos }\end{array}$ & $\begin{array}{l}\text { Prof. Esp. } \\
\text { Horácio } \\
\text { Shigueru } \\
\text { Chikota }\end{array}$ & 2016 \\
\hline 43 & $\begin{array}{l}\text { Patrícia Wazlawick } \\
\text { http://buscatextual.cnpq.br/bus } \\
\text { catextual/visualizacv.do?id=K47 } \\
\text { 53659Y5 }\end{array}$ & $\begin{array}{l}\text { Especialização em } \\
\text { Psicologia com abordagem } \\
\text { em Ontopsicologia } \\
\text { Universidade Estatal de } \\
\text { São Petersburgo, Rússia } \\
\text { (SPbU) }\end{array}$ & $\begin{array}{l}\text { Universidade Estatal } \\
\text { de São Petersburgo, } \\
\text { Rússia (SPbU) }\end{array}$ & $\begin{array}{l}\text { Dinâmica de } \\
\text { desenvolvimento da } \\
\text { personalidade no processo } \\
\text { de aprendizagem: o } \\
\text { exemplo da Faculdade } \\
\text { Antonio }\end{array}$ & $\begin{array}{l}\text { Profa Dra. } \\
\text { Victoria } \\
\text { Dmitrieva }\end{array}$ & 2014 \\
\hline & & & & Meneghetti & & \\
\hline
\end{tabular}


Saber Humano, ISSN 2446-6298, V. 9, n. 15, p. 186-423, jul./dez. 2019.

\begin{tabular}{|c|c|c|c|c|c|c|}
\hline 28 & Aldo Diego Ibanos & $\begin{array}{l}\text { Especialização em Gestão } \\
\text { do Conhecimento e o } \\
\text { Paradigma } \\
\text { Ontopsicológico } \\
\text { Faculdade Antonio } \\
\text { Meneghetti (AMF) }\end{array}$ & $\begin{array}{l}\text { Faculdade Antonio } \\
\text { Meneghetti (AMF) }\end{array}$ & $\begin{array}{l}\text { Música e saúde: a } \\
\text { influêcia da música no } \\
\text { desenvolvimento humano }\end{array}$ & $\begin{array}{l}\text { Profa. Dra. } \\
\text { Carmen } \\
\text { Ivanete } \\
\text { D'Agostini } \\
\text { Spanhol }\end{array}$ & 2014 \\
\hline 29 & Ana Cristina Cunha & $\begin{array}{l}\text { Especialização em Gestão } \\
\text { do Conhecimento e o } \\
\text { Paradigma } \\
\text { Ontopsicológico } \\
\text { Faculdade Antonio } \\
\text { Meneghetti (AMF) }\end{array}$ & $\begin{array}{l}\text { Faculdade Antonio } \\
\text { Meneghetti (AMF) }\end{array}$ & $\begin{array}{l}\text { Liderança feminina: } \\
\text { características e } \\
\text { importância à identidade } \\
\text { da mulher }\end{array}$ & $\begin{array}{l}\text { Profa. Dra. } \\
\text { Carmen } \\
\text { Ivanete } \\
\text { D'Agostini } \\
\text { Spanhol }\end{array}$ & 2014 \\
\hline 30 & $\begin{array}{l}\text { Ana Marli Bulegon } \\
\text { http://lattes.cnpq.br/131509651 } \\
5847809\end{array}$ & $\begin{array}{l}\text { Especialização em Gestão } \\
\text { do Conhecimento e o } \\
\text { Paradigma } \\
\text { Ontopsicológico } \\
\text { Faculdade Antonio } \\
\text { Meneghetti (AMF) }\end{array}$ & $\begin{array}{l}\text { Faculdade Antonio } \\
\text { Meneghetti (AMF) }\end{array}$ & $\begin{array}{l}\text { Contribuições da Psicotea } \\
\text { para o ensino e a } \\
\text { aprendizagem de } \\
\text { conceitos de matemática }\end{array}$ & $\begin{array}{l}\text { Profa. Dra. } \\
\text { Helena } \\
\text { Biasotto }\end{array}$ & 2014 \\
\hline 31 & $\begin{array}{l}\text { Beatriz Machri de Pellegrini } \\
\text { http://lattes.cnpq.br/052887607 } \\
5373247\end{array}$ & $\begin{array}{l}\text { Especialização em Gestão } \\
\text { do Conhecimento e o } \\
\text { Paradigma } \\
\text { Ontopsicológico } \\
\text { Faculdade Antonio } \\
\text { Meneghetti (AMF) }\end{array}$ & $\begin{array}{l}\text { Faculdade Antonio } \\
\text { Meneghetti (AMF) }\end{array}$ & $\begin{array}{l}\text { O sentido do trabalho: a } \\
\text { visão humanista e a } \\
\text { aposentadoria }\end{array}$ & $\begin{array}{l}\text { Profa. Drá. } \\
\text { Noemi Boer }\end{array}$ & 2014 \\
\hline
\end{tabular}


Saber Humano, ISSN 2446-6298, V. 9, n. 15, p. 186-423, jul./dez. 2019.

\begin{tabular}{|c|c|c|c|c|c|c|}
\hline 32 & $\begin{array}{l}\text { Beatriz Machri de Pellegrini } \\
\text { http://lattes.cnpq.br/052887607 } \\
5373247\end{array}$ & $\begin{array}{l}\text { Especialização em } \\
\text { Psicologia com abordagem } \\
\text { em Ontopsicologia } \\
\text { Universidade Estatal de } \\
\text { São Petersburgo, Rússia } \\
\text { (SPbU) }\end{array}$ & $\begin{array}{l}\text { Universidade Estatal } \\
\text { de São Petersburgo, } \\
\text { Rússia (SPbU) }\end{array}$ & $\begin{array}{l}\text { O sentido do trabalho } \\
\text { para as pessoas na fase da } \\
\text { idade madura }\end{array}$ & $\begin{array}{l}\text { Profa. Dra. } \\
\text { Victoria } \\
\text { Dimitrieva }\end{array}$ & 2014 \\
\hline 33 & Bernardina Amantino & $\begin{array}{l}\text { Especialização em Gestão } \\
\text { do Conhecimento e o } \\
\text { Paradigma } \\
\text { Ontopsicológico } \\
\text { Faculdade Antonio } \\
\text { Meneghetti (AMF) }\end{array}$ & $\begin{array}{l}\text { Faculdade Antonio } \\
\text { Meneghetti (AMF) }\end{array}$ & $\begin{array}{l}\text { A psicologia das roupas e } \\
\text { a OntoArte na moda }\end{array}$ & $\begin{array}{l}\text { Profa. Dra. } \\
\text { Noemi Boer }\end{array}$ & 2014 \\
\hline 34 & Bernardina Amantino & $\begin{array}{l}\text { Especialização em } \\
\text { Psicologia com abordagem } \\
\text { em Ontopsicologia } \\
\text { Universidade Estatal de } \\
\text { São Petersburgo, Rússia } \\
\text { (SPbU) }\end{array}$ & $\begin{array}{l}\text { Universidade Estatal } \\
\text { de São Petersburgo, } \\
\text { Rússia (SPbU) }\end{array}$ & $\begin{array}{l}\text { Estética como reforço da } \\
\text { própria identidade }\end{array}$ & $\begin{array}{l}\text { Profa Drạ } \\
\text { Marina } \\
\text { Salitova }\end{array}$ & 2014 \\
\hline 35 & $\begin{array}{l}\text { Bruna Marquetti Dallepiane } \\
\text { http://lattes.cnpq.br/882987315 } \\
2834068\end{array}$ & $\begin{array}{l}\text { Especialização em Gestão } \\
\text { do Conhecimento e o } \\
\text { Paradigma } \\
\text { Ontopsicológico } \\
\text { Faculdade Antonio } \\
\text { Meneghetti (AMF) }\end{array}$ & $\begin{array}{l}\text { Faculdade Antonio } \\
\text { Meneghetti (AMF) }\end{array}$ & $\begin{array}{l}\text { Resultados da Pedagogia } \\
\text { Ontopsicológica aplicada } \\
\text { em projetos sociais } \\
\text { desenvolvidos pela } \\
\text { Fundação Antonio } \\
\text { Meneghetti }\end{array}$ & $\begin{array}{l}\text { Profa. Dra } \\
\text { Estela Maris } \\
\text { Giordani }\end{array}$ & 2014 \\
\hline
\end{tabular}


Saber Humano, ISSN 2446-6298, V. 9, n. 15, p. 186-423, jul./dez. 2019.

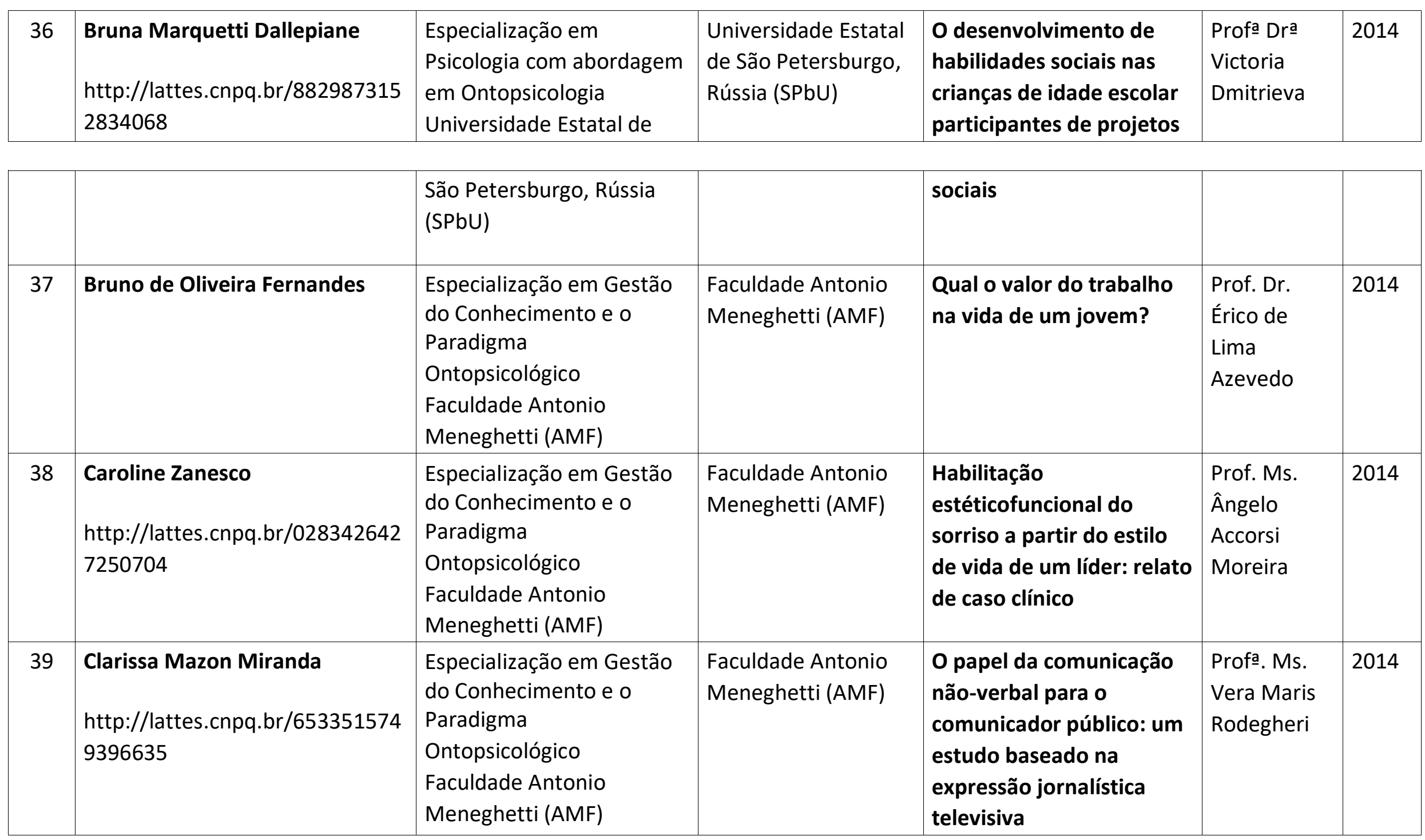


Saber Humano, ISSN 2446-6298, V. 9, n. 15, p. 186-423, jul./dez. 2019.

\begin{tabular}{|c|c|c|c|c|c|c|}
\hline 40 & $\begin{array}{l}\text { Claudiane Weber } \\
\text { http://lattes.cnpq.br/917648567 } \\
8404469\end{array}$ & $\begin{array}{l}\text { Especialização em Gestão } \\
\text { do Conhecimento e o } \\
\text { Paradigma } \\
\text { Ontopsicológico } \\
\text { Faculdade Antonio } \\
\text { Meneghetti (AMF) }\end{array}$ & $\begin{array}{l}\text { Faculdade Antonio } \\
\text { Meneghetti (AMF) }\end{array}$ & $\begin{array}{l}\text { A díade jovem e } \\
\text { ambiente: o rural no } \\
\text { horizonte sul brasileiro }\end{array}$ & $\begin{array}{l}\text { Profa Dra. } \\
\text { Helena } \\
\text { Bisotto }\end{array}$ & 2014 \\
\hline 41 & Cléo Rossetto & $\begin{array}{l}\text { Especialização em Gestão } \\
\text { do Conhecimento e o } \\
\text { Paradigma } \\
\text { Ontopsicológico } \\
\text { Faculdade Antonio } \\
\text { Meneghetti (AMF) }\end{array}$ & $\begin{array}{l}\text { Faculdade Antonio } \\
\text { Meneghetti (AMF) }\end{array}$ & $\begin{array}{l}\text { Em Si ôntico: novo critério } \\
\text { epistêmico jurídico }\end{array}$ & $\begin{array}{l}\text { Prof. Dr. } \\
\text { Josemar } \\
\text { Sidinei } \\
\text { Soares }\end{array}$ & 2014 \\
\hline 42 & Denise Kimmel de Souza & $\begin{array}{l}\text { Especialização em Gestão } \\
\text { do Conhecimento e o } \\
\text { Paradigma } \\
\text { Ontopsicológico } \\
\text { Faculdade Antonio } \\
\text { Meneghetti (AMF) }\end{array}$ & $\begin{array}{l}\text { Faculdade Antonio } \\
\text { Meneghetti (AMF) }\end{array}$ & \begin{tabular}{|l} 
Filosofia Perene: a base \\
para resgatar na ciência os \\
valores humanos
\end{tabular} & $\begin{array}{l}\text { Prof. Dr. } \\
\text { Alécio Vidor }\end{array}$ & 2014 \\
\hline 43 & $\begin{array}{l}\text { Fernanda Goulart Martins } \\
\text { http://lattes.cnpq.br/732296845 } \\
7724239\end{array}$ & $\begin{array}{l}\text { Especialização em Gestão } \\
\text { do Conhecimento e o } \\
\text { Paradigma } \\
\text { Ontopsicológico } \\
\text { Faculdade Antonio } \\
\text { Meneghetti (AMF) }\end{array}$ & $\begin{array}{l}\text { Faculdade Antonio } \\
\text { Meneghetti (AMF) }\end{array}$ & $\begin{array}{l}\text { Análise dos sonhos no } \\
\text { processo humano de } \\
\text { tomada de decisão: a } \\
\text { relevância da Psicoterapia } \\
\text { Ontopsicológica }\end{array}$ & $\begin{array}{l}\text { Profa. Ms. } \\
\text { Maria } \\
\text { Tereza } \\
\text { Andreolla }\end{array}$ & 2014 \\
\hline
\end{tabular}


Saber Humano, ISSN 2446-6298, V. 9, n. 15, p. 186-423, jul./dez. 2019.

\begin{tabular}{|c|c|c|c|c|c|c|}
\hline 44 & Fábio José Pires da Silva & $\begin{array}{l}\text { Especialização em } \\
\text { Psicologia com abordagem } \\
\text { em Ontopsicologia } \\
\text { Universidade Estatal de } \\
\text { São Petersburgo, Rússia } \\
\text { (SPbU) }\end{array}$ & $\begin{array}{l}\text { Universidade Estatal } \\
\text { de São Petersburgo, } \\
\text { Rússia (SPbU) }\end{array}$ & $\begin{array}{l}\text { A visão de homem } \\
\text { protagonista responsável } \\
\text { como critério para a } \\
\text { eficiência na formação: } \\
\text { uma análise do modelo de } \\
\text { Educação a Distância } \\
\text { como alternativa } \\
\text { contemporânea }\end{array}$ & $\begin{array}{l}\text { Prof. Dr. } \\
\text { Alexey } \\
\text { Ostrower }\end{array}$ & 2014 \\
\hline 45 & Graciela Schramm & $\begin{array}{l}\text { Especialização em Gestão } \\
\text { do Conhecimento e o } \\
\text { Paradigma } \\
\text { Ontopsicológico } \\
\text { Faculdade Antonio } \\
\text { Meneghetti (AMF) }\end{array}$ & $\begin{array}{l}\text { Faculdade Antonio } \\
\text { Meneghetti (AMF) }\end{array}$ & $\begin{array}{l}\text { Ontopsicologia e Gestão } \\
\text { do Autoconhecimento }\end{array}$ & $\begin{array}{l}\text { Profa. Ms. } \\
\text { Vera Lúcia } \\
\text { Rodegheri }\end{array}$ & 2014 \\
\hline
\end{tabular}


Saber Humano, ISSN 2446-6298, V. 9, n. 15, p. 186-423, jul./dez. 2019.

\begin{tabular}{|c|c|c|c|c|c|c|}
\hline 47 & Guilherme S. Sombrio & $\begin{array}{l}\text { Especialização em } \\
\text { Psicologia com abordagem } \\
\text { em Ontopsicologia } \\
\text { Universidade Estatal de } \\
\text { São Petersburgo, Rússia } \\
\text { (SPbU) }\end{array}$ & $\begin{array}{l}\text { Universidade Estatal } \\
\text { de São Petersburgo, } \\
\text { Rússia (SPbU) }\end{array}$ & $\begin{array}{l}\text { As dinâmicas do homem e } \\
\text { a vivência do tempo: um } \\
\text { estudo com jovens } \\
\text { inovadores }\end{array}$ & $\begin{array}{l}\text { Profa Dra } \\
\text { Marina } \\
\text { Salitova }\end{array}$ & 2014 \\
\hline 48 & Márcio Luis Miorelli & $\begin{array}{l}\text { Especialização em } \\
\text { Psicologia com abordagem } \\
\text { em Ontopsicologia } \\
\text { Universidade Estatal de } \\
\text { São Petersburgo, Rússia } \\
\text { (SPbU) }\end{array}$ & $\begin{array}{l}\text { Universidade Estatal } \\
\text { de São Petersburgo, } \\
\text { Rússia (SPbU) }\end{array}$ & $\begin{array}{l}\text { Características de } \\
\text { personalidade e } \\
\text { motivações de } \\
\text { empresários líderes que } \\
\text { atuam em entidades } \\
\text { empresariais associativas }\end{array}$ & $\begin{array}{l}\text { Profa Dra } \\
\text { Marina } \\
\text { Salitova }\end{array}$ & 2014 \\
\hline 49 & Maria Anita Medeiros & $\begin{array}{l}\text { Especialização em } \\
\text { Psicologia com abordagem } \\
\text { em Ontopsicologia } \\
\text { Universidade Estatal de } \\
\text { São Petersburgo, Rússia } \\
\text { (SPbU) }\end{array}$ & $\begin{array}{l}\text { Universidade Estatal } \\
\text { de São Petersburgo, } \\
\text { Rússia (SPbU) }\end{array}$ & $\begin{array}{l}\text { Sucessão familiar e } \\
\text { continuidade na gestão da } \\
\text { propriedade rural no } \\
\text { estado do Mato Grosso do } \\
\text { Sul }\end{array}$ & $\begin{array}{l}\text { Profa Dra } \\
\text { Marina } \\
\text { Salitova }\end{array}$ & 2014 \\
\hline 50 & Joana de Jesus & $\begin{array}{l}\text { Especialização em Gestão } \\
\text { do Conhecimento e o } \\
\text { Paradigma } \\
\text { Ontopsicológico } \\
\text { Faculdade Antonio } \\
\text { Meneghetti (AMF) }\end{array}$ & $\begin{array}{l}\text { Faculdade Antonio } \\
\text { Meneghetti (AMF) }\end{array}$ & $\begin{array}{l}\text { A inteligência humana } \\
\text { feminina para a tomada } \\
\text { de poder }\end{array}$ & $\begin{array}{l}\text { Profa. Ms. } \\
\text { Josiane } \\
\text { Beatriz } \\
\text { Piccin } \\
\text { Barbieri }\end{array}$ & 2014 \\
\hline
\end{tabular}


Saber Humano, ISSN 2446-6298, V. 9, n. 15, p. 186-423, jul./dez. 2019.

\begin{tabular}{|c|c|c|c|c|c|c|}
\hline 51 & João Carlos Leonardi & $\begin{array}{l}\text { Especialização em Gestão } \\
\text { do Conhecimento e o } \\
\text { Paradigma } \\
\text { Ontopsicológico } \\
\text { Faculdade Antonio } \\
\text { Meneghetti (AMF) }\end{array}$ & $\begin{array}{l}\text { Faculdade Antonio } \\
\text { Meneghetti (AMF) }\end{array}$ & $\begin{array}{l}\text { O papel do líder na } \\
\text { construção de uma cultura } \\
\text { organizacional }\end{array}$ & $\begin{array}{l}\text { Profa. Ms. } \\
\text { Josiane } \\
\text { Beatriz } \\
\text { Picicin } \\
\text { Barbieri }\end{array}$ & 2014 \\
\hline 52 & João Feltrin & $\begin{array}{l}\text { Especialização em Gestão } \\
\text { do Conhecimento e o } \\
\text { Paradigma } \\
\text { Ontopsicológico } \\
\text { Faculdade Antonio } \\
\text { Meneghetti (AMF) }\end{array}$ & $\begin{array}{l}\text { Faculdade Antonio } \\
\text { Meneghetti (AMF) }\end{array}$ & $\begin{array}{l}\text { O critério ético em } \\
\text { Aristóteles e Meneghetti }\end{array}$ & $\begin{array}{l}\text { Prof. Dr. } \\
\text { Josemar } \\
\text { Sidinei } \\
\text { Soares }\end{array}$ & 2014 \\
\hline 53 & José Alfredo Nedel Filho & $\begin{array}{l}\text { Especialização em Gestão } \\
\text { do Conhecimento e o } \\
\text { Paradigma } \\
\text { Ontopsicológico }\end{array}$ & $\begin{array}{l}\text { Faculdade Antonio } \\
\text { Meneghetti (AMF) }\end{array}$ & $\begin{array}{l}0 \text { inconsciente humano. } \\
\text { Ensaio histórico }\end{array}$ & $\begin{array}{l}\text { Profa. Ms. } \\
\text { Ângelo } \\
\text { Accorsi } \\
\text { Moreira }\end{array}$ & 2014 \\
\hline & & $\begin{array}{l}\text { Faculdade Antonio } \\
\text { Meneghetti (AMF) }\end{array}$ & & & & \\
\hline 54 & $\begin{array}{l}\text { Jussara Foletto } \\
\text { http://lattes.cnpq.br/580960541 } \\
6154903\end{array}$ & $\begin{array}{l}\text { Especialização em Gestão } \\
\text { do Conhecimento e o } \\
\text { Paradigma } \\
\text { Ontopsicológico } \\
\text { Faculdade Antonio } \\
\text { Meneghetti (AMF) }\end{array}$ & $\begin{array}{l}\text { Faculdade Antonio } \\
\text { Meneghetti (AMF) }\end{array}$ & $\begin{array}{l}\text { Características do perfil de } \\
\text { lideranças femininas e } \\
\text { masculinas do } \\
\text { agronegócio do Rio } \\
\text { Grande do Sul }\end{array}$ & $\begin{array}{l}\text { Profa. Dra. } \\
\text { Estela Maris } \\
\text { Giordani }\end{array}$ & 2014 \\
\hline
\end{tabular}


Saber Humano, ISSN 2446-6298, V. 9, n. 15, p. 186-423, jul./dez. 2019.

\begin{tabular}{|c|c|c|c|c|c|c|}
\hline 55 & Lilian Werner Philippi da Silva & $\begin{array}{l}\text { Especialização em Gestão } \\
\text { do Conhecimento e o } \\
\text { Paradigma } \\
\text { Ontopsicológico } \\
\text { Faculdade Antonio } \\
\text { Meneghetti (AMF) }\end{array}$ & $\begin{array}{l}\text { Faculdade Antonio } \\
\text { Meneghetti (AMF) }\end{array}$ & $\begin{array}{l}\text { Considerações sobre a } \\
\text { aplicação da Pedagogia } \\
\text { Ontopsicológica a jovens: } \\
\text { um relato de experiência }\end{array}$ & $\begin{array}{l}\text { Prof. Ms. } \\
\text { Ângelo } \\
\text { Accorsi } \\
\text { Moreira }\end{array}$ & 2014 \\
\hline 56 & Liliane Dalbosco Carpenedo & $\begin{array}{l}\text { Especialização em Gestão } \\
\text { do Conhecimento e o } \\
\text { Paradigma } \\
\text { Ontopsicológico } \\
\text { Faculdade Antonio } \\
\text { Meneghetti (AMF) }\end{array}$ & $\begin{array}{l}\text { Faculdade Antonio } \\
\text { Meneghetti (AMF) }\end{array}$ & $\begin{array}{l}\text { Função feminina: uma } \\
\text { abordagem e proposições } \\
\text { da Escola Ontopsicológica } \\
\text { à sua realização e } \\
\text { aplicação no mercado de } \\
\text { trabalho }\end{array}$ & $\begin{array}{l}\text { Prof.a Ms. } \\
\text { Carolina } \\
\text { Schuskel } \\
\text { Miranda }\end{array}$ & 2014 \\
\hline 57 & Luísa Barcelos de Oliveira & $\begin{array}{l}\text { Especialização em Gestão } \\
\text { do Conhecimento e o } \\
\text { Paradigma } \\
\text { Ontopsicológico } \\
\text { Faculdade Antonio } \\
\text { Meneghetti (AMF) }\end{array}$ & $\begin{array}{l}\text { Faculdade Antonio } \\
\text { Meneghetti (AMF) }\end{array}$ & $\begin{array}{l}\text { O nascimento do eu na } \\
\text { Psicoterapia de } \\
\text { Autenticação }\end{array}$ & $\begin{array}{l}\text { Profa. Ms. } \\
\text { Josiane } \\
\text { Beatriz } \\
\text { Piccin } \\
\text { Barbieri }\end{array}$ & 2014 \\
\hline 58 & Luiz Fernando Somenzi & $\begin{array}{l}\text { Especialização em Gestão } \\
\text { do Conhecimento e o } \\
\text { Paradigma } \\
\text { Ontopsicológico } \\
\text { Faculdade Antonio } \\
\text { Meneghetti (AMF) }\end{array}$ & $\begin{array}{l}\text { Faculdade Antonio } \\
\text { Meneghetti (AMF) }\end{array}$ & $\begin{array}{l}\text { Ambiente de trabalho: } \\
\text { liderança, clima } \\
\text { psicológico e eficiência }\end{array}$ & $\begin{array}{l}\text { Profa. Drạ. } \\
\text { Estela Maris } \\
\text { Giordani }\end{array}$ & 2014 \\
\hline
\end{tabular}


Saber Humano, ISSN 2446-6298, V. 9, n. 15, p. 186-423, jul./dez. 2019.

\begin{tabular}{|c|c|c|c|c|c|c|}
\hline 59 & Luiz Fernando Somenzi & $\begin{array}{l}\text { Especialização em } \\
\text { Psicologia com abordagem } \\
\text { em Ontopsicologia. } \\
\text { Universidade Estatal de } \\
\text { São Petersburgo, Rússia } \\
\text { (SPbU) }\end{array}$ & $\begin{array}{l}\text { Universidade Estatal } \\
\text { de São Petersburgo, } \\
\text { Rússia (SPbU) }\end{array}$ & $\begin{array}{l}\text { Ambiente de trabalho: } \\
\text { liderança, clima } \\
\text { psicológico e eficiência }\end{array}$ & $\begin{array}{l}\text { Profa Dra } \\
\text { Natalia } \\
\text { Gorchakova }\end{array}$ & 2014 \\
\hline 60 & Márcio Luiz Miorelli & $\begin{array}{l}\text { Especialização em Gestão } \\
\text { do Conhecimento e o } \\
\text { Paradigma } \\
\text { Ontopsicológico } \\
\text { Faculdade Antonio } \\
\text { Meneghetti (AMF) }\end{array}$ & $\begin{array}{l}\text { Faculdade Antonio } \\
\text { Meneghetti (AMF) }\end{array}$ & $\begin{array}{l}\text { Características de } \\
\text { personalidade de } \\
\text { empresários líderes } \\
\text { atuantes em entidades } \\
\text { empresariais }\end{array}$ & $\begin{array}{l}\text { Prof. Ms. } \\
\text { Ângelo } \\
\text { Accorsi } \\
\text { Moreira }\end{array}$ & 2014 \\
\hline 61 & Márcio Vieira dos Santos & $\begin{array}{l}\text { Especialização em Gestão } \\
\text { do Conhecimento e o } \\
\text { Paradigma } \\
\text { Ontopsicológico } \\
\text { Faculdade Antonio } \\
\text { Meneghetti (AMF) }\end{array}$ & $\begin{array}{l}\text { Faculdade Antonio } \\
\text { Meneghetti (AMF) }\end{array}$ & $\begin{array}{l}\text { Como a Ontopsicologia } \\
\text { pode ajudar juízes na } \\
\text { justiça do trabalho }\end{array}$ & $\begin{array}{l}\text { Prof. Dr. } \\
\text { Josemar } \\
\text { Sidinei } \\
\text { Soares }\end{array}$ & 2014 \\
\hline 62 & Maria Anita Medeiros & $\begin{array}{l}\text { Especialização em Gestão } \\
\text { do Conhecimento e o } \\
\text { Paradigma }\end{array}$ & $\begin{array}{l}\text { Faculdade Antonio } \\
\text { Meneghetti (AMF) }\end{array}$ & $\begin{array}{l}\text { Sucessão e continuidade } \\
\text { da empresa familiar do } \\
\text { ramo do agronegócio: um }\end{array}$ & $\begin{array}{l}\text { Profa. Dra } \\
\text { Noemi Boer }\end{array}$ & 2014 \\
\hline & & $\begin{array}{l}\text { Ontopsicológico } \\
\text { Faculdade Antonio } \\
\text { Meneghetti (AMF) }\end{array}$ & & $\begin{array}{l}\text { estudo de abordagem } \\
\text { teórica }\end{array}$ & & \\
\hline
\end{tabular}


Saber Humano, ISSN 2446-6298, V. 9, n. 15, p. 186-423, jul./dez. 2019.

\begin{tabular}{|c|c|c|c|c|c|c|}
\hline 63 & Maria Lúcia Teixeira Carrara & $\begin{array}{l}\text { Especialização em Gestão } \\
\text { do Conhecimento e o } \\
\text { Paradigma } \\
\text { Ontopsicológico } \\
\text { Faculdade Antonio } \\
\text { Meneghetti (AMF) }\end{array}$ & $\begin{array}{l}\text { Faculdade Antonio } \\
\text { Meneghetti (AMF) }\end{array}$ & $\begin{array}{l}\text { Percepção da estética da } \\
\text { embalagem da empresa } \\
\text { Lilium Recanto a partir } \\
\text { dos princípios da } \\
\text { Ontopsicologia e da } \\
\text { OntoArte }\end{array}$ & $\begin{array}{l}\text { Profa. Ms. } \\
\text { Ana Maris } \\
\text { Petry }\end{array}$ & 2014 \\
\hline 64 & 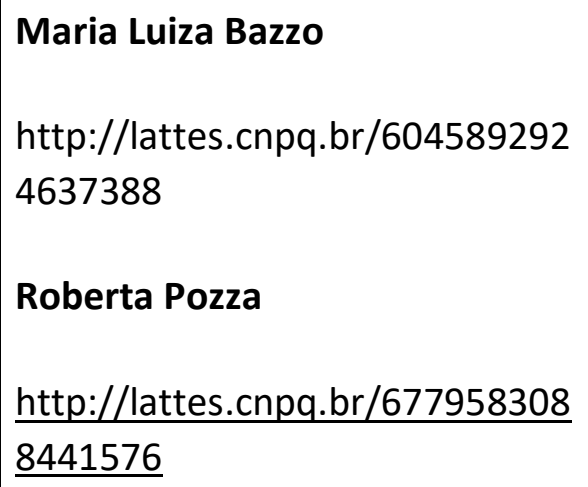 & $\begin{array}{l}\text { Especialização em Gestão } \\
\text { do Conhecimento e o } \\
\text { Paradigma } \\
\text { Ontopsicológico } \\
\text { Faculdade Antonio } \\
\text { Meneghetti (AMF) }\end{array}$ & $\begin{array}{l}\text { Faculdade Antonio } \\
\text { Meneghetti (AMF) }\end{array}$ & $\begin{array}{l}\text { O conceito atual de } \\
\text { psicossomática: a busca } \\
\text { da causalidade psíquica }\end{array}$ & $\begin{array}{l}\text { Prof. Dr. } \\
\text { Érico de } \\
\text { Lima } \\
\text { Azevedo }\end{array}$ & 2014 \\
\hline 65 & Mônica Oliveira da Silva & $\begin{array}{l}\text { Especialização em Gestão } \\
\text { do Conhecimento e o } \\
\text { Paradigma } \\
\text { Ontopsicológico } \\
\text { Faculdade Antonio } \\
\text { Meneghetti (AMF) }\end{array}$ & $\begin{array}{l}\text { Faculdade Antonio } \\
\text { Meneghetti (AMF) }\end{array}$ & $\begin{array}{l}\text { Expectativas de } \\
\text { estudantes universitários } \\
\text { sobre intercâmbio e } \\
\text { experiência no exterior }\end{array}$ & $\begin{array}{l}\text { Prof. Ms. } \\
\text { Ângelo } \\
\text { Accorsi } \\
\text { Moreira }\end{array}$ & 2014 \\
\hline 66 & Patrícia Martins & $\begin{array}{l}\text { Especialização em Gestão } \\
\text { do Conhecimento e o } \\
\text { Paradigma }\end{array}$ & $\begin{array}{l}\text { Faculdade Antonio } \\
\text { Meneghetti (AMF) }\end{array}$ & $\begin{array}{l}\text { A contribuição da } \\
\text { Metodologia } \\
\text { Ontopsicológica no }\end{array}$ & $\begin{array}{l}\text { Profa. Ms. } \\
\text { Maria } \\
\text { Tereza }\end{array}$ & 2014 \\
\hline
\end{tabular}


Saber Humano, ISSN 2446-6298, V. 9, n. 15, p. 186-423, jul./dez. 2019.

\begin{tabular}{|c|c|c|c|c|c|c|}
\hline & & $\begin{array}{l}\text { Ontopsicológico } \\
\text { Faculdade Antonio } \\
\text { Meneghetti (AMF) }\end{array}$ & & $\begin{array}{l}\text { processo de seleção de } \\
\text { pessoas }\end{array}$ & Andreola & \\
\hline 67 & Patrícia Rossato & $\begin{array}{l}\text { Especialização em Gestão } \\
\text { do Conhecimento e o } \\
\text { Paradigma } \\
\text { Ontopsicológico } \\
\text { Faculdade Antonio } \\
\text { Meneghetti (AMF) }\end{array}$ & $\begin{array}{l}\text { Faculdade Antonio } \\
\text { Meneghetti (AMF) }\end{array}$ & $\begin{array}{l}\text { Educação ao saber servir } \\
\text { no Atelier Escola Viva }\end{array}$ & $\begin{array}{l}\text { Profa. Dra } \\
\text { Estela Maris } \\
\text { Giordani }\end{array}$ & 2014 \\
\hline 68 & $\begin{array}{l}\text { Rosana Niederauer Marques } \\
\text { http://lattes.cnpq.br/946200284 } \\
7088127\end{array}$ & $\begin{array}{l}\text { Especialização em Gestão } \\
\text { do Conhecimento e o } \\
\text { Paradigma } \\
\text { Ontopsicológico } \\
\text { Faculdade Antonio } \\
\text { Meneghetti (AMF) }\end{array}$ & $\begin{array}{l}\text { Faculdade Antonio } \\
\text { Meneghetti (AMF) }\end{array}$ & $\begin{array}{l}\text { A influência da música no } \\
\text { jovem na sociedade atual }\end{array}$ & $\begin{array}{l}\text { Profa. Ms. } \\
\text { Maria } \\
\text { Tereza } \\
\text { Andreola }\end{array}$ & 2014 \\
\hline 69 & $\begin{array}{l}\text { Rosane Maria Neves } \\
\text { http://lattes.cnpq.br/046583421 } \\
3841012\end{array}$ & $\begin{array}{l}\text { Especialização em Gestão } \\
\text { do Conhecimento e o } \\
\text { Paradigma } \\
\text { Ontopsicológico } \\
\text { Faculdade Antonio } \\
\text { Meneghetti (AMF) }\end{array}$ & $\begin{array}{l}\text { Faculdade Antonio } \\
\text { Meneghetti (AMF) }\end{array}$ & $\begin{array}{l}\text { Proposta lúdica para } \\
\text { aprendizagem FOIL }\end{array}$ & $\begin{array}{l}\text { Profa. Dra } \\
\text { Adriane } \\
\text { Maria Moro } \\
\text { Mendes }\end{array}$ & 2014 \\
\hline 70 & Rosane Zolin & $\begin{array}{l}\text { Especialização em Gestão } \\
\text { do Conhecimento e o } \\
\text { Paradigma } \\
\text { Ontopsicológico } \\
\text { Faculdade Antonio } \\
\text { Meneghetti (AMF) }\end{array}$ & $\begin{array}{l}\text { Faculdade Antonio } \\
\text { Meneghetti (AMF) }\end{array}$ & $\begin{array}{l}\text { O percurso da } \\
\text { autenticidade: de Rogers a } \\
\text { Meneghetti }\end{array}$ & $\begin{array}{l}\text { Prof. Dr. } \\
\text { Alécio Vidor }\end{array}$ & 2014 \\
\hline
\end{tabular}




\begin{tabular}{|c|c|c|c|c|c|c|}
\hline 71 & Roula Kozak & $\begin{array}{l}\text { Especialização em Gestão } \\
\text { do Conhecimento e o } \\
\text { Paradigma } \\
\text { Ontopsicológico } \\
\text { Faculdade Antonio } \\
\text { Meneghetti (AMF) }\end{array}$ & $\begin{array}{l}\text { Faculdade Antonio } \\
\text { Meneghetti (AMF) }\end{array}$ & $\begin{array}{l}\text { Particularidades } \\
\text { psicológicas da relação de } \\
\text { fidelização entre pacientes } \\
\text { e médicos especialistas } \\
\text { em Dermatologia }\end{array}$ & $\begin{array}{l}\text { Prof. Dr. } \\
\text { Érico de } \\
\text { Lima } \\
\text { Azevedo }\end{array}$ & 2014 \\
\hline 72 & Roula Kozak & $\begin{array}{l}\text { Especialização em } \\
\text { Psicologia com abordagem } \\
\text { em Ontopsicologia } \\
\text { Universidade Estatal de } \\
\text { São Petersburgo, Rússia } \\
\text { (SPbU) }\end{array}$ & $\begin{array}{l}\text { Universidade Estatal } \\
\text { de São Petersburgo, } \\
\text { Rússia (SPbU) }\end{array}$ & $\begin{array}{l}\text { Particularidades } \\
\text { Psicológicas da relação de } \\
\text { fidelização entre pacientes } \\
\text { e médicos especialistas } \\
\text { em Dermatologia }\end{array}$ & $\begin{array}{l}\text { Profa Dra } \\
\text { Natalia } \\
\text { Gorchakova }\end{array}$ & 2014 \\
\hline 73 & $\begin{array}{l}\text { Simone Terezinha Zanon } \\
\text { http://lattes.cnpq.br/679354362 } \\
0053896\end{array}$ & $\begin{array}{l}\text { Especialização em Gestão } \\
\text { do Conhecimento e o } \\
\text { Paradigma } \\
\text { Ontopsicológico } \\
\text { Faculdade Antonio } \\
\text { Meneghetti (AMF) }\end{array}$ & $\begin{array}{l}\text { Faculdade Antonio } \\
\text { Meneghetti (AMF) }\end{array}$ & $\begin{array}{l}\text { As competências } \\
\text { comportamentais do } \\
\text { contador: um estudo de } \\
\text { abordagem teórica }\end{array}$ & $\begin{array}{l}\text { Prof. Ms. } \\
\text { Claudio } \\
\text { Correa } \\
\text { Carrara }\end{array}$ & 2014 \\
\hline 74 & $\begin{array}{l}\text { Viviane Elias Portela } \\
\text { http://lattes.cnpq.br/237771074 } \\
1871472\end{array}$ & $\begin{array}{l}\text { Especialização em Gestão } \\
\text { do Conhecimento e o } \\
\text { Paradigma } \\
\text { Ontopsicológico } \\
\text { Faculdade Antonio } \\
\text { Meneghetti (AMF) }\end{array}$ & $\begin{array}{l}\text { Faculdade Antonio } \\
\text { Meneghetti (AMF) }\end{array}$ & $\begin{array}{l}\text { Projeto Flauta: histórico, } \\
\text { fundamentos e resultados }\end{array}$ & $\begin{array}{l}\text { Profa. Dra } \\
\text { Estela Maris } \\
\text { Giordani }\end{array}$ & 2014 \\
\hline
\end{tabular}


Saber Humano, ISSN 2446-6298, V. 9, n. 15, p. 186-423, jul./dez. 2019.

\begin{tabular}{|c|c|c|c|c|c|c|}
\hline 75 & $\begin{array}{l}\text { Patrícia Wazlawick } \\
\text { http://buscatextual.cnpq.br/bus } \\
\text { catextual/visualizacv.do?id=K47 }\end{array}$ & $\begin{array}{l}\text { Especialização em Gestão } \\
\text { do Conhecimento e o } \\
\text { Paradigma } \\
\text { Ontopsicológico }\end{array}$ & $\begin{array}{l}\text { Faculdade Antonio } \\
\text { Meneghetti (AMF) }\end{array}$ & $\begin{array}{l}\text { Para engendrar a Técnica } \\
\text { de Personalidade: } \\
\text { Resultados da Pedagogia } \\
\text { Ontopsicológica aplicada }\end{array}$ & $\begin{array}{l}\text { Prof. Ms. } \\
\text { Wesley } \\
\text { Lacerda e } \\
\text { Silva }\end{array}$ & 2014 \\
\hline & 53659Y5 & $\begin{array}{l}\text { Faculdade Antonio } \\
\text { Meneghetti (AMF) }\end{array}$ & & $\begin{array}{l}\text { na formação pessoal e } \\
\text { profissional de jovens no } \\
\text { ensino superior } \\
\text { universitário }\end{array}$ & & \\
\hline 76 & $\begin{array}{l}\text { Fernanda Goulart Martins } \\
\text { http://buscatextual.cnpq.br/bus } \\
\text { catextual/visualizacv.do?id=K43 } \\
\text { 87644P3 }\end{array}$ & $\begin{array}{l}\text { Especialização em } \\
\text { Psicologia com abordagem } \\
\text { em Ontopsicologia } \\
\text { Universidade Estatal de } \\
\text { São Petersburgo, Rússia } \\
\text { (SPbU) }\end{array}$ & $\begin{array}{l}\text { Universidade Estatal } \\
\text { de São Petersburgo, } \\
\text { Rússia (SPbU) }\end{array}$ & $\begin{array}{l}\text { A relevância da análise } \\
\text { dos sonhos na clínica } \\
\text { psicológica }\end{array}$ & $\begin{array}{l}\text { Profa. Dra } \\
\text { Nathalya } \\
\text { Gortchakova }\end{array}$ & 2014 \\
\hline 78 & $\begin{array}{l}\text { Clarissa Mazon Miranda } \\
\text { http://buscatextual.cnpq.br/bus } \\
\text { catextual/visualizacv.do?id=K44 } \\
\text { 57476J5 }\end{array}$ & $\begin{array}{l}\text { Especialização em } \\
\text { Psicologia com abordagem } \\
\text { em Ontopsicologia } \\
\text { Universidade Estatal de } \\
\text { São Petersburgo, Rússia } \\
\text { (SPbU) }\end{array}$ & $\begin{array}{l}\text { Universidade Estatal } \\
\text { de São Petersburgo, } \\
\text { Rússia (SPbU) }\end{array}$ & $\begin{array}{l}\text { A Linguagem não-verbal } \\
\text { no Jornalista de TV: Um } \\
\text { Estudo de Caso }\end{array}$ & $\begin{array}{l}\text { Profa. Dra. } \\
\text { Natalia } \\
\text { Grishna }\end{array}$ & 2014 \\
\hline
\end{tabular}


Saber Humano, ISSN 2446-6298, V. 9, n. 15, p. 186-423, jul./dez. 2019.

\begin{tabular}{|c|c|c|c|c|c|c|}
\hline 79 & Adriana Bertoldi & $\begin{array}{l}\text { Especialização em Gestão } \\
\text { do Conhecimento e o } \\
\text { Paradigma } \\
\text { Ontopsicológico } \\
\text { Faculdade Antonio } \\
\text { Meneghetti (AMF) }\end{array}$ & $\begin{array}{l}\text { Faculdade Antonio } \\
\text { Meneghetti (AMF) }\end{array}$ & $\begin{array}{l}\text { Requisitos do Consultor } \\
\text { na Implantação da Gestão } \\
\text { da Qualidade }\end{array}$ & $\begin{array}{l}\text { Profa. Dra. } \\
\text { Nádia Isabel } \\
\text { de Souza }\end{array}$ & 2013 \\
\hline 80 & $\begin{array}{l}\text { Arlete Salante } \\
\text { http://lattes.cnpq.br/658028273 } \\
0152522\end{array}$ & $\begin{array}{l}\text { Especialização em Gestão } \\
\text { do Conhecimento e o } \\
\text { Paradigma } \\
\text { Ontopsicológico } \\
\text { Faculdade Antonio } \\
\text { Meneghetti (AMF) }\end{array}$ & $\begin{array}{l}\text { Faculdade Antonio } \\
\text { Meneghetti (AMF) }\end{array}$ & $\begin{array}{l}\text { Satisfação Profissional na } \\
\text { Geração Y }\end{array}$ & $\begin{array}{l}\text { Profa. Ms. } \\
\text { Ana Maris } \\
\text { Petry }\end{array}$ & 2013 \\
\hline 81 & Artur Lorentz & $\begin{array}{l}\text { Especialização em Gestão } \\
\text { do Conhecimento e o } \\
\text { Paradigma } \\
\text { Ontopsicológico } \\
\text { Faculdade Antonio } \\
\text { Meneghetti (AMF) }\end{array}$ & $\begin{array}{l}\text { Faculdade Antonio } \\
\text { Meneghetti (AMF) }\end{array}$ & $\begin{array}{l}\text { A intuição nos processos } \\
\text { de inovação tecnológica: } \\
\text { qual a relação? }\end{array}$ & $\begin{array}{l}\text { Profa. Dra. } \\
\text { Soraia } \\
\text { Schutel }\end{array}$ & 2013 \\
\hline 82 & Carlos Alberto Genari & $\begin{array}{l}\text { Especialização em Gestão } \\
\text { do Conhecimento e o } \\
\text { Paradigma } \\
\text { Ontopsicológico } \\
\text { Faculdade Antonio } \\
\text { Meneghetti (AMF) }\end{array}$ & $\begin{array}{l}\text { Faculdade Antonio } \\
\text { Meneghetti (AMF) }\end{array}$ & $\begin{array}{l}\text { A restituição da } \\
\text { capacidade competitiva } \\
\text { pelo reforço da unidade } \\
\text { de ação e da identidade } \\
\text { empresarial }\end{array}$ & $\begin{array}{l}\text { Profa. Dra. } \\
\text { Estela Maris } \\
\text { Giordani }\end{array}$ & 2013 \\
\hline
\end{tabular}


Saber Humano, ISSN 2446-6298, V. 9, n. 15, p. 186-423, jul./dez. 2019.

\begin{tabular}{|c|c|c|c|c|c|c|}
\hline 83 & Cinara Graeff & $\begin{array}{l}\text { Especialização em Gestão } \\
\text { do Conhecimento e o } \\
\text { Paradigma } \\
\text { Ontopsicológico } \\
\text { Faculdade Antonio } \\
\text { Meneghetti (AMF) }\end{array}$ & $\begin{array}{l}\text { Faculdade Antonio } \\
\text { Meneghetti (AMF) }\end{array}$ & $\begin{array}{l}\text { O papel do Ministério } \\
\text { Público do Trabalho para a } \\
\text { melhoria das condições de } \\
\text { saúde e segurança nas } \\
\text { organizações }\end{array}$ & $\begin{array}{l}\text { Profa. Drá } \\
\text { Nádia Isabel } \\
\text { de Souza }\end{array}$ & 2013 \\
\hline \multirow[t]{2}{*}{84} & Élcio Brazão Brandão Diniz & $\begin{array}{l}\text { Especialização em Gestão } \\
\text { do Conhecimento e o } \\
\text { Paradigma } \\
\text { Ontopsicológico. }\end{array}$ & $\begin{array}{l}\text { Faculdade Antonio } \\
\text { Meneghetti (AMF) }\end{array}$ & $\begin{array}{l}\text { Emprego da Metodologia } \\
\text { Ontospicológica na } \\
\text { seleção de parceiros e } \\
\text { colaboradores }\end{array}$ & $\begin{array}{l}\text { Profa. Ms. } \\
\text { Ana Maris } \\
\text { Petry }\end{array}$ & 2013 \\
\hline & & $\begin{array}{l}\text { Faculdade Antonio } \\
\text { Menegheti (AMF) }\end{array}$ & & & & \\
\hline 85 & Elisandro Elias Ubatuba & $\begin{array}{l}\text { Especialização em Gestão } \\
\text { do Conhecimento e o } \\
\text { Paradigma } \\
\text { Ontopsicológico. } \\
\text { Faculdade Antonio } \\
\text { Menegheti (AMF) }\end{array}$ & $\begin{array}{l}\text { Faculdade Antonio } \\
\text { Meneghetti (AMF) }\end{array}$ & $\begin{array}{l}\text { Quem é o jovem } \\
\text { empreendedor que estuda } \\
\text { Ontopsicologia }\end{array}$ & $\begin{array}{l}\text { Profa. Dra. } \\
\text { Adriane } \\
\text { Maria Moro } \\
\text { Mendes }\end{array}$ & 2013 \\
\hline 86 & Everson Tavares & $\begin{array}{l}\text { Especialização em Gestão } \\
\text { do Conhecimento e o } \\
\text { Paradigma } \\
\text { Ontopsicológico. } \\
\text { Faculdade Antonio } \\
\text { Menegheti (AMF) }\end{array}$ & $\begin{array}{l}\text { Faculdade Antonio } \\
\text { Meneghetti (AMF) }\end{array}$ & $\begin{array}{l}\text { Atitude psicológica do } \\
\text { líder na construção de sua } \\
\text { carreira: ambição e amor } \\
\text { ao próprio trabalho }\end{array}$ & $\begin{array}{l}\text { Profa. Ms. } \\
\text { Josiane } \\
\text { Beatriz } \\
\text { Piccin } \\
\text { Barbieri }\end{array}$ & 2013 \\
\hline
\end{tabular}


Saber Humano, ISSN 2446-6298, V. 9, n. 15, p. 186-423, jul./dez. 2019.

\begin{tabular}{|c|c|c|c|c|c|c|}
\hline 87 & Fábio de Oliveira Rodrigues & $\begin{array}{l}\text { Especialização em Gestão } \\
\text { do Conhecimento e o } \\
\text { Paradigma } \\
\text { Ontopsicológico. } \\
\text { Faculdade Antonio } \\
\text { Menegheti (AMF) }\end{array}$ & $\begin{array}{l}\text { Faculdade Antonio } \\
\text { Meneghetti (AMF) }\end{array}$ & $\begin{array}{l}\text { Estudo de caso em que a } \\
\text { formação empreendedora } \\
\text { do jovem contribui para a } \\
\text { criação de um negócio } \\
\text { inovador na área de } \\
\text { Produção Musical: a } \\
\text { gravação de áudio em } \\
\text { domicílio }\end{array}$ & $\begin{array}{l}\text { Profa. Dra. } \\
\text { Patrícia } \\
\text { Wazlawick }\end{array}$ & 2013 \\
\hline 88 & Fredi Moroni e Eliane Magnam & $\begin{array}{l}\text { Especialização em Gestão } \\
\text { do Conhecimento e o } \\
\text { Paradigma } \\
\text { Ontopsicológico. } \\
\text { Faculdade Antonio }\end{array}$ & $\begin{array}{l}\text { Faculdade Antonio } \\
\text { Meneghetti (AMF) }\end{array}$ & $\begin{array}{l}\text { Manual de formação de } \\
\text { consultores de vendas }\end{array}$ & $\begin{array}{l}\text { Profa. Dra. } \\
\text { Soraia } \\
\text { Schutel }\end{array}$ & 2013 \\
\hline & & Menegheti (AMF) & & & & \\
\hline 89 & Gilmar Brighmann & $\begin{array}{l}\text { Especialização em Gestão } \\
\text { do Conhecimento e o } \\
\text { Paradigma } \\
\text { Ontopsicológico. } \\
\text { Faculdade Antonio } \\
\text { Menegheti (AMF) }\end{array}$ & $\begin{array}{l}\text { Faculdade Antonio } \\
\text { Meneghetti (AMF) }\end{array}$ & $\begin{array}{l}\text { A profissionalização da } \\
\text { gestão financeira e a } \\
\text { forma mentis empresarial }\end{array}$ & $\begin{array}{l}\text { Prof. Ms. } \\
\text { Ângelo } \\
\text { Accorsi } \\
\text { Moreira }\end{array}$ & 2013 \\
\hline 90 & Helena Camacho & $\begin{array}{l}\text { Especialização em Gestão } \\
\text { do Conhecimento e o } \\
\text { Paradigma } \\
\text { Ontopsicológico. } \\
\text { Faculdade Antonio }\end{array}$ & $\begin{array}{l}\text { Faculdade Antonio } \\
\text { Meneghetti (AMF) }\end{array}$ & $\begin{array}{l}\text { Planejamento de Carreira: } \\
\text { uma responsabilidade do } \\
\text { indivíduo }\end{array}$ & $\begin{array}{l}\text { Profa. Dra. } \\
\text { Patrícia } \\
\text { Wazlawick }\end{array}$ & 2013 \\
\hline
\end{tabular}


Saber Humano, ISSN 2446-6298, V. 9, n. 15, p. 186-423, jul./dez. 2019.

\begin{tabular}{|c|c|c|c|c|c|c|}
\hline & & Menegheti (AMF) & & & & \\
\hline 91 & Henrique Gerstner & $\begin{array}{l}\text { Especialização em Gestão } \\
\text { do Conhecimento e o } \\
\text { Paradigma } \\
\text { Ontopsicológico. } \\
\text { Faculdade Antonio } \\
\text { Menegheti (AMF) }\end{array}$ & $\begin{array}{l}\text { Faculdade Antonio } \\
\text { Meneghetti (AMF) }\end{array}$ & $\begin{array}{l}\text { Qualificação do corpo } \\
\text { docente das Escolas QI nas } \\
\text { competências elencadas } \\
\text { no DNA QI }\end{array}$ & $\begin{array}{l}\text { Profa. Ms. } \\
\text { Estela Maris } \\
\text { Giordani }\end{array}$ & 2013 \\
\hline 92 & $\begin{array}{l}\text { Ivo da Cunha Ferreira Junior, } \\
\text { Lucia Helena Zanardi, Nesterson } \\
\text { da Siva Gomes, Thiago da Silva } \\
\text { Rodrigues dos Santos }\end{array}$ & $\begin{array}{l}\text { Especialização em Gestão } \\
\text { do Conhecimento e o } \\
\text { Paradigma } \\
\text { Ontopsicológico. } \\
\text { Faculdade Antonio } \\
\text { Menegheti (AMF) }\end{array}$ & $\begin{array}{l}\text { Faculdade Antonio } \\
\text { Meneghetti (AMF) }\end{array}$ & $\begin{array}{l}\text { Aportes da Teoria } \\
\text { Ontopsicológica para a } \\
\text { intervenção na cultura } \\
\text { organizacional }\end{array}$ & $\begin{array}{l}\text { Profa. Ms. } \\
\text { Josiane } \\
\text { Beatriz } \\
\text { Piccin } \\
\text { Barbieri }\end{array}$ & 2013 \\
\hline \multirow[t]{2}{*}{93} & João Carlos Dal'Aqua & $\begin{array}{l}\text { Especialização em Gestão } \\
\text { do Conhecimento e o } \\
\text { Paradigma }\end{array}$ & $\begin{array}{l}\text { Faculdade Antonio } \\
\text { Meneghetti (AMF) }\end{array}$ & $\begin{array}{l}\text { Sucessão em empresas } \\
\text { familiares: uma } \\
\text { contribuição da }\end{array}$ & $\begin{array}{l}\text { Profa. Ms. } \\
\text { Vera Lúcia } \\
\text { Rodegheri }\end{array}$ & 2013 \\
\hline & & $\begin{array}{l}\text { Ontopsicológico. } \\
\text { Faculdade Antonio } \\
\text { Menegheti (AMF) }\end{array}$ & & Metodologia FOIL & & \\
\hline
\end{tabular}


Saber Humano, ISSN 2446-6298, V. 9, n. 15, p. 186-423, jul./dez. 2019.

\begin{tabular}{|c|c|c|c|c|c|c|}
\hline 94 & José Luiz Richetti & $\begin{array}{l}\text { Especialização em Gestão } \\
\text { do Conhecimento e o } \\
\text { Paradigma } \\
\text { Ontopsicológico. } \\
\text { Faculdade Antonio } \\
\text { Menegheti (AMF) }\end{array}$ & $\begin{array}{l}\text { Faculdade Antonio } \\
\text { Meneghetti (AMF) }\end{array}$ & $\begin{array}{l}\text { O significado do trabalho } \\
\text { e dignidade da pessoa } \\
\text { humana como } \\
\text { fundamentos do Estado } \\
\text { Democrático de Direito } \\
\text { Brasileiro }\end{array}$ & $\begin{array}{l}\text { Prof. Dr. } \\
\text { Josemar } \\
\text { Sidinei } \\
\text { Soares }\end{array}$ & 2013 \\
\hline 95 & $\begin{array}{l}\text { Juliane Neves Fiorezi } \\
\text { http://lattes.cnpq.br/673498830 } \\
1281583\end{array}$ & $\begin{array}{l}\text { Especialização em Gestão } \\
\text { do Conhecimento e o } \\
\text { Paradigma } \\
\text { Ontopsicológico. } \\
\text { Faculdade Antonio } \\
\text { Menegheti (AMF) }\end{array}$ & $\begin{array}{l}\text { Faculdade Antonio } \\
\text { Meneghetti (AMF) }\end{array}$ & $\begin{array}{l}\text { Competências do Gestor } \\
\text { Cultural em Economia } \\
\text { Criativa }\end{array}$ & $\begin{array}{l}\text { Prof. Ms. } \\
\text { Wesley } \\
\text { Lacerda e } \\
\text { Silva }\end{array}$ & 2013 \\
\hline 96 & Letícia Viana & $\begin{array}{l}\text { Especialização em Gestão } \\
\text { do Conhecimento e o } \\
\text { Paradigma } \\
\text { Ontopsicológico. } \\
\text { Faculdade Antonio } \\
\text { Menegheti (AMF) }\end{array}$ & $\begin{array}{l}\text { Faculdade Antonio } \\
\text { Meneghetti (AMF) }\end{array}$ & $\begin{array}{l}\text { A Gestão de Pessoas na } \\
\text { Indústria Criativa: como } \\
\text { trabalhar com o tipo } \\
\text { criativo }\end{array}$ & $\begin{array}{l}\text { Profa. Ms. } \\
\text { Carolina } \\
\text { Schuskel } \\
\text { Miranda }\end{array}$ & 2013 \\
\hline 97 & Luciana dos Santos & $\begin{array}{l}\text { Especialização em Gestão } \\
\text { do Conhecimento e o } \\
\text { Paradigma } \\
\text { Ontopsicológico. } \\
\text { Faculdade Antonio } \\
\text { Menegheti (AMF) }\end{array}$ & $\begin{array}{l}\text { Faculdade Antonio } \\
\text { Meneghetti (AMF) }\end{array}$ & $\begin{array}{l}\text { Tecendo meu projeto de } \\
\text { vida entrelaçado à } \\
\text { formação profissional de } \\
\text { (outros) jovens: } \\
\text { capacitação e formação } \\
\text { de proefessores na } \\
\text { educação musical }\end{array}$ & $\begin{array}{l}\text { Profa. Dra. } \\
\text { Patrícia } \\
\text { Wazlawick }\end{array}$ & 2013 \\
\hline
\end{tabular}


Saber Humano, ISSN 2446-6298, V. 9, n. 15, p. 186-423, jul./dez. 2019.

\begin{tabular}{|c|c|c|c|c|c|c|}
\hline 98 & Marcelo Pfleger & $\begin{array}{l}\text { Especialização em Gestão } \\
\text { do Conhecimento e o } \\
\text { Paradigma } \\
\text { Ontopsicológico. } \\
\text { Faculdade Antonio } \\
\text { Menegheti (AMF) }\end{array}$ & $\begin{array}{l}\text { Faculdade Antonio } \\
\text { Meneghetti (AMF) }\end{array}$ & $\begin{array}{l}\text { A humanização do } \\
\text { trabalho através da } \\
\text { evolução da Tecnologia da } \\
\text { Informação: } \\
\text { CAMADAWEB }\end{array}$ & $\begin{array}{l}\text { Prof. Dr. } \\
\text { Érico de } \\
\text { Lima } \\
\text { Azevedo }\end{array}$ & 2013 \\
\hline 99 & Marcelo Selhorst & $\begin{array}{l}\text { Especialização em Gestão } \\
\text { do Conhecimento e o } \\
\text { Paradigma } \\
\text { Ontopsicológico. } \\
\text { Faculdade Antonio } \\
\text { Menegheti (AMF) }\end{array}$ & $\begin{array}{l}\text { Faculdade Antonio } \\
\text { Meneghetti, AMF }\end{array}$ & $\begin{array}{l}\text { Limites objetivos e } \\
\text { subjetivos da atuação do } \\
\text { advogado na tomada de } \\
\text { decisões do líder }\end{array}$ & $\begin{array}{l}\text { Prof. Dr. } \\
\text { Josemar } \\
\text { Sidinei } \\
\text { Soares }\end{array}$ & 2013 \\
\hline 100 & Mariana Brito Araújo & $\begin{array}{l}\text { Especialização em Gestão } \\
\text { do Conhecimento e o } \\
\text { Paradigma } \\
\text { Ontopsicológico. } \\
\text { Faculdade Antonio } \\
\text { Menegheti (AMF) }\end{array}$ & $\begin{array}{l}\text { Faculdade Antonio } \\
\text { Meneghetti (AMF) }\end{array}$ & $\begin{array}{l}\text { Magistratura e } \\
\text { Humanismo: da } \\
\text { conformidade Lógica } \\
\text { Jurídica ao critério ôntico } \\
\text { - o Caso Raposa Serra do } \\
\text { Sol }\end{array}$ & $\begin{array}{l}\text { Prof. Dr. } \\
\text { Josemar } \\
\text { Sidinei } \\
\text { Soares }\end{array}$ & 2013 \\
\hline 101 & Marina Moreira da Costa & $\begin{array}{l}\text { Especialização em Gestão } \\
\text { do Conhecimento e o } \\
\text { Paradigma } \\
\text { Ontopsicológico. } \\
\text { Faculdade Antonio } \\
\text { Menegheti (AMF) }\end{array}$ & $\begin{array}{l}\text { Faculdade Antonio } \\
\text { Meneghetti (AMF) }\end{array}$ & $\begin{array}{l}\text { O poder da imagem } \\
\text { fotográfica nas mídias } \\
\text { sociais }\end{array}$ & $\begin{array}{l}\text { Profa. Dra. } \\
\text { Estela Maris } \\
\text { Giordani }\end{array}$ & 2013 \\
\hline 102 & Marina Prevedello & $\begin{array}{l}\text { Especialização em Gestão } \\
\text { do Conhecimento e o } \\
\text { Paradigma }\end{array}$ & $\begin{array}{l}\text { Faculdade Antonio } \\
\text { Meneghetti (AMF) }\end{array}$ & $\begin{array}{l}\text { Modos de liderança e os } \\
\text { impactos nos negócios }\end{array}$ & $\begin{array}{l}\text { Dra. Estela } \\
\text { Maris } \\
\text { Giordani }\end{array}$ & 2013 \\
\hline
\end{tabular}


Saber Humano, ISSN 2446-6298, V. 9, n. 15, p. 186-423, jul./dez. 2019.

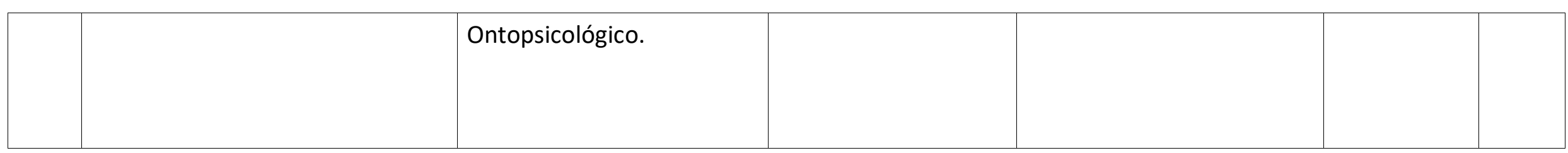

\begin{tabular}{|c|c|c|c|c|c|c|}
\hline & & $\begin{array}{l}\text { Faculdade Antonio } \\
\text { Menegheti (AMF) }\end{array}$ & & & & \\
\hline 103 & Marvyn Ezequiel Brandt & $\begin{array}{l}\text { Especialização em Gestão } \\
\text { do Conhecimento e o } \\
\text { Paradigma } \\
\text { Ontopsicológico. } \\
\text { Faculdade Antonio } \\
\text { Menegheti (AMF) }\end{array}$ & $\begin{array}{l}\text { Faculdade Antonio } \\
\text { Meneghetti (AMF) }\end{array}$ & $\begin{array}{l}\text { Comunicação da } \\
\text { Identidade Kimyto }\end{array}$ & $\begin{array}{l}\text { Profa. Dra. } \\
\text { Soraia } \\
\text { Schutel }\end{array}$ & 2013 \\
\hline
\end{tabular}




\begin{tabular}{|c|c|c|c|c|c|c|}
\hline 106 & $\begin{array}{l}\text { Tereza Cristina Melo de Brito } \\
\text { Carvalho } \\
\text { http://buscatextual.cnpq.br/bus } \\
\text { catextual/visualizacv.do?id=K47 } \\
\text { 87479E6 }\end{array}$ & $\begin{array}{l}\text { Especialização em } \\
\text { Psicologia com } \\
\text { abordagem em } \\
\text { Ontopsicologia. } \\
\text { Universidade Estatal de } \\
\text { São Petersburgo, Rússia. }\end{array}$ & $\begin{array}{l}\text { Universidade Estatal } \\
\text { de São Petersburgo, } \\
\text { Rússia. }\end{array}$ & $\begin{array}{l}\text { Avaliação do impacto de } \\
\text { política de valorização do } \\
\text { humano na melhoria da } \\
\text { Qualidade de Serviços de } \\
\text { TIC (Tecnologia de } \\
\text { Informação e } \\
\text { Comunicação) }\end{array}$ & $\begin{array}{l}\text { Profa. Dra. } \\
\text { Natalia } \\
\text { Grishina }\end{array}$ & 2013 \\
\hline \multirow[t]{2}{*}{107} & Kátia Klar Renner & Especialização em & Universidade Estatal & Particularidades da & Profa. Dra & 2013 \\
\hline & $\begin{array}{l}\text { http://lattes.cnpq.br/564995744 } \\
9883276\end{array}$ & $\begin{array}{l}\text { Ontopsicologia Social. } \\
\text { Universidade Estatal de São } \\
\text { Petersburgo, Rússia. }\end{array}$ & $\begin{array}{l}\text { de São Petersburgo, } \\
\text { Rússia. }\end{array}$ & $\begin{array}{l}\text { percepção da música } \\
\text { instrumental moderna } \\
\text { pelos alunos da escola } \\
\text { brasileira }\end{array}$ & $\begin{array}{l}\text { Veronica } \\
\text { Odintsov }\end{array}$ & \\
\hline 108 & $\begin{array}{l}\text { Tereza Cristina Melo de Brito } \\
\text { Carvalho } \\
\text { http://buscatextual.cnpq.br/bus } \\
\text { catextual/visualizacv.do?id=K47 } \\
87479 E 6\end{array}$ & $\begin{array}{l}\text { Especialização em } \\
\text { Ontopsicologia Social. } \\
\text { Universidade Estatal de São } \\
\text { Petersburgo, Rússia. }\end{array}$ & $\begin{array}{l}\text { Universidade Estatal } \\
\text { de São Petersburgo, } \\
\text { Rússia. }\end{array}$ & $\begin{array}{l}\text { Características } \\
\text { psicológicas individuais } \\
\text { dos dirigentes como fator } \\
\text { de sucesso das mudanças } \\
\text { organizacionais (usando } \\
\text { exemplo de Empresas TI) }\end{array}$ & $\begin{array}{l}\text { Profa. Dra. } \\
\text { Natalia } \\
\text { Grishina }\end{array}$ & 2013 \\
\hline 109 & Ariovaldo Ceratti & $\begin{array}{l}\text { Especialização em } \\
\text { Ontopsicologia Social. } \\
\text { Universidade Estatal de São } \\
\text { Petersburgo, Rússia. }\end{array}$ & $\begin{array}{l}\text { Universidade Estatal } \\
\text { de São Petersburgo, } \\
\text { Rússia. }\end{array}$ & $\begin{array}{l}\text { Particularidades } \\
\text { psicológicas dos gestores } \\
\text { empresariais da } \\
\text { agricultura na adoção } \\
\text { de mudanças }\end{array}$ & $\begin{array}{l}\text { Profa. Dra. } \\
\text { Natalia } \\
\text { Grishina }\end{array}$ & 2013 \\
\hline
\end{tabular}


Saber Humano, ISSN 2446-6298, V. 9, n. 15, p. 186-423, jul./dez. 2019.

\begin{tabular}{|c|c|c|c|c|c|c|}
\hline 110 & Marcelo Girade Corrêa & $\begin{array}{l}\text { Especialização em } \\
\text { Ontopsicologia Social. } \\
\text { Universidade Estatal de São } \\
\text { Petersburgo, Rússia. }\end{array}$ & $\begin{array}{l}\text { Universidade Estatal } \\
\text { de São Petersburgo, } \\
\text { Rússia. }\end{array}$ & $\begin{array}{l}\text { As particularidades } \\
\text { psicológicas da percepção } \\
\text { e da atitude aos conflitos }\end{array}$ & $\begin{array}{l}\text { Profa. Dra. } \\
\text { Natalia } \\
\text { Grishina }\end{array}$ & 2013 \\
\hline 111 & $\begin{array}{l}\text { Noemi Boer } \\
\text { http://lattes.cnpq.br/706795750 } \\
7021073\end{array}$ & $\begin{array}{l}\text { Especialização em } \\
\text { Ontopsicologia Social. } \\
\text { Universidade Estatal de São } \\
\text { Petersburgo, Rússia. }\end{array}$ & $\begin{array}{l}\text { Universidade Estatal } \\
\text { de São Petersburgo, } \\
\text { Rússia. }\end{array}$ & $\begin{array}{l}\text { Peculiaridades } \\
\text { psicológicas dos } \\
\text { estudantes de diferentes } \\
\text { etapas de ensino (tendo } \\
\text { como exemplo a atitude } \\
\text { para com o meio }\end{array}$ & $\begin{array}{l}\text { Profa Drạ } \\
\text { Marina } \\
\text { Salitova }\end{array}$ & 2013 \\
\hline
\end{tabular}

\begin{tabular}{|c|c|c|c|c|c|c|}
\hline & & & & ambiente e ao ensino) & & \\
\hline 113 & $\begin{array}{l}\text { Cláudio Correa Carrara } \\
\text { http://buscatextual.cnpq.br/bus } \\
\text { catextual/visualizacv.do?id=K43 } \\
\text { 29101U5 }\end{array}$ & $\begin{array}{l}\text { Especialização em } \\
\text { Psicologia com abordagem } \\
\text { em Ontopsicologia. } \\
\text { Universidade Estatal de } \\
\text { São Petersburgo, Rússia. }\end{array}$ & $\begin{array}{l}\text { Universidade Estatal } \\
\text { de São Petersburgo, } \\
\text { Rússia. }\end{array}$ & $\begin{array}{l}\text { A Forma Mentis do } \\
\text { Empreendedor e o } \\
\text { resultado econômico } \\
\text { empresarial }\end{array}$ & $\begin{array}{l}\text { Profa. Dra. } \\
\text { Natalia } \\
\text { Grishina }\end{array}$ & 2011 \\
\hline
\end{tabular}


Saber Humano, ISSN 2446-6298, V. 9, n. 15, p. 186-423, jul./dez. 2019.

\begin{tabular}{|c|c|c|c|c|c|c|}
\hline 114 & $\begin{array}{l}\text { Josemar Sidinei Soares } \\
\text { http://buscatextual.cnpq.br/bus } \\
\text { catextual/visualizacv.do?id=K47 } \\
\text { 06660P7 }\end{array}$ & $\begin{array}{l}\text { Especialização em } \\
\text { Psicologia Social. } \\
\text { Universidade Estatal de } \\
\text { São Petersburgo, Rússia. }\end{array}$ & $\begin{array}{l}\text { Universidade Estatal } \\
\text { de São Petersburgo, } \\
\text { Rússia. }\end{array}$ & $\begin{array}{l}\text { O trabalho como } \\
\text { manifestação do Em Si } \\
\text { ôntico na história: uma } \\
\text { análise da percepção da } \\
\text { ideia de trabalho em } \\
\text { jovens universitários }\end{array}$ & $\begin{array}{l}\text { Profa. Dra. } \\
\text { Natalia } \\
\text { Grishina }\end{array}$ & 2011 \\
\hline 115 & $\begin{array}{l}\text { Ana Claudia Valentini } \\
\text { Montenegro } \\
\text { http://lattes.cnpq.br/164008319 } \\
8751229\end{array}$ & $\begin{array}{l}\text { Especialização em } \\
\text { Psicologia Social. } \\
\text { Universidade Estatal de } \\
\text { São Petersburgo, Rússia. }\end{array}$ & $\begin{array}{l}\text { Universidade Estatal } \\
\text { de São Petersburgo, } \\
\text { Rússia. }\end{array}$ & $\begin{array}{l}\text { O desenvolvimento da } \\
\text { personalidade do } \\
\text { empreendedor no ramo } \\
\text { do Programa Educacional } \\
\text { MBA }\end{array}$ & $\begin{array}{l}\text { Profa. Dra. } \\
\text { Victoria } \\
\text { Dmitrieva }\end{array}$ & 2011 \\
\hline 116 & Christine Farias Conti & $\begin{array}{l}\text { Especialização em } \\
\text { Psicologia Social. } \\
\text { Universidade Estatal de } \\
\text { São Petersburgo, Rússia. }\end{array}$ & $\begin{array}{l}\text { Universidade Estatal } \\
\text { de São Petersburgo, } \\
\text { Rússia. }\end{array}$ & $\begin{array}{l}\text { Imagem corporal nos } \\
\text { adolescentes }\end{array}$ & $\begin{array}{l}\text { Profa. } \\
\text { Natalia } \\
\text { Gorchakova }\end{array}$ & 2011 \\
\hline 118 & Alessandra Ribeiro Fernandes & $\begin{array}{l}\text { Especialização em } \\
\text { Psicologia Social. } \\
\text { Universidade Estatal de } \\
\text { São Petersburgo, Rússia. }\end{array}$ & $\begin{array}{l}\text { Especialização em } \\
\text { Psicologia Social. } \\
\text { Universidade Estatal } \\
\text { de São Petersburgo, } \\
\text { Rússia. }\end{array}$ & $\begin{array}{l}\text { A correspondência do } \\
\text { ambiente residencial às } \\
\text { particularidades } \\
\text { psicológicas da pessoa } \\
\text { como fator do seu }\end{array}$ & $\begin{array}{l}\text { Profa. Dra } \\
\text { Tatiana } \\
\text { Kharitonova }\end{array}$ & 2011 \\
\hline
\end{tabular}


Saber Humano, ISSN 2446-6298, V. 9, n. 15, p. 186-423, jul./dez. 2019.

\begin{tabular}{|c|c|c|c|c|c|c|}
\hline & & & & bemestar & & \\
\hline 119 & Roberto Argenta & $\begin{array}{l}\text { Especialização em } \\
\text { Psicologia Social. } \\
\text { Universidade Estatal de São } \\
\text { Petersburgo, Rússia. SPBU }\end{array}$ & $\begin{array}{l}\text { Universidade Estatal } \\
\text { de São Petersburgo, } \\
\text { Rússia. SPBU }\end{array}$ & $\begin{array}{l}\text { Mudança da cultura } \\
\text { organizacional: a } \\
\text { formação de } \\
\text { competências } \\
\text { competitivas }\end{array}$ & $\begin{array}{l}\text { Profa. Dra. } \\
\text { Natalia } \\
\text { Grishina }\end{array}$ & 2011 \\
\hline 120 & Almir Francisco Folletto & $\begin{array}{l}\text { Especialização em } \\
\text { Psicologia Social. } \\
\text { Universidade Estatal de } \\
\text { São Petersburgo, Rússia. }\end{array}$ & $\begin{array}{l}\text { Universidade Estatal } \\
\text { de São Petersburgo, } \\
\text { Rússia. }\end{array}$ & $\begin{array}{l}\text { Abordagem } \\
\text { Ontopsicológica para a } \\
\text { humanização das relações } \\
\text { do trabalho no } \\
\text { Setor Agrícola }\end{array}$ & $\begin{array}{l}\text { Profa. Dra. } \\
\text { Natalia } \\
\text { Grishina }\end{array}$ & 2011 \\
\hline 122 & James César Sperotto & $\begin{array}{l}\text { Especialização em } \\
\text { Psicologia Social. } \\
\text { Universidade Estatal de } \\
\text { São Petersburgo, Rússia. }\end{array}$ & $\begin{array}{l}\text { Universidade Estatal } \\
\text { de São Petersburgo, } \\
\text { Rússia. }\end{array}$ & $\begin{array}{l}\text { Características } \\
\text { psicológicas da } \\
\text { experiência de } \\
\text { participação da Cinelogia }\end{array}$ & $\begin{array}{l}\text { Profa. Dra. } \\
\text { Natalia } \\
\text { Grishina }\end{array}$ & 2011 \\
\hline
\end{tabular}


Saber Humano, ISSN 2446-6298, V. 9, n. 15, p. 186-423, jul./dez. 2019.

\begin{tabular}{|c|c|c|c|c|c|c|}
\hline 123 & $\begin{array}{l}\text { Carmen Ivanete D’Agostini } \\
\text { Spanhol } \\
\text { http://buscatextual.cnpq.br/bus } \\
\text { catextual/visualizacv.do?metodo } \\
\text { =apresentar\&id=K4723280Y3 }\end{array}$ & $\begin{array}{l}\text { Curso de Especialização } \\
\text { Lato Sensu “O } \\
\text { Empreendedor e a Cultura } \\
\text { Humanista", Faculdade } \\
\text { Antonio Meneghetti } \\
\text { (AMF) }\end{array}$ & $\begin{array}{l}\text { Faculdade Antonio } \\
\text { Meneghetti (AMF) }\end{array}$ & $\begin{array}{l}\text { Avaliação da mudança do } \\
\text { estilo de vida dos jovens }\end{array}$ & $\begin{array}{l}\text { Profa Dra } \\
\text { Adriane } \\
\text { Maria Moro } \\
\text { Mendes }\end{array}$ & 2011 \\
\hline 124 & $\begin{array}{l}\text { Rafael Padilha dos Santos } \\
\text { http://buscatextual.cnpq.br/bus } \\
\text { catextual/visualizacv.do?id=K47 } \\
\text { 37412D6 }\end{array}$ & $\begin{array}{l}\text { Especialização em } \\
\text { Psicologia Social. } \\
\text { Universidade Estatal de } \\
\text { São Petersburgo, Rússia. }\end{array}$ & $\begin{array}{l}\text { Universidade Estatal } \\
\text { de São Petersburgo, } \\
\text { Rússia. }\end{array}$ & $\begin{array}{l}\text { A formação da tendência } \\
\text { ética no processo de } \\
\text { aprendizagem }\end{array}$ & $\begin{array}{l}\text { Profa. Dra. } \\
\text { Natalia } \\
\text { Grishina }\end{array}$ & 2011 \\
\hline 125 & $\begin{array}{l}\text { Ricardo Schaefer } \\
\text { http://buscatextual.cnpq.br/bus } \\
\text { catextual/visualizacv.do?id=K47 } \\
64272 Z 0\end{array}$ & $\begin{array}{l}\text { Especialização em } \\
\text { Ontopsicologia Social. } \\
\text { Universidade Estatal de } \\
\text { São Petersburgo, Rússia. }\end{array}$ & $\begin{array}{l}\text { Universidade Estatal } \\
\text { de São Petersburgo, } \\
\text { Rússia. }\end{array}$ & $\begin{array}{l}\text { O processo de } \\
\text { gatekeeping na produção } \\
\text { e percepção da notícia }\end{array}$ & $\begin{array}{l}\text { Profa. Dra. } \\
\text { Natalia } \\
\text { Grishina }\end{array}$ & 2011 \\
\hline 126 & $\begin{array}{l}\text { Ângelo Accorsi Moreira } \\
\text { http://buscatextual.cnpq.br/bus } \\
\text { catextual/visualizacv.do?id=K47 }\end{array}$ & $\begin{array}{l}\text { Especialização em } \\
\text { Psicologia com abordagem } \\
\text { em Ontopsicologia. } \\
\text { Universidade Estatal de }\end{array}$ & $\begin{array}{l}\text { Universidade Estatal } \\
\text { de São Petersburgo, } \\
\text { Rússia. }\end{array}$ & $\begin{array}{l}\text { Abordagem Pedagógica à } \\
\text { Formação de Pessoas nas } \\
\text { Organizações }\end{array}$ & $\begin{array}{l}\text { Profa. Dra. } \\
\text { Natalia } \\
\text { Grishina }\end{array}$ & 2011 \\
\hline & 71598A2 & São Petersburgo, Rússia. & & & & \\
\hline
\end{tabular}


Saber Humano, ISSN 2446-6298, V. 9, n. 15, p. 186-423, jul./dez. 2019.

\begin{tabular}{|c|c|c|c|c|c|c|}
\hline 127 & $\begin{array}{l}\text { Janine Coelho Ouriques } \\
\text { http://buscatextual.cnpq.br/bus } \\
\text { catextual/visualizacv.do?id=K47 } \\
\text { 53690P2 }\end{array}$ & $\begin{array}{l}\text { Especialização em } \\
\text { Psicologia com abordagem } \\
\text { em Ontopsicologia. } \\
\text { Universidade Estatal de } \\
\text { São Petersburgo, Rússia. }\end{array}$ & $\begin{array}{l}\text { Universidade Estatal } \\
\text { de São Petersburgo, } \\
\text { Rússia. }\end{array}$ & $\begin{array}{l}\text { As particularidades } \\
\text { psicológicas da percepção } \\
\text { da corporeidade }\end{array}$ & $\begin{array}{l}\text { Profa. Dra. } \\
\text { Natalia } \\
\text { Grishina }\end{array}$ & 2011 \\
\hline 128 & $\begin{array}{l}\text { Helena Biasotto } \\
\text { http://buscatextual.cnpq.br/bus } \\
\text { catextual/visualizacv.do?id=K47 } \\
\text { 76562E0 }\end{array}$ & $\begin{array}{l}\text { Especialização em } \\
\text { Psicologia com abordagem } \\
\text { em Ontopsicologia. } \\
\text { Universidade Estatal de } \\
\text { São Petersburgo, Rússia. }\end{array}$ & $\begin{array}{l}\text { Universidade Estatal } \\
\text { de São Petersburgo, } \\
\text { Rússia. }\end{array}$ & $\begin{array}{l}\text { Ensino Superior com a } \\
\text { Teoria e o Método } \\
\text { Ontopsicológico: o case } \\
\text { Faculdade Antonio } \\
\text { Meneghetti }\end{array}$ & $\begin{array}{l}\text { Profa. Dra. } \\
\text { Natalia } \\
\text { Grishina }\end{array}$ & 2009 \\
\hline 129 & $\begin{array}{l}\text { Wesley Lacerda e Silva } \\
\text { http://lattes.cnpq.br/702719475 } \\
9158382 \\
\text { http://buscatextual.cnpq.br/bus } \\
\text { catextual/visualizacv.do?id=K44 } \\
\text { 27014E6 }\end{array}$ & $\begin{array}{l}\text { Especialização em } \\
\text { Ontopsicologia. } \\
\text { Universidade Estatal de } \\
\text { São Petersburgo, Rússia. }\end{array}$ & $\begin{array}{l}\text { Universidade Estatal } \\
\text { de São Petersburgo, } \\
\text { Rússia. }\end{array}$ & $\begin{array}{l}\text { Aspectos da liderança e } \\
\text { seu impacto no } \\
\text { desempenho profissional }\end{array}$ & $\begin{array}{l}\text { Profa. Dra. } \\
\text { Natalia } \\
\text { Grishina }\end{array}$ & 2007 \\
\hline 130 & $\begin{array}{l}\text { Silvania Terezinha Moll } \\
\text { http://lattes.cnpq.br/121866090 } \\
7418557\end{array}$ & $\begin{array}{l}\text { Especialização em } \\
\text { Ontopsicologia. } \\
\text { Universidade Estatal de } \\
\text { São Petersburgo, Rússia. }\end{array}$ & $\begin{array}{l}\text { Universidade Estatal } \\
\text { de São Petersburgo, } \\
\text { Rússia. }\end{array}$ & $\begin{array}{l}\text { Influência da Psicologia da } \\
\text { Genitura no exercício do } \\
\text { poder e da liderança }\end{array}$ & $\begin{array}{l}\text { Profa. Dra. } \\
\text { Natalia } \\
\text { Grishina }\end{array}$ & 2007 \\
\hline
\end{tabular}


Saber Humano, ISSN 2446-6298, V. 9, n. 15, p. 186-423, jul./dez. 2019.

\begin{tabular}{|c|c|c|c|c|c|c|}
\hline 131 & Renato Arns & $\begin{array}{l}\text { Especialização em } \\
\text { Ontopsicologia. } \\
\text { Universidade Estatal de } \\
\text { São Petersburgo, Rússia. }\end{array}$ & $\begin{array}{l}\text { Universidade Estatal } \\
\text { de São Petersburgo, } \\
\text { Rússia. }\end{array}$ & $\begin{array}{l}\text { O sonho como ferramenta } \\
\text { de trabalho profissional }\end{array}$ & $\begin{array}{l}\text { Profa. Dra. } \\
\text { Natalia } \\
\text { Grishina }\end{array}$ & 2007 \\
\hline 132 & Mary Leda Baggio & $\begin{array}{l}\text { Especialização em } \\
\text { Ontopsicologia. } \\
\text { Universidade Estatal de } \\
\text { São Petersburgo, Rússia. }\end{array}$ & $\begin{array}{l}\text { Universidade Estatal } \\
\text { de São Petersburgo, } \\
\text { Rússia. }\end{array}$ & $\begin{array}{l}\text { Dalla donna famiglia alla } \\
\text { donna impresaria (Da } \\
\text { mulher dona de casa à } \\
\text { mulher empresária) }\end{array}$ & $\begin{array}{l}\text { Profa. Dra. } \\
\text { Natalia } \\
\text { Grishina }\end{array}$ & 2007 \\
\hline 133 & $\begin{array}{l}\text { Marisa do Carmo Bontorin } \\
\text { http://lattes.cnpq.br/564927717 } \\
7311965\end{array}$ & $\begin{array}{l}\text { Especialização em } \\
\text { Ontopsicologia. } \\
\text { Universidade Estatal de } \\
\text { São Petersburgo, Rússia. }\end{array}$ & $\begin{array}{l}\text { Universidade Estatal } \\
\text { de São Petersburgo, } \\
\text { Rússia. }\end{array}$ & $\begin{array}{l}\text { Estudo das características } \\
\text { de personalidade e a sua } \\
\text { correlação com a } \\
\text { satisfação pós- tratamento } \\
\text { médico de } \\
\text { problema estético }\end{array}$ & $\begin{array}{l}\text { Profa. Dra. } \\
\text { Natalia } \\
\text { Grishina }\end{array}$ & 2007 \\
\hline 134 & $\begin{array}{l}\text { Maria Luiza Andreola } \\
\text { http://lattes.cnpq.br/018107688 } \\
2047659\end{array}$ & $\begin{array}{l}\text { Especialização em } \\
\text { Ontopsicologia. } \\
\text { Universidade Estatal de } \\
\text { São Petersburgo, Rússia. }\end{array}$ & $\begin{array}{l}\text { Universidade Estatal } \\
\text { de São Petersburgo, } \\
\text { Rússia. }\end{array}$ & $\begin{array}{l}\text { Motivação à estética em } \\
\text { mulheres de 35-45 anos }\end{array}$ & $\begin{array}{l}\text { Profa. Dra. } \\
\text { Natalia } \\
\text { Grishina }\end{array}$ & 2007 \\
\hline 135 & $\begin{array}{l}\text { Magda Werner Philippi } \\
\text { http://lattes.cnpq.br/643999491 } \\
3712474\end{array}$ & $\begin{array}{l}\text { Especialização em } \\
\text { Ontopsicologia. } \\
\text { Universidade Estatal de } \\
\text { São Petersburgo, Rússia. }\end{array}$ & $\begin{array}{l}\text { Universidade Estatal } \\
\text { de São Petersburgo, } \\
\text { Rússia. }\end{array}$ & $\begin{array}{l}\text { A criatividade na Escola de } \\
\text { Ensino Fundamental: } \\
\text { um estudo de caso }\end{array}$ & $\begin{array}{l}\text { Profa. Dra. } \\
\text { Natalia } \\
\text { Grishina }\end{array}$ & 2007 \\
\hline
\end{tabular}


Saber Humano, ISSN 2446-6298, V. 9, n. 15, p. 186-423, jul./dez. 2019.

\begin{tabular}{|c|c|c|c|c|c|c|}
\hline 136 & $\begin{array}{l}\text { Érico de Lima Azevedo } \\
\text { http://lattes.cnpq.br/215177404 } \\
1320119\end{array}$ & $\begin{array}{l}\text { Especialização em } \\
\text { Ontopsicologia. } \\
\text { Universidade Estatal de } \\
\text { São Petersburgo, Rússia. }\end{array}$ & $\begin{array}{l}\text { Universidade Estatal } \\
\text { de São Petersburgo, } \\
\text { Rússia. }\end{array}$ & $\begin{array}{l}\text { L'In Sè ontico come criterio } \\
\text { della scelta economica } \\
\text { individuale }\end{array}$ & $\begin{array}{l}\text { Profa. Dra. } \\
\text { Natalia } \\
\text { Grishina }\end{array}$ & 2007 \\
\hline 137 & Claudete Inês Pelicioli & $\begin{array}{l}\text { Especialização em } \\
\text { Ontopsicologia. } \\
\text { Universidade Estatal de } \\
\text { São Petersburgo, Rússia. }\end{array}$ & $\begin{array}{l}\text { Universidade Estatal } \\
\text { de São Petersburgo, } \\
\text { Rússia. }\end{array}$ & $\begin{array}{l}\text { A subjetividade do } \\
\text { operardor na análise e } \\
\text { solução do caso jurídico }\end{array}$ & $\begin{array}{l}\text { Profa. Dra. } \\
\text { Natalia } \\
\text { Grishina }\end{array}$ & 2007 \\
\hline 138 & $\begin{array}{l}\text { Mami Ueno } \\
\text { http://lattes.cnpq.br/457330393 } \\
8473496\end{array}$ & $\begin{array}{l}\text { Especialização em } \\
\text { Ontopsicologia. } \\
\text { Universidade Estatal de } \\
\text { São Petersburgo, Rússia. }\end{array}$ & $\begin{array}{l}\text { Universidade Estatal } \\
\text { de São Petersburgo, } \\
\text { Rússia. }\end{array}$ & $\begin{array}{l}\text { Aplicação da } \\
\text { Ontopsicologia no campo } \\
\text { empresarial: a } \\
\text { assertividade ao sucesso }\end{array}$ & $\begin{array}{l}\text { Profa. Dra } \\
\text { Natalia } \\
\text { Grishina }\end{array}$ & 2007 \\
\hline 140 & $\begin{array}{l}\text { Adriane Maria Moro Mendes } \\
\text { http://lattes.cnpq.br/031910073 } \\
7730135\end{array}$ & $\begin{array}{l}\text { Especialização em } \\
\text { Psicologia com abordagem } \\
\text { em Ontopsicologia, } \\
\text { Universidade Estatal de } \\
\text { São Petersburgo, Rússia. }\end{array}$ & $\begin{array}{l}\text { Universidade Estatal } \\
\text { de São Petersburgo, } \\
\text { São Petersburgo, } \\
\text { Rússia }\end{array}$ & $\begin{array}{l}\text { O conceito de saúde entre } \\
\text { estudantes de Medicina e } \\
\text { de Psicologia }\end{array}$ & $\begin{array}{l}\text { Profa. Dra. } \\
\text { Natalia } \\
\text { Grishina }\end{array}$ & 2003 \\
\hline
\end{tabular}


Saber Humano, ISSN 2446-6298, V. 9, n. 15, p. 186-423, jul./dez. 2019.

\begin{tabular}{|c|c|c|c|c|c|c|}
\hline 141 & Izaías Penso & $\begin{array}{l}\text { Especialização em } \\
\text { Psicologia com abordagem } \\
\text { em Ontopsicologia, } \\
\text { Universidade Estatal de } \\
\text { São Petersburgo, Rússia. }\end{array}$ & $\begin{array}{l}\text { Universidade Estatal } \\
\text { de São Petersburgo, } \\
\text { São Petersburgo, } \\
\text { Rússia }\end{array}$ & $\begin{array}{l}\text { O inconsciente do } \\
\text { empresário e os } \\
\text { resultados econômicos de } \\
\text { sua empresa }\end{array}$ & $\begin{array}{l}\text { Profa. Dra. } \\
\text { Natalia } \\
\text { Grishina }\end{array}$ & 2003 \\
\hline 142 & Maria Lúcia Diniz & Especialização em & Universidade Estatal & As características da & Profa. Dra. & 2003 \\
\hline 143 & $\begin{array}{l}\text { Nádia Isabel de Souza } \\
\text { http://lattes.cnpq.br/136066657 } \\
2048374\end{array}$ & $\begin{array}{l}\text { Especialização em } \\
\text { Psicologia com abordagem } \\
\text { em Ontopsicologia da } \\
\text { Universidade Estatal de } \\
\text { São Petersburgo, Rússia }\end{array}$ & $\begin{array}{l}\text { Universidade Estatal } \\
\text { de São Petersburgo, } \\
\text { São Petersburgo, } \\
\text { Rússia }\end{array}$ & $\begin{array}{l}\text { Indicadores de cansaço e o } \\
\text { critério de sanidade } \\
\text { organizacional }\end{array}$ & $\begin{array}{l}\text { Profa. Dra. } \\
\text { Natalia } \\
\text { Grishina }\end{array}$ & \\
\hline
\end{tabular}


Saber Humano, ISSN 2446-6298, V. 9, n. 15, p. 186-423, jul./dez. 2019.

\begin{tabular}{|c|c|c|c|c|c|c|}
\hline 145 & $\begin{array}{l}\text { Annalisa Cangelosi } \\
\text { http://lattes.cnpq.br/854397986 } \\
1166148\end{array}$ & $\begin{array}{l}\text { Curso de Especialização em } \\
\text { Psicologia com abordagem } \\
\text { em } \\
\text { Ontopsicologia da } \\
\text { Universidade Estatal de } \\
\text { São Petersburgo, Rússia. }\end{array}$ & $\begin{array}{l}\text { Universidade Estatal } \\
\text { de São Petersburgo, } \\
\text { São Petersburgo, } \\
\text { Rússia }\end{array}$ & $\begin{array}{l}\text { La melolistica come } \\
\text { applicazione del metodo } \\
\text { ontopsicologico alla realtà } \\
\text { corporea: analisi delle } \\
\text { modificazioni avvenute } \\
\text { nella sfera personale, } \\
\text { lavorativa e sociale in } \\
\text { soggetti tra i } 25 \text { e i } 35 \\
\text { anni, come risultato della } \\
\text { pratica della }\end{array}$ & $\begin{array}{l}\text { Profa. Dra. } \\
\text { Natalia } \\
\text { Grishina }\end{array}$ & 2003 \\
\hline & & & & melolistica & & \\
\hline 146 & $\begin{array}{l}\text { Maria Alice Castilho Schuch } \\
\text { http://lattes.cnpq.br/576820254 } \\
2112018\end{array}$ & $\begin{array}{l}\text { Especialização em } \\
\text { Psicologia com ênfase em } \\
\text { Ontopsicologia. } \\
\text { Universidade Estatal de } \\
\text { São Petersburgo, Rússia. }\end{array}$ & $\begin{array}{l}\text { Universidade Estatal } \\
\text { de São Petersburgo, } \\
\text { Rússia. }\end{array}$ & $\begin{array}{l}\text { A mudança na percepção } \\
\text { de si e da situação de vida } \\
\text { nas mulheres: práxis } \\
\text { ontopsicológica }\end{array}$ & $\begin{array}{l}\text { Profa. Dra. } \\
\text { Larissa } \\
\text { Tsvetkova }\end{array}$ & 2003 \\
\hline 147 & $\begin{array}{l}\text { Estela Maris Giordani } \\
\text { http://lattes.cnpq.br/261369485 } \\
3235546\end{array}$ & $\begin{array}{l}\text { Especialização em } \\
\text { Psicologia com ênfase em } \\
\text { Ontopsicologia. } \\
\text { Universidade Estatal de } \\
\text { São Petersburgo, Rússia. }\end{array}$ & $\begin{array}{l}\text { Universidade Estatal } \\
\text { de São Petersburgo, } \\
\text { Rússia. }\end{array}$ & $\begin{array}{l}\text { Le particularità della } \\
\text { percezione dell'immagine } \\
\text { dell'io degl'insegnanti } \\
\text { universitari dai soggetti } \\
\text { della attività scolastica }\end{array}$ & $\begin{array}{l}\text { Prof. Dr. } \\
\text { Serguey } \\
\text { Artomonov }\end{array}$ & 2003 \\
\hline
\end{tabular}


Saber Humano, ISSN 2446-6298, V. 9, n. 15, p. 186-423, jul./dez. 2019.

\begin{tabular}{|c|c|c|c|c|c|c|}
\hline 148 & $\begin{array}{l}\text { Ana Maris Petry } \\
\text { http://lattes.cnpq.br/522408743 } \\
4361870\end{array}$ & $\begin{array}{l}\text { Especialização em } \\
\text { Psicologia com ênfase em } \\
\text { Ontopsicologia. } \\
\text { Universidade Estatal de São } \\
\text { Petersburgo, Rússia. }\end{array}$ & $\begin{array}{l}\text { Universidade Estatal } \\
\text { de São Petersburgo, } \\
\text { Rússia. }\end{array}$ & $\begin{array}{l}\text { A nova abordagem do } \\
\text { Complexo de Édipo }\end{array}$ & $\begin{array}{l}\text { Profa. Dra. } \\
\text { Larissa } \\
\text { Golovei }\end{array}$ & 2003 \\
\hline 149 & $\begin{array}{l}\text { Vera Lúcia Rodegheri } \\
\text { http://lattes.cnpq.br/615533377 } \\
3844146\end{array}$ & $\begin{array}{l}\text { Especialização em } \\
\text { Psicologia com ênfase em } \\
\text { Ontopsicologia. } \\
\text { Universidade Estatal de São } \\
\text { Petersburgo, Rússia. }\end{array}$ & $\begin{array}{l}\text { Universidade Estatal } \\
\text { de São Petersburgo, } \\
\text { Rússia. }\end{array}$ & $\begin{array}{l}\text { Metodo Ontopsicologico } \\
\text { aplicato alla consulenza } \\
\text { delle organizazzioni }\end{array}$ & $\begin{array}{l}\text { Profa. Dra. } \\
\text { Natalia } \\
\text { Grishina }\end{array}$ & 2003 \\
\hline 150 & $\begin{array}{l}\text { Maria Tereza Andreola } \\
\text { http://lattes.cnpq.br/861353163 } \\
3546268\end{array}$ & $\begin{array}{l}\text { Especialização em } \\
\text { Ontopsicologia, Centro de } \\
\text { Ensino Unificado de } \\
\text { Brasília, CEUB. }\end{array}$ & $\begin{array}{l}\text { Centro de Ensino } \\
\text { Unificado de Brasília, } \\
\text { CEUB. }\end{array}$ & $\begin{array}{l}\text { Quando o técnico de } \\
\text { saúde torna-se alimento } \\
\text { da patodinâmica } \\
\text { ecossistêmica do cliente }\end{array}$ & $\begin{array}{l}\text { Prof. Dr. } \\
\text { Godeardo } \\
\text { Baquero } \\
\text { Miguel }\end{array}$ & 1997 \\
\hline \multirow[t]{2}{*}{151} & Estela Maris Giordani & Especialização em & Centro de Ensino & & & 1997 \\
\hline & $\begin{array}{l}\text { http://lattes.cnpq.br/261369485 } \\
3235546\end{array}$ & $\begin{array}{l}\text { Ontopsicologia, Centro de } \\
\text { Ensino Unificado de } \\
\text { Brasília, CEUB. }\end{array}$ & $\begin{array}{l}\text { Unificado de Brasília, } \\
\text { CEUB. }\end{array}$ & & & \\
\hline 152 & $\begin{array}{l}\text { Ana Maris Petry } \\
\text { http://lattes.cnpq.br/522408743 } \\
4361870\end{array}$ & $\begin{array}{l}\text { Especialização em } \\
\text { Ontopsicologia, Centro de } \\
\text { Ensino Unificado de } \\
\text { Brasília, CEUB. }\end{array}$ & $\begin{array}{l}\text { Centro de Ensino } \\
\text { Unificado de Brasília, } \\
\text { CEUB. }\end{array}$ & $\begin{array}{l}\text { A interpretação dos } \\
\text { sonhos }\end{array}$ & & 1997 \\
\hline
\end{tabular}


Saber Humano, ISSN 2446-6298, V. 9, n. 15, p. 186-423, jul./dez. 2019.

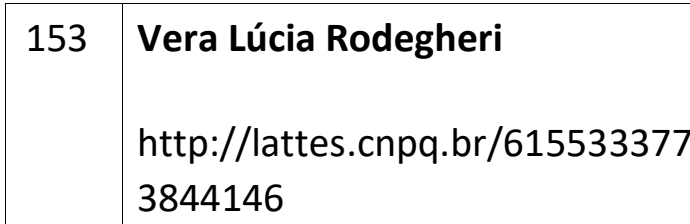

\begin{tabular}{|l|l|l} 
Especialização em & Centro de Ensino & A psique feminina \\
Ontopsicologia, Centro de & Unificado de Brasília, & \\
Ensino Unificado de & CEUB. & \\
Brasília, CEUB. & & \\
\hline
\end{tabular}

TRABALHOS DE CONCLUSÃO DE CURSO (TCC) DE CURSO DE

MBA LATO SENSU 
Saber Humano, ISSN 2446-6298, V. 9, n. 15, p. 186-423, jul./dez. 2019.

\begin{tabular}{|c|c|c|c|c|c|c|}
\hline 1 & Gabriela Pelicioli Baldança & $\begin{array}{l}\text { Curso de } \\
\text { PósGraduação MBA } \\
\text { Identidade } \\
\text { Empresarial, AMF }\end{array}$ & $\begin{array}{l}\text { Faculdade } \\
\text { Antonio } \\
\text { Meneghetti } \\
\text { (AMF) }\end{array}$ & $\begin{array}{l}\text { Do Direito do Trabalho } \\
\text { ao trabalho como } \\
\text { instrumento para } \\
\text { realização da pessoa } \\
\text { humana }\end{array}$ & $\begin{array}{l}\text { Profá Ms. Maria Tereza } \\
\text { Andreola }\end{array}$ & 2019 \\
\hline 2 & Rafael de Nadal Milani & $\begin{array}{l}\text { Curso de } \\
\text { PósGraduação MBA } \\
\text { Identidade } \\
\text { Empresarial, AMF }\end{array}$ & $\begin{array}{l}\text { Faculdade } \\
\text { Antonio } \\
\text { Meneghetti } \\
\text { (AMF) }\end{array}$ & $\begin{array}{l}\text { Novidades } \\
\text { complementares às } \\
\text { técnicas de negociação: } \\
\text { uma trajetória de } \\
\text { estudos em } \\
\text { Ontopsicologia aplicados } \\
\text { à prática profissional }\end{array}$ & $\begin{array}{l}\text { Profa Ms./Doutoranda } \\
\text { Fernanda Martins }\end{array}$ & 2019 \\
\hline 3 & Deizi Santa Lucia & $\begin{array}{l}\text { Curso de } \\
\text { PósGraduação MBA } \\
\text { Identidade } \\
\text { Empresarial, AMF }\end{array}$ & $\begin{array}{l}\text { Faculdade } \\
\text { Antonio } \\
\text { Meneghetti } \\
\text { (AMF) }\end{array}$ & $\begin{array}{l}\text { DSL Postos Santa Lúcia: } \\
\text { Missão, Visão e Valores }\end{array}$ & $\begin{array}{l}\text { Profa Dra Adriane Maria } \\
\text { Moro Mendes }\end{array}$ & 2019 \\
\hline 4 & Cristian Ceron do Amaral & $\begin{array}{l}\text { Curso de } \\
\text { PósGraduação MBA } \\
\text { Identidade }\end{array}$ & $\begin{array}{l}\text { Faculdade } \\
\text { Antonio } \\
\text { Meneghetti }\end{array}$ & $\begin{array}{l}\text { Norte! Um (per)curso } \\
\text { sobre Propósito de Vida, } \\
\text { Identidade e }\end{array}$ & $\begin{array}{l}\text { Profa Ms. Juliane Neves } \\
\text { Fiorezi }\end{array}$ & 2019 \\
\hline & & Empresarial, AMF & (AMF) & $\begin{array}{l}\text { Planejamento } \\
\text { Estratégico Pessoal }\end{array}$ & & \\
\hline
\end{tabular}


Saber Humano, ISSN 2446-6298, V. 9, n. 15, p. 186-423, jul./dez. 2019.

\begin{tabular}{|c|c|c|c|c|c|c|}
\hline 5 & Lisieli Rorato Dotto & $\begin{array}{l}\text { Curso de } \\
\text { PósGraduação MBA } \\
\text { Identidade } \\
\text { Empresarial, AMF }\end{array}$ & $\begin{array}{l}\text { Faculdade } \\
\text { Antonio } \\
\text { Meneghetti } \\
\text { (AMF) }\end{array}$ & $\begin{array}{l}\text { Orientação Acadêmica } \\
\text { no mundo de incertezas } \\
\text { estudantis no Ensino } \\
\text { Superior: criação e } \\
\text { desenvolvimento de um } \\
\text { Setor de Permanência e } \\
\text { Apoio Estudantil }\end{array}$ & $\begin{array}{l}\text { Profa Dra Patrícia } \\
\text { Wazlawick }\end{array}$ & 2019 \\
\hline 6 & $\begin{array}{l}\text { José Luiz da Silva Rodrigues } \\
\text { Filho }\end{array}$ & $\begin{array}{l}\text { Curso de } \\
\text { PósGraduação MBA } \\
\text { Identidade } \\
\text { Empresarial, AMF }\end{array}$ & $\begin{array}{l}\text { Faculdade } \\
\text { Antonio } \\
\text { Meneghetti } \\
\text { (AMF) }\end{array}$ & $\begin{array}{l}\text { A trajetória pessoal, } \\
\text { acadêmica e } \\
\text { profissional, a partir do } \\
\text { conhecimento, estudo e } \\
\text { aplicação da Formação } \\
\text { FOIL }\end{array}$ & $\begin{array}{l}\text { Prof. Dr. Ricardo } \\
\text { Schaefer }\end{array}$ & 2019 \\
\hline 7 & Roberta Reinehr & $\begin{array}{l}\text { Curso de } \\
\text { PósGraduação MBA } \\
\text { Identidade } \\
\text { Empresarial, AMF }\end{array}$ & $\begin{array}{l}\text { Faculdade } \\
\text { Antonio } \\
\text { Meneghetti } \\
\text { (AMF) }\end{array}$ & $\begin{array}{l}\text { Conflitos em âmbito } \\
\text { empresarial e sua } \\
\text { resolução: uma análise } \\
\text { ontopsicológica }\end{array}$ & $\begin{array}{l}\text { Prof. Dr. Josemar Sidinei } \\
\text { Soares }\end{array}$ & 2019 \\
\hline 8 & Viviane Thaís de Araújo & $\begin{array}{l}\text { Curso de } \\
\text { PósGraduação MBA } \\
\text { Identidade } \\
\text { Empresarial, AMF }\end{array}$ & $\begin{array}{l}\text { Faculdade } \\
\text { Antonio } \\
\text { Meneghetti } \\
\text { (AMF) }\end{array}$ & $\begin{array}{l}\text { A tradução do meu valor } \\
\text { de vida dentro do meu } \\
\text { negócio: uma narrativa } \\
\text { autobiográfica }\end{array}$ & $\begin{array}{l}\text { Prof. Ms. Wesley } \\
\text { Lacerda e Silva }\end{array}$ & 2019 \\
\hline 9 & Fábio Pilecco & $\begin{array}{l}\text { Curso de } \\
\text { PósGraduação MBA } \\
\text { Identidade } \\
\text { Empresarial, AMF }\end{array}$ & $\begin{array}{l}\text { Faculdade } \\
\text { Antonio } \\
\text { Meneghetti } \\
\text { (AMF) }\end{array}$ & $\begin{array}{l}\text { Aplicação prática da } \\
\text { Ontopsicologia nos } \\
\text { próximos ciclos } \\
\text { sistêmicos de } \\
\text { acumulação de Arrigui e }\end{array}$ & $\begin{array}{l}\text { Prof. Dr. Rafael Padilha } \\
\text { dos Santos }\end{array}$ & 2019 \\
\hline
\end{tabular}


Saber Humano, ISSN 2446-6298, V. 9, n. 15, p. 186-423, jul./dez. 2019.

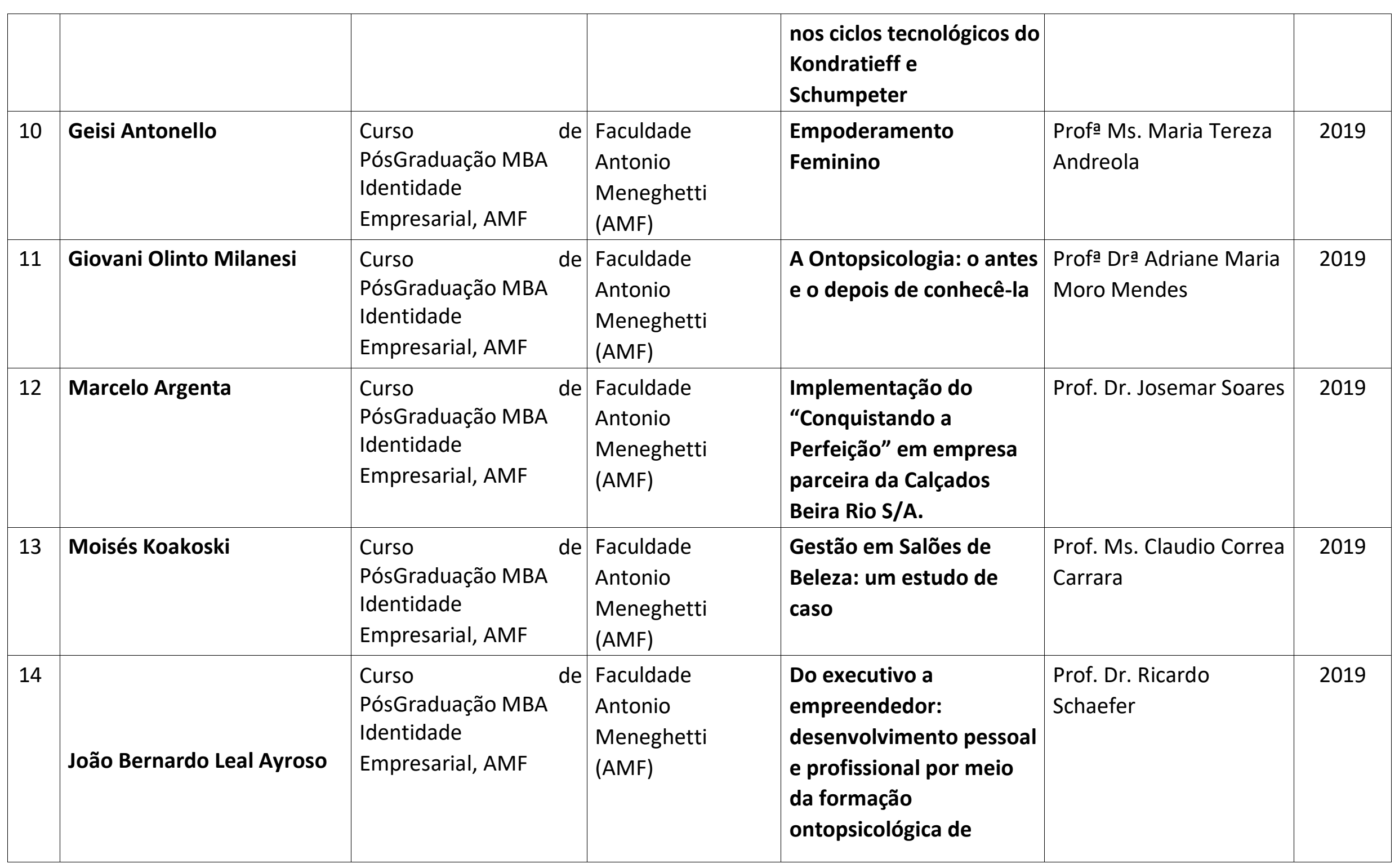


Saber Humano, ISSN 2446-6298, V. 9, n. 15, p. 186-423, jul./dez. 2019.

\begin{tabular}{|c|c|c|c|c|c|c|}
\hline & & & & liderança & & \\
\hline \multirow[t]{2}{*}{15} & Ariane Espindola & Curso de Pós- & Faculdade & Contribuição da & Prof. Ms. Wesley & 2019 \\
\hline & & $\begin{array}{l}\text { Graduação MBA } \\
\text { Identidade } \\
\text { Empresarial, AMF }\end{array}$ & $\begin{array}{l}\text { Antonio } \\
\text { Meneghetti } \\
\text { (AMF) }\end{array}$ & $\begin{array}{l}\text { Ontopsicologia na } \\
\text { formação de equipes de } \\
\text { alto desempenho: uma } \\
\text { proposta de } \\
\text { desenvolvimento para } \\
\text { um time de Engenharia } \\
\text { Global }\end{array}$ & Lacerda e Silva & \\
\hline 17 & Jaqueline Maria Fischer & $\begin{array}{l}\text { Curso de } \\
\text { PósGraduação MBA } \\
\text { Identidade } \\
\text { Empresarial, AMF }\end{array}$ & $\begin{array}{l}\text { Faculdade } \\
\text { Antonio } \\
\text { Meneghetti } \\
\text { (AMF) }\end{array}$ & $\begin{array}{l}\text { A relação entre o tempo } \\
\text { livre e uso das mídias } \\
\text { sociais e seu impacto na } \\
\text { vida das mulheres }\end{array}$ & $\begin{array}{l}\text { Profa Dra Claudiane } \\
\text { Weber }\end{array}$ & 2019 \\
\hline
\end{tabular}


Saber Humano, ISSN 2446-6298, V. 9, n. 15, p. 186-423, jul./dez. 2019.

\begin{tabular}{|c|c|c|c|c|c|c|}
\hline 18 & Luciana Thais Becker & $\begin{array}{l}\text { Curso de } \\
\text { PósGraduação MBA } \\
\text { Identidade } \\
\text { Empresarial, AMF }\end{array}$ & $\begin{array}{l}\text { Faculdade } \\
\text { Antonio } \\
\text { Meneghetti } \\
\text { (AMF) }\end{array}$ & $\begin{array}{l}\text { A aplicação prática da } \\
\text { Ontopsicologia na } \\
\text { abertura de um novo } \\
\text { negócio: uma narrativa } \\
\text { autobiográfica }\end{array}$ & $\begin{array}{l}\text { Profa. Ms./Doutoranda } \\
\text { Fernanda Martins }\end{array}$ & 2019 \\
\hline 19 & Débora Spohr & $\begin{array}{l}\text { Curso de } \\
\text { PósGraduação MBA } \\
\text { Identidade } \\
\text { Empresarial, AMF }\end{array}$ & $\begin{array}{l}\text { Faculdade } \\
\text { Antonio } \\
\text { Meneghetti } \\
\text { (AMF) } \\
\end{array}$ & $\begin{array}{l}\text { Estética Vital como } \\
\text { critério para um novo } \\
\text { modelo de Gestão em } \\
\text { Processos }\end{array}$ & $\begin{array}{l}\text { Profa. Ms. Carolina } \\
\text { Schuskel Miranda }\end{array}$ & 2019 \\
\hline \multirow[t]{2}{*}{20} & Carlos Cristiano Hoffmeister & $\begin{array}{l}\text { Curso de } \\
\text { PósGraduação MBA } \\
\text { Identidade } \\
\text { Empresarial, AMF }\end{array}$ & $\begin{array}{l}\text { Faculdade } \\
\text { Antonio } \\
\text { Meneghetti } \\
\text { (AMF) }\end{array}$ & $\begin{array}{l}\text { Geovisão: Geração de } \\
\text { informações para } \\
\text { rentabilização das } \\
\text { oportunidades de }\end{array}$ & $\begin{array}{l}\text { Profa Dra Ana Marli } \\
\text { Bulegon }\end{array}$ & 2019 \\
\hline & & & & $\begin{array}{l}\text { mercado com foco no } \\
\text { aumento das vendas }\end{array}$ & & \\
\hline
\end{tabular}

\begin{tabular}{|c|l|l|l|l|l|}
\hline No & \multicolumn{1}{|c|}{ Autor } & \multicolumn{1}{|c|}{ Curso/Programa } & \multicolumn{1}{|c|}{ Universidade } & \multicolumn{1}{c|}{ Título } & \multicolumn{1}{c|}{ Orientador } \\
\hline 1 & Aline Zini Backes & $\begin{array}{l}\text { MBA Business } \\
\text { Intuition - Identidade } \\
\text { Empresarial }\end{array}$ & $\begin{array}{l}\text { Faculdade } \\
\text { Antonio } \\
\text { Meneghetti, AMF }\end{array}$ & $\begin{array}{l}\text { Avaliação por } \\
\text { competências do líder: } \\
\text { um estudo } \\
\text { autobiográfico }\end{array}$ & $\begin{array}{l}\text { Profa. Ms. Josiane } \\
\text { Beatriz Piccin Barbieri }\end{array}$ \\
& & & & \\
\hline
\end{tabular}


Saber Humano, ISSN 2446-6298, V. 9, n. 15, p. 186-423, jul./dez. 2019.

\begin{tabular}{|c|c|c|c|c|c|c|}
\hline 2 & Ana Paula Coelho Tonolli & $\begin{array}{l}\text { MBA Business } \\
\text { Intuition - Identidade } \\
\text { Empresarial }\end{array}$ & $\begin{array}{l}\text { Faculdade } \\
\text { Antonio } \\
\text { Meneghetti, AMF }\end{array}$ & $\begin{array}{l}\text { A contribuição da } \\
\text { Ontopsicologia na } \\
\text { formação contínua do } \\
\text { professor de língua } \\
\text { inglesa }\end{array}$ & $\begin{array}{l}\text { Profa. Ms. Ana Maris } \\
\text { Petry }\end{array}$ & 2017 \\
\hline 3 & Cristian Schlickmann & $\begin{array}{l}\text { MBA Business } \\
\text { Intuition - Identidade } \\
\text { Empresarial }\end{array}$ & $\begin{array}{l}\text { Faculdade } \\
\text { Antonio } \\
\text { Meneghetti, AMF }\end{array}$ & $\begin{array}{l}\text { O reforço da própria } \\
\text { identidade como base } \\
\text { para o desenvolvimento } \\
\text { profissional e } \\
\text { crescimento empresarial }\end{array}$ & $\begin{array}{l}\text { Prof. Dr.Ricardo } \\
\text { Schaefer }\end{array}$ & 2017 \\
\hline 4 & Daniela Crestani & $\begin{array}{l}\text { MBA Business } \\
\text { Intuition - Identidade } \\
\text { Empresarial }\end{array}$ & $\begin{array}{l}\text { Faculdade } \\
\text { Antonio } \\
\text { Meneghetti, AMF }\end{array}$ & $\begin{array}{l}\text { Estudo teórico da } \\
\text { autossabotagem e suas } \\
\text { implicações no líder }\end{array}$ & $\begin{array}{l}\text { Profa. Dra. Carmen } \\
\text { Ivanete D’Agostini } \\
\text { Spanhol }\end{array}$ & 2017 \\
\hline
\end{tabular}


Saber Humano, ISSN 2446-6298, V. 9, n. 15, p. 186-423, jul./dez. 2019.

\begin{tabular}{|c|c|c|c|c|c|c|}
\hline 6 & Giovani da Silva Paz & $\begin{array}{l}\text { MBA Business } \\
\text { Intuition - Identidade } \\
\text { Empresarial }\end{array}$ & $\begin{array}{l}\text { Faculdade } \\
\text { Antonio } \\
\text { Meneghetti, AMF }\end{array}$ & $\begin{array}{l}\text { A autossabotagem do } \\
\text { líder e o tempo livre } \\
\text { como oportunidade de } \\
\text { retomada do ponto- } \\
\text { força }\end{array}$ & $\begin{array}{l}\text { Prof. Dr. Josemar } \\
\text { Sidinei Soares }\end{array}$ & 2017 \\
\hline 7 & Jorge Rohden & $\begin{array}{l}\text { MBA Business } \\
\text { Intuition - Identidade } \\
\text { Empresarial }\end{array}$ & $\begin{array}{l}\text { Faculdade } \\
\text { Antonio } \\
\text { Meneghetti, AMF }\end{array}$ & $\begin{array}{l}\text { Análise do } \\
\text { desenvolvimento do líder } \\
\text { a partir dos } 21 \text { pontos do } \\
\text { empresário propostos } \\
\text { por Antonio Meneghetti: } \\
\text { um estudo } \\
\text { de caso }\end{array}$ & $\begin{array}{l}\text { Profa. Dra. Adriane } \\
\text { Maria Moro Mendes }\end{array}$ & 2017 \\
\hline 8 & Jovita Grassi Saraiva & $\begin{array}{l}\text { MBA Business } \\
\text { Intuition - Identidade } \\
\text { Empresarial }\end{array}$ & $\begin{array}{l}\text { Faculdade } \\
\text { Antonio } \\
\text { Meneghetti, AMF }\end{array}$ & $\begin{array}{l}\text { Construção da identidade } \\
\text { visual de produto para a } \\
\text { marca Molekinha a fim } \\
\text { de } \\
\text { torná-la um desejo de } \\
\text { consumo }\end{array}$ & $\begin{array}{l}\text { Profa. Dra. Ana Marli } \\
\text { Bulegon }\end{array}$ & 2017 \\
\hline 9 & Jusélia Paula da Silva & MBA Business & Faculdade & Biblioteca Humanitas: a & Profa. Ms. Vera Lúcia & 2017 \\
\hline & & $\begin{array}{l}\text { Intuition - Identidade } \\
\text { Empresarial }\end{array}$ & $\begin{array}{l}\text { Antonio } \\
\text { Meneghetti, AMF }\end{array}$ & $\begin{array}{l}\text { história através das } \\
\text { memórias individuais }\end{array}$ & Rodegheri & \\
\hline
\end{tabular}


Saber Humano, ISSN 2446-6298, V. 9, n. 15, p. 186-423, jul./dez. 2019.

\begin{tabular}{|c|c|c|c|c|c|c|}
\hline 10 & Karine Scherer & $\begin{array}{l}\text { MBA Business } \\
\text { Intuition - Identidade } \\
\text { Empresarial }\end{array}$ & $\begin{array}{l}\text { Faculdade } \\
\text { Antonio } \\
\text { Meneghetti, AMF }\end{array}$ & $\begin{array}{l}\text { Aprendizagem técnica e } \\
\text { o desenvolvimento da } \\
\text { forma mentis dos alunos } \\
\text { de Administração para } \\
\text { uma formação } \\
\text { profissional } \\
\text { fundamentada em } \\
\text { valores humanistas: um } \\
\text { estudo introdutório }\end{array}$ & $\begin{array}{l}\text { Profa. Dra. Patrícia } \\
\text { Wazlawick }\end{array}$ & 2017 \\
\hline 11 & Liziane Stangerlin & $\begin{array}{l}\text { MBA Business } \\
\text { Intuition - Identidade } \\
\text { Empresarial }\end{array}$ & $\begin{array}{l}\text { Faculdade } \\
\text { Antonio } \\
\text { Meneghetti, AMF }\end{array}$ & $\begin{array}{l}\text { A correlação entre o ato } \\
\text { de delegar e a genitura } \\
\text { do líder }\end{array}$ & $\begin{array}{l}\text { Profa. Ms. Maria Tereza } \\
\text { Andreola }\end{array}$ & 2017 \\
\hline 12 & $\begin{array}{l}\text { Luiz Henrique Menegon } \\
\text { Dutra }\end{array}$ & $\begin{array}{l}\text { MBA Business } \\
\text { Intuition - Identidade } \\
\text { Empresarial }\end{array}$ & $\begin{array}{l}\text { Faculdade } \\
\text { Antonio } \\
\text { Meneghetti, AMF }\end{array}$ & $\begin{array}{l}\text { Estudo autobiográfico da } \\
\text { criação de uma } \\
\text { personalidade } \\
\text { empresarial: Prof. Luiz } \\
\text { Henrique }\end{array}$ & $\begin{array}{l}\text { Profa. Dra. Adriane } \\
\text { Maria Moro Mendes }\end{array}$ & 2017 \\
\hline 13 & Nilce Meneghetti Barichelo & $\begin{array}{l}\text { MBA Business } \\
\text { Intuition - Identidade } \\
\text { Empresarial }\end{array}$ & $\begin{array}{l}\text { Faculdade } \\
\text { Antonio } \\
\text { Meneghetti, AMF }\end{array}$ & $\begin{array}{l}\text { A comunicação não } \\
\text { verbal: a linguagem } \\
\text { corporal como forma } \\
\text { estratégica dentro de } \\
\text { uma empresa }\end{array}$ & $\begin{array}{l}\text { Profa. Dra. Estela Maris } \\
\text { Giordani }\end{array}$ & 2017 \\
\hline & & & & & & \\
\hline
\end{tabular}


Saber Humano, ISSN 2446-6298, V. 9, n. 15, p. 186-423, jul./dez. 2019.

\begin{tabular}{|c|c|c|c|c|c|c|}
\hline 14 & Reinaldo Pereira & $\begin{array}{l}\text { MBA Business } \\
\text { Intuition - Identidade } \\
\text { Empresarial }\end{array}$ & $\begin{array}{l}\text { Faculdade } \\
\text { Antonio } \\
\text { Meneghetti, AMF }\end{array}$ & $\begin{array}{l}\text { Estudo para } \\
\text { desenvolvimento de } \\
\text { metodologia para análise } \\
\text { de custos e formação de } \\
\text { preços, para } \\
\text { comercialização de } \\
\text { veículos de locação } \\
\text { inativos }\end{array}$ & $\begin{array}{l}\text { Profa. Ms. Josiane } \\
\text { Beatriz Piccin Barbieri }\end{array}$ & 2017 \\
\hline 16 & Rute Feitosa & $\begin{array}{l}\text { MBA Business } \\
\text { Intuition - Identidade } \\
\text { Empresarial }\end{array}$ & $\begin{array}{l}\text { Faculdade } \\
\text { Antonio } \\
\text { Meneghetti, AMF }\end{array}$ & $\begin{array}{l}\text { Desenvolvimento de } \\
\text { ferramenta tecnológica } \\
\text { como diferencial } \\
\text { competitivo }\end{array}$ & $\begin{array}{l}\text { Profa. Ms. Josiane } \\
\text { Beatriz Piccin Barbieri }\end{array}$ & 2017 \\
\hline 17 & Simone Phollmann Pozzatti & $\begin{array}{l}\text { MBA Business } \\
\text { Intuition - Identidade } \\
\text { Empresarial }\end{array}$ & $\begin{array}{l}\text { Faculdade } \\
\text { Antonio } \\
\text { Meneghetti, AMF }\end{array}$ & $\begin{array}{l}\text { Processo da estratégia } \\
\text { empresarial para garantir } \\
\text { o resultado do } \\
\text { planejamento } \\
\text { estratégico }\end{array}$ & $\begin{array}{l}\text { Profa. Dra. Patrícia } \\
\text { Wazlawick }\end{array}$ & 2017 \\
\hline 18 & Tainá Moreira da Silva & $\begin{array}{l}\text { MBA Business } \\
\text { Intuition - Identidade }\end{array}$ & Faculdade Antonio & $\begin{array}{l}\text { Projeto Aprimorar: } \\
\text { treinamento para }\end{array}$ & $\begin{array}{l}\text { Profa. Drạ. Vera Lúcia } \\
\text { Rodegheri }\end{array}$ & 2017 \\
\hline
\end{tabular}


Saber Humano, ISSN 2446-6298, V. 9, n. 15, p. 186-423, jul./dez. 2019.

\begin{tabular}{|c|c|c|c|c|c|c|}
\hline & & Empresarial & Meneghetti, AMF & $\begin{array}{l}\text { equipes de operadores } \\
\text { de telemarketing ativo }\end{array}$ & & \\
\hline 19 & Vagner Backes & $\begin{array}{l}\text { MBA Business } \\
\text { Intuition - Identidade } \\
\text { Empresarial }\end{array}$ & $\begin{array}{l}\text { Faculdade } \\
\text { Antonio } \\
\text { Meneghetti, AMF }\end{array}$ & $\begin{array}{l}\text { Parceria entre uma } \\
\text { empresa brasileira e uma } \\
\text { empresa holandesa no } \\
\text { segmento de lavanderias } \\
\text { industriais }\end{array}$ & Profa. Dra. Noemi Boer & 2017 \\
\hline 20 & Valéria lezzi Pinto & $\begin{array}{l}\text { MBA Business } \\
\text { Intuition - Identidade } \\
\text { Empresarial }\end{array}$ & $\begin{array}{l}\text { Faculdade } \\
\text { Antonio } \\
\text { Meneghetti, AMF }\end{array}$ & $\begin{array}{l}\text { Estética como critério de } \\
\text { gestão na obtenção de } \\
\text { resultados mais eficazes }\end{array}$ & $\begin{array}{l}\text { Prof. Dr. Josemar } \\
\text { Sidinei Soares }\end{array}$ & 2017 \\
\hline
\end{tabular}

\begin{tabular}{|l|l|l|l|l|l|}
\hline 21 & Alaor José Cirolini & $\begin{array}{l}\text { MBA Business } \\
\text { Intuition - Identidade } \\
\text { Empresarial }\end{array}$ & $\begin{array}{l}\text { Faculdade } \\
\text { Antonio } \\
\text { Meneghetti, AMF }\end{array}$ & $\begin{array}{l}\text { Conquistar e fidelizar } \\
\text { clientes no Agronegócio: } \\
\text { um levantamento entre } \\
\text { os produtores de soja de } \\
\text { Restinga Sêca (RS) }\end{array}$ & $\begin{array}{l}\text { Prof. Esp. Almir } \\
\text { Francisco Foletto }\end{array}$ \\
\hline 22 & Arlete Tibes da Silva & $\begin{array}{l}\text { MBA Business } \\
\text { Intuition- Identidade } \\
\text { Empresarial }\end{array}$ & $\begin{array}{l}\text { Faculdade } \\
\text { Antonio } \\
\text { Meneghetti, AMF }\end{array}$ & $\begin{array}{l}\text { A relação entre o } \\
\text { crescimento do } \\
\text { empresário e a estética } \\
\text { do ambiente empresarial }\end{array}$ & $\begin{array}{l}\text { Profa. Ms. Maria Tereza } \\
\text { Andreolla }\end{array}$ \\
\hline 23 & Diego Bertolini & $\begin{array}{l}\text { MBA Business } \\
\text { Intuition - Identidade } \\
\text { Empresarial }\end{array}$ & $\begin{array}{l}\text { Faculdade } \\
\text { Antonio } \\
\text { Meneghetti, AMF }\end{array}$ & $\begin{array}{l}\text { Núcleo de prospecção de } \\
\text { negócios na área de } \\
\text { Vinho e Enoturismo }\end{array}$ & $\begin{array}{l}\text { Prof. Dr. Ricardo } \\
\text { Schaefer }\end{array}$ \\
\hline
\end{tabular}




\begin{tabular}{|c|c|c|c|c|c|c|}
\hline 24 & Eloy Demarchi Teixeira & $\begin{array}{l}\text { MBA Business } \\
\text { Intuition - Identidade } \\
\text { Empresarial }\end{array}$ & $\begin{array}{l}\text { Faculdade } \\
\text { Antonio } \\
\text { Meneghetti, AMF }\end{array}$ & $\begin{array}{l}\text { A relação entre } \\
\text { inteligência, ambição e } \\
\text { abordagem ao estudo no } \\
\text { jovem ingressante } \\
\text { universitário }\end{array}$ & $\begin{array}{l}\text { Profa. Dra. Patrícia } \\
\text { Wazlawick }\end{array}$ & 2016 \\
\hline 25 & Felipe Carpenedo Gabriel & $\begin{array}{l}\text { MBA Business } \\
\text { Intuition - Identidade } \\
\text { Empresarial }\end{array}$ & $\begin{array}{l}\text { Faculdade } \\
\text { Antonio } \\
\text { Meneghetti, AMF }\end{array}$ & $\begin{array}{l}\text { O elemento humano } \\
\text { exato como fator } \\
\text { determinante para uma } \\
\text { decisão otimal: Uma } \\
\text { abordagem da teoria } \\
\text { ontopsicológica }\end{array}$ & $\begin{array}{l}\text { Profa . Ms. Ana Maris } \\
\text { Petry }\end{array}$ & 2016 \\
\hline 26 & $\begin{array}{l}\text { Fernanda Lencina de } \\
\text { Oliveira Bortoluzzi }\end{array}$ & $\begin{array}{l}\text { MBA Business } \\
\text { Intuition - Identidade } \\
\text { Empresarial }\end{array}$ & $\begin{array}{l}\text { Faculdade } \\
\text { Antonio } \\
\text { Meneghetti, AMF }\end{array}$ & $\begin{array}{l}\text { Experiência de liderança } \\
\text { através da autobiografia }\end{array}$ & $\begin{array}{l}\text { Profa . Dra . Maria Alice } \\
\text { Castilho Schuch }\end{array}$ & 2016 \\
\hline 27 & $\begin{array}{l}\text { lara Aparecida Franco } \\
\text { Sperotto }\end{array}$ & $\begin{array}{l}\text { MBA Business } \\
\text { Intuition - Identidade } \\
\text { Empresarial }\end{array}$ & $\begin{array}{l}\text { Faculdade } \\
\text { Antonio } \\
\text { Meneghetti, AMF }\end{array}$ & $\begin{array}{l}\text { Mulher e liderança: uma } \\
\text { narrativa autobiográfica }\end{array}$ & $\begin{array}{l}\text { Profa. Ms. Josiane } \\
\text { Beatriz Piccin Barbieri }\end{array}$ & 2016 \\
\hline 28 & $\begin{array}{l}\text { Ilse Maria Biason } \\
\text { Guimarães }\end{array}$ & $\begin{array}{l}\text { MBA Business } \\
\text { Intuition - Identidade } \\
\text { Empresarial }\end{array}$ & $\begin{array}{l}\text { Faculdade } \\
\text { Antonio } \\
\text { Meneghetti, AMF }\end{array}$ & $\begin{array}{l}\text { Materiotecas: um estudo } \\
\text { de caso de implantação } \\
\text { no Setor Calçadista } \\
\text { brasileiro }\end{array}$ & $\begin{array}{l}\text { Prof . Dr. Josemar } \\
\text { Sidinei Soares }\end{array}$ & 2016 \\
\hline
\end{tabular}


Saber Humano, ISSN 2446-6298, V. 9, n. 15, p. 186-423, jul./dez. 2019.

\begin{tabular}{|c|c|c|c|c|c|c|}
\hline 29 & Jaqueline Santos da Veiga & $\begin{array}{l}\text { MBA Business } \\
\text { Intuition - Identidade } \\
\text { Empresarial }\end{array}$ & $\begin{array}{l}\text { Faculdade } \\
\text { Antonio } \\
\text { Meneghetti, AMF }\end{array}$ & $\begin{array}{l}\text { Treinamento e } \\
\text { desenvolvimento dos } \\
\text { profissionais do mercado } \\
\text { externo através da Escola } \\
\text { de Mercado analisando } \\
\text { resultados de vendas }\end{array}$ & $\begin{array}{l}\text { Profa . Dra. . Ana Marli } \\
\text { Bulegon }\end{array}$ & 2016 \\
\hline 30 & $\begin{array}{l}\text { João Henrique Pickcius } \\
\text { Celant }\end{array}$ & $\begin{array}{l}\text { MBA Business } \\
\text { Intuition - Identidade } \\
\text { Empresarial }\end{array}$ & $\begin{array}{l}\text { Faculdade } \\
\text { Antonio } \\
\text { Meneghetti, AMF }\end{array}$ & $\begin{array}{l}\text { O homem frente ao } \\
\text { conflito na perspectiva } \\
\text { ontopsicológica e suas } \\
\text { implicações para o } \\
\text { Direito }\end{array}$ & $\begin{array}{l}\text { Prof. Esp. Marcelo } \\
\text { Girade }\end{array}$ & 2016 \\
\hline 31 & Lenita Daros & $\begin{array}{l}\text { MBA Business } \\
\text { Intuition - Identidade } \\
\text { Empresarial }\end{array}$ & $\begin{array}{l}\text { Faculdade } \\
\text { Antonio } \\
\text { Meneghetti, AMF }\end{array}$ & $\begin{array}{l}\text { O direcionamento de } \\
\text { uma negociação } \\
\text { corporativa por meio do } \\
\text { campo semântico }\end{array}$ & $\begin{array}{l}\text { Prof. Esp. Marcelo } \\
\text { Girade }\end{array}$ & 2016 \\
\hline 32 & $\begin{array}{l}\text { Leonardo Guedes da Luz } \\
\text { Martins }\end{array}$ & $\begin{array}{l}\text { MBA Business } \\
\text { Intuition - Identidade } \\
\text { Empresarial }\end{array}$ & $\begin{array}{l}\text { Faculdade } \\
\text { Antonio } \\
\text { Meneghetti, AMF }\end{array}$ & $\begin{array}{l}\text { A relação homemanimal } \\
\text { como uma variável na } \\
\text { produtividade }\end{array}$ & $\begin{array}{l}\text { Profa. Dra. Adriane } \\
\text { Maria Moro Mendes }\end{array}$ & 2016 \\
\hline 33 & $\begin{array}{l}\text { Lucas Message de } \\
\text { Oliveira }\end{array}$ & $\begin{array}{l}\text { MBA Business } \\
\text { Intuition - Identidade } \\
\text { Empresarial }\end{array}$ & $\begin{array}{l}\text { Faculdade } \\
\text { Antonio } \\
\text { Meneghetti, AMF }\end{array}$ & $\begin{array}{l}\text { Empresa Explorer Call } \\
\text { Center: } \\
\text { turnover/rotatividade de } \\
\text { pessoas }\end{array}$ & $\begin{array}{l}\text { Profa. Ms. Vera Lúcia } \\
\text { Rodegheri }\end{array}$ & 2016 \\
\hline 34 & $\begin{array}{l}\text { Maria Claudete Kickow } \\
\text { Forell }\end{array}$ & $\begin{array}{l}\text { MBA Business } \\
\text { Intuition - Identidade }\end{array}$ & $\begin{array}{l}\text { Faculdade } \\
\text { Antonio }\end{array}$ & $\begin{array}{l}\text { Unidade de ação entre } \\
\text { Setores Financeiro e }\end{array}$ & $\begin{array}{l}\text { Profa. Ms. Beatriz } \\
\text { Machri de Pellegrini }\end{array}$ & 2016 \\
\hline
\end{tabular}


Saber Humano, ISSN 2446-6298, V. 9, n. 15, p. 186-423, jul./dez. 2019.

\begin{tabular}{|c|c|c|c|c|c|c|}
\hline & & Empresarial & Meneghetti, AMF & Comercial & & \\
\hline 35 & Mônica Menezes da Silva & $\begin{array}{l}\text { MBA Business } \\
\text { Intuition - Identidade } \\
\text { Empresarial }\end{array}$ & $\begin{array}{l}\text { Faculdade } \\
\text { Antonio } \\
\text { Meneghetti, AMF }\end{array}$ & $\begin{array}{l}\text { Princípios de } \\
\text { Ontopsicologia e } \\
\text { OntoArte em decorações } \\
\text { estéticas artesanais de } \\
\text { festas infantis }\end{array}$ & $\begin{array}{l}\text { Profa. Dra. Estela Maris } \\
\text { Giordani }\end{array}$ & 2016 \\
\hline \multirow[t]{2}{*}{36} & Ricardo Rimoldi Dotto & $\begin{array}{l}\text { MBA Business } \\
\text { Intuition - Identidade }\end{array}$ & Faculdade Antonio & $\begin{array}{l}\text { Gestão logística aplicada } \\
\text { ao setor de distribuição }\end{array}$ & $\begin{array}{l}\text { Prof. Ms. Cláudio Correa } \\
\text { Carrara }\end{array}$ & 2016 \\
\hline & & Empresarial & Meneghetti, AMF & $\begin{array}{l}\text { de alimentos: um estudo } \\
\text { de caso na empresa } \\
\text { Dismaria Distribuidora }\end{array}$ & & \\
\hline 37 & Victor Luis Arnold & $\begin{array}{l}\text { MBA Business } \\
\text { Intuition - Identidade } \\
\text { Empresarial }\end{array}$ & $\begin{array}{l}\text { Faculdade } \\
\text { Antonio } \\
\text { Meneghetti, AMF }\end{array}$ & Comunicação Interna & $\begin{array}{l}\text { Prof. Ms. Ângelo Accorsi } \\
\text { Moreira }\end{array}$ & 2016 \\
\hline
\end{tabular}

\begin{tabular}{|l|l|l|l|l|l|}
\hline 38 & Mozes Queiroz e Marco Antonio & $\begin{array}{l}\text { MBA Business } \\
\text { Intuition - } \\
\text { Identidade } \\
\text { Empresarial }\end{array}$ & $\begin{array}{l}\text { Antonio } \\
\text { Meneghetti } \\
\text { Faculdade, } \\
\text { AMF }\end{array}$ & $\begin{array}{l}\text { Contratação eficaz } \\
\text { dentro da visão } \\
\text { ontopsicológica } \\
\text { avaliando os valores do } \\
\text { candidato }\end{array}$ & $\begin{array}{l}\text { Prof. Dr. Érico de } \\
\text { Lima Azevedo }\end{array}$ \\
\hline
\end{tabular}


Saber Humano, ISSN 2446-6298, V. 9, n. 15, p. 186-423, jul./dez. 2019.

\begin{tabular}{|c|c|c|c|c|c|c|}
\hline 39 & Fernanda Requia e Bruno dos Santos & $\begin{array}{l}\text { MBA Business } \\
\text { Intuition - } \\
\text { Identidade } \\
\text { Empresarial }\end{array}$ & $\begin{array}{l}\text { Antonio } \\
\text { Meneghetti } \\
\text { Faculdade, } \\
\text { AMF }\end{array}$ & $\begin{array}{l}\text { A importância do código } \\
\text { de conduta e ética nas } \\
\text { orgnizações }\end{array}$ & $\begin{array}{l}\text { Profa. Ms. Josiane } \\
\text { Beatriz Piccin } \\
\text { Barbieri }\end{array}$ & 2015 \\
\hline 40 & Cristine Conti & $\begin{array}{l}\text { MBA Business } \\
\text { Intuition - } \\
\text { Identidade } \\
\text { Empresarial }\end{array}$ & $\begin{array}{l}\text { Antonio } \\
\text { Meneghetti } \\
\text { Faculdade, } \\
\text { AMF }\end{array}$ & $\begin{array}{l}\text { Planejamento } \\
\text { estratégico do Barona } \\
\text { Gastronomia }\end{array}$ & $\begin{array}{l}\text { Profa. Esp. Joana } \\
\text { de Jesus }\end{array}$ & 2015 \\
\hline 41 & Anita Brandt & $\begin{array}{l}\text { MBA Business } \\
\text { Intuition - } \\
\text { Identidade } \\
\text { Empresarial }\end{array}$ & $\begin{array}{l}\text { Antonio } \\
\text { Meneghetti } \\
\text { Faculdade, } \\
\text { AMF }\end{array}$ & $\begin{array}{l}\text { Como desenvolver uma } \\
\text { liderança mais eficaz por } \\
\text { meio do aprimoramento } \\
\text { do processo de } \\
\text { delegação }\end{array}$ & $\begin{array}{l}\text { Profa. Dra. } \\
\text { Patrícia } \\
\text { Wazlawick }\end{array}$ & 2015 \\
\hline \multirow[t]{2}{*}{42} & Jansara Carvalho & $\begin{array}{l}\text { MBA Business } \\
\text { Intuition - }\end{array}$ & $\begin{array}{l}\text { Antonio } \\
\text { Meneghetti }\end{array}$ & $\begin{array}{l}\text { Gestão do conhecimento } \\
\text { e }\end{array}$ & $\begin{array}{l}\text { Profạ. Drạ. } \\
\text { Adriane Maria }\end{array}$ & 2015 \\
\hline & & $\begin{array}{l}\text { Identidade } \\
\text { Empresarial }\end{array}$ & $\begin{array}{l}\text { Faculdade, } \\
\text { AMF }\end{array}$ & $\begin{array}{l}\text { tecnologia aplicados ao } \\
\text { processo de pré-venda: } \\
\text { Proposta de projeto } \\
\text { destinada ao Grupo } \\
\text { META IT Services }\end{array}$ & Moro Mendes & \\
\hline 43 & Thiéle Muraro & $\begin{array}{l}\text { MBA Business } \\
\text { Intuition - } \\
\text { Identidade } \\
\text { Empresarial }\end{array}$ & $\begin{array}{l}\text { Antonio } \\
\text { Meneghetti } \\
\text { Faculdade, } \\
\text { AMF }\end{array}$ & $\begin{array}{l}\text { A concessão de crédito: } \\
\text { racionalidade e intuição }\end{array}$ & $\begin{array}{l}\text { Prof. Dr. Érico de } \\
\text { Lima Azevedo }\end{array}$ & 2015 \\
\hline
\end{tabular}


Saber Humano, ISSN 2446-6298, V. 9, n. 15, p. 186-423, jul./dez. 2019.

\begin{tabular}{|c|c|c|c|c|c|c|}
\hline 44 & Júlio Pujol & $\begin{array}{l}\text { MBA Business } \\
\text { Intuition - } \\
\text { Identidade } \\
\text { Empresarial }\end{array}$ & $\begin{array}{l}\text { Antonio } \\
\text { Meneghetti } \\
\text { Faculdade, } \\
\text { AMF }\end{array}$ & $\begin{array}{l}\text { Nova Polis Assessoria e } \\
\text { Capacitação }\end{array}$ & $\begin{array}{l}\text { Profa. Ms. Josiane } \\
\text { Beatriz Piccin } \\
\text { Barbieri }\end{array}$ & 2015 \\
\hline 45 & Claudete Inês Pelicioli & $\begin{array}{l}\text { MBA Business } \\
\text { Intuition - } \\
\text { Identidade } \\
\text { Empresarial }\end{array}$ & $\begin{array}{l}\text { Antonio } \\
\text { Meneghetti } \\
\text { Faculdade, } \\
\text { AMF }\end{array}$ & $\begin{array}{l}\text { Da ambivalência à } \\
\text { liderança: um estudo de } \\
\text { caso }\end{array}$ & $\begin{array}{l}\text { Profa. Ms. Josiane } \\
\text { Beatriz Piccin } \\
\text { Barbieri }\end{array}$ & 2015 \\
\hline 48 & Lygia de Almeida Marques & $\begin{array}{l}\text { MBA Business } \\
\text { Intuition - } \\
\text { Identidade } \\
\text { Empresarial }\end{array}$ & $\begin{array}{l}\text { Antonio } \\
\text { Meneghetti } \\
\text { Faculdade, } \\
\text { AMF }\end{array}$ & $\begin{array}{l}\text { Contribuições da Escola } \\
\text { Ontopsicológica ao } \\
\text { processo de Arquitetura } \\
\text { de Interiores }\end{array}$ & $\begin{array}{l}\text { Profa. Ms. Ana } \\
\text { Maris Petry }\end{array}$ & 2015 \\
\hline
\end{tabular}


Saber Humano, ISSN 2446-6298, V. 9, n. 15, p. 186-423, jul./dez. 2019.

\begin{tabular}{|c|c|c|c|c|c|c|}
\hline 49 & Ivo Malmann & $\begin{array}{l}\text { MBA Business } \\
\text { Intuition - } \\
\text { Identidade } \\
\text { Empresarial }\end{array}$ & $\begin{array}{l}\text { Antonio } \\
\text { Meneghetti } \\
\text { Faculdade, } \\
\text { AMF }\end{array}$ & $\begin{array}{l}\text { ICM Obras e Serviço de } \\
\text { Engenharia LTDA: Plano } \\
\text { de Negócios }\end{array}$ & $\begin{array}{l}\text { Profa. Beatriz } \\
\text { Machri de } \\
\text { Pellegrini }\end{array}$ & 2015 \\
\hline 50 & Ricardo Kurtz & $\begin{array}{l}\text { MBA Business } \\
\text { Intuition - } \\
\text { Identidade } \\
\text { Empresarial }\end{array}$ & $\begin{array}{l}\text { Antonio } \\
\text { Meneghetti } \\
\text { Faculdade, } \\
\text { AMF }\end{array}$ & $\begin{array}{l}\text { Fatores críticos de } \\
\text { sucesso na implantação } \\
\text { de sistemas ERP } \\
\text { relativos às capacidades } \\
\text { das empresas usuárias }\end{array}$ & $\begin{array}{l}\text { Prof. Ms. Wesley } \\
\text { Lacerda e Silva }\end{array}$ & 2015 \\
\hline 51 & Priscila Zinczynszyn & $\begin{array}{l}\text { MBA Business } \\
\text { Intuition - } \\
\text { Identidade } \\
\text { Empresarial }\end{array}$ & $\begin{array}{l}\text { Antonio } \\
\text { Meneghetti } \\
\text { Faculdade, } \\
\text { AMF }\end{array}$ & $\begin{array}{l}\text { A importância do } \\
\text { conceito de } \\
\text { transferência e seus } \\
\text { desdobramentos na } \\
\text { relação advogado e } \\
\text { cliente }\end{array}$ & $\begin{array}{l}\text { Prof. Ms. Ângelo } \\
\text { Accorsi Moreira }\end{array}$ & 2015 \\
\hline 53 & Neomir Grando & $\begin{array}{l}\text { MBA Business } \\
\text { Intuition - }\end{array}$ & $\begin{array}{l}\text { Antonio } \\
\text { Meneghetti }\end{array}$ & $\begin{array}{l}\text { Como a tecnologia } \\
\text { auxilia no bem-estar }\end{array}$ & $\begin{array}{l}\text { Profa. Dra. Estela } \\
\text { Maris Giordani }\end{array}$ & 2015 \\
\hline
\end{tabular}


Saber Humano, ISSN 2446-6298, V. 9, n. 15, p. 186-423, jul./dez. 2019.

\begin{tabular}{|c|c|c|c|c|c|c|}
\hline & & $\begin{array}{l}\text { Identidade } \\
\text { Empresarial }\end{array}$ & $\begin{array}{l}\text { Faculdade, } \\
\text { AMF }\end{array}$ & $\begin{array}{l}\text { dos colaboradores e no } \\
\text { desempenho de suas } \\
\text { tarefas: estudo de caso } \\
\text { em uma empresa de } \\
\text { calçados }\end{array}$ & & \\
\hline 54 & Alexandra Fernandes & $\begin{array}{l}\text { MBA Business } \\
\text { Intuition - } \\
\text { Identidade } \\
\text { Empresarial }\end{array}$ & $\begin{array}{l}\text { Antonio } \\
\text { Meneghetti } \\
\text { Faculdade, } \\
\text { AMF }\end{array}$ & $\begin{array}{l}\text { Proposta de aplicação } \\
\text { da Pedagogia } \\
\text { Ontopsicológica para a } \\
\text { educação infantil para } \\
\text { crianças na idade de } 4 \text { a } \\
6 \text { anos }\end{array}$ & $\begin{array}{l}\text { Profa. Dra. } \\
\text { Patrícia } \\
\text { Wazlawick }\end{array}$ & 2015 \\
\hline 55 & Carla Janaína Teixeira & $\begin{array}{l}\text { MBA Business } \\
\text { Intuition - } \\
\text { Identidade } \\
\text { Empresarial }\end{array}$ & $\begin{array}{l}\text { Antonio } \\
\text { Meneghetti } \\
\text { Faculdade, } \\
\text { AMF }\end{array}$ & $\begin{array}{l}\text { Construção de um } \\
\text { Manual de Boas Práticas } \\
\text { de atendimento para o } \\
\text { setor de suporte de } \\
\text { sistema RM, } \\
\text { administrativo } \\
\text { financeiro da } \\
\text { Mantenedora das } \\
\text { Escolas e Faculdades QI }\end{array}$ & $\begin{array}{l}\text { Profa. Ms. Vera } \\
\text { Lúcia Rodegheri }\end{array}$ & 2015 \\
\hline 56 & Luiz Augusto Maffini & $\begin{array}{l}\text { MBA Business } \\
\text { Intuition - } \\
\text { Identidade } \\
\text { Empresarial }\end{array}$ & $\begin{array}{l}\text { Antonio } \\
\text { Meneghetti } \\
\text { Faculdade, } \\
\text { AMF }\end{array}$ & $\begin{array}{l}\text { Estudo de caso de uma } \\
\text { campanha publicitária } \\
\text { das Escolas e Faculdades } \\
\text { QI: uma análise dos } \\
\text { aspectos de liderança } \\
\text { dos protagonistas }\end{array}$ & $\begin{array}{l}\text { Profa. Ms. Vera } \\
\text { Lúcia Rodegheri }\end{array}$ & 2015 \\
\hline
\end{tabular}




\begin{tabular}{|c|c|c|c|c|c|c|}
\hline 57 & Caroline Vogel de Oliveira & $\begin{array}{l}\text { MBA Business } \\
\text { Intuition - } \\
\text { Identidade } \\
\text { Empresarial }\end{array}$ & $\begin{array}{l}\text { Antonio } \\
\text { Meneghetti } \\
\text { Faculdade, } \\
\text { AMF }\end{array}$ & $\begin{array}{l}\text { Aplicação prática e } \\
\text { econômica de uma } \\
\text { intuição: Chocolates } \\
\text { Carol Brandt }\end{array}$ & $\begin{array}{l}\text { Prof. Ms. Cláudio } \\
\text { Correa Carrara }\end{array}$ & 2015 \\
\hline 58 & Ademar Silva Junior & $\begin{array}{l}\text { MBA Business } \\
\text { Intuition \& } \\
\text { Agronegócios, } \\
\text { Faculdade Antonio } \\
\text { Menegheti (AMF) }\end{array}$ & $\begin{array}{l}\text { Faculdade } \\
\text { Antonio } \\
\text { Meneghetti, } \\
\text { AMF }\end{array}$ & $\begin{array}{l}\text { A sucessão na } \\
\text { contemporaneidade do } \\
\text { Agronegócio Familiar }\end{array}$ & $\begin{array}{l}\text { Profa. Dra. Noemi } \\
\text { Boer }\end{array}$ & 2013 \\
\hline 59 & Almir Foletto & $\begin{array}{l}\text { MBA Business } \\
\text { Intuition \& } \\
\text { Agronegócios, } \\
\text { Faculdade Antonio } \\
\text { Menegheti (AMF) }\end{array}$ & $\begin{array}{l}\text { Faculdade } \\
\text { Antonio } \\
\text { Meneghetti, } \\
\text { AMF }\end{array}$ & $\begin{array}{l}\text { Relação homem } \\
\text { natureza e a função do } \\
\text { líder no agronegócio }\end{array}$ & $\begin{array}{l}\text { Prof. Dr. Alécio } \\
\text { Vidor }\end{array}$ & 2013 \\
\hline 60 & Edinei Minuzzi Ereno & $\begin{array}{l}\text { MBA Business } \\
\text { Intuition \& } \\
\text { Agronegócios, } \\
\text { Faculdade Antonio } \\
\text { Menegheti (AMF) }\end{array}$ & $\begin{array}{l}\text { Faculdade } \\
\text { Antonio } \\
\text { Meneghetti, } \\
\text { AMF }\end{array}$ & $\begin{array}{l}\text { Reestruturação } \\
\text { administrativa de uma } \\
\text { empresa agropecuária } \\
\text { orizícola - Alegrete RS }\end{array}$ & $\begin{array}{l}\text { Profa. Dra. } \\
\text { Reginete Panceri }\end{array}$ & 2013 \\
\hline 61 & $\begin{array}{l}\text { Emerson Luciano Cavalli e Homero Lopes } \\
\text { Mendonça }\end{array}$ & $\begin{array}{l}\text { MBA Business } \\
\text { Intuition \& } \\
\text { Agronegócios, } \\
\text { Faculdade Antonio } \\
\text { Menegheti (AMF) }\end{array}$ & $\begin{array}{l}\text { Faculdade } \\
\text { Antonio } \\
\text { Meneghetti, } \\
\text { AMF }\end{array}$ & $\begin{array}{l}\text { O MBA Agronegócio da } \\
\text { AMF: mudanças } \\
\text { pessoais, profissionais e } \\
\text { desafios }\end{array}$ & $\begin{array}{l}\text { Profa. Drạ. Estela } \\
\text { Maris Giordani }\end{array}$ & 2013 \\
\hline
\end{tabular}


Saber Humano, ISSN 2446-6298, V. 9, n. 15, p. 186-423, jul./dez. 2019.

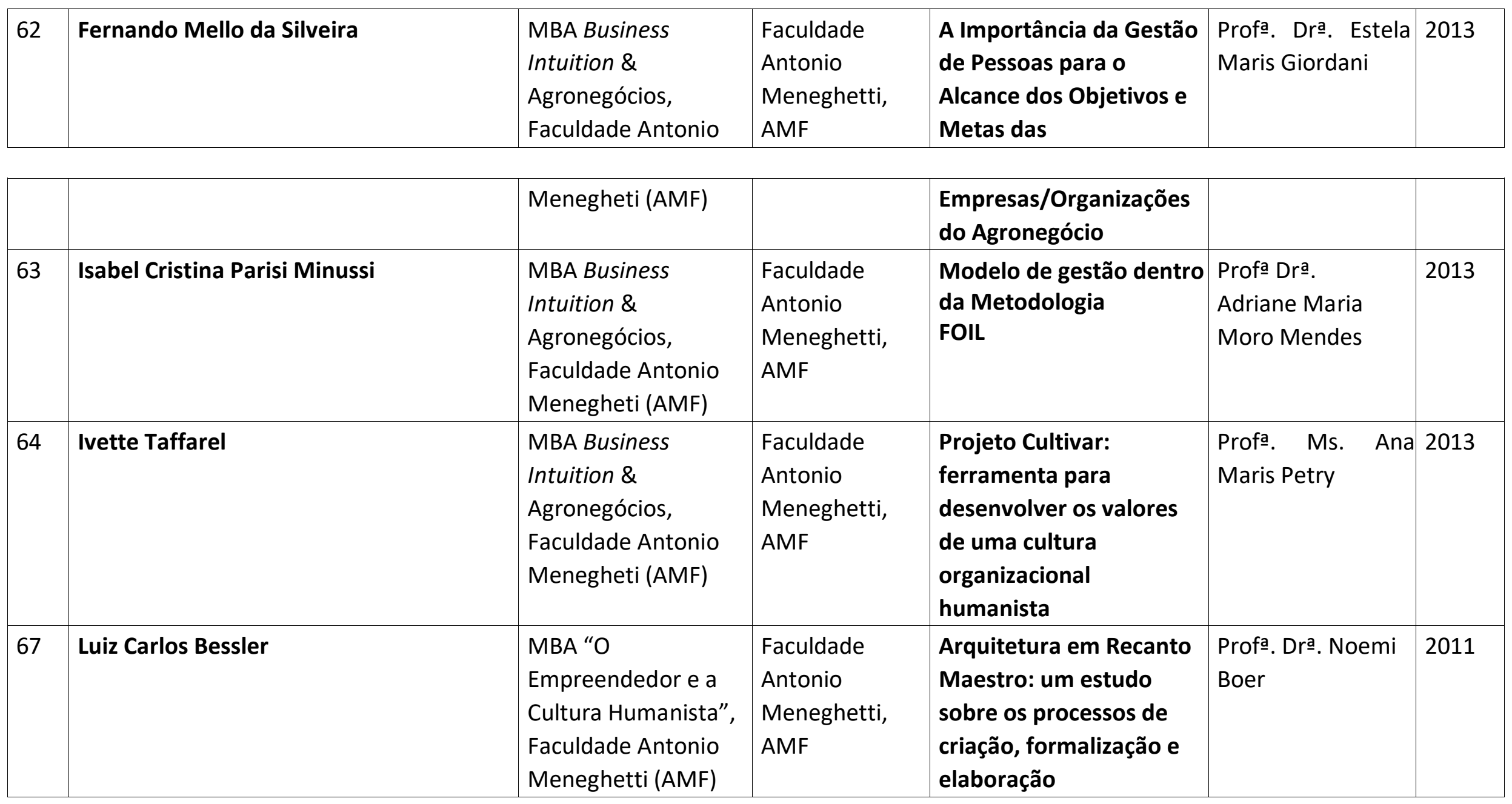


Saber Humano, ISSN 2446-6298, V. 9, n. 15, p. 186-423, jul./dez. 2019.

\begin{tabular}{|c|c|c|c|c|c|c|}
\hline 68 & Carmen Ivanete D'Agostini Spanhol & $\begin{array}{l}\text { MBA “O } \\
\text { Empreendedor e a } \\
\text { Cultura Humanista", } \\
\text { Faculdade Antonio } \\
\text { Meneghetti (AMF) }\end{array}$ & $\begin{array}{l}\text { Faculdade } \\
\text { Antonio } \\
\text { Meneghetti, } \\
\text { AMF }\end{array}$ & $\begin{array}{l}\text { Avaliação da mudança de } \\
\text { estilo de vida dos jovens }\end{array}$ & $\begin{array}{l}\text { Dra . Adriane } \\
\text { Maria Moro } \\
\text { Mendes }\end{array}$ & 2011 \\
\hline \multirow[t]{2}{*}{69} & Caroline Zanesco & $\begin{array}{l}\text { MBA “O } \\
\text { Empreendedor e a } \\
\text { Cultura Humanista", } \\
\text { Faculdade Antonio } \\
\text { Meneghetti (AMF) }\end{array}$ & $\begin{array}{l}\text { Faculdade } \\
\text { Antonio } \\
\text { Meneghetti, } \\
\text { AMF }\end{array}$ & $\begin{array}{l}\text { Avaliação qualitativa da } \\
\text { satisfação e dos } \\
\text { diferenciais dos serviços } \\
\text { odontológicos prestados } \\
\text { no Distrito }\end{array}$ & $\begin{array}{l}\text { Profa. Ms. Ana } \\
\text { Cláudia Valentini } \\
\text { Montenegro }\end{array}$ & 2011 \\
\hline & & & & Recanto Maestro-RS & & \\
\hline 70 & Reges Antonio Bronzatti & $\begin{array}{l}\text { MBA “O } \\
\text { Empreendedor e a } \\
\text { Cultura Humanista", } \\
\text { Faculdade Antonio } \\
\text { Meneghetti (AMF) }\end{array}$ & $\begin{array}{l}\text { Faculdade } \\
\text { Antonio } \\
\text { Meneghetti, } \\
\text { AMF }\end{array}$ & $\begin{array}{l}\text { Avaliação do grau de } \\
\text { maturidade dos } \\
\text { processos de gestão de } \\
\text { contratos de software e } \\
\text { serviços de tecnologia } \\
\text { da informação em } \\
\text { empresas do Rio Grande } \\
\text { do Sul }\end{array}$ & $\begin{array}{l}\text { Profa. Dra. Noemi } \\
\text { Boer }\end{array}$ & 2011 \\
\hline 71 & Luiz Fernando Somenzi & $\begin{array}{l}\text { MBA “O } \\
\text { Empreendedor e a } \\
\text { Cultura Humanista”, } \\
\text { Faculdade Antonio } \\
\text { Meneghetti (AMF) }\end{array}$ & $\begin{array}{l}\text { Faculdade } \\
\text { Antonio } \\
\text { Meneghetti, } \\
\text { AMF }\end{array}$ & $\begin{array}{l}\text { A Cultura Humanista } \\
\text { como variável da tomada } \\
\text { de decisão para a } \\
\text { aquisição de imobiliário } \\
\text { corporativo }\end{array}$ & $\begin{array}{l}\text { Prof. Ms. Wesley } \\
\text { Lacerda e Silva }\end{array}$ & 2011 \\
\hline
\end{tabular}


Saber Humano, ISSN 2446-6298, V. 9, n. 15, p. 186-423, jul./dez. 2019.

\begin{tabular}{|c|c|c|c|c|c|c|}
\hline 72 & João Carlos Leonardi & $\begin{array}{l}\text { MBA “O } \\
\text { Empreendedor e a } \\
\text { Cultura Humanista", } \\
\text { Faculdade Antonio } \\
\text { Meneghetti (AMF) }\end{array}$ & $\begin{array}{l}\text { Faculdade } \\
\text { Antonio } \\
\text { Meneghetti, } \\
\text { AMF }\end{array}$ & $\begin{array}{l}\text { A Pedagogia } \\
\text { Ontopsicológica na } \\
\text { formação dos jovens e o } \\
\text { conceito de life long } \\
\text { learning para a } \\
\text { profissionalização da } \\
\text { empresa }\end{array}$ & $\begin{array}{l}\text { Profa. Dra. Estela } \\
\text { Maris Giordani }\end{array}$ & 2011 \\
\hline 73 & Roula Kozak & $\begin{array}{l}\text { MBA “O } \\
\text { Empreendedor e a } \\
\text { Cultura Humanista", } \\
\text { Faculdade Antonio } \\
\text { Meneghetti (AMF) }\end{array}$ & $\begin{array}{l}\text { Faculdade } \\
\text { Antonio } \\
\text { Meneghetti, } \\
\text { AMF }\end{array}$ & \begin{tabular}{|l|} 
A percepção do cliente \\
sobre o serviço na clínica \\
médica e a formação \\
continuada do médico \\
contribuindo para o \\
êxito da atuação \\
profissional \\
\end{tabular} & $\begin{array}{l}\text { Profa. Dra. } \\
\text { Patrícia } \\
\text { Wazlawick }\end{array}$ & 2011 \\
\hline
\end{tabular}


Saber Humano, ISSN 2446-6298, V. 9, n. 15, p. 186-423, jul./dez. 2019.

\begin{tabular}{|c|c|c|c|c|c|c|}
\hline 75 & Roberta Pozza & $\begin{array}{l}\text { MBA “O } \\
\text { Empreendedor e a } \\
\text { Cultura Humanista", } \\
\text { Faculdade Antonio } \\
\text { Meneghetti (AMF) }\end{array}$ & $\begin{array}{l}\text { Faculdade } \\
\text { Antonio } \\
\text { Meneghetti, } \\
\text { AMF }\end{array}$ & $\begin{array}{l}\text { Da intuição à } \\
\text { autossabotagem: a } \\
\text { pesquisa } \\
\text { Ontopsicológica nos } \\
\text { correlatos } \\
\text { neurofisiológicos do } \\
\text { processo } \\
\text { perceptivocognitivo do } \\
\text { empreendedor }\end{array}$ & $\begin{array}{l}\text { Prof. Dr. Érico de } \\
\text { Lima Azevedo }\end{array}$ & 2011 \\
\hline 76 & Márcio Miorelli & $\begin{array}{l}\text { MBA “O } \\
\text { Empreendedor e a } \\
\text { Cultura Humanista", } \\
\text { Faculdade Antonio } \\
\text { Meneghetti (AMF) }\end{array}$ & $\begin{array}{l}\text { Faculdade } \\
\text { Antonio } \\
\text { Meneghetti, } \\
\text { AMF }\end{array}$ & $\begin{array}{l}\text { Desenvolvimento e } \\
\text { formação de equipes de } \\
\text { liderança utilizando } \\
\text { pressupostos } \\
\text { metodológicos da FOIL }\end{array}$ & $\begin{array}{l}\text { Profa. Dra. } \\
\text { Adriane Maria } \\
\text { Moro Mendes }\end{array}$ & 2011 \\
\hline 78 & Liliane Carpenedo & $\begin{array}{l}\text { MBA "O } \\
\text { Empreendedor e a } \\
\text { Cultura Humanista", } \\
\text { Faculdade Antonio }\end{array}$ & $\begin{array}{l}\text { Faculdade } \\
\text { Antonio } \\
\text { Meneghetti, } \\
\text { AMF }\end{array}$ & $\begin{array}{l}\text { Estudo teórico da } \\
\text { aplicação da } \\
\text { racionalidade sobre a } \\
\text { intuição na liderança e }\end{array}$ & $\begin{array}{l}\text { Dra. Patrícia } \\
\text { Wazlawick }\end{array}$ & 2011 \\
\hline & & Meneghetti (AMF) & & $\begin{array}{l}\text { gestão, segundo a visão } \\
\text { da Ciência } \\
\text { Ontopsicológica }\end{array}$ & & \\
\hline
\end{tabular}


Saber Humano, ISSN 2446-6298, V. 9, n. 15, p. 186-423, jul./dez. 2019.

\begin{tabular}{|c|c|c|c|c|c|c|}
\hline 79 & Izaías Penso & $\begin{array}{l}\text { MBA “O } \\
\text { Empreendedor e a } \\
\text { Cultura Humanista", } \\
\text { Faculdade Antonio } \\
\text { Meneghetti (AMF) }\end{array}$ & $\begin{array}{l}\text { Faculdade } \\
\text { Antonio } \\
\text { Meneghetti, } \\
\text { AMF }\end{array}$ & $\begin{array}{l}\text { Formação life long } \\
\text { learning e } \\
\text { Ontopsicologia }\end{array}$ & $\begin{array}{l}\text { Prof. Dr. Alécio } \\
\text { Vidor }\end{array}$ & 2011 \\
\hline 80 & Vicente Medeiros & $\begin{array}{l}\text { MBA “O } \\
\text { Empreendedor e a } \\
\text { Cultura Humanista", } \\
\text { Faculdade Antonio } \\
\text { Meneghetti (AMF) }\end{array}$ & $\begin{array}{l}\text { Faculdade } \\
\text { Antonio } \\
\text { Meneghetti, } \\
\text { AMF }\end{array}$ & $\begin{array}{l}\text { Genialidade do líder: } \\
\text { guia para comunicar a } \\
\text { real identidade de uma } \\
\text { empresa }\end{array}$ & $\begin{array}{l}\text { Profa. Ms. Ana } \\
\text { Cláudia Valentini } \\
\text { Montenegro }\end{array}$ & 2011 \\
\hline 81 & Maria Adamoli & $\begin{array}{l}\text { MBA “O } \\
\text { Empreendedor e a } \\
\text { Cultura Humanista", } \\
\text { Faculdade Antonio } \\
\text { Meneghetti (AMF) }\end{array}$ & $\begin{array}{l}\text { Faculdade } \\
\text { Antonio } \\
\text { Meneghetti, } \\
\text { AMF }\end{array}$ & $\begin{array}{l}\text { Identificação, } \\
\text { preparação e } \\
\text { desenvolvimento de } \\
\text { líderes: um estudo em } \\
\text { empresas do norte do } \\
\text { Estado do Rio Grande do } \\
\text { Sul }\end{array}$ & $\begin{array}{l}\text { Profa. Dra. Noemi } \\
\text { Boer }\end{array}$ & 2011 \\
\hline 83 & Simone Zanon & $\begin{array}{l}\text { MBA “O } \\
\text { Empreendedor e a } \\
\text { Cultura Humanista", }\end{array}$ & $\begin{array}{l}\text { Faculdade } \\
\text { Antonio } \\
\text { Meneghetti, }\end{array}$ & $\begin{array}{l}\text { Incentivos fiscais: } \\
\text { responsabilidade social } \\
\text { das empresas como }\end{array}$ & $\begin{array}{l}\text { Profa. Ms. } \\
\text { Reginete Panceri }\end{array}$ & 2011 \\
\hline
\end{tabular}


Saber Humano, ISSN 2446-6298, V. 9, n. 15, p. 186-423, jul./dez. 2019.

\begin{tabular}{|c|c|c|c|c|c|c|}
\hline & & $\begin{array}{l}\text { Faculdade Antonio } \\
\text { Meneghetti (AMF) }\end{array}$ & AMF & $\begin{array}{l}\text { forma de viabilizar a } \\
\text { formação humanista }\end{array}$ & & \\
\hline 84 & Delci Kolves & $\begin{array}{l}\text { MBA O } \\
\text { Empreendedor e a } \\
\text { Cultura Humanista. } \\
\text { Faculdade Antonio } \\
\text { Meneghetti, AMF }\end{array}$ & $\begin{array}{l}\text { Faculdade } \\
\text { Antonio } \\
\text { Meneghetti, } \\
\text { AMF }\end{array}$ & $\begin{array}{l}\text { Incubadora de } \\
\text { Empresas usando } \\
\text { Metodologia } \\
\text { Ontopsicológica no } \\
\text { Recanto Maestro }\end{array}$ & $\begin{array}{l}\text { Profa. Dra. Soraia } \\
\text { Schutel }\end{array}$ & 2011 \\
\hline 86 & Luiz Vanderlei Heidrich & $\begin{array}{l}\text { MBA “O } \\
\text { Empreendedor e a } \\
\text { Cultura Humanista”, } \\
\text { Faculdade Antonio } \\
\text { Meneghetti (AMF) }\end{array}$ & $\begin{array}{l}\text { Faculdade } \\
\text { Antonio } \\
\text { Meneghetti, } \\
\text { AMF }\end{array}$ & $\begin{array}{l}\text { O encantamento e a } \\
\text { estética oportunizando } \\
\text { crescimento e maior } \\
\text { participação no mercado } \\
\text { de moda calçadista na } \\
\text { América do Sul }\end{array}$ & $\begin{array}{l}\text { Profa. Ms. Ana } \\
\text { Maris Petry }\end{array}$ & 2011 \\
\hline 87 & $\begin{array}{l}\text { Ana Cristina Cassani } \\
\text { Cunha }\end{array}$ & $\begin{array}{l}\text { MBA “O } \\
\text { Empreendedor e a } \\
\text { Cultura Humanista", } \\
\text { Faculdade Antonio } \\
\text { Meneghetti (AMF) }\end{array}$ & $\begin{array}{l}\text { Faculdade } \\
\text { Antonio } \\
\text { Meneghetti, } \\
\text { AMF }\end{array}$ & $\begin{array}{l}\text { O desenvolvimento do } \\
\text { planejamento } \\
\text { estratégico para a } \\
\text { evolução da empresa }\end{array}$ & $\begin{array}{l}\text { Profa. Ms. Beatriz } \\
\text { Machri de } \\
\text { Pellegrini }\end{array}$ & 2011 \\
\hline
\end{tabular}


Saber Humano, ISSN 2446-6298, V. 9, n. 15, p. 186-423, jul./dez. 2019.

\begin{tabular}{|c|c|c|c|c|c|c|}
\hline 88 & Íria Martins & $\begin{array}{l}\text { MBA “O } \\
\text { Empreendedor e a } \\
\text { Cultura Humanista”, } \\
\text { Faculdade Antonio }\end{array}$ & $\begin{array}{l}\text { Faculdade } \\
\text { Antonio } \\
\text { Meneghetti, } \\
\text { AMF }\end{array}$ & $\begin{array}{l}\text { O humanismo na } \\
\text { formação do homem } \\
\text { pessoa em função social }\end{array}$ & $\begin{array}{l}\text { Prof. Dr. Alécio } \\
\text { Vidor }\end{array}$ & 2011 \\
\hline & & Meneghetti (AMF) & & & & \\
\hline 89 & Moisés Ceratti & $\begin{array}{l}\text { MBA “O } \\
\text { Empreendedor e a } \\
\text { Cultura Humanista", } \\
\text { Faculdade Antonio } \\
\text { Meneghetti (AMF) }\end{array}$ & $\begin{array}{l}\text { Faculdade } \\
\text { Antonio } \\
\text { Meneghetti, } \\
\text { AMF }\end{array}$ & $\begin{array}{l}\text { O líder e os } \\
\text { colaboradores como } \\
\text { maior valor em uma } \\
\text { organização que prima } \\
\text { pela qualidade: Estudo } \\
\text { de Caso. }\end{array}$ & $\begin{array}{l}\text { Profa. Ms. Josiane } \\
\text { Beatriz Piccin } \\
\text { Barbieri }\end{array}$ & 2011 \\
\hline 90 & André Carvalho de Fraga & $\begin{array}{l}\text { MBA “O } \\
\text { Empreendedor e a } \\
\text { Cultura Humanista”, } \\
\text { Faculdade Antonio } \\
\text { Meneghetti (AMF) }\end{array}$ & $\begin{array}{l}\text { Faculdade } \\
\text { Antonio } \\
\text { Meneghetti, } \\
\text { AMF }\end{array}$ & $\begin{array}{l}\text { O método de capacitação } \\
\text { contínua (life long } \\
\text { learning) para equipes } \\
\text { comerciais na primeira } \\
\text { hora do dia }\end{array}$ & $\begin{array}{l}\text { Profa. Dra. Estela } \\
\text { Maris Giordani }\end{array}$ & 2011 \\
\hline 91 & Mara Lucia Pierdoná & $\begin{array}{l}\text { MBA “O } \\
\text { Empreendedor e a } \\
\text { Cultura Humanista", } \\
\text { Faculdade Antonio } \\
\text { Meneghetti (AMF) }\end{array}$ & $\begin{array}{l}\text { Faculdade } \\
\text { Antonio } \\
\text { Meneghetti, } \\
\text { AMF }\end{array}$ & $\begin{array}{l}\text { Quando o líder é o } \\
\text { causador dos problemas } \\
\text { que sofre: análise de } \\
\text { um caso de } \\
\text { psicossomática } \\
\text { empresarial }\end{array}$ & $\begin{array}{l}\text { Profa. Ms. Ana } \\
\text { Maris Petry }\end{array}$ & 2011 \\
\hline
\end{tabular}


Saber Humano, ISSN 2446-6298, V. 9, n. 15, p. 186-423, jul./dez. 2019.

\begin{tabular}{|c|c|c|c|c|c|c|}
\hline 92 & $\begin{array}{l}\text { Cleomar José Guerra Ereno e Gilberto } \\
\text { Pilecco }\end{array}$ & $\begin{array}{l}\text { MBA “O } \\
\text { Empreendedor e a } \\
\text { Cultura Humanista", } \\
\text { Faculdade Antonio } \\
\text { Meneghetti (AMF) }\end{array}$ & $\begin{array}{l}\text { Faculdade } \\
\text { Antonio } \\
\text { Meneghetti, } \\
\text { AMF }\end{array}$ & $\begin{array}{l}\text { Sucessão nas empresas } \\
\text { familiares: a importância } \\
\text { do líder }\end{array}$ & $\begin{array}{l}\text { Profa. Ms. Josiane } \\
\text { Beatriz Piccin } \\
\text { Barbieri }\end{array}$ & 2011 \\
\hline 93 & Maria Luiza Bazzo & $\begin{array}{l}\text { MBA “O } \\
\text { Empreendedor e a } \\
\text { Cultura Humanista", } \\
\text { Faculdade Antonio } \\
\text { Meneghetti (AMF) }\end{array}$ & $\begin{array}{l}\text { Faculdade } \\
\text { Antonio } \\
\text { Meneghetti, } \\
\text { AMF }\end{array}$ & $\begin{array}{l}\text { Variação subjetiva em } \\
\text { protocolos de pesquisa: } \\
\text { o campo semântico no } \\
\text { simples da vida }\end{array}$ & $\begin{array}{l}\text { Prof. Dr. Érico de } \\
\text { Lima Azevedo }\end{array}$ & 2011 \\
\hline 94 & Nádia Isabel de Souza & $\begin{array}{l}\text { MBA “Gestão de } \\
\text { Negócios e } \\
\text { Intuição"/Business } \\
\text { Intuition, Faculdade } \\
\text { Antonio Meneghetti } \\
\text { (AMF) }\end{array}$ & $\begin{array}{l}\text { Faculdade } \\
\text { Antonio } \\
\text { Meneghetti, } \\
\text { AMF }\end{array}$ & $\begin{array}{l}\text { A contribuição do } \\
\text { Projeto OIKOS para o } \\
\text { alcance do } 7^{\circ} \text { ODM no } \\
\text { Recanto Maestro-RS }\end{array}$ & $\begin{array}{l}\text { Profa. Dra. Soraia } \\
\text { Schutel }\end{array}$ & 2010 \\
\hline
\end{tabular}


Saber Humano, ISSN 2446-6298, V. 9, n. 15, p. 186-423, jul./dez. 2019.

\begin{tabular}{|c|c|c|c|c|c|c|}
\hline 96 & Maria Tereza Andreola & $\begin{array}{l}\text { MBA “Gestão de } \\
\text { Negócios e } \\
\text { Intuição"/Business } \\
\text { Intuition, Faculdade } \\
\text { Antonio Meneghetti } \\
\text { (AMF) }\end{array}$ & $\begin{array}{l}\text { Faculdade } \\
\text { Antonio } \\
\text { Meneghetti, } \\
\text { AMF }\end{array}$ & $\begin{array}{l}\text { A formação } \\
\text { ontopsicológica do } \\
\text { jovem líder e a } \\
\text { sociedade do futuro: } \\
\text { uma visão para os } 8 \\
\text { Objetivos de } \\
\text { Desenvolvimento do } \\
\text { Milênio (ODM) da } \\
\text { ONU }\end{array}$ & $\begin{array}{l}\text { Profa. Ms. Ana } \\
\text { Maris Petry }\end{array}$ & 2010 \\
\hline 97 & Letícia Balen Zereu Batistela & $\begin{array}{l}\text { MBA “Gestão de } \\
\text { Negócios e } \\
\text { Intuição"/Business } \\
\text { Intuition, Faculdade } \\
\text { Antonio Meneghetti } \\
\text { (AMF) }\end{array}$ & $\begin{array}{l}\text { Faculdade } \\
\text { Antonio } \\
\text { Meneghetti, } \\
\text { AMF }\end{array}$ & $\begin{array}{l}\text { A função do assessor } \\
\text { jurídico para sucesso na } \\
\text { tomada de decisão do } \\
\text { empresário }\end{array}$ & $\begin{array}{l}\text { Profa. Dra. Soraia } \\
\text { Schutel }\end{array}$ & 2010 \\
\hline
\end{tabular}


Saber Humano, ISSN 2446-6298, V. 9, n. 15, p. 186-423, jul./dez. 2019.

\begin{tabular}{|c|c|c|c|c|c|c|}
\hline 99 & João Feltrin & $\begin{array}{l}\text { MBA “Gestão de } \\
\text { Negócios e } \\
\text { Intuição"/Business } \\
\text { Intuition, Faculdade } \\
\text { Antonio Meneghetti } \\
\text { (AMF) }\end{array}$ & $\begin{array}{l}\text { Faculdade } \\
\text { Antonio } \\
\text { Meneghetti, } \\
\text { AMF }\end{array}$ & $\begin{array}{l}\text { A responsabilidade do } \\
\text { empreendedor } \\
\text { individual e suas } \\
\text { perspectivas } \\
\text { jurídicas }\end{array}$ & $\begin{array}{l}\text { Prof. Dr. Érico de } \\
\text { Lima Azevedo }\end{array}$ & 2010 \\
\hline 100 & Camilo Geremia & $\begin{array}{l}\text { MBA “Gestão de } \\
\text { Negócios e } \\
\text { Intuição"/Business } \\
\text { Intuition, Faculdade } \\
\text { Antonio Meneghetti } \\
\text { (AMF) }\end{array}$ & $\begin{array}{l}\text { Faculdade } \\
\text { Antonio } \\
\text { Meneghetti, } \\
\text { AMF }\end{array}$ & $\begin{array}{l}\text { As pessoas como } \\
\text { diferencial na excelência } \\
\text { dos serviços: Estudo de } \\
\text { caso do Restaurante } \\
\text { Canta } \\
\text { Maria }\end{array}$ & $\begin{array}{l}\text { Profa. Ms. } \\
\text { Reginete Panceri }\end{array}$ & 2010 \\
\hline 101 & Tarcísio Bastos Schaefer & $\begin{array}{l}\text { MBA “Gestão de } \\
\text { Negócios e } \\
\text { Intuição"/Business } \\
\text { Intuition, Faculdade } \\
\text { Antonio Meneghetti } \\
\text { (AMF) }\end{array}$ & $\begin{array}{l}\text { Faculdade } \\
\text { Antonio } \\
\text { Meneghetti, } \\
\text { AMF }\end{array}$ & Business Surf Intuition & $\begin{array}{l}\text { Profa. Dra. } \\
\text { Adriane Maria } \\
\text { Moro Mendes }\end{array}$ & 2010 \\
\hline 102 & Cristiane Mendes Steigleder & $\begin{array}{l}\text { MBA “Gestão de } \\
\text { Negócios e } \\
\text { Intuição"/Business } \\
\text { Intuition, Faculdade } \\
\text { Antonio Meneghetti } \\
\text { (AMF) }\end{array}$ & $\begin{array}{l}\text { Faculdade } \\
\text { Antonio } \\
\text { Meneghetti, } \\
\text { AMF }\end{array}$ & $\begin{array}{l}\text { Consultoria } \\
\text { empresarial: assessoria } \\
\text { na carreira de } \\
\text { executivos }\end{array}$ & $\begin{array}{l}\text { Profa. Ms. Ana } \\
\text { Maris Petry }\end{array}$ & 2010 \\
\hline
\end{tabular}


Saber Humano, ISSN 2446-6298, V. 9, n. 15, p. 186-423, jul./dez. 2019.

\begin{tabular}{|c|c|c|c|c|c|c|}
\hline 103 & Márcio Vieira dos Santos & $\begin{array}{l}\text { MBA “Gestão de } \\
\text { Negócios e } \\
\text { Intuição"/Business } \\
\text { Intuition, Faculdade } \\
\text { Antonio Meneghetti } \\
\text { (AMF) }\end{array}$ & $\begin{array}{l}\text { Faculdade } \\
\text { Antonio } \\
\text { Meneghetti, } \\
\text { AMF }\end{array}$ & $\begin{array}{l}\text { Contrato: principal } \\
\text { ferramenta reguladora } \\
\text { da materialização do } \\
\text { projeto do indivíduo } \\
\text { frente à sociedade }\end{array}$ & $\begin{array}{l}\text { Prof. Dr. Josemar } \\
\text { Sidinei Soares }\end{array}$ & 2010 \\
\hline 104 & Maria Lúcia Teixeira de Souza Carrara & $\begin{array}{l}\text { MBA “Gestão de } \\
\text { Negócios e } \\
\text { Intuição"/Business } \\
\text { Intuition, Faculdade } \\
\text { Antonio Meneghetti } \\
\text { (AMF) }\end{array}$ & $\begin{array}{l}\text { Faculdade } \\
\text { Antonio } \\
\text { Meneghetti, } \\
\text { AMF }\end{array}$ & $\begin{array}{l}\text { Desenvolvimento de um } \\
\text { produto ecobiológico }\end{array}$ & $\begin{array}{l}\text { Profa. Dra. Soraia } \\
\text { Schutel }\end{array}$ & 2010 \\
\hline 105 & Ricardo Cardoso Abel & $\begin{array}{l}\text { MBA “Gestão de } \\
\text { Negócios e } \\
\text { Intuição"/Business } \\
\text { Intuition, Faculdade } \\
\text { Antonio Meneghetti } \\
\text { (AMF) }\end{array}$ & $\begin{array}{l}\text { Faculdade } \\
\text { Antonio } \\
\text { Meneghetti, } \\
\text { AMF }\end{array}$ & $\begin{array}{l}\text { Empreendedorismo hoje } \\
\text { aplicado no sistema de } \\
\text { ensino universitário }\end{array}$ & $\begin{array}{l}\text { Profa. Ms. Ana } \\
\text { Maris Petry }\end{array}$ & 2010 \\
\hline 106 & $\begin{array}{l}\text { Maria Alice Schuch } \\
\text { http://lattes.cnpq.br/5768202542112018 }\end{array}$ & $\begin{array}{l}\text { MBA “Gestão de } \\
\text { Negócios e } \\
\text { Intuição"/Business } \\
\text { Intuition, Faculdade } \\
\text { Antonio Meneghetti } \\
\text { (AMF) }\end{array}$ & $\begin{array}{l}\text { Faculdade } \\
\text { Antonio } \\
\text { Meneghetti, } \\
\text { AMF }\end{array}$ & $\begin{array}{l}\text { Estratégia Empresarial: } \\
\text { Planejamento e } \\
\text { Implementação }\end{array}$ & $\begin{array}{l}\text { Profa. Ms. Vera } \\
\text { Lúcia Rodegheri }\end{array}$ & 2010 \\
\hline
\end{tabular}


Saber Humano, ISSN 2446-6298, V. 9, n. 15, p. 186-423, jul./dez. 2019.

\begin{tabular}{|c|c|c|c|c|c|c|}
\hline 107 & Joana de Jesus & $\begin{array}{l}\text { MBA “Gestão de } \\
\text { Negócios e } \\
\text { Intuição"/Business } \\
\text { Intuition, Faculdade } \\
\text { Antonio Meneghetti } \\
\text { (AMF) }\end{array}$ & $\begin{array}{l}\text { Faculdade } \\
\text { Antonio } \\
\text { Meneghetti, } \\
\text { AMF }\end{array}$ & $\begin{array}{l}\text { Estudo da aplicação da } \\
\text { intuição no processo de } \\
\text { vendas }\end{array}$ & $\begin{array}{l}\text { Profa. Dra. } \\
\text { Adriane Maria } \\
\text { Moro Mendes }\end{array}$ & 2010 \\
\hline 108 & Mônica Oliveira da Silva & $\begin{array}{l}\text { MBA “Gestão de } \\
\text { Negócios e } \\
\text { Intuição"/Business } \\
\text { Intuition, Faculdade } \\
\text { Antonio Meneghetti } \\
\text { (AMF) }\end{array}$ & $\begin{array}{l}\text { Faculdade } \\
\text { Antonio } \\
\text { Meneghetti, } \\
\text { AMF }\end{array}$ & $\begin{array}{l}\text { Formação e preparação } \\
\text { de jovens e adolescentes } \\
\text { para intercâmbio } \\
\text { estudantil }\end{array}$ & $\begin{array}{l}\text { Profa. Dra. Estela } \\
\text { Maris Giordani }\end{array}$ & 2010 \\
\hline 109 & Renato Arns & $\begin{array}{l}\text { MBA “Gestão de } \\
\text { Negócios e } \\
\text { Intuição"/Business } \\
\text { Intuition, Faculdade } \\
\text { Antonio Meneghetti } \\
\text { (AMF) }\end{array}$ & $\begin{array}{l}\text { Faculdade } \\
\text { Antonio } \\
\text { Meneghetti, } \\
\text { AMF }\end{array}$ & $\begin{array}{l}\text { Formatação de um curso } \\
\text { MBA em Gestão de } \\
\text { Agronegócio }\end{array}$ & $\begin{array}{l}\text { Profa. Dra. Helena } \\
\text { Biasotto }\end{array}$ & 2010 \\
\hline 110 & Bernardina Amantino & $\begin{array}{l}\text { MBA “Gestão de } \\
\text { Negócios e } \\
\text { Intuição"/Business } \\
\text { Intuition, Faculdade } \\
\text { Antonio Meneghetti } \\
\text { (AMF) }\end{array}$ & $\begin{array}{l}\text { Faculdade } \\
\text { Antonio } \\
\text { Meneghetti, } \\
\text { AMF }\end{array}$ & Moda como Educação & $\begin{array}{l}\text { Profa. Dra. Soraia } \\
\text { Schutel }\end{array}$ & 2010 \\
\hline
\end{tabular}


Saber Humano, ISSN 2446-6298, V. 9, n. 15, p. 186-423, jul./dez. 2019.

\begin{tabular}{|c|c|c|c|c|c|c|}
\hline 111 & Kazumi Futatsugi & $\begin{array}{l}\text { MBA “Gestão de } \\
\text { Negócios e } \\
\text { Intuição"/Business } \\
\text { Intuition, Faculdade } \\
\text { Antonio Meneghetti } \\
\text { (AMF) }\end{array}$ & $\begin{array}{l}\text { Faculdade } \\
\text { Antonio } \\
\text { Meneghetti, } \\
\text { AMF }\end{array}$ & $\begin{array}{l}\text { O saber servir como } \\
\text { papel do colaborador } \\
\text { no interior das } \\
\text { organizações }\end{array}$ & $\begin{array}{l}\text { Prof. Ms. Wesley } \\
\text { Lacerda e Silva }\end{array}$ & 2010 \\
\hline 112 & Beatriz Machri de Pellegrini & $\begin{array}{l}\text { MBA “Gestão de } \\
\text { Negócios e } \\
\text { Intuição"/Business } \\
\text { Intuition, Faculdade } \\
\text { Antonio Meneghetti } \\
\text { (AMF) }\end{array}$ & $\begin{array}{l}\text { Faculdade } \\
\text { Antonio } \\
\text { Meneghetti, } \\
\text { AMF }\end{array}$ & $\begin{array}{l}\text { O sentido do trabalho } \\
\text { para o líder }\end{array}$ & $\begin{array}{l}\text { Profa. Ms. Ana } \\
\text { Maris Petry }\end{array}$ & 2010 \\
\hline 113 & Ana Paula Mariano Pregardier & $\begin{array}{l}\text { MBA “Gestão de } \\
\text { Negócios e } \\
\text { Intuição"/Business } \\
\text { Intuition, Faculdade } \\
\text { Antonio Meneghetti } \\
\text { (AMF) }\end{array}$ & $\begin{array}{l}\text { Faculdade } \\
\text { Antonio } \\
\text { Meneghetti, } \\
\text { AMF }\end{array}$ & $\begin{array}{l}\text { Residence de } \\
\text { Autenticação: relação } \\
\text { entre conceituação e } \\
\text { exercício do } \\
\text { autossustento em jovens }\end{array}$ & $\begin{array}{l}\text { Profa. Ms. Josiane } \\
\text { Beatriz Piccin } \\
\text { Barbieri }\end{array}$ & 2010 \\
\hline 114 & Mary Leda Baggio & $\begin{array}{l}\text { MBA “Gestão de } \\
\text { Negócios e } \\
\text { Intuição"/Business } \\
\text { Intuition, Faculdade } \\
\text { Antonio Meneghetti } \\
\text { (AMF) }\end{array}$ & $\begin{array}{l}\text { Faculdade } \\
\text { Antonio } \\
\text { Meneghetti, } \\
\text { AMF }\end{array}$ & $\begin{array}{l}\text { Trajetória empresarial e } \\
\text { intuição: o case do } \\
\text { nascimento, } \\
\text { desenvolvimento e } \\
\text { evolução de uma } \\
\text { indústria têxtil de } \\
\text { tapeçaria }\end{array}$ & $\begin{array}{l}\text { Profa. Dra. Soraia } \\
\text { Schutel }\end{array}$ & 2010 \\
\hline
\end{tabular}


LIVROS PUBLICADOS COM FUNDAMENTAÇÃO TEÓRICA NA CIÊNCIA ONTOPSICOLÓGICA NO BRASIL 
Saber Humano, ISSN 2446-6298, V. 9, n. 15, p. 186-423, jul./dez. 2019.

\begin{tabular}{|c|c|c|c|c|c|}
\hline № & Autor & Título do Livro & Edição & Editora & Ano \\
\hline 1 & $\begin{array}{l}\text { Alécio Vidor } \\
\text { http://lattes.cnpq.br/8800301017909637 }\end{array}$ & $\begin{array}{l}\text { O Fundamento da } \\
\text { Ciência }\end{array}$ & 1a edição & $\begin{array}{l}\text { Ontopsicológica Editora } \\
\text { Universitária }\end{array}$ & 2018 \\
\hline 2 & $\begin{array}{l}\text { Ana Maris Petry } \\
\text { http://lattes.cnpq.br/5224087434361870 }\end{array}$ & Por que sonhamos? & 1a edição & $\begin{array}{l}\text { Ontopsicológica Editora } \\
\text { Universitária }\end{array}$ & 2016 \\
\hline 3 & $\begin{array}{l}\text { Alécio Vidor } \\
\text { http://lattes.cnpq.br/8800301017909637 }\end{array}$ & $\begin{array}{l}\text { Filosofia Pura: a atividade } \\
\text { psíquica deve mater-se } \\
\text { em nexo ontológico }\end{array}$ & 1a edição & $\begin{array}{l}\text { Ontopsicológica Editora } \\
\text { Universitária }\end{array}$ & 2015 \\
\hline 4 & $\begin{array}{l}\text { Alécio Vidor } \\
\text { http://lattes.cnpq.br/8800301017909637 }\end{array}$ & $\begin{array}{l}\text { Opinião ou Ciência: } \\
\text { Tecnologia X Vida }\end{array}$ & 1a edição & $\begin{array}{l}\text { Ontopsicológica Editora } \\
\text { Universitária }\end{array}$ & 2014 \\
\hline 5 & $\begin{array}{l}\text { Alécio Vidor } \\
\text { http://lattes.cnpq.br/8800301017909637 }\end{array}$ & $\begin{array}{l}\text { Relação entre pais e } \\
\text { filhos: a origem dos } \\
\text { problemas }\end{array}$ & 2a edição & $\begin{array}{l}\text { Ontopsicológica Editora } \\
\text { Universitária }\end{array}$ & 2014 \\
\hline
\end{tabular}

\begin{tabular}{|c|l|l|l|l|}
\hline 6 & Alécio Vidor & $\begin{array}{l}\text { Fenomenologia e } \\
\text { Ontopsicologia: De } \\
\text { Husserl a Meneghetti }\end{array}$ & 1á edição & $\begin{array}{l}\text { Ontopsicológica Editora } \\
\text { Universitária }\end{array}$ \\
\hline
\end{tabular}


Saber Humano, ISSN 2446-6298, V. 9, n. 15, p. 186-423, jul./dez. 2019.

\begin{tabular}{|c|c|c|c|c|c|}
\hline 7 & $\begin{array}{l}\text { Ana Maris Petry } \\
\text { http://lattes.cnpq.br/5224087434361870 }\end{array}$ & $\begin{array}{l}\text { Prospecto } \\
\text { HistóricoCientífico do } \\
\text { Acadêmico } \\
\text { Professor Antonio } \\
\text { Meneghetti }\end{array}$ & 1a edição & $\begin{array}{l}\text { Ontopsicológica Editora } \\
\text { Universitária }\end{array}$ & 2014 \\
\hline 8 & $\begin{array}{l}\text { Alécio Vidor } \\
\text { http://lattes.cnpq.br/8800301017909637 }\end{array}$ & Filosofia Elementar & 1a edição & IESDE Brasil/SA & 2008 \\
\hline 9 & $\begin{array}{l}\text { Alécio Vidor } \\
\text { http://lattes.cnpq.br/8800301017909637 }\end{array}$ & $\begin{array}{l}\text { Bases da análise clínica e } \\
\text { a versão científica dos } \\
\text { sonhos }\end{array}$ & 1a edição & $\begin{array}{l}\text { Editora da Universidade Regional } \\
\text { Integrada do Alto Uruguai e das } \\
\text { Missões }\end{array}$ & 2001 \\
\hline 10 & $\begin{array}{l}\text { Alécio Vidor } \\
\text { http://lattes.cnpq.br/8800301017909637 }\end{array}$ & $\begin{array}{l}\text { Sensibilidade, Natureza } \\
\text { Humana e Educação }\end{array}$ & 1a edição & $\begin{array}{l}\text { Editora da Universidade Regional } \\
\text { Integrada do Alto Uruguai e das } \\
\text { Missões }\end{array}$ & 1999 \\
\hline 11 & $\begin{array}{l}\text { Alécio Vidor } \\
\text { http://lattes.cnpq.br/8800301017909637 }\end{array}$ & $\begin{array}{l}\text { A gênese da alienação } \\
\text { psicológica e a } \\
\text { Ontopsicologia }\end{array}$ & 1a edição & $\begin{array}{l}\text { Editora da Universidade Regional } \\
\text { Integrada do Alto Uruguai e das } \\
\text { Missões }\end{array}$ & 1996 \\
\hline 12 & $\begin{array}{l}\text { Alécio Vidor } \\
\text { http://lattes.cnpq.br/8800301017909637 }\end{array}$ & $\begin{array}{l}\text { A Epistemologia } \\
\text { Interdisciplinar: o homem } \\
\text { e seu conhecimento }\end{array}$ & 2a edição & $\begin{array}{l}\text { Editora da Universidade Federal } \\
\text { de Santa Maria (UFSM) }\end{array}$ & 1991 \\
\hline
\end{tabular}


Saber Humano, ISSN 2446-6298, V. 9, n. 15, p. 186-423, jul./dez. 2019.

\begin{tabular}{|c|c|c|c|c|c|}
\hline 13 & $\begin{array}{l}\text { Alécio Vidor } \\
\text { http://lattes.cnpq.br/8800301017909637 }\end{array}$ & $\begin{array}{l}\text { Uma nova Psicologia para } \\
\text { a Pedagogia }\end{array}$ & 2a edição & $\begin{array}{l}\text { Editora da Universidade Regional } \\
\text { Integrada do Alto Uruguai e das } \\
\text { Missões }\end{array}$ & 1996 \\
\hline 14 & $\begin{array}{l}\text { Alécio Vidor } \\
\text { http://lattes.cnpq.br/8800301017909637 }\end{array}$ & $\begin{array}{l}\text { Uma nova Psicologia para } \\
\text { a Pedagogia }\end{array}$ & 1a edição & $\begin{array}{l}\text { Editora da Universidade Regional } \\
\text { Integrada do Alto Uruguai e das } \\
\text { Missões }\end{array}$ & 1991 \\
\hline 15 & $\begin{array}{l}\text { Alécio Vidor } \\
\text { http://lattes.cnpq.br/8800301017909637 }\end{array}$ & $\begin{array}{l}\text { A Epistemologia } \\
\text { Interdisciplinar: o homem } \\
\text { e seu conhecimento }\end{array}$ & 1a edição & $\begin{array}{l}\text { Editora da Universidade Federal } \\
\text { de Santa Maria (UFSM) }\end{array}$ & 1975 \\
\hline 16 & $\begin{array}{l}\text { Alécio Vidor } \\
\text { http://lattes.cnpq.br/8800301017909637 }\end{array}$ & $\begin{array}{l}\text { Relação entre pais e } \\
\text { filhos: a origem dos } \\
\text { problemas }\end{array}$ & 1a edição & Editora Berthier & 1974 \\
\hline 17 & $\begin{array}{l}\text { Alécio Vidor } \\
\text { http://lattes.cnpq.br/8800301017909637 }\end{array}$ & A Educação Não-diretiva & 1a edição & Editora Berthier & 1974 \\
\hline 18 & $\begin{array}{l}\text { Alécio Vidor } \\
\text { http://lattes.cnpq.br/8800301017909637 }\end{array}$ & $\begin{array}{l}\text { Relações entre Pais e } \\
\text { Filhos }\end{array}$ & 1ạ edição & Editora Berthier & 1974 \\
\hline
\end{tabular}

OBS.: Na relação de livros acima não estão inclusos os livros de autoria do Acadêmico Professor Antonio Meneghetti. Para verificar qual é a obra dele completa em língua portuguesa e publicada no Brasil, vide Currículo Lattes de Antonio Meneghetti no endereço: http://lattes.cnpq.br/8161413607019539 


\section{CAPÍTULOS DE LIVROS PUBLICADOS COM FUNDAMENTAÇÃO TEÓRICA E RELATOS DE PESQUISAS EXPERIMENTAIS NA CIÊNCIA ONTOPSICOLÓGICA NO BRASIL}

\begin{tabular}{|c|c|c|c|c|c|c|}
\hline № & Autor & Título do Capítulo & Título do Livro & Volume & Páginas & Ano \\
\hline 1 & $\begin{array}{l}\text { Antonio Meneghetti } \\
\text { http://lattes.cnpq.br/8161413607019539 }\end{array}$ & $\begin{array}{l}\text { Prolusão à refundação de } \\
\text { um critério ético no } \\
\text { interior do Humanismo }\end{array}$ & $\begin{array}{l}\text { Formando Lideranças } \\
\text { para o } \\
\text { Desenvolvimento } \\
\text { Futuro - } \\
\text { Compartilhando } \\
\text { Experiências }\end{array}$ & 1a edição & $25-32$ & 2019 \\
\hline 2 & Juliane Nevez Fiorezi & $\begin{array}{l}\text { Antonio Meneghetti } \\
\text { Faculdade: onde o } \\
\text { mundo-da-vida escorre } \\
\text { como realidade histórica }\end{array}$ & $\begin{array}{l}\text { Formando Lideranças } \\
\text { para o } \\
\text { Desenvolvimento } \\
\text { Futuro - } \\
\text { Compartilhando } \\
\text { Experiências }\end{array}$ & 1’a edição & $35-42$ & 2019 \\
\hline 3 & Fernanda Goulart Martins & $\begin{array}{l}\text { Formação profissional } \\
\text { através do protagonismo } \\
\text { responsável: uma } \\
\text { proposta educacional para } \\
\text { a sociedade atual e futura }\end{array}$ & $\begin{array}{l}\text { Formando Lideranças } \\
\text { para o } \\
\text { Desenvolvimento } \\
\text { Futuro - } \\
\text { Compartilhando } \\
\text { Experiências }\end{array}$ & 1a edição & $43-47$ & 2019 \\
\hline
\end{tabular}


Saber Humano, ISSN 2446-6298, V. 9, n. 15, p. 186-423, jul./dez. 2019.

\begin{tabular}{|c|c|c|c|c|c|c|}
\hline 4 & Augusto Roberto Gehrke & $\begin{array}{l}\text { Os pilares para a } \\
\text { formação integral de um } \\
\text { profissional }\end{array}$ & $\begin{array}{l}\text { Formando Lideranças } \\
\text { para o } \\
\text { Desenvolvimento }\end{array}$ & 1a edição & $49-54$ & 2019 \\
\hline & & & $\begin{array}{l}\text { Futuro - } \\
\text { Compartilhando } \\
\text { Experiências } \\
\end{array}$ & & & \\
\hline 5 & Giovana Alves Dellazzana & $\begin{array}{l}\text { O diferencial de } \\
\text { formação profissional da } \\
\text { FOIL }\end{array}$ & $\begin{array}{l}\text { Formando Lideranças } \\
\text { para o } \\
\text { Desenvolvimento } \\
\text { Futuro - } \\
\text { Compartilhando } \\
\text { Experiências }\end{array}$ & 1a edição & $55-57$ & 2019 \\
\hline 6 & Bruno Fleck da Silva & $\begin{array}{l}\text { A autopoiese } \\
\text { ônticohumanisra como } \\
\text { critério ético-jurídico: } \\
\text { equacionando direitos e } \\
\text { devers na perspectiva de } \\
\text { um Humanismo Perene }\end{array}$ & $\begin{array}{l}\text { Formando Lideranças } \\
\text { para o } \\
\text { Desenvolvimento } \\
\text { Futuro - } \\
\text { Compartilhando } \\
\text { Experiências }\end{array}$ & 1ạ edição & $61-78$ & 2019 \\
\hline 7 & Luiza Brutti Ribeiro & $\begin{array}{l}\text { O desenvolvimento } \\
\text { futuro através da atuação } \\
\text { de líderes formados com } \\
\text { um viés ontopsicológico }\end{array}$ & $\begin{array}{l}\text { Formando Lideranças } \\
\text { para o } \\
\text { Desenvolvimento } \\
\text { Futuro - } \\
\text { Compartilhando } \\
\text { Experiências }\end{array}$ & 1ạ edição & $79-98$ & 2019 \\
\hline
\end{tabular}


Saber Humano, ISSN 2446-6298, V. 9, n. 15, p. 186-423, jul./dez. 2019.

\begin{tabular}{|c|c|c|c|c|c|c|}
\hline 8 & $\begin{array}{l}\text { Patrícia Wazlawick } \\
\text { Ricardo Schaefer } \\
\text { Clarissa Miranda }\end{array}$ & $\begin{array}{l}\text { Transform(ações) e } \\
\text { resultados na dialética do } \\
\text { devir responsável: jovens } \\
\text { construindo o futuro com } \\
\text { os ODS }\end{array}$ & $\begin{array}{l}\text { Formando Lideranças } \\
\text { para o } \\
\text { Desenvolvimento } \\
\text { Futuro - } \\
\text { Compartilhando } \\
\text { Experiências }\end{array}$ & 1a edição & $99-120$ & 2019 \\
\hline \multirow[t]{2}{*}{9} & Juliane Neves Fiorezi & A sustentabilidade em & Formando Lideranças & 1ae edição & $123-125$ & 2019 \\
\hline & & $\begin{array}{l}\text { seu aspecto integral: } \\
\text { exemplos de apliação no } \\
\text { âmbito empresarial }\end{array}$ & $\begin{array}{l}\text { para o } \\
\text { Desenvolvimento } \\
\text { Futuro- } \\
\text { Compartilhando } \\
\text { Experiências } \\
\end{array}$ & & & \\
\hline 10 & Milton José Killing & $\begin{array}{l}\text { Programa Origem } \\
\text { Sustentável: exemplo de } \\
\text { transformação de uma } \\
\text { cadeia produtiva }\end{array}$ & $\begin{array}{l}\text { Formando Lideranças } \\
\text { para o } \\
\text { Desenvolvimento } \\
\text { Futuro - } \\
\text { Compartilhando } \\
\text { Experiências }\end{array}$ & 1a edição & $127-133$ & 2019 \\
\hline 11 & Mário Zanatta & $\begin{array}{l}\text { Um exemplo de } \\
\text { sustentabilidade aplicado } \\
\text { ao varejo: práticas } \\
\text { realizadas pelo Grupo } \\
\text { Calcenter }\end{array}$ & $\begin{array}{l}\text { Formando Lideranças } \\
\text { para o } \\
\text { Desenvolvimento } \\
\text { Futuro - } \\
\text { Compartilhando } \\
\text { Experiências }\end{array}$ & 1ạ edição & $135-145$ & 2019 \\
\hline
\end{tabular}


Saber Humano, ISSN 2446-6298, V. 9, n. 15, p. 186-423, jul./dez. 2019.

\begin{tabular}{|c|l|l|l|c|c|}
\hline 12 & Roberto Argenta & $\begin{array}{l}\text { Humanismo empresarial } \\
\text { para o desenvolvimento } \\
\text { sustentável: o case da } \\
\text { Calçados Beira Rio }\end{array}$ & $\begin{array}{l}\text { Formando Lideranças } \\
\text { para o } \\
\text { Desenvolvimento } \\
\text { Futuro - } \\
\text { Compartilhando } \\
\text { Experiências }\end{array}$ & 1 edição & $147-154$ \\
\hline 13 & Leonardo Fraiman & $\begin{array}{l}\text { Projeto de Vida e atitude } \\
\text { empreendedora: } \\
\text { apresentação da } \\
\text { Metodologia OPEE }\end{array}$ & $\begin{array}{l}\text { Formando Lideranças } \\
\text { para o } \\
\text { Desenvolvimento } \\
\text { Futuro - } \\
\text { Compartilhando }\end{array}$ & $157-172$ \\
\hline
\end{tabular}

\begin{tabular}{|c|c|c|c|c|c|c|}
\hline & & & Experiências & & & \\
\hline 14 & Florentino Mayuri & $\begin{array}{l}\text { Reflexões sobre o dilema } \\
\text { na formação de líderes } \\
\text { para o futuro }\end{array}$ & $\begin{array}{l}\text { Formando Lideranças } \\
\text { para o } \\
\text { Desenvolvimento } \\
\text { Futuro - } \\
\text { Compartilhando } \\
\text { Experiências }\end{array}$ & 1a edição & $173-176$ & 2019 \\
\hline 15 & $\begin{array}{l}\text { Eugénia Maria da Silva Tavares } \\
\text { Ana Maria Marques Pinto Moreira }\end{array}$ & $\begin{array}{l}\text { Fazer a Ponte: a } \\
\text { inovadora experiência da } \\
\text { Escola da Ponte }\end{array}$ & $\begin{array}{l}\text { Formando Lideranças } \\
\text { para o } \\
\text { Desenvolvimento } \\
\text { Futuro - } \\
\text { Compartilhando } \\
\text { Experiências }\end{array}$ & 1a edição & $177-182$ & 2019 \\
\hline
\end{tabular}


Saber Humano, ISSN 2446-6298, V. 9, n. 15, p. 186-423, jul./dez. 2019.

\begin{tabular}{|c|c|c|c|c|c|c|}
\hline 16 & Fernanda Goulart Martins & $\begin{array}{l}\text { O jovem-líder em } \\
\text { autoposição criativa: das } \\
\text { exigências do sistema à } \\
\text { realização de si mesmo }\end{array}$ & $\begin{array}{l}\text { Formando Lideranças } \\
\text { para o } \\
\text { Desenvolvimento } \\
\text { Futuro - } \\
\text { Compartilhando } \\
\text { Experiências }\end{array}$ & 1ạ edição & 185-193 & 2019 \\
\hline 17 & Victoria Dmitrieva & $\begin{array}{l}\text { Desenvolvimento do } \\
\text { potencial humanista dos } \\
\text { jovens na época de } \\
\text { transformações digitais }\end{array}$ & $\begin{array}{l}\text { Formando Lideranças } \\
\text { para o } \\
\text { Desenvolvimento } \\
\text { Futuro - } \\
\text { Compartilhando } \\
\text { Experiências }\end{array}$ & 1ạ edição & 195-203 & 2019 \\
\hline 18 & Tommy Akira Goto & $\begin{array}{l}\text { O que pode esperar a } \\
\text { juventude da Psicologia? } \\
\text { Da crise do sentido ao }\end{array}$ & $\begin{array}{l}\text { Formando Lideranças } \\
\text { para o } \\
\text { Desenvolvimento }\end{array}$ & 1a edição & $205-222$ & 2019 \\
\hline
\end{tabular}

\begin{tabular}{|l|l|l|l|l|l|}
\hline & & sentido da crise & $\begin{array}{l}\text { Futuro - } \\
\text { Compartilhando } \\
\text { Experiências }\end{array}$ & \\
\hline 19 & Patrick Milano & $\begin{array}{l}\text { Formando Lideranças } \\
\text { para o } \\
\text { Desenvolvimento } \\
\text { Futuro - importância da para } \\
\text { Compartilhando } \\
\text { Experiências }\end{array}$ & $\begin{array}{l}\text { 1a edição } \\
\text { internacionalidade } \\
\text { um jovem }\end{array}$ & $225-231$ \\
\hline
\end{tabular}


Saber Humano, ISSN 2446-6298, V. 9, n. 15, p. 186-423, jul./dez. 2019.

\begin{tabular}{|c|c|c|c|c|c|c|}
\hline 20 & Nizio Maia Netto & $\begin{array}{l}\text { A cidadania mundial: } \\
\text { como a } \\
\text { internacionalidade } \\
\text { contribui no } \\
\text { desenvolvimento de } \\
\text { jovens com identidade e } \\
\text { consciência de mundo }\end{array}$ & $\begin{array}{l}\text { Formando Lideranças } \\
\text { para o } \\
\text { Desenvolvimento } \\
\text { Futuro - } \\
\text { Compartilhando } \\
\text { Experiências }\end{array}$ & 1a edição & $233-238$ & 2019 \\
\hline 21 & Valentina Neis Caraffa & $\begin{array}{l}\text { A internacionalização dos } \\
\text { jovens em tempos } \\
\text { líquidos }\end{array}$ & $\begin{array}{l}\text { Formando Lideranças } \\
\text { para o } \\
\text { Desenvolvimento } \\
\text { Futuro - } \\
\text { Compartilhando } \\
\text { Experiências }\end{array}$ & 1a edição & $239-244$ & 2019 \\
\hline 22 & Ana Paula Bolzan Monteiro & $\begin{array}{l}\text { O desenvolvimento do } \\
\text { jovem líder por meio de } \\
\text { uma formação } \\
\text { internacional }\end{array}$ & $\begin{array}{l}\text { Formando Lideranças } \\
\text { para o } \\
\text { Desenvolvimento } \\
\text { Futuro - } \\
\text { Compartilhando } \\
\text { Experiências }\end{array}$ & 1a edição & $245-249$ & 2019 \\
\hline 23 & Alécio Vidor & $\begin{array}{l}\text { Pesquisa em } \\
\text { Ontopsicologia }\end{array}$ & $\begin{array}{l}\text { Ontopsicologia Ciência } \\
\text { Interdisciplinar }\end{array}$ & III & $23-32$ & 2017 \\
\hline 24 & Helena Biasotto & $\begin{array}{l}\text { Teorias do conhecimento } \\
\text { e os paradigmas } \\
\text { educacionais: uma revisão } \\
\text { histórica }\end{array}$ & $\begin{array}{l}\text { Ontopsicologia Ciência } \\
\text { Interdisciplinar }\end{array}$ & III & $33-48$ & 2017 \\
\hline
\end{tabular}


Saber Humano, ISSN 2446-6298, V. 9, n. 15, p. 186-423, jul./dez. 2019.

\begin{tabular}{|c|c|c|c|c|c|c|}
\hline 25 & Annalisa Cangelosi & $\begin{array}{l}\text { Ontologia: da Parmenide } \\
\text { a Meneghetti }\end{array}$ & $\begin{array}{l}\text { Ontopsicologia Ciência } \\
\text { Interdisciplinar }\end{array}$ & III & $49-76$ & 2017 \\
\hline 26 & Patrícia Wazlawick & $\begin{array}{l}\text { Heisenberg \& Meneghetti: } \\
\text { Estudos histórico- } \\
\text { epistemológicos para } \\
\text { compreensão das } \\
\text { relações entre } \\
\text { informação, } \\
\text { conhecimento, campo } \\
\text { semântico e } \\
\text { intencionalidade }\end{array}$ & $\begin{array}{l}\text { Ontopsicologia Ciência } \\
\text { Interdisciplinar }\end{array}$ & III & 77-106 & 2017 \\
\hline 27 & Patrícia Wazlawick & $\begin{array}{l}\text { Desdobramentos } \\
\text { histórico-sociais da } \\
\text { conferência da Unesco de } \\
\text { 2007: análise } \\
\text { ontopsicológica acerca da } \\
\text { realidade de formação das } \\
\text { novas gerações }\end{array}$ & $\begin{array}{l}\text { Ontopsicologia Ciência } \\
\text { Interdisciplinar }\end{array}$ & III & $107-136$ & 2017 \\
\hline 28 & Ricardo Schaefer & $\begin{array}{l}\text { Formação dos jovens no } \\
\text { Recanto Maestro: } \\
\text { desenvolvimento integral } \\
\text { para o protagonismo }\end{array}$ & $\begin{array}{l}\text { Ontopsicologia Ciência } \\
\text { Interdisciplinar }\end{array}$ & III & $137-160$ & 2017 \\
\hline
\end{tabular}

responsável 
Saber Humano, ISSN 2446-6298, V. 9, n. 15, p. 186-423, jul./dez. 2019.

\begin{tabular}{|c|c|c|c|c|c|c|}
\hline 29 & $\begin{array}{l}\text { Clarissa Mazon Miranda } \\
\text { Claudio Carrara } \\
\text { Michael Penna }\end{array}$ & $\begin{array}{l}\text { O fazer artístico na } \\
\text { Orquestra Jovem Recanto } \\
\text { Maestro: uma } \\
\text { experiência de } \\
\text { aprendizado estético e } \\
\text { ético }\end{array}$ & $\begin{array}{l}\text { Ontopsicologia Ciência } \\
\text { Interdisciplinar }\end{array}$ & III & $161-170$ & 2017 \\
\hline 30 & Lygia Almeida Marques & $\begin{array}{l}\text { Contribuições da Escola } \\
\text { Ontopsicológica ao } \\
\text { processo de projeto de } \\
\text { Arquitetura de Interiores }\end{array}$ & $\begin{array}{l}\text { Ontopsicologia Ciência } \\
\text { Interdisciplinar }\end{array}$ & III & 171-198 & 2017 \\
\hline 31 & Bernardina Amantino & $\begin{array}{l}\text { A psicologia das roupas e } \\
\text { a OntoArte na moda }\end{array}$ & $\begin{array}{l}\text { Ontopsicologia Ciência } \\
\text { Interdisciplinar }\end{array}$ & III & $199-224$ & 2017 \\
\hline 32 & $\begin{array}{l}\text { Estela Maris Giordani Gabriela } \\
\text { Mombelli }\end{array}$ & $\begin{array}{l}\text { Pedagogia } \\
\text { Ontopsicológica na } \\
\text { prática de orientação de } \\
\text { estágio em pedagogia: } \\
\text { anos iniciais }\end{array}$ & $\begin{array}{l}\text { Ontopsicologia Ciência } \\
\text { Interdisciplinar }\end{array}$ & III & $225-248$ & 2017 \\
\hline 33 & Patrícia Michelotti & $\begin{array}{l}\text { Despertando a formação } \\
\text { inteligente: } \\
\text { transformando o prazer } \\
\text { da leitura em } \\
\text { conhecimento integral a } \\
\text { crianças, adolescentes e } \\
\text { jovens }\end{array}$ & $\begin{array}{l}\text { Ontopsicologia Ciência } \\
\text { Interdisciplinar }\end{array}$ & III & $249-270$ & 2017 \\
\hline 34 & $\begin{array}{l}\text { Estela Maris Giordani } \\
\text { Elisiana Maria Cassol Tanscheit Daiane } \\
\text { Maira Soccal }\end{array}$ & $\begin{array}{l}\text { A leitura inteligente no } \\
\text { ensino médio: aplicação } \\
\text { dos princípios da }\end{array}$ & $\begin{array}{l}\text { Ontopsicologia Ciência } \\
\text { Interdisciplinar }\end{array}$ & III & $271-296$ & 2017 \\
\hline
\end{tabular}


Saber Humano, ISSN 2446-6298, V. 9, n. 15, p. 186-423, jul./dez. 2019.

\begin{tabular}{|c|c|c|c|c|c|c|}
\hline & & $\begin{array}{l}\text { Pedagogia } \\
\text { Ontopsicológica }\end{array}$ & & & & \\
\hline 35 & Eloisa Vieira Ribeiro & $\begin{array}{l}\text { Aplicação da Pedagogia } \\
\text { Ontopsicológica nos } \\
\text { projetos da Fundação } \\
\text { Antonio Meneghetti: } \\
\text { uma análise do conteúdo }\end{array}$ & $\begin{array}{l}\text { Ontopsicologia Ciência } \\
\text { Interdisciplinar }\end{array}$ & III & 297-318 & 2017 \\
\hline 36 & Ana Marli Bulegon & $\begin{array}{l}\text { Contribuições da Psicotea } \\
\text { para o desenvolvimento } \\
\text { de aspectos psicológicos } \\
\text { nos estudantes de } \\
\text { matemática financeira }\end{array}$ & $\begin{array}{l}\text { Ontopsicologia Ciência } \\
\text { Interdisciplinar }\end{array}$ & III & 319-342 & 2017 \\
\hline 37 & Carmen Ivanete D'Agostini Spanhol & $\begin{array}{l}\text { Narrativa autobiográfica: } \\
\text { a escolha otimal, mediada } \\
\text { pela percepção } \\
\text { organísmica }\end{array}$ & $\begin{array}{l}\text { Ontopsicologia Ciência } \\
\text { Interdisciplinar }\end{array}$ & III & $343-356$ & 2017 \\
\hline 38 & $\begin{array}{l}\text { Taline Souza Mendes Ricardo } \\
\text { Schaefer }\end{array}$ & $\begin{array}{l}\text { Identidade da empresa: } \\
\text { estudos de casos } \\
\text { múltiplos sobre práticas } \\
\text { de integração de } \\
\text { colaboradores em rede de } \\
\text { empresas do setor } \\
\text { gastronômico do Rio } \\
\text { Grande do Sul }\end{array}$ & $\begin{array}{l}\text { Ontopsicologia Ciência } \\
\text { Interdisciplinar }\end{array}$ & III & $357-374$ & 2017 \\
\hline
\end{tabular}


Saber Humano, ISSN 2446-6298, V. 9, n. 15, p. 186-423, jul./dez. 2019.

\begin{tabular}{|c|l|l|l|c|c|}
\hline 39 & $\begin{array}{l}\text { Érico de Lima Azevedo } \\
\text { Horácio Chikota } \\
\text { Marlise Aparecida Bassani } \\
\text { Maria Luiza Bazzo }\end{array}$ & $\begin{array}{l}\text { Psicologia e Saúde: a } \\
\text { experiência prática da } \\
\text { Escola Ontopsicológica }\end{array}$ & $\begin{array}{l}\text { Ontopsicologia Ciência } \\
\text { Interdisciplinar }\end{array}$ & III & $375-395$ \\
\hline Roberta Pozza & & & 2017 \\
\hline
\end{tabular}

\begin{tabular}{|c|c|c|c|c|c|c|}
\hline № & Autor & Título do Capítulo & Título do Livro & Volume & Páginas & Ano \\
\hline 1 & $\begin{array}{l}\text { Alécio Vidor } \\
\text { Cleoci Rockenbach }\end{array}$ & Psicologia e Ontopsicologia & $\begin{array}{l}\text { Ontopsicologia Ciência } \\
\text { Interdisciplinar }\end{array}$ & II & $23-48$ & $201 \epsilon$ \\
\hline 2 & Ricardo Schaefer & $\begin{array}{l}\text { A Filosofia Perene como } \\
\text { conhecimento propedêutico } \\
\text { à compreensão e aplicação } \\
\text { da Ciência Ontopsicológica }\end{array}$ & $\begin{array}{l}\text { Ontopsicologia Ciência } \\
\text { Interdisciplinar }\end{array}$ & II & $49-68$ & 2016 \\
\hline 3 & Patrícia Wazlawick & $\begin{array}{l}\text { O problema crítico do } \\
\text { conhecimento: “o homem é } \\
\text { capaz de conhecer o real?” } \\
\text { Interlocuções filosóficas } \\
\text { entre Sócrates, Kant, } \\
\text { Heisenberg, Husserl - A } \\
\text { Crise }\end{array}$ & $\begin{array}{l}\text { Ontopsicologia Ciência } \\
\text { Interdisciplinar }\end{array}$ & II & $69-108$ & $201 \epsilon$ \\
\hline
\end{tabular}


Saber Humano, ISSN 2446-6298, V. 9, n. 15, p. 186-423, jul./dez. 2019.

\begin{tabular}{|c|c|c|c|c|c|c|}
\hline 4 & Patrícia Wazlawick & $\begin{array}{l}\text { Antonio Meneghetti e a } \\
\text { Ontopsicologia como solução } \\
\text { ao problema crítico do } \\
\text { conhecimento e a } \\
\text { refundação crítica da ciência } \\
\text { - A Resposta }\end{array}$ & $\begin{array}{l}\text { Ontopsicologia Ciência } \\
\text { Interdisciplinar }\end{array}$ & II & $109-130$ & 2016 \\
\hline 5 & $\begin{array}{l}\text { Agatha Depiné Érico } \\
\text { Azevedo }\end{array}$ & $\begin{array}{l}\text { Consultoria Ontopsicológica } \\
\text { empresarial e o Em Si ôntico } \\
\text { do empreendedor como } \\
\text { critério }\end{array}$ & $\begin{array}{l}\text { Ontopsicologia Ciência } \\
\text { Interdisciplinar }\end{array}$ & II & 131-154 & 2016 \\
\hline 6 & $\begin{array}{l}\text { Estela Maris Giordani } \\
\text { Daniele Barros Vargas Furtado }\end{array}$ & $\begin{array}{l}\text { Leitura inteligente e o } \\
\text { processo de apropriação do } \\
\text { conhecimento a partir da } \\
\text { Pedagogia Ontopsicológica }\end{array}$ & $\begin{array}{l}\text { Ontopsicologia Ciência } \\
\text { Interdisciplinar }\end{array}$ & II & $155-178$ & 2016 \\
\hline 7 & $\begin{array}{l}\text { Liliane de Araújo Mancebo } \\
\text { Denise Castilhos de Araújo }\end{array}$ & $\begin{array}{l}\text { Arte, expressividade e } \\
\text { criatividade: a OntoArte de } \\
\text { Antonio Meneghetti }\end{array}$ & $\begin{array}{l}\text { Ontopsicologia Ciência } \\
\text { Interdisciplinar }\end{array}$ & II & $179-202$ & 2016 \\
\hline 8 & José Luiz Richetti & $\begin{array}{l}\text { O significado do trabalho e } \\
\text { dignidade da pessoa humana } \\
\text { como fundamentos do } \\
\text { Estado democrático de } \\
\text { direito brasileiro }\end{array}$ & $\begin{array}{l}\text { Ontopsicologia Ciência } \\
\text { Interdisciplinar }\end{array}$ & II & $203-232$ & 2016 \\
\hline
\end{tabular}


Saber Humano, ISSN 2446-6298, V. 9, n. 15, p. 186-423, jul./dez. 2019.

\begin{tabular}{|c|c|c|c|c|c|c|}
\hline 9 & $\begin{array}{l}\text { Márcio Sudati Rodrigues } \\
\text { Josiane Barbieri }\end{array}$ & $\begin{array}{l}\text { Importância do processo } \\
\text { sucessório em empresas } \\
\text { familiares do Agronegócio: } \\
\text { contribuições da } \\
\text { Ontopsicologia }\end{array}$ & $\begin{array}{l}\text { Ontopsicologia Ciência } \\
\text { Interdisciplinar }\end{array}$ & II & $233-256$ & 2016 \\
\hline 10 & $\begin{array}{l}\text { Maria Tereza Andreola } \\
\text { Adriane Maria Moro Mendes }\end{array}$ & $\begin{array}{l}\text { Pesquisa empírica sobre a } \\
\text { relação entre estrutura } \\
\text { caracterial da personalidade } \\
\text { e a AIDS }\end{array}$ & $\begin{array}{l}\text { Ontopsicologia Ciência } \\
\text { Interdisciplinar }\end{array}$ & II & $257-282$ & 2016 \\
\hline 11 & $\begin{array}{l}\text { Juliane Neves Fiorezi } \\
\text { Horácio Shigueru Chikota }\end{array}$ & $\begin{array}{l}\text { Aferição dos efeitos em nível } \\
\text { físico-biológico mediante } \\
\text { aplicação da Melolística com } \\
\text { jovens de } 18 \text { a } 25 \text { anos }\end{array}$ & $\begin{array}{l}\text { Ontopsicologia Ciência } \\
\text { Interdisciplinar }\end{array}$ & II & 283-306 & 2016 \\
\hline 12 & $\begin{array}{l}\text { Carmen Ivanete D'Agostini } \\
\text { Spanhol }\end{array}$ & $\begin{array}{l}\text { Avaliação da mudança de } \\
\text { estilo de vida dos jovens }\end{array}$ & $\begin{array}{l}\text { Ontopsicologia Ciência } \\
\text { Interdisciplinar }\end{array}$ & II & $307-342$ & 2016 \\
\hline 13 & Claudiane Weber & $\begin{array}{l}\text { As particularidades da vida } \\
\text { do campo: jovens e ambiente }\end{array}$ & $\begin{array}{l}\text { Ontopsicologia Ciência } \\
\text { Interdisciplinar }\end{array}$ & II & $343-368$ & 2016 \\
\hline 14 & Eloy Demarchi Teixeira & $\begin{array}{l}\text { Contexto de ensino } \\
\text { fundamentado na Pedagogia } \\
\text { Ontopsicológica: um estudo } \\
\text { com ingressantes } \\
\text { universitários da Antonio } \\
\text { Meneghetti Faculdade }\end{array}$ & $\begin{array}{l}\text { Ontopsicologia Ciência } \\
\text { Interdisciplinar }\end{array}$ & II & $369-392$ & 2016 \\
\hline
\end{tabular}


Saber Humano, ISSN 2446-6298, V. 9, n. 15, p. 186-423, jul./dez. 2019.

\begin{tabular}{|c|l|l|l|c|c|}
\hline 15 & $\begin{array}{l}\text { Edson Ceratti } \\
\text { Vera Lúcia Rodegheri }\end{array}$ & $\begin{array}{l}\text { Formação do líder e a } \\
\text { Consultoria Ontopsicológica: } \\
\text { um estudo de natureza } \\
\text { autobiográfica }\end{array}$ & $\begin{array}{l}\text { Ontopsicologia Ciência } \\
\text { Interdisciplinar }\end{array}$ & II & $393-420$ \\
\hline 16 & $\begin{array}{l}\text { Carmen Ivanete D'Agostini } \\
\text { Spanhol } \\
\text { Noemi Boer }\end{array}$ & $\begin{array}{l}\text { A docência no entendimento } \\
\text { de professores universitários } \\
\text { com formação no Método } \\
\text { Ontopsicológico }\end{array}$ & $\begin{array}{l}\text { Ontopsicologia Ciência } \\
\text { Interdisciplinar }\end{array}$ & II & $421-442$ \\
\hline
\end{tabular}

\begin{tabular}{|c|c|c|c|c|c|c|}
\hline № & Autor & Título do Capítulo & Título do Livro & Volume & Páginas & Ano \\
\hline 1 & Alécio Vidor & A Filosofia Pura é Ontologia & $\begin{array}{l}\text { Ontopsicologia Ciência } \\
\text { Interdisciplinar }\end{array}$ & 1 & $15-24$ & 2015 \\
\hline 2 & $\begin{array}{l}\text { Horácio Chikota Roberta } \\
\text { Pozza }\end{array}$ & $\begin{array}{l}\text { Da intuição à } \\
\text { autossabotagem: a pesquisa } \\
\text { ontopsicológica nos } \\
\text { correlatos neurofisiológicos } \\
\text { do processo } \\
\text { perceptivocognitivo do } \\
\text { empreendedor }\end{array}$ & $\begin{array}{l}\text { Ontopsicologia Ciência } \\
\text { Interdisciplinar }\end{array}$ & 1 & $25-58$ & 2015 \\
\hline
\end{tabular}

\begin{tabular}{|c|l|l|l|l|l|}
\hline 3 & Ana Maris Petry & $\begin{array}{l}\text { A Consultoria } \\
\text { Ontopsicológica Empresarial: } \\
\text { uma abordagem humanista } \\
\text { às organizações }\end{array}$ & $\begin{array}{l}\text { Ontopsicologia Ciência } \\
\text { Interdisciplinar }\end{array}$ & 1 & $59-102$ \\
\hline
\end{tabular}


Saber Humano, ISSN 2446-6298, V. 9, n. 15, p. 186-423, jul./dez. 2019.

\begin{tabular}{|c|c|c|c|c|c|c|}
\hline 4 & Patrícia Wazlawick & $\begin{array}{l}\text { Quando se toma o todo pela } \\
\text { parte: porque Ontopsicologia } \\
\text { não é } \\
\text { Psicologia }\end{array}$ & $\begin{array}{l}\text { Ontopsicologia Ciência } \\
\text { Interdisciplinar }\end{array}$ & 1 & $103-134$ & 2015 \\
\hline 5 & $\begin{array}{l}\text { Érico de Lima Azevedo } \\
\text { Adriane Maria Moro Mendes }\end{array}$ & $\begin{array}{l}\text { A investigação empírica do } \\
\text { nexo ontológico no } \\
\text { comportamento decisório } \\
\text { humano como índice da } \\
\text { necessidade de revisão do } \\
\text { modelo da racionalidade } \\
\text { limitada }\end{array}$ & $\begin{array}{l}\text { Ontopsicologia Ciência } \\
\text { Interdisciplinar }\end{array}$ & 1 & $135-180$ & 2015 \\
\hline 6 & Adriane Maria Moro Mendes & $\begin{array}{l}\text { Gestão do Conhecimento e } \\
\text { Ontopsicologia }\end{array}$ & $\begin{array}{l}\text { Ontopsicologia Ciência } \\
\text { Interdisciplinar }\end{array}$ & 1 & $181-196$ & 2015 \\
\hline 7 & $\begin{array}{l}\text { Clarissa Mazon Miranda } \\
\text { Ricardo Schaefer } \\
\text { Vicente Reis Medeiros }\end{array}$ & $\begin{array}{l}\text { O jornalismo como mediador } \\
\text { de consciência e operador de } \\
\text { realidade }\end{array}$ & $\begin{array}{l}\text { Ontopsicologia Ciência } \\
\text { Interdisciplinar }\end{array}$ & 1 & $197-216$ & 2015 \\
\hline 8 & Estela Maris Giordani & $\begin{array}{l}\text { Pedagogia Ontopsicológica: } \\
\text { a formação integral da pessoa } \\
\text { protagonista responsável }\end{array}$ & $\begin{array}{l}\text { Ontopsicologia Ciência } \\
\text { Interdisciplinar }\end{array}$ & 1 & $217-254$ & 2015 \\
\hline 9 & $\begin{array}{l}\text { Patrícia Wazlawick } \\
\text { Viviane Elias Portela } \\
\text { Glauber Benetti Carvalho }\end{array}$ & $\begin{array}{l}\text { Responsabilidade social em } \\
\text { ritmo de música: Projeto } \\
\text { Flauta e Pedagogia } \\
\text { Ontopsicológica }\end{array}$ & $\begin{array}{l}\text { Ontopsicologia Ciência } \\
\text { Interdisciplinar }\end{array}$ & 1 & $255-281$ & 2015 \\
\hline
\end{tabular}




\section{ARTIGOS CIENTÍFICOS COM FUNDAMENTAÇÃO NA CIÊNCIA ONTOPSICOLÓGICA PUBLICADOS NO BRASIL (PESQUISA TEÓRICA E PESQUISA EXPERIMENTAL)}

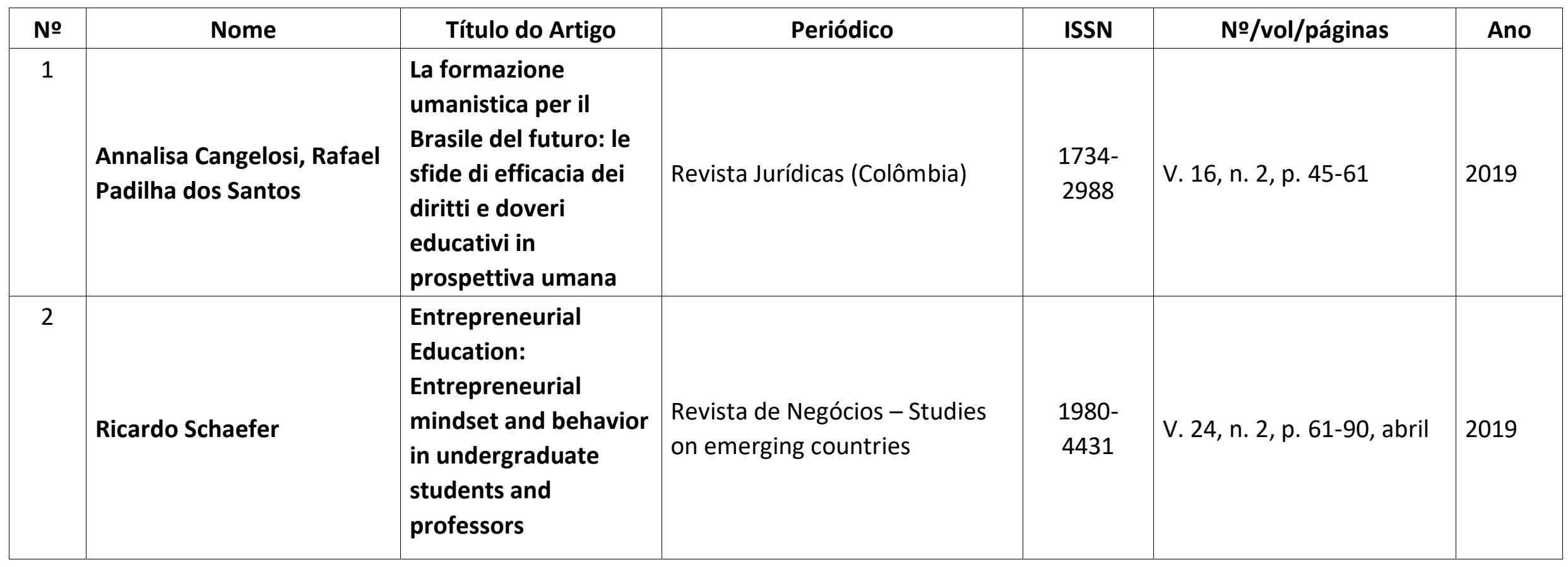


Saber Humano, ISSN 2446-6298, V. 9, n. 15, p. 186-423, jul./dez. 2019.

\begin{tabular}{|c|c|c|c|c|c|c|}
\hline 3 & Patrícia Wazlawick & $\begin{array}{l}\text { Apresentação - } \\
\text { Cadernos Especiais de } \\
\text { Pequena Tese do } \\
\text { Bacharelado em } \\
\text { Ontopsicologia }\end{array}$ & $\begin{array}{l}\text { Saber Humano: Revista } \\
\text { Científica da Faculdade } \\
\text { Antonio Meneghetti }\end{array}$ & 24466298 & N.3. p. 6-8 & 2019 \\
\hline 4 & Bruno Fleck da Silva & $\begin{array}{l}\text { Editorial - Cadernos } \\
\text { Especiais de Pequena } \\
\text { Tese do Bacharelado } \\
\text { em Ontopsicologia }\end{array}$ & $\begin{array}{l}\text { Saber Humano: Revista } \\
\text { Científica da Faculdade } \\
\text { Antonio Meneghetti }\end{array}$ & 24466298 & N.3. p. 4-5 & 2019 \\
\hline 5 & Ademar Silva Junior & $\begin{array}{l}\text { Como recuperar a } \\
\text { exatidão de natureza? }\end{array}$ & $\begin{array}{l}\text { Cadernos de Ontopsicologia: } \\
\text { Iniciação Científica do } \\
\text { Bacharelado em } \\
\text { Ontopsicologia. Saber } \\
\text { Humano: Revista Científica da } \\
\text { Faculdade Antonio Meneghetti } \\
\text { Resultado de Projeto de } \\
\text { Pesquisa em Iniciação } \\
\text { Científica/Projeto Pequena Tese } \\
\text { do Curso de Bacharelado em } \\
\text { Ontopsicologia-AMF }\end{array}$ & 24466298 & V.8 n.13/p. 8-17 & 2019 \\
\hline
\end{tabular}


Saber Humano, ISSN 2446-6298, V. 9, n. 15, p. 186-423, jul./dez. 2019.

\begin{tabular}{|c|c|c|c|c|c|c|}
\hline 6 & Alessandra Heinz & $\begin{array}{l}\text { Intencionalidade e } \\
\text { Miricismo Cotidiano }\end{array}$ & $\begin{array}{l}\text { Cadernos de Ontopsicologia: } \\
\text { Iniciação Científica do } \\
\text { Bacharelado em } \\
\text { Ontopsicologia. Saber } \\
\text { Humano: Revista Científica da } \\
\text { Faculdade Antonio Meneghetti } \\
\text { Resultado de Projeto de } \\
\text { Pesquisa em Iniciação } \\
\text { Científica/Projeto Pequena Tese } \\
\text { do Curso de Bacharelado em } \\
\text { Ontopsicologia-AMF }\end{array}$ & 24466298 & V.8 n.13/p. 18-24 & 2019 \\
\hline 7 & Amauri Paulo Cervo & $\begin{array}{l}\text { Considerações sobre a } \\
\text { aplicação da }\end{array}$ & $\begin{array}{l}\text { Cadernos de Ontopsicologia: } \\
\text { Iniciação Científica do }\end{array}$ & 24466298 & V.8 n.13/p. 25-34 & 2019 \\
\hline
\end{tabular}


Saber Humano, ISSN 2446-6298, V. 9, n. 15, p. 186-423, jul./dez. 2019.

\begin{tabular}{|c|c|c|c|c|c|c|}
\hline 8 & Carla Sewald Vieira & $\begin{array}{l}\text { Homem: eterno } \\
\text { aprendiz }\end{array}$ & $\begin{array}{l}\text { Cadernos de Ontopsicologia: } \\
\text { Iniciação Científica do } \\
\text { Bacharelado em } \\
\text { Ontopsicologia. Saber } \\
\text { Humano: Revista Científica da } \\
\text { Faculdade Antonio Meneghetti } \\
\text { Resultado de Projeto de } \\
\text { Pesquisa em Iniciação } \\
\text { Científica/Projeto Pequena Tese } \\
\text { do Curso de Bacharelado em } \\
\text { Ontopsicologia-AMF }\end{array}$ & 24466298 & V.8 n.13/p. 35-46 & 2019 \\
\hline 9 & $\begin{array}{l}\text { Carmen Ivanete } \\
\text { D'Agostini Spanhol }\end{array}$ & $\begin{array}{l}\text { Narrativa } \\
\text { Autobiográfica: a } \\
\text { escolha otimal } \\
\text { mediada pela } \\
\text { percepção } \\
\text { organísmica }\end{array}$ & $\begin{array}{l}\text { Cadernos de Ontopsicologia: } \\
\text { Iniciação Científica do } \\
\text { Bacharelado em } \\
\text { Ontopsicologia. Saber } \\
\text { Humano: Revista Científica da } \\
\text { Faculdade Antonio Meneghetti } \\
\text { Resultado de Projeto de } \\
\text { Pesquisa em Iniciação }\end{array}$ & 24466298 & V.8 n.13/p. 47-58 & 2019 \\
\hline & & & $\begin{array}{l}\text { Científica/Projeto Pequena Tese } \\
\text { do Curso de Bacharelado em } \\
\text { Ontopsicologia-AMF }\end{array}$ & & & \\
\hline
\end{tabular}


Saber Humano, ISSN 2446-6298, V. 9, n. 15, p. 186-423, jul./dez. 2019.

\begin{tabular}{|c|c|c|c|c|c|c|}
\hline 10 & Claudia Vicentini & $\begin{array}{l}\text { A trajetória da mulher } \\
\text { empresária e o campo } \\
\text { semântico }\end{array}$ & $\begin{array}{l}\text { Cadernos de Ontopsicologia: } \\
\text { Iniciação Científica do } \\
\text { Bacharelado em } \\
\text { Ontopsicologia. Saber } \\
\text { Humano: Revista Científica da } \\
\text { Faculdade Antonio Meneghetti } \\
\text { Resultado de Projeto de } \\
\text { Pesquisa em Iniciação } \\
\text { Científica/Projeto Pequena Tese } \\
\text { do Curso de Bacharelado em } \\
\text { Ontopsicologia-AMF }\end{array}$ & 24466298 & V.8 n.13/p. 59-69 & 2019 \\
\hline 11 & Délis Stona & $\begin{array}{l}\text { A exatidão de } \\
\text { consciência do } \\
\text { pesquisador científico } \\
\text { com base nas } \\
\text { premissas da } \\
\text { Escola } \\
\text { Ontopsicológica }\end{array}$ & $\begin{array}{l}\text { Cadernos de Ontopsicologia: } \\
\text { Iniciação Científica do } \\
\text { Bacharelado em } \\
\text { Ontopsicologia. Saber } \\
\text { Humano: Revista Científica da } \\
\text { Faculdade Antonio Meneghetti } \\
\text { Resultado de Projeto de } \\
\text { Pesquisa em Iniciação } \\
\text { Científica/Projeto Pequena Tese } \\
\text { do Curso de Bacharelado em } \\
\text { Ontopsicologia-AMF }\end{array}$ & 24466298 & V.8 n.13/p. 70-79 & 2019 \\
\hline 121 & Eunice Escosteguy & Filosofia e Informação & $\begin{array}{l}\text { Cadernos de Ontopsicologia: } \\
\text { Iniciação Científica do } \\
\text { Bacharelado em }\end{array}$ & 24466298 & V.8 n.13/p. 80-88 & 2019 \\
\hline
\end{tabular}


Saber Humano, ISSN 2446-6298, V. 9, n. 15, p. 186-423, jul./dez. 2019.

\begin{tabular}{|c|c|c|c|c|c|c|}
\hline & & & $\begin{array}{l}\text { Ontopsicologia. Saber } \\
\text { Humano: Revista Científica da } \\
\text { Faculdade Antonio Meneghetti } \\
\text { Resultado de Projeto de } \\
\text { Pesquisa em Iniciação } \\
\text { Científica/Projeto Pequena Tese } \\
\text { do Curso de Bacharelado em } \\
\text { Ontopsicologia-AMF }\end{array}$ & & & \\
\hline
\end{tabular}


Saber Humano, ISSN 2446-6298, V. 9, n. 15, p. 186-423, jul./dez. 2019.

\begin{tabular}{|l|l|l|l|l|l|}
\hline 14 & & $\begin{array}{l}\text { Cadernos de Ontopsicologia: } \\
\text { Iniciação Científica do } \\
\text { Bacharelado em } \\
\text { Ontopsicologia. Saber } \\
\text { Humano: Revista Científica da } \\
\text { Faculdade Antonio Meneghetti } \\
\text { Hesica e Além: } \\
\text { transcendendo a } \\
\text { indeterminação } \\
\text { Werner Heisenberg } \\
\text { Resultado de Projeto de } \\
\text { Pesquisa em Iniciação } \\
\text { Científica/Projeto Pequena }\end{array}$ & 24466298 \\
\hline
\end{tabular}

\begin{tabular}{|l|l|l|l|l|l|}
\hline 15 & & $\begin{array}{l}\text { Tese do Curso de Bacharelado } \\
\text { em Ontopsicologia-AMF }\end{array}$ & \\
\hline Maria Aparecida Ragalzi & $\begin{array}{l}\text { Cadernos de Ontopsicologia: } \\
\text { Iniciação Científica do } \\
\text { Bacharelado em } \\
\text { Ontopsicologia. Saber } \\
\text { Humano: Revista Científica da } \\
\text { Campo Semântico: } \\
\text { como reconquistar a } \\
\text { linguagem primária da } \\
\text { natureza humana }\end{array}$ & $\begin{array}{l}\text { Faculdade Antonio Meneghetti } \\
\text { Resultado de Projeto de } \\
\text { Pesquisa em Iniciação } \\
\text { Científica/Projeto Pequena Tese } \\
\text { do Curso de Bacharelado em } \\
\text { Ontopsicologia-AMF }\end{array}$ & 24466298 \\
\hline
\end{tabular}


Saber Humano, ISSN 2446-6298, V. 9, n. 15, p. 186-423, jul./dez. 2019.

\begin{tabular}{|c|c|c|c|c|c|c|}
\hline 16 & Mariana Brito Araújo & $\begin{array}{l}\text { Da relação entre } \\
\text { Direito Ambiental, } \\
\text { meio ambiente e ser } \\
\text { humano: anotações } \\
\text { prospectivas para } \\
\text { uma análise }\end{array}$ & $\begin{array}{l}\text { Cadernos de Ontopsicologia: } \\
\text { Iniciação Científica do } \\
\text { Bacharelado em } \\
\text { Ontopsicologia. Saber } \\
\text { Humano: Revista Científica da } \\
\text { Faculdade Antonio Meneghetti } \\
\text { Resultado de Projeto de } \\
\text { Pesquisa em Iniciação } \\
\text { Científica/Projeto Pequena Tese } \\
\text { do Curso de Bacharelado em } \\
\text { Ontopsicologia-AMF }\end{array}$ & 24466298 & V.8 n.13/p. 121-142 & 2019 \\
\hline 17 & Michael Fragomeni Penna & $\begin{array}{l}\text { Storytelling: Curso em } \\
\text { uma história. Que } \\
\text { histórias posso contar } \\
\text { para ensinar }\end{array}$ & $\begin{array}{l}\text { Cadernos de Ontopsicologia: } \\
\text { Iniciação Científica do } \\
\text { Bacharelado em } \\
\text { Ontopsicologia. Saber }\end{array}$ & 24466298 & V.8 n.13/p. 143-155 & 2019 \\
\hline
\end{tabular}


Saber Humano, ISSN 2446-6298, V. 9, n. 15, p. 186-423, jul./dez. 2019.

\begin{tabular}{|c|c|c|c|c|c|c|}
\hline 18 & José Alfredo Nedel Filho & A gênese do dinheiro & $\begin{array}{l}\text { Cadernos de Ontopsicologia: } \\
\text { Iniciação Científica do } \\
\text { Bacharelado em } \\
\text { Ontopsicologia. Saber } \\
\text { Humano: Revista Científica da } \\
\text { Faculdade Antonio Meneghetti } \\
\text { Resultado de Projeto de } \\
\text { Pesquisa em Iniciação } \\
\text { Científica/Projeto Pequena Tese } \\
\text { do Curso de Bacharelado em } \\
\text { Ontopsicologia-AMF }\end{array}$ & 24466298 & V.8 n.13/p. 156-173 & 2019 \\
\hline 19 & $\begin{array}{l}\text { Patrícia Gabriela Bilha } \\
\text { Salles }\end{array}$ & $\begin{array}{l}\text { Pedagogia } \\
\text { Ontopsicológica: um } \\
\text { novo modo de fazer } \\
\text { Pedagogia }\end{array}$ & $\begin{array}{l}\text { Cadernos de Ontopsicologia: } \\
\text { Iniciação Científica do } \\
\text { Bacharelado em } \\
\text { Ontopsicologia. Saber } \\
\text { Humano: Revista Científica da } \\
\text { Faculdade Antonio Meneghetti } \\
\text { Resultado de Projeto de } \\
\text { Pesquisa em Iniciação } \\
\text { Científica/Projeto Pequena } \\
\text { Tese do Curso de Bacharelado }\end{array}$ & 24466298 & V.8 n.13/p. $174-180$ & 2019 \\
\hline
\end{tabular}

em Ontopsicologia-AMF 
Saber Humano, ISSN 2446-6298, V. 9, n. 15, p. 186-423, jul./dez. 2019.

\begin{tabular}{|c|c|c|c|c|c|c|}
\hline 20 & Rosane Maria Neves & $\begin{array}{l}\text { Estilo de Vida e } \\
\text { exatidão de } \\
\text { consciência: solução } \\
\text { exitosa na realização } \\
\text { pessoal do operador } \\
\text { social }\end{array}$ & $\begin{array}{l}\text { Cadernos de Ontopsicologia: } \\
\text { Iniciação Científica do } \\
\text { Bacharelado em } \\
\text { Ontopsicologia. Saber } \\
\text { Humano: Revista Científica da } \\
\text { Faculdade Antonio Meneghetti } \\
\text { Resultado de Projeto de } \\
\text { Pesquisa em Iniciação } \\
\text { Científica/Projeto Pequena Tese } \\
\text { do Curso de Bacharelado em } \\
\text { Ontopsicologia-AMF }\end{array}$ & 24466298 & V.8 n.13/p. 181-194 & 2019 \\
\hline 21 & Rosangela Alves Nabarros & $\begin{array}{l}\text { O reencontro com o } \\
\text { próprio projeto de } \\
\text { natureza: construindo } \\
\text { a própria existência }\end{array}$ & $\begin{array}{l}\text { Cadernos de Ontopsicologia: } \\
\text { Iniciação Científica do } \\
\text { Bacharelado em } \\
\text { Ontopsicologia. Saber } \\
\text { Humano: Revista Científica da } \\
\text { Faculdade Antonio Meneghetti } \\
\text { Resultado de Projeto de } \\
\text { Pesquisa em Iniciação } \\
\text { Científica/Projeto Pequena Tese } \\
\text { do Curso de Bacharelado em } \\
\text { Ontopsicologia-AMF }\end{array}$ & 24466298 & V.8 n.13/p. 195-203 & 2019 \\
\hline 22 & $\begin{array}{l}\text { Tereza Cristina Melo de } \\
\text { Brito Carvalho }\end{array}$ & $\begin{array}{l}\text { Explicação sobre a } \\
\text { Técnica "Teste do } \\
\text { Anel Bi-Digital } \\
\text { (BDORT)" segundo a } \\
\text { 2ótica da Ciência }\end{array}$ & $\begin{array}{l}\text { Cadernos de Ontopsicologia: } \\
\text { Iniciação Científica do } \\
\text { Bacharelado em } \\
\text { Ontopsicologia. Saber } \\
\text { Humano: Revista Científica da }\end{array}$ & 24466298 & V.8 n.13/p. 204-220 & 2019 \\
\hline
\end{tabular}


Saber Humano, ISSN 2446-6298, V. 9, n. 15, p. 186-423, jul./dez. 2019.

\begin{tabular}{|c|c|c|c|c|c|c|}
\hline & & Ontopsicológica & $\begin{array}{l}\text { Faculdade Antonio Meneghetti } \\
\text { Resultado de Projeto de } \\
\text { Pesquisa em Iniciação } \\
\text { Científica/Projeto Pequena Tese } \\
\text { do Curso de Bacharelado em } \\
\text { Ontopsicologia-AMF }\end{array}$ & & & \\
\hline 23 & Vanessa Alves Nabarros & $\begin{array}{l}\text { A resposta da } \\
\text { Ontopsicologia ao } \\
\text { problema crítico do } \\
\text { conhecimento: a } \\
\text { questão exatidão do } \\
\text { pesquisador }\end{array}$ & $\begin{array}{l}\text { Cadernos de Ontopsicologia: } \\
\text { Iniciação Científica do } \\
\text { Bacharelado em } \\
\text { Ontopsicologia. Saber } \\
\text { Humano: Revista Científica da } \\
\text { Faculdade Antonio Meneghetti } \\
\text { Resultado de Projeto de } \\
\text { Pesquisa em Iniciação } \\
\text { Científica/Projeto Pequena Tese } \\
\text { do Curso de Bacharelado em } \\
\text { Ontopsicologia-AMF }\end{array}$ & 24466298 & V.8 n.13/p. 221-233 & 2019 \\
\hline
\end{tabular}


Saber Humano, ISSN 2446-6298, V. 9, n. 15, p. 186-423, jul./dez. 2019.

\begin{tabular}{|l|l|l|l|l|l|}
\hline 24 & & $\begin{array}{l}\text { Cadernos de Ontopsicologia: } \\
\text { Iniciação Científica do } \\
\text { Bacharelado em } \\
\text { Ontopsicologia. Saber } \\
\text { Humano: Revista Científica da } \\
\text { O organismo como } \\
\text { base epistemológica: } \\
\text { o problema crítico do } \\
\text { conhecimento e a } \\
\text { Ontopsicologia }\end{array}$ & $\begin{array}{l}\text { Faculdade Antonio Meneghetti } \\
\text { Resultado de Projeto de } \\
\text { Pesquisa em Iniciação } \\
\text { Científica/Projeto Pequena Tese } \\
\text { do Curso de Bacharelado em } \\
\text { Ontopsicologia-AMF }\end{array}$ & 24466298 \\
\hline
\end{tabular}

\begin{tabular}{|l|l|l|l|l|l|}
\hline 25 & $\begin{array}{l}\text { Apresentação Quando } \\
\text { os jovens estudam, } \\
\text { leem, pesquisam e } \\
\text { produzem } \\
\text { conhecimento com a } \\
\text { Ontopsicologia: } \\
\text { projeto de Iniciação } \\
\text { Científica do } \\
\text { Bacharelado em } \\
\text { Ontopsicologia }\end{array}$ & $\begin{array}{l}\text { Saber Humano: Revista } \\
\text { Científica da Faculdade } \\
\text { Antonio Meneghetti }\end{array}$ & 24466298 & N.2p.4-8 \\
\hline
\end{tabular}


Saber Humano, ISSN 2446-6298, V. 9, n. 15, p. 186-423, jul./dez. 2019.

\begin{tabular}{|c|c|c|c|c|c|c|}
\hline 26 & $\begin{array}{l}\text { Fernando Ítalo Minello } \\
\text { Juliana Mayumi Nishi } \\
\text { Leodir Mauri Löber } \\
\text { Márica Grohmann } \\
\text { Zampieri } \\
\text { Ricardo Schaefer }\end{array}$ & $\begin{array}{l}\text { Valores pessoais, } \\
\text { atitudes e intenção } \\
\text { empreendedora: um } \\
\text { estudo com } \\
\text { estudantes de } \\
\text { graduação em } \\
\text { administração }\end{array}$ & $\begin{array}{l}\text { E\&G - Revista Economia e } \\
\text { Gestão }\end{array}$ & 19846606 & V.17, p.23 & 2018 \\
\hline 27 & Bruno Fleck da Silva & $\begin{array}{l}\text { Editorial - Cadernos } \\
\text { Especiais de Pequena } \\
\text { Tese do Bacharelado } \\
\text { em Ontopsicologia }\end{array}$ & $\begin{array}{l}\text { Saber Humano: Revista } \\
\text { Científica da Faculdade } \\
\text { Antonio Meneghetti }\end{array}$ & 24466298 & N.3. p. 9 & 2018 \\
\hline 28 & $\begin{array}{l}\text { Karine Cristina Scherer } \\
\text { Patrícia Wazlawick }\end{array}$ & $\begin{array}{l}\text { Aprendizagem técnica } \\
\text { e o }\end{array}$ & $\begin{array}{l}\text { Saber Humano: Revista } \\
\text { Científica da Faculdade }\end{array}$ & 24466298 & V.8 n.12/p.7-30 & 2018 \\
\hline & & $\begin{array}{l}\text { desenvolvimento da } \\
\text { forma mentis dos } \\
\text { alunos de } \\
\text { Administração para } \\
\text { uma formação } \\
\text { profissional } \\
\text { fundamentada em } \\
\text { valores humanistas: } \\
\text { um estudo }\end{array}$ & Antonio Meneghetti & & & \\
\hline
\end{tabular}


Saber Humano, ISSN 2446-6298, V. 9, n. 15, p. 186-423, jul./dez. 2019.

\begin{tabular}{|c|c|c|c|c|c|c|}
\hline & & introdutório & & & & \\
\hline 29 & $\begin{array}{l}\text { Dinara Simone Pozzatti } \\
\text { Patrícia Wazlawick }\end{array}$ & $\begin{array}{l}\text { Processo da estratégia } \\
\text { empresarial e o líder } \\
\text { de ação }\end{array}$ & $\begin{array}{l}\text { Saber Humano: Revista } \\
\text { Científica da Faculdade } \\
\text { Antonio Meneghetti }\end{array}$ & 24466298 & V.8 n.12/p. 143-167 & 2018 \\
\hline 30 & Érico de Lima Azevedo & $\begin{array}{l}\text { Raízes históricas e } \\
\text { epistemológicas da } \\
\text { Ontopsicologia }\end{array}$ & $\begin{array}{l}\text { Saber Humano: Revista } \\
\text { Científica da Faculdade } \\
\text { Antonio Meneghetti }\end{array}$ & 24466298 & V.8n.13/p. 6-27 & 2018 \\
\hline 31 & $\begin{array}{l}\text { Durval Luiz de Faria } \\
\text { Ida Elizabeth Cardinalli } \\
\text { Nathália Perin }\end{array}$ & $\begin{array}{l}\text { Morte e } \\
\text { Renascimento: } \\
\text { reflexões entre a } \\
\text { psicoterapia e o } \\
\text { tratamento de } \\
\text { doenças }\end{array}$ & $\begin{array}{l}\text { Saber Humano: Revista } \\
\text { Científica da Faculdade } \\
\text { Antonio Meneghetti }\end{array}$ & 24466298 & V.8 n.13/p. $28-42$ & 2018 \\
\hline 32 & $\begin{array}{l}\text { Carmen Ivanete } \\
\text { D'Agostini Spanhol }\end{array}$ & $\begin{array}{l}\text { Da Comunicação Tele } \\
\text { (J.Moreno) à } \\
\text { informação de Campo } \\
\text { Semântico (A. } \\
\text { Menghetti): }\end{array}$ & $\begin{array}{l}\text { Saber Humano: Revista } \\
\text { Científica da Faculdade } \\
\text { Antonio Meneghetti }\end{array}$ & 24466298 & V.8 n.13/p. 43-64 & 2018 \\
\hline
\end{tabular}


Saber Humano, ISSN 2446-6298, V. 9, n. 15, p. 186-423, jul./dez. 2019.

\begin{tabular}{|c|c|c|c|c|c|c|}
\hline & & $\begin{array}{l}\text { diferentes olhares } \\
\text { para a mesma } \\
\text { informação em } \\
\text { consultoria }\end{array}$ & & & & \\
\hline 33 & Estevão de Souza Silva & $\begin{array}{l}\text { As escolhas de } \\
\text { formação pessoal e } \\
\text { profissional de um } \\
\text { jovem protagonista } \\
\text { responsável }\end{array}$ & $\begin{array}{l}\text { Cadernos de Ontopsicologia: } \\
\text { Iniciação Científica do } \\
\text { Bacharelado em } \\
\text { Ontopsicologia. Saber } \\
\text { Humano: Revista Científica da } \\
\text { Faculdade Antonio Meneghetti } \\
\text { Resultado de Projeto de } \\
\text { Pesquisa em Iniciação } \\
\text { Científica/Projeto Pequena Tese } \\
\text { do Curso de Bacharelado em } \\
\text { Ontopsicologia-AMF }\end{array}$ & 24466298 & V.8 n.13/p. 10-17 & 2018 \\
\hline
\end{tabular}


Saber Humano, ISSN 2446-6298, V. 9, n. 15, p. 186-423, jul./dez. 2019.

\begin{tabular}{|c|c|c|c|c|c|c|}
\hline 35 & $\begin{array}{l}\text { Fernando Duarte Martins } \\
\text { de Oliveira }\end{array}$ & $\begin{array}{l}\text { Educação Marcial: a } \\
\text { contribuição da }\end{array}$ & $\begin{array}{l}\text { Cadernos de Ontopsicologia: } \\
\text { Iniciação Científica do }\end{array}$ & 24466298 & V.8 n.13/p. $29-40$ & 2018 \\
\hline & & $\begin{array}{l}\text { escola de artes } \\
\text { marciais no processo } \\
\text { formativo do jovem } \\
\text { protagonista } \\
\text { responsável }\end{array}$ & $\begin{array}{l}\text { Bacharelado em } \\
\text { Ontopsicologia. Saber } \\
\text { Humano: Revista Científica da } \\
\text { Faculdade Antonio Meneghetti } \\
\text { Resultado de Projeto de } \\
\text { Pesquisa em Iniciação } \\
\text { Científica/Projeto Pequena Tese } \\
\text { do Curso de Bacharelado em } \\
\text { Ontopsicologia-AMF }\end{array}$ & & & \\
\hline 36 & Gustavo Fronza de Prá & $\begin{array}{l}\text { Aceno sobre Jovem e } \\
\text { Existência }\end{array}$ & $\begin{array}{l}\text { Cadernos de Ontopsicologia: } \\
\text { Iniciação Científica do } \\
\text { Bacharelado em } \\
\text { Ontopsicologia. Saber } \\
\text { Humano: Revista Científica da } \\
\text { Faculdade Antonio Meneghetti } \\
\text { Resultado de Projeto de } \\
\text { Pesquisa em Iniciação } \\
\text { Científica/Projeto Pequena Tese } \\
\text { do Curso de Bacharelado em } \\
\text { Ontopsicologia-AMF }\end{array}$ & 24466298 & V.8 n.13/p. 41-50 & 2018 \\
\hline
\end{tabular}


Saber Humano, ISSN 2446-6298, V. 9, n. 15, p. 186-423, jul./dez. 2019.

\begin{tabular}{|l|l|l|l|l|l|}
\hline 37 & & $\begin{array}{l}\text { Cadernos de Ontopsicologia: } \\
\text { Iniciação Científica do } \\
\text { Bacharelado em } \\
\text { Ontopsicologia. Saber } \\
\text { Humano: Revista Científica da } \\
\text { Baculdade Antonio Meneghetti } \\
\text { Breve análise sobre a } \\
\text { relação homem e } \\
\text { sociedade }\end{array}$ & $\begin{array}{l}\text { Resultado de Projeto de } \\
\text { Pesquisa em Iniciação }\end{array}$ & V.8 n.13/p. 51-63 \\
\hline
\end{tabular}

\begin{tabular}{|c|c|c|c|c|c|c|}
\hline & & & $\begin{array}{l}\text { Científica/Projeto Pequena Tese } \\
\text { do Curso de Bacharelado em } \\
\text { Ontopsicologia-AMF }\end{array}$ & & & \\
\hline 38 & $\begin{array}{l}\text { Gustavo Henrique } \\
\text { Florêncio }\end{array}$ & $\begin{array}{l}\text { Relação entre } \\
\text { inteligências: } \\
\text { formação de jovens } \\
\text { no Centro } \\
\text { Internacional de Arte } \\
\text { e Cultura Humanista } \\
\text { Recanto Maestro }\end{array}$ & $\begin{array}{l}\text { Cadernos de Ontopsicologia: } \\
\text { Iniciação Científica do } \\
\text { Bacharelado em } \\
\text { Ontopsicologia. Saber } \\
\text { Humano: Revista Científica da } \\
\text { Faculdade Antonio Meneghetti } \\
\text { Resultado de Projeto de } \\
\text { Pesquisa em Iniciação } \\
\text { Científica/Projeto Pequena Tese } \\
\text { do Curso de Bacharelado em } \\
\text { Ontopsicologia-AMF }\end{array}$ & 24466298 & V.8 n.13/p. $64-75$ & 2018 \\
\hline
\end{tabular}


Saber Humano, ISSN 2446-6298, V. 9, n. 15, p. 186-423, jul./dez. 2019.

\begin{tabular}{|c|c|c|c|c|c|c|}
\hline 39 & Henrique Marafiga Martins & $\begin{array}{l}\text { O futuro da Educação: } \\
\text { uma solução } \\
\text { metodológica } \\
\text { inspirada na } \\
\text { Pedagogia } \\
\text { Ontopsicológica }\end{array}$ & $\begin{array}{l}\text { Cadernos de Ontopsicologia: } \\
\text { Iniciação Científica do } \\
\text { Bacharelado em } \\
\text { Ontopsicologia. Saber } \\
\text { Humano: Revista Científica da } \\
\text { Faculdade Antonio Meneghetti } \\
\text { Resultado de Projeto de } \\
\text { Pesquisa em Iniciação } \\
\text { Científica/Projeto Pequena Tese } \\
\text { do Curso de Bacharelado em } \\
\text { Ontopsicologia-AMF }\end{array}$ & 24466298 & V.8 n.13/p. 76-93 & 2018 \\
\hline 40 & Ivo Canísio Mallmann & $\begin{array}{l}\text { Pedagogia da ação } \\
\text { prática na empresa }\end{array}$ & $\begin{array}{l}\text { Cadernos de Ontopsicologia: } \\
\text { Iniciação Científica do } \\
\text { Bacharelado em }\end{array}$ & 24466298 & V.8 n.13/p. 94-116 & 2018 \\
\hline
\end{tabular}

\begin{tabular}{|l|l|l|}
\hline & & Ontopsicologia. Saber \\
Humano: Revista Científica da \\
Faculdade Antonio Meneghetti \\
Resultado de Projeto de \\
Pesquisa em Iniciação \\
Científica/Projeto Pequena Tese \\
do Curso de Bacharelado em \\
Ontopsicologia-AMF
\end{tabular} \mid


Saber Humano, ISSN 2446-6298, V. 9, n. 15, p. 186-423, jul./dez. 2019.

\begin{tabular}{|c|c|c|c|c|c|c|}
\hline 41 & Ivo Canísio Mallmann & $\begin{array}{l}\text { O papel do indivíduo } \\
\text { para o } \\
\text { desenvolvimento da } \\
\text { sociedade }\end{array}$ & $\begin{array}{l}\text { Cadernos de Ontopsicologia: } \\
\text { Iniciação Científica do } \\
\text { Bacharelado em } \\
\text { Ontopsicologia. Saber } \\
\text { Humano: Revista Científica da } \\
\text { Faculdade Antonio Meneghetti } \\
\text { Resultado de Projeto de } \\
\text { Pesquisa em Iniciação } \\
\text { Científica/Projeto Pequena Tese } \\
\text { do Curso de Bacharelado em } \\
\text { Ontopsicologia-AMF }\end{array}$ & 24466298 & V.8 n.13/p. 117-128 & 2018 \\
\hline 42 & $\begin{array}{l}\text { Luiz Victor Azevedo } \\
\text { Gazzaneo }\end{array}$ & $\begin{array}{l}\text { O homem como } \\
\text { coeficiente de solução } \\
\text { no Direito e na } \\
\text { sociedade }\end{array}$ & $\begin{array}{l}\text { Cadernos de Ontopsicologia: } \\
\text { Iniciação Científica do } \\
\text { Bacharelado em } \\
\text { Ontopsicologia. Saber } \\
\text { Humano: Revista Científica da } \\
\text { Faculdade Antonio Meneghetti } \\
\text { Resultado de Projeto de } \\
\text { Pesquisa em Iniciação } \\
\text { Científica/Projeto Pequena }\end{array}$ & 24466298 & V.8 n.13/p. 129-144 & 2018 \\
\hline & & & $\begin{array}{l}\text { Tese do Curso de Bacharelado } \\
\text { em Ontopsicologia-AMF }\end{array}$ & & & \\
\hline
\end{tabular}


Saber Humano, ISSN 2446-6298, V. 9, n. 15, p. 186-423, jul./dez. 2019.

\begin{tabular}{|c|c|c|c|c|c|c|}
\hline 43 & $\begin{array}{l}\text { Natália dos Santos } \\
\text { Conceição }\end{array}$ & $\begin{array}{l}\text { A formação do jovem: } \\
\text { relação entre } \\
\text { os principais } \\
\text { estereótipos e a } \\
\text { responsabilidade } \\
\text { pessoal }\end{array}$ & $\begin{array}{l}\text { Cadernos de Ontopsicologia: } \\
\text { Iniciação Científica do } \\
\text { Bacharelado em } \\
\text { Ontopsicologia. Saber } \\
\text { Humano: Revista Científica da } \\
\text { Faculdade Antonio Meneghetti } \\
\text { Resultado de Projeto de } \\
\text { Pesquisa em Iniciação } \\
\text { Científica/Projeto Pequena Tese } \\
\text { do Curso de Bacharelado em } \\
\text { Ontopsicologia-AMF }\end{array}$ & 24466298 & V.8 n.13/p. $145-153$ & 2018 \\
\hline 44 & $\begin{array}{l}\text { Ricardo Rechnden } \\
\text { Barcellos }\end{array}$ & $\begin{array}{l}\text { A análise } \\
\text { ontopsicológica da } \\
\text { pessoa e a } \\
\text { intervenção }\end{array}$ & $\begin{array}{l}\text { Cadernos de Ontopsicologia: } \\
\text { Iniciação Científica do } \\
\text { Bacharelado em } \\
\text { Ontopsicologia. Saber } \\
\text { Humano: Revista Científica da } \\
\text { Faculdade Antonio Meneghetti } \\
\text { Resultado de Projeto de } \\
\text { Pesquisa em Iniciação } \\
\text { Científica/Projeto Pequena Tese } \\
\text { do Curso de Bacharelado em } \\
\text { Ontopsicologia-AMF }\end{array}$ & 24466298 & V.8 n.13/p. 154-168 & 2018 \\
\hline 45 & $\begin{array}{l}\text { Ricardo Rechnden } \\
\text { Barcellos }\end{array}$ & Metanoia & $\begin{array}{l}\text { Cadernos de Ontopsicologia: } \\
\text { Iniciação Científica do } \\
\text { Bacharelado em } \\
\text { Ontopsicologia. Saber }\end{array}$ & 24466298 & V.8 n.13/p. 169-181 & 2018 \\
\hline
\end{tabular}


Saber Humano, ISSN 2446-6298, V. 9, n. 15, p. 186-423, jul./dez. 2019.

\begin{tabular}{|c|c|c|c|c|c|c|}
\hline & & & $\begin{array}{l}\text { Humano: Revista Científica da } \\
\text { Faculdade Antonio Meneghetti } \\
\text { Resultado de Projeto de } \\
\text { Pesquisa em Iniciação } \\
\text { Científica/Projeto Pequena Tese } \\
\text { do Curso de Bacharelado em } \\
\text { Ontopsicologia-AMF }\end{array}$ & & & \\
\hline 47 & Ricardo Schaefer & $\begin{array}{l}\text { Mentalidade } \\
\text { Empreendedora: do } \\
\text { modo de pensar ao } \\
\text { modo de agir do } \\
\text { indivíduo } \\
\text { empreendedor }\end{array}$ & $\begin{array}{l}\text { A Revista de } \\
\text { Empreendedorismo e Gestão de } \\
\text { Pequenas Empresas - } \\
\text { REGEPE }\end{array}$ & 23162058 & V. 6/p. 495-524 & 2017 \\
\hline
\end{tabular}


Saber Humano, ISSN 2446-6298, V. 9, n. 15, p. 186-423, jul./dez. 2019.

\begin{tabular}{|c|l|l|l|l|l|}
\hline 48 & & $\begin{array}{l}\text { Escrever, pensar, ler, } \\
\text { estudar, pesquisar: } \\
\text { produzindo as } \\
\text { Pequenas Teses do }\end{array}$ & $\begin{array}{l}\text { Saber Humano: Revista } \\
\text { Científica da Faculdade } \\
\text { Antonio Meneghetti }\end{array}$ & 24466298 & N.2/p. 1-7 \\
\hline
\end{tabular}

\begin{tabular}{|c|c|c|c|c|c|c|}
\hline & & $\begin{array}{l}\text { Bacharelado em } \\
\text { Ontopsicologia da } \\
\text { Faculdade Antonio } \\
\text { Meneghetti }\end{array}$ & & & & \\
\hline 49 & $\begin{array}{l}\text { Elena Volkova } \\
\text { Olga Milkhalyuk } \\
\text { Patrícia Wazlawick } \\
\text { Ricardo Schaefer } \\
\text { Tatiana Vereitnova } \\
\text { Victoria Dmitrieva }\end{array}$ & $\begin{array}{l}\text { Para a definição do } \\
\text { conceito de } \\
\text { socialização positiva } \\
\text { de jovens }\end{array}$ & $\begin{array}{l}\text { RIC@. Revista Interdisciplinar } \\
\text { Científica Aplicada }\end{array}$ & 19807031 & V.11/p. 78-100 & 2017 \\
\hline 50 & Patrícia Wazlawick & $\begin{array}{l}\text { Formação e } \\
\text { desenvolvimento } \\
\text { pessoal e profissional } \\
\text { de jovens } \\
\text { universitários: } \\
\text { resultados da } \\
\text { aplicação da } \\
\text { Pedagogia } \\
\text { Ontopsicológica }\end{array}$ & $\begin{array}{l}\text { Revista Nuances: Estudos sobre } \\
\text { Educação }\end{array}$ & 22360441 & V.28 n.2/ p. 191-211 & 2017 \\
\hline
\end{tabular}


Saber Humano, ISSN 2446-6298, V. 9, n. 15, p. 186-423, jul./dez. 2019.

\begin{tabular}{|c|l|l|l|l|l|}
\hline 51 & Alécio Vidor & $\begin{array}{l}\text { Pesquisa em } \\
\text { Ontopsicologia }\end{array}$ & $\begin{array}{l}\text { Saber Humano: Revista } \\
\text { Científica da Faculdade } \\
\text { Antonio Meneghetti }\end{array}$ & 24466298 & V.7 n.10/ p. 5-13 \\
\hline 52 & $\begin{array}{l}\text { Carmen Ivanete } \\
\text { D'Agostini Spanhol }\end{array}$ & $\begin{array}{l}\text { Antonio Meneghetti: } \\
\text { oformalizador da } \\
\text { Ontopsicologia e as } \\
\text { instituições formais } \\
\text { de ensino que }\end{array}$ & $\begin{array}{l}\text { Cadernos Especiais de Pequena } \\
\text { Tese - Saber Humano: Revista } \\
\text { Científica da Faculdade } \\
\text { Antonio Meneghetti }\end{array}$ & 24466298 & N.2/p.60-82 \\
\hline
\end{tabular}

\begin{tabular}{|l|l|l|l|l|l|}
\hline & $\begin{array}{l}\text { respaldam o novo } \\
\text { saber no mundo }\end{array}$ & & & \\
\hline 53 & Ricardo Schaefer & $\begin{array}{l}\text { Saber Humano: Revista } \\
\text { Científica da Faculdade } \\
\text { Antonio Meneghetti } \\
\text { Cadernos de Ontopsicologia: } \\
\text { Iniciação Científica do } \\
\text { Bacharelado em Ontopsicologia. } \\
\text { Resultado de Projeto de } \\
\text { Pesquisa em Iniciação } \\
\text { Científica/Projeto Pequena Tese } \\
\text { para o protagonismo integral } \\
\text { responsável: as } \\
\text { dimensões da } \\
\text { formação do jovem no de Bacharelado em } \\
\text { Recanto Maestro } \\
\text { Ontopsicologia-AMF }\end{array}$ & V.7n.2/p. 32 \\
\hline
\end{tabular}


Saber Humano, ISSN 2446-6298, V. 9, n. 15, p. 186-423, jul./dez. 2019.

\begin{tabular}{|c|c|c|c|c|c|c|}
\hline 54 & Eloy Demarchi Teixeira & $\begin{array}{l}\text { A Responsabilidade, } \\
\text { autonomia e } \\
\text { abordagem profunda } \\
\text { ao estudo como } \\
\text { resultado da } \\
\text { Pedagogia } \\
\text { Ontopsicológica: um } \\
\text { estudo com } \\
\text { ingressantes } \\
\text { universitários da } \\
\text { Antonio Meneghetti } \\
\text { Faculdade }\end{array}$ & $\begin{array}{l}\text { Saber Humano: Revista } \\
\text { Científica da Faculdade } \\
\text { Antonio Meneghetti } \\
\text { Cadernos de Ontopsicologia: } \\
\text { Iniciação Científica do } \\
\text { Bacharelado em Ontopsicologia. } \\
\text { Resultado de Projeto de } \\
\text { Pesquisa em Iniciação } \\
\text { Científica/Projeto Pequena Tese } \\
\text { do Curso de Bacharelado em } \\
\text { Ontopsicologia-AMF }\end{array}$ & 24466298 & V.7 n.2 /p. 94-115 & 2017 \\
\hline 55 & Adalberto Panzan Junior & $\begin{array}{l}\text { Contribuição da } \\
\text { Ontopsicologia para a } \\
\text { compreensão do } \\
\text { conhecimento } \\
\text { humano: estudo dos } \\
\text { conceitos de } \\
\text { importantes } \\
\text { estudiosos do período } \\
\text { do Renascimento ao } \\
\text { Empirismo }\end{array}$ & $\begin{array}{l}\text { Saber Humano: Revista } \\
\text { Científica da Faculdade } \\
\text { Antonio Meneghetti } \\
\text { Cadernos de Ontopsicologia: } \\
\text { Iniciação Científica do } \\
\text { Bacharelado em Ontopsicologia. } \\
\text { Resultado de Projeto de } \\
\text { Pesquisa em Iniciação } \\
\text { Científica/Projeto Pequena Tese } \\
\text { do Curso de Bacharelado em } \\
\text { Ontopsicologia-AMF }\end{array}$ & 24466298 & N.2/p.7-28 & 2017 \\
\hline
\end{tabular}


Saber Humano, ISSN 2446-6298, V. 9, n. 15, p. 186-423, jul./dez. 2019.

\begin{tabular}{|c|c|c|c|c|c|c|}
\hline 56 & Carla Sewald & $\begin{array}{l}\text { Perceber-se e } \\
\text { aprender-se: caminho } \\
\text { para o } \\
\text { autoconhecimento }\end{array}$ & $\begin{array}{l}\text { Saber Humano: Revista } \\
\text { Científica da Faculdade } \\
\text { Antonio Meneghetti } \\
\text { Cadernos de Ontopsicologia: } \\
\text { Iniciação Científica do } \\
\text { Bacharelado em Ontopsicologia. } \\
\text { Resultado de Projeto de } \\
\text { Pesquisa em Iniciação } \\
\text { Científica/Projeto Pequena Tese } \\
\text { do Curso de Bacharelado em } \\
\text { Ontopsicologia-AMF }\end{array}$ & 24466298 & N.2/p. 42-59 & 2017 \\
\hline 57 & Cláudia Vicentini & $\begin{array}{l}\text { Inteligência ao } \\
\text { Feminino }\end{array}$ & $\begin{array}{l}\text { Saber Humano: Revista } \\
\text { Científica da Faculdade } \\
\text { Antonio Meneghetti } \\
\text { Cadernos de Ontopsicologia: }\end{array}$ & 24466298 & N.2/p. 83-93 & 2017 \\
\hline
\end{tabular}

\begin{tabular}{|l|l|l|}
\hline & Iniciação Científica do \\
Bacharelado em Ontopsicologia. & Resultado de Projeto de \\
Pesquisa em Iniciação & Científica/Projeto Pequena Tese \\
do Curso de Bacharelado em & Ontopsicologia-AMF & \\
\hline
\end{tabular}


Saber Humano, ISSN 2446-6298, V. 9, n. 15, p. 186-423, jul./dez. 2019.

\begin{tabular}{|c|c|c|c|c|c|c|}
\hline 58 & Délis Stona & $\begin{array}{l}\text { Ontopsicologia e } \\
\text { Psicologia: a função } \\
\text { principal que } \\
\text { distingue essas duas } \\
\text { grandes Ciências }\end{array}$ & $\begin{array}{l}\text { Saber Humano: Revista } \\
\text { Científica da Faculdade } \\
\text { Antonio Meneghetti } \\
\text { Cadernos de Ontopsicologia: } \\
\text { Iniciação Científica do } \\
\text { Bacharelado em Ontopsicologia. } \\
\text { Resultado de Projeto de } \\
\text { Pesquisa em Iniciação } \\
\text { Científica/Projeto Pequena Tese } \\
\text { do Curso de Bacharelado em } \\
\text { Ontopsicologia-AMF }\end{array}$ & 24466298 & N.2/p. 83-93 & 2017 \\
\hline 59 & Hans Egon Horstmann & $\begin{array}{l}\text { A Ontopsicologia } \\
\text { como resolução ao } \\
\text { problema crítico do } \\
\text { conhecimento: um } \\
\text { diálogo entre Werner } \\
\text { Heisenberg e Antonio } \\
\text { Meneghetti }\end{array}$ & $\begin{array}{l}\text { Saber Humano: Revista } \\
\text { Científica da Faculdade } \\
\text { Antonio Meneghetti } \\
\text { Cadernos de Ontopsicologia: } \\
\text { Iniciação Científica do } \\
\text { Bacharelado em Ontopsicologia. } \\
\text { Resultado de Projeto de }\end{array}$ & 24466298 & N.2/p. 116-133 & 2017 \\
\hline & & & $\begin{array}{l}\text { Pesquisa em Iniciação } \\
\text { Científica/Projeto Pequena Tese } \\
\text { do Curso de Bacharelado em } \\
\text { Ontopsicologia-AMF }\end{array}$ & & & \\
\hline
\end{tabular}


Saber Humano, ISSN 2446-6298, V. 9, n. 15, p. 186-423, jul./dez. 2019.

\begin{tabular}{|c|c|c|c|c|c|c|}
\hline 60 & José Nedel Filho & Intelecto e Vontade & $\begin{array}{l}\text { Saber Humano: Revista } \\
\text { Científica da Faculdade } \\
\text { Antonio Meneghetti } \\
\text { Cadernos de Ontopsicologia: } \\
\text { Iniciação Científica do } \\
\text { Bacharelado em Ontopsicologia. } \\
\text { Resultado de Projeto de } \\
\text { Pesquisa em Iniciação } \\
\text { Científica/Projeto Pequena Tese } \\
\text { do Curso de Bacharelado } \\
\text { em } \\
\text { OntopsicologiaAMFCadernos de } \\
\text { Ontopsicologia: Iniciação } \\
\text { Científica do Bacharelado em } \\
\text { Ontopsicologia. } \\
\text { Resultado de Projeto de } \\
\text { Pesquisa em Iniciação } \\
\text { Científica/Projeto Pequena Tese } \\
\text { do Curso de Bacharelado em } \\
\text { Ontopsicologia-AMF }\end{array}$ & 24466298 & N.2/p. 145-156 & 2017 \\
\hline
\end{tabular}


Saber Humano, ISSN 2446-6298, V. 9, n. 15, p. 186-423, jul./dez. 2019.

\begin{tabular}{|c|c|c|c|c|c|c|}
\hline 61 & $\begin{array}{l}\text { Lilian Werner Philippi da } \\
\text { Silva }\end{array}$ & $\begin{array}{l}\text { Alimentação e } \\
\text { Percepção }\end{array}$ & $\begin{array}{l}\text { Saber Humano: Revista } \\
\text { Científica da Faculdade } \\
\text { Antonio Meneghetti } \\
\text { Cadernos de Ontopsicologia: } \\
\text { Iniciação Científica do } \\
\text { Bacharelado em Ontopsicologia. } \\
\text { Resultado de Projeto de } \\
\text { Pesquisa em Iniciação } \\
\text { Científica/Projeto Pequena Tese } \\
\text { do Curso de Bacharelado em } \\
\text { Ontopsicologia-AMF }\end{array}$ & 24466298 & N.2/p. 134-144 & 2017 \\
\hline 62 & Gustavo Oliveira & $\begin{array}{l}\text { O mecanismo } \\
\text { deflector no processo } \\
\text { perceptivo-cognitivo: } \\
\text { qual o critério de } \\
\text { verdade para a } \\
\text { construção das } \\
\text { ciências }\end{array}$ & $\begin{array}{l}\text { Saber Humano: Revista } \\
\text { Científica da Faculdade } \\
\text { Antonio Meneghetti } \\
\text { Cadernos de Ontopsicologia: } \\
\text { Iniciação Científica do } \\
\text { Bacharelado em Ontopsicologia. } \\
\text { Resultado de Projeto de } \\
\text { Pesquisa em Iniciação } \\
\text { Científica/Projeto Pequena Tese } \\
\text { do Curso de Bacharelado em } \\
\text { Ontopsicologia-AMF }\end{array}$ & 24466298 & N.2/p. 260-277 & 2017 \\
\hline 63 & Marcelo Pfleger & $\begin{array}{l}\text { A formação do } \\
\text { "homem redondo": } \\
\text { Tipos Psicológicos de } \\
\text { Jung e a Ciência }\end{array}$ & $\begin{array}{l}\text { Saber Humano: Revista } \\
\text { Científica da Faculdade } \\
\text { Antonio Meneghetti } \\
\text { Cadernos de Ontopsicologia: }\end{array}$ & 24466298 & N.2/p. 288-313 & 2017 \\
\hline
\end{tabular}


Saber Humano, ISSN 2446-6298, V. 9, n. 15, p. 186-423, jul./dez. 2019.

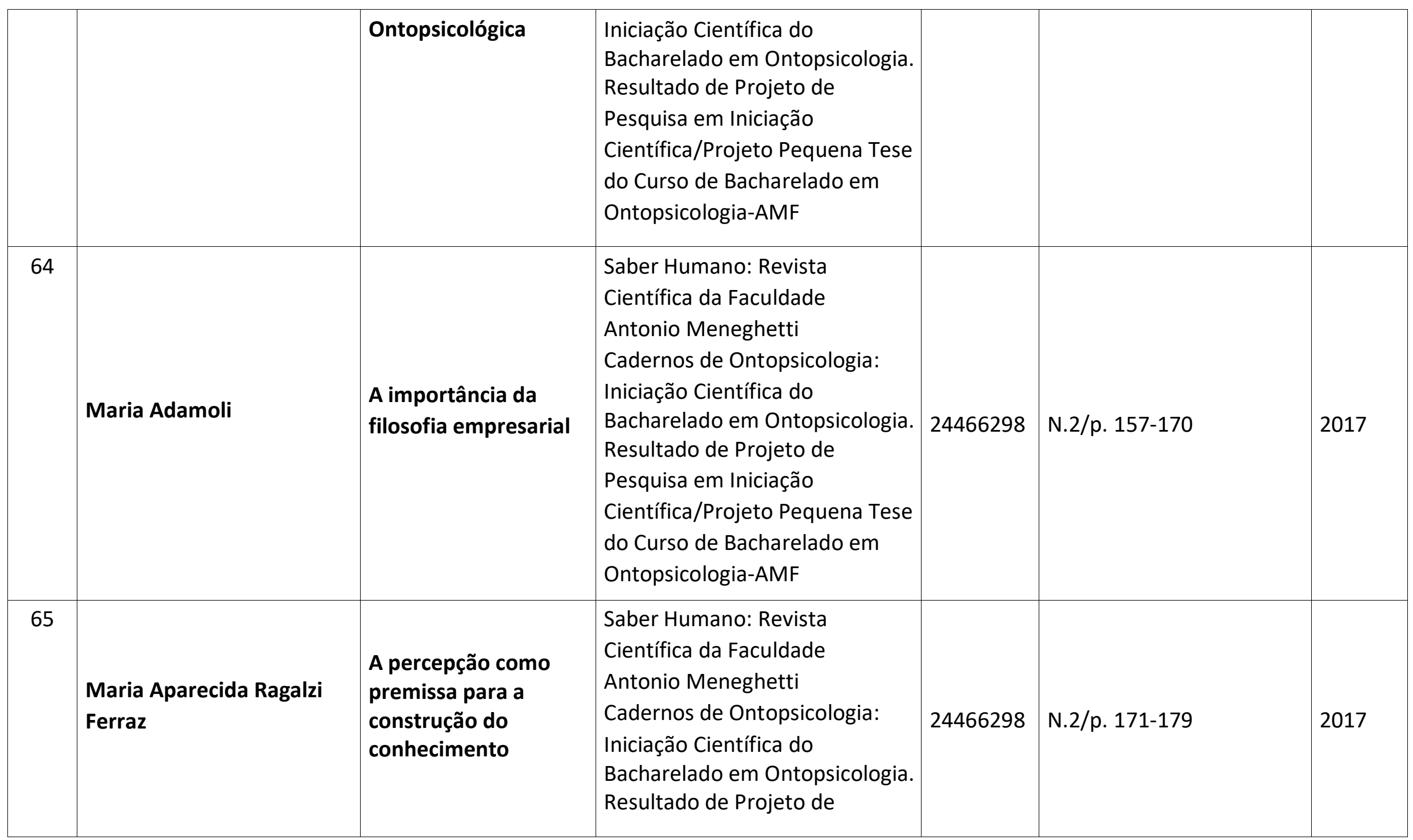


Saber Humano, ISSN 2446-6298, V. 9, n. 15, p. 186-423, jul./dez. 2019.

\begin{tabular}{|c|c|c|c|c|c|c|}
\hline & & & $\begin{array}{l}\text { Pesquisa em Iniciação } \\
\text { Científica/Projeto Pequena Tese } \\
\text { do Curso de Bacharelado em } \\
\text { Ontopsicologia-AMF }\end{array}$ & & & \\
\hline 66 & Ricardo Schaefer & $\begin{array}{l}\text { A Formação de } \\
\text { Novos } \\
\text { Empreendedores: } \\
\text { Natureza da } \\
\text { Aprendizagem e } \\
\text { Educação } \\
\text { Empreendedoras }\end{array}$ & $\begin{array}{l}\text { Revista da Micro E Pequena } \\
\text { Empresa (FACCAMP) }\end{array}$ & 19822537 & V. $11 /$ p. $2-20$ & 2017 \\
\hline 67 & Mariana de Brito Araújo & $\begin{array}{l}\text { Direito e Arte: } \\
\text { garantia de civilidade } \\
\text { como premissa à } \\
\text { plenitude do projeto } \\
\text { individual }\end{array}$ & $\begin{array}{l}\text { Saber Humano: Revista } \\
\text { Científica da Faculdade } \\
\text { Antonio Meneghetti } \\
\text { Cadernos de Ontopsicologia: } \\
\text { Iniciação Científica do } \\
\text { Bacharelado em Ontopsicologia. } \\
\text { Resultado de Projeto de } \\
\text { Pesquisa em Iniciação } \\
\text { Científica/Projeto Pequena Tese } \\
\text { do Curso de Bacharelado em } \\
\text { Ontopsicologia-AMF }\end{array}$ & 24466298 & N.2/p. 180-201 & 2017 \\
\hline
\end{tabular}


Saber Humano, ISSN 2446-6298, V. 9, n. 15, p. 186-423, jul./dez. 2019.

\begin{tabular}{|c|c|c|c|c|c|c|}
\hline 68 & Michael Fragomeni Penna & $\begin{array}{l}\text { Vida ativa: a prática } \\
\text { de um instrumento } \\
\text { musical como } \\
\text { ferramenta de } \\
\text { transformação no }\end{array}$ & $\begin{array}{l}\text { Saber Humano: Revista } \\
\text { Científica da Faculdade } \\
\text { Antonio Meneghetti } \\
\text { Cadernos de Ontopsicologia: } \\
\text { Iniciação Científica do }\end{array}$ & 24466298 & N.2/p. 278-287 & 2017 \\
\hline & & $\begin{array}{l}\text { uso do tempo livre em } \\
\text { alunos da Orquestra } \\
\text { Jovem } \\
\text { Recanto Maestro }\end{array}$ & $\begin{array}{l}\text { Bacharelado em Ontopsicologia. } \\
\text { Resultado de Projeto de } \\
\text { Pesquisa em Iniciação } \\
\text { Científica/Projeto Pequena Tese } \\
\text { do Curso de Bacharelado em } \\
\text { Ontopsicologia-AMF }\end{array}$ & & & \\
\hline
\end{tabular}


Saber Humano, ISSN 2446-6298, V. 9, n. 15, p. 186-423, jul./dez. 2019.

\begin{tabular}{|c|c|c|c|c|c|c|}
\hline 69 & Mônica Oliveira & $\begin{array}{l}\text { A importância do } \\
\text { miricismo cotidiano } \\
\text { para a retomada da } \\
\text { percepção } \\
\text { organísmica }\end{array}$ & $\begin{array}{l}\text { Saber Humano: Revista } \\
\text { Científica da Faculdade } \\
\text { Antonio Meneghetti } \\
\text { Cadernos de Ontopsicologia: } \\
\text { Iniciação Científica do }\end{array}$ & 24466298 & N.2/p. 202-206 & 2017 \\
\hline & & & $\begin{array}{l}\text { Bacharelado em Ontopsicologia. } \\
\text { Resultado de Projeto de } \\
\text { Pesquisa em Iniciação } \\
\text { Científica/Projeto Pequena Tese } \\
\text { do Curso de Bacharelado em } \\
\text { Ontopsicologia-AMF }\end{array}$ & & & \\
\hline 70 & $\begin{array}{l}\text { Patrícia Gabriela Bilha } \\
\text { Salles }\end{array}$ & $\begin{array}{l}\text { Formação Humanista } \\
\text { Ontopsicológica de } \\
\text { Jovens }\end{array}$ & $\begin{array}{l}\text { Saber Humano: Revista } \\
\text { Científica da Faculdade } \\
\text { Antonio Meneghetti } \\
\text { Cadernos de Ontopsicologia: } \\
\text { Iniciação Científica do } \\
\text { Bacharelado em Ontopsicologia. } \\
\text { Resultado de Projeto de } \\
\text { Pesquisa em Iniciação } \\
\text { Científica/Projeto Pequena Tese } \\
\text { do Curso de Bacharelado em } \\
\text { Ontopsicologia-AMF }\end{array}$ & 24466298 & N.2/p. 207-217 & 2017 \\
\hline
\end{tabular}


Saber Humano, ISSN 2446-6298, V. 9, n. 15, p. 186-423, jul./dez. 2019.

\begin{tabular}{|l|l|l|l|l|l|}
\hline 71 & & $\begin{array}{l}\text { Saber Humano: Revista } \\
\text { Sociedade e } \\
\text { Socialização: revisão } \\
\text { conceitual à luz do da Faculdade } \\
\text { Paradigma } \\
\text { Ontopsicológico }\end{array}$ & $\begin{array}{l}\text { Antonio Meneghetti } \\
\text { Cadernos de Ontopsicologia: } \\
\text { Iniciação Científica do } \\
\text { Bacharelado em Ontopsicologia. } \\
\text { Resultado de Projeto de } \\
\text { Pesquisa em Iniciação }\end{array}$ & 24466298 & N.2/p. $314-331$ \\
\hline
\end{tabular}

\begin{tabular}{|l|l|l|l|l|}
\hline & & $\begin{array}{l}\text { Científica/Projeto Pequena Tese } \\
\text { do Curso de Bacharelado em } \\
\text { Ontopsicologia-AMF }\end{array}$ & \\
\hline
\end{tabular}


Saber Humano, ISSN 2446-6298, V. 9, n. 15, p. 186-423, jul./dez. 2019.

\begin{tabular}{|c|c|c|c|c|c|c|}
\hline 72 & Rosângela Alves Nabarros & $\begin{array}{l}\text { A empresa, a } \\
\text { formação de jovens e } \\
\text { a Ontopsicologia }\end{array}$ & $\begin{array}{l}\text { Saber Humano: Revista } \\
\text { Científica da Faculdade } \\
\text { Antonio Meneghetti } \\
\text { Cadernos de Ontopsicologia: } \\
\text { Iniciação Científica do } \\
\text { Bacharelado em Ontopsicologia. } \\
\text { Resultado de Projeto de } \\
\text { Pesquisa em Iniciação } \\
\text { Científica/Projeto Pequena Tese } \\
\text { do Curso de Bacharelado em } \\
\text { Ontopsicologia- } \\
\text { AMFResultado de Projeto de } \\
\text { Pesquisa em Iniciação } \\
\text { Científica/Projeto Pequena Tese } \\
\text { do Curso de Bacharelado em } \\
\text { Ontopsicologia-AMF }\end{array}$ & 24466298 & $\begin{array}{l}\text { Caderno Especial de } \\
\text { Ontopsicologia - } \\
\text { Iniciação Científica do } \\
\text { Curso de Bacharelado em } \\
\text { Ontopsicologia. /p. 218- } \\
228\end{array}$ & 2017 \\
\hline
\end{tabular}


Saber Humano, ISSN 2446-6298, V. 9, n. 15, p. 186-423, jul./dez. 2019.

\begin{tabular}{|c|c|c|c|c|c|c|}
\hline & & & $\begin{array}{l}\text { Resultado de Projeto de } \\
\text { Pesquisa em Iniciação } \\
\text { Científica/Projeto Pequena Tese } \\
\text { do Curso de Bacharelado em } \\
\text { Ontopsicologia-AMF }\end{array}$ & & & \\
\hline 74 & $\begin{array}{l}\text { Alécio Vidor } \\
\text { Cleoci Werle Rockenbach }\end{array}$ & $\begin{array}{l}\text { A Psicologia e a } \\
\text { Ontologia como } \\
\text { pressupostos ao } \\
\text { conhecimento e } \\
\text { evolução do humano }\end{array}$ & $\begin{array}{l}\text { Saber Humano: Revista } \\
\text { Científica da Faculdade } \\
\text { Antonio Meneghetti }\end{array}$ & 24466298 & V.6 n.8, p. $11-28$ & 2016 \\
\hline 75 & $\begin{array}{l}\text { Elena Volkova } \\
\text { Jusélia Silva } \\
\text { Olga Milkhalyuk } \\
\text { Patrícia Wazlawick } \\
\text { Patrícia Salles } \\
\text { Ricardo Schaefer } \\
\text { Victoria Dmitrieva } \\
\text { Tatiana Vereitnova }\end{array}$ & $\begin{array}{l}\text { Sobre a socialização } \\
\text { dos jovens modernos: } \\
\text { breve discussão entre } \\
\text { conceitos da } \\
\text { Sociologia, da } \\
\text { Psicologia Social e } \\
\text { Histórico-Cultural }\end{array}$ & $\begin{array}{l}\text { REMEA: Revista Eletrônica do } \\
\text { Mestrado de Educação } \\
\text { Ambiental (FURG) }\end{array}$ & 15171256 & V.33/p. 331-343 & 2016 \\
\hline 76 & Patrícia Wazlawick & $\begin{array}{l}\text { Editorial - Cadernos } \\
\text { Especias de Pequena } \\
\text { Tese do Bacharelado } \\
\text { em Ontopsicologia }\end{array}$ & $\begin{array}{l}\text { Saber Humano: Revista } \\
\text { Científica da Faculdade } \\
\text { Antonio Meneghetti }\end{array}$ & 24466298 & N.1/p. 1-2 & 2016 \\
\hline
\end{tabular}


Saber Humano, ISSN 2446-6298, V. 9, n. 15, p. 186-423, jul./dez. 2019.

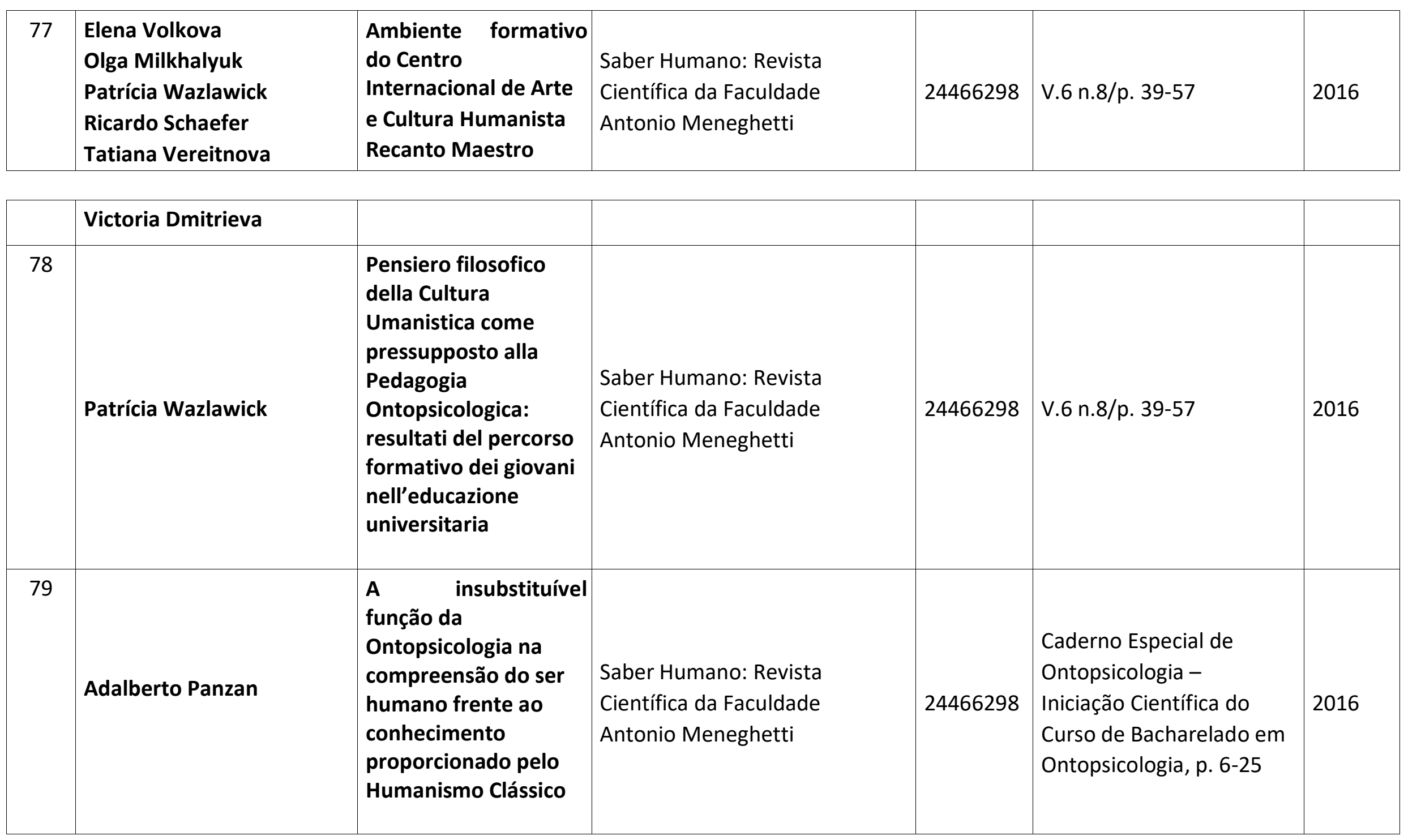


Saber Humano, ISSN 2446-6298, V. 9, n. 15, p. 186-423, jul./dez. 2019.

\begin{tabular}{|l|l|l|l|l|l|}
\hline 80 & Adelaide dos Santos Dias & $\begin{array}{l}\text { Apronfundamento } \\
\text { teórico sobre as } \\
\text { imagens oníricas e a } \\
\text { correlação com os } \\
\text { valores do Em Si } \\
\text { organísmico e os } \\
\text { valores sistêmicos }\end{array}$ & $\begin{array}{l}\text { Saber Humano: Revista } \\
\text { Científica da Faculdade } \\
\text { Antonio Meneghetti }\end{array}$ & 24466298 & $\begin{array}{l}\text { Caderno Especial de } \\
\text { Ontopsicologia- } \\
\text { Iniciação Científica do } \\
\text { Curso de Bacharelado em } \\
\text { Ontopsicologia, p. 26-34 }\end{array}$ \\
\\
\hline
\end{tabular}

\begin{tabular}{|c|c|c|c|c|c|c|}
\hline & & sociais & & & & \\
\hline 81 & Ademar Silva Junior & O que é a alma? & $\begin{array}{l}\text { Saber Humano: Revista } \\
\text { Científica da Faculdade } \\
\text { Antonio Meneghetti }\end{array}$ & 24466298 & $\begin{array}{l}\text { Caderno Especial de } \\
\text { Ontopsicologia - } \\
\text { Iniciação Científica do } \\
\text { Curso de Bacharelado em } \\
\text { Ontopsicologia, p. 35-48 }\end{array}$ & 2016 \\
\hline 82 & Alessandra Heinz & $\begin{array}{l}\text { A razão do homem } \\
\text { como certificadora } \\
\text { de ciência }\end{array}$ & $\begin{array}{l}\text { Saber Humano: Revista } \\
\text { Científica da Faculdade } \\
\text { Antonio Meneghetti }\end{array}$ & 24466298 & $\begin{array}{l}\text { Caderno Especial de } \\
\text { Ontopsicologia - } \\
\text { Iniciação Científica do } \\
\text { Curso de Bacharelado em } \\
\text { Ontopsicologia, p. 49-56 }\end{array}$ & 2016 \\
\hline 83 & Amauri Paulo Cervo & $\begin{array}{l}\text { Algumas } \\
\text { considerações sobre } \\
\text { Lógica }\end{array}$ & $\begin{array}{l}\text { Saber Humano: Revista } \\
\text { Científica da Faculdade } \\
\text { Antonio Meneghetti }\end{array}$ & 24466298 & $\begin{array}{l}\text { Caderno Especial de } \\
\text { Ontopsicologia - } \\
\text { Iniciação Científica do } \\
\text { Curso de Bacharelado em } \\
\text { Ontopsicologia, p. 74-89 }\end{array}$ & 2016 \\
\hline
\end{tabular}


Saber Humano, ISSN 2446-6298, V. 9, n. 15, p. 186-423, jul./dez. 2019.

\begin{tabular}{|c|l|l|l|l|l|}
\hline 84 & Andréia Ferreira Gomes & $\begin{array}{l}\text { Humanismo } \\
\text { Histórico: estudo de } \\
\text { sua evolução para } \\
\text { chegar à felicidade e } \\
\text { realização }\end{array}$ & $\begin{array}{l}\text { Saber Humano: Revista } \\
\text { Científica da Faculdade } \\
\text { Antonio Meneghetti }\end{array}$ & 24466298 & $\begin{array}{l}\text { Caderno Especial de } \\
\text { Ontopsicologia - } \\
\text { Iniciação Científica do } \\
\text { Curso de Bacharelado em } \\
\text { Ontopsicologia, p. 379390 }\end{array}$ \\
\hline 85 & Bernardina Amantino & $\begin{array}{l}\text { A raíz do teatro } \\
\text { feminino }\end{array}$ & $\begin{array}{l}\text { Saber Humano: Revista } \\
\text { Científica da Faculdade } \\
\text { Antonio Meneghetti }\end{array}$ & 24466298 & $\begin{array}{l}\text { Caderno Especial de } \\
\text { Ontopsicologia - } \\
\text { Iniciação Científica do } \\
\text { Curso de Bacharelado em } \\
\text { Ontopsicologia, p. 404- }\end{array}$ \\
\hline
\end{tabular}

\begin{tabular}{|c|l|l|l|l|l|}
\hline 86 & Adelaide Dos Santos Dias & $\begin{array}{l}\text { Do hilemorfismo ao } \\
\text { código biológico dos } \\
\text { sonhos segundo a } \\
\text { Ontopsicologia }\end{array}$ & $\begin{array}{l}\text { Saber Humano: Revista } \\
\text { Científica da Faculdade } \\
\text { Antonio Meneghetti }\end{array}$ & 24466298 & $\begin{array}{l}\text { Caderno Especial de } \\
\text { Ontopsicologia - } \\
\text { Iniciação Científica do } \\
\text { Curso de Bacharelado em } \\
\text { Ontopsicologia, p. 29-41 }\end{array}$ \\
\hline 87 & Carla Sewald Vieira & $\begin{array}{l}\text { Homem: o centro e a } \\
\text { medida de todas as } \\
\text { coisas }\end{array}$ & $\begin{array}{l}\text { Saber Humano: Revista } \\
\text { Científica da Faculdade } \\
\text { Antonio Meneghetti }\end{array}$ & $\begin{array}{l}\text { Caderno Especial de } \\
\text { Ontopsicologia - } \\
\text { Iniciação Científica do } \\
\text { Curso de Bacharelado em } \\
\text { Ontopsicologia, p. 277290 }\end{array}$ \\
201766298 \\
\hline
\end{tabular}


Saber Humano, ISSN 2446-6298, V. 9, n. 15, p. 186-423, jul./dez. 2019.

\begin{tabular}{|c|c|c|c|c|c|c|}
\hline 88 & $\begin{array}{l}\text { Carmen Ivanete } \\
\text { D'Agostini Spanhol }\end{array}$ & $\begin{array}{l}\text { Hora de colher os } \\
\text { frutos: a tomada de } \\
\text { decisão por meio do } \\
\text { sonho }\end{array}$ & $\begin{array}{l}\text { Saber Humano: Revista } \\
\text { Científica da Faculdade } \\
\text { Antonio Meneghetti }\end{array}$ & 24466298 & $\begin{array}{l}\text { Caderno Especial de } \\
\text { Ontopsicologia - } \\
\text { Iniciação Científica do } \\
\text { Curso de Bacharelado em } \\
\text { Ontopsicologia, p. } 324346\end{array}$ & 2016 \\
\hline 89 & Caroline Voguel & $\begin{array}{l}\text { A metafísica do Ser: } \\
\text { um estudo filosófico } \\
\text { para a vida }\end{array}$ & $\begin{array}{l}\text { Saber Humano: Revista } \\
\text { Científica da Faculdade } \\
\text { Antonio Meneghetti }\end{array}$ & 24466298 & $\begin{array}{l}\text { Caderno Especial de } \\
\text { Ontopsicologia - } \\
\text { Iniciação Científica do } \\
\text { Curso de Bacharelado em } \\
\text { Ontopsicologia, p. } 291298\end{array}$ & 2016 \\
\hline 90 & Claudia Maria Vicentini & $\begin{array}{l}\text { A lógica utilizada pela } \\
\text { mulher líder na gestão }\end{array}$ & $\begin{array}{l}\text { Saber Humano: Revista } \\
\text { Científica da Faculdade } \\
\text { Antonio Meneghetti }\end{array}$ & 24466298 & $\begin{array}{l}\text { Caderno Especial de } \\
\text { Ontopsicologia - } \\
\text { Iniciação Científica do } \\
\text { Curso de Bacharelado em }\end{array}$ & 2016 \\
\hline
\end{tabular}

\begin{tabular}{|c|l|l|l|l|l|}
\hline & & & Ontopsicologia, p. 118135 \\
\hline 91 & Délis Stona & $\begin{array}{l}\text { A importância da } \\
\text { formação humanista } \\
\text { para o jovem } \\
\text { contemporâneo }\end{array}$ & $\begin{array}{l}\text { Saber Humano: Revista } \\
\text { Científica da Faculdade } \\
\text { Antonio Meneghetti }\end{array}$ & 24466298 & $\begin{array}{l}\text { Caderno Especial de } \\
\text { Ontopsicologia - } \\
\text { Iniciação Científica do } \\
\text { Curso de Bacharelado em } \\
\text { Ontopsicologia, p. 191198 }\end{array}$ \\
2016 \\
\hline
\end{tabular}


Saber Humano, ISSN 2446-6298, V. 9, n. 15, p. 186-423, jul./dez. 2019.

\begin{tabular}{|c|c|c|c|c|c|c|}
\hline 92 & Eloy Demarchi Teixeira & $\begin{array}{l}\text { Utilização do tempo } \\
\text { livre na formação } \\
\text { integral }\end{array}$ & $\begin{array}{l}\text { Saber Humano: Revista } \\
\text { Científica da Faculdade } \\
\text { Antonio Meneghetti }\end{array}$ & 24466298 & $\begin{array}{l}\text { Caderno Especial de } \\
\text { Ontopsicologia - } \\
\text { Iniciação Científica do } \\
\text { Curso de Bacharelado em } \\
\text { Ontopsicologia, p. 57-73 }\end{array}$ & 2016 \\
\hline 93 & Gabriel de Souza Carrara & $\begin{array}{l}\text { Os jovens e o nexo } \\
\text { ontológico }\end{array}$ & $\begin{array}{l}\text { Saber Humano: Revista } \\
\text { Científica da Faculdade } \\
\text { Antonio Meneghetti }\end{array}$ & 24466298 & $\begin{array}{l}\text { Caderno Especial de } \\
\text { Ontopsicologia - } \\
\text { Iniciação Científica do } \\
\text { Curso de Bacharelado em } \\
\text { Ontopsicologia, p. } 180190\end{array}$ & 2016 \\
\hline 94 & $\begin{array}{l}\text { Gustavo dos Santos } \\
\text { Oliveira }\end{array}$ & $\begin{array}{l}\text { O pensamento de São } \\
\text { Tomás de Aquino e a } \\
\text { Ontopsicologia: uma } \\
\text { breve elucidação } \\
\text { acerca do } \\
\text { conceito de intelecto }\end{array}$ & $\begin{array}{l}\text { Saber Humano: Revista } \\
\text { Científica da Faculdade } \\
\text { Antonio Meneghetti }\end{array}$ & 24466298 & $\begin{array}{l}\text { Caderno Especial de } \\
\text { Ontopsicologia - } \\
\text { Iniciação Científica do } \\
\text { Curso de Bacharelado em } \\
\text { Ontopsicologia, p. 90-103 }\end{array}$ & 2016 \\
\hline 95 & Hans Egon Horstmann & A práxis na bottega & Saber Humano: Revista & 24466298 & Caderno Especial de & 2016 \\
\hline & & $\begin{array}{l}\text { renascentista à luz da } \\
\text { Ontopsicologia: uma } \\
\text { proposta prática }\end{array}$ & $\begin{array}{l}\text { Científica da Faculdade Antonio } \\
\text { Meneghetti }\end{array}$ & & $\begin{array}{l}\text { Ontopsicologia - } \\
\text { Iniciação Científica do } \\
\text { Curso de Bacharelado em } \\
\text { Ontopsicologia, p. } 104117\end{array}$ & \\
\hline
\end{tabular}


Saber Humano, ISSN 2446-6298, V. 9, n. 15, p. 186-423, jul./dez. 2019.

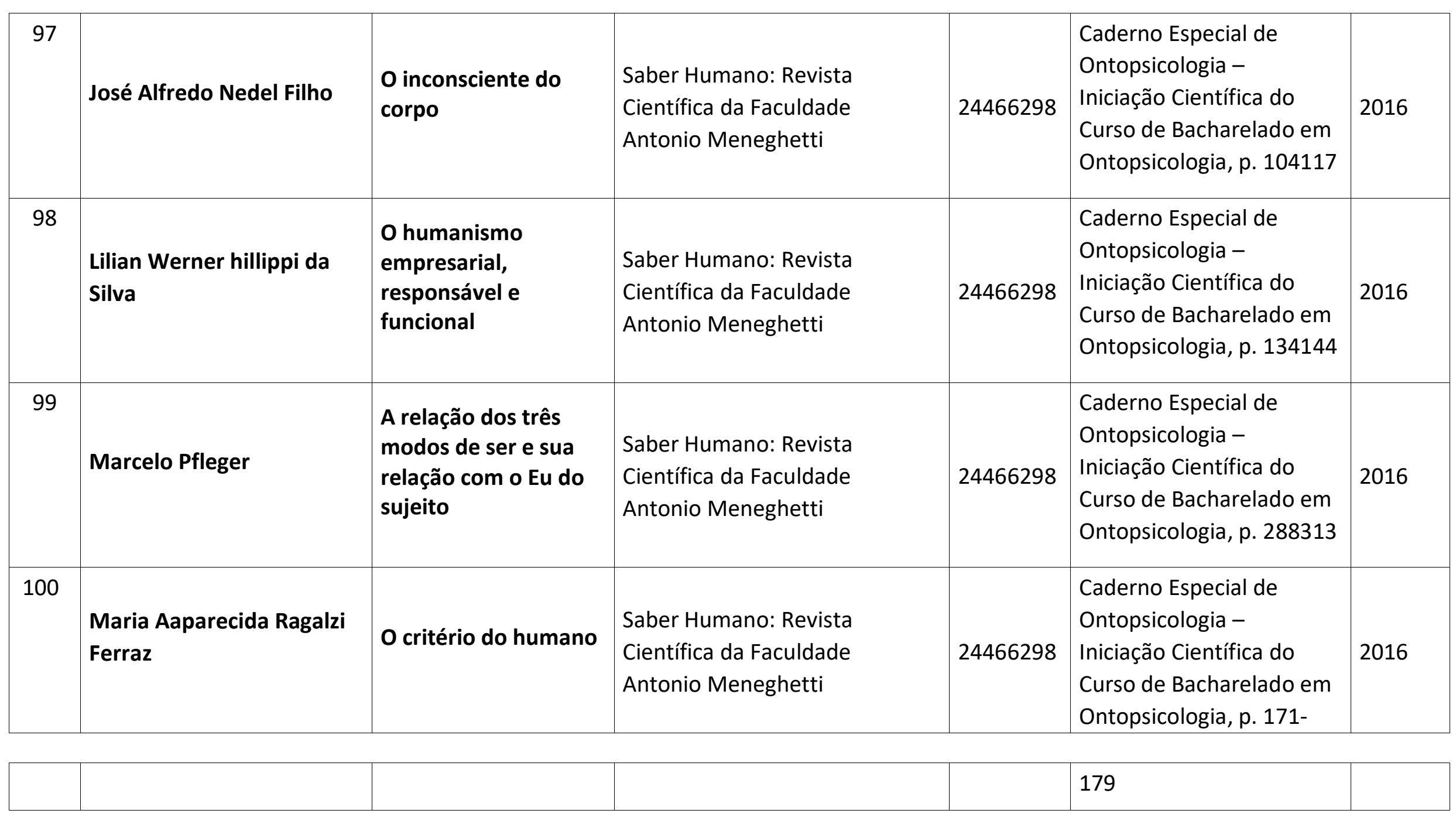


Saber Humano, ISSN 2446-6298, V. 9, n. 15, p. 186-423, jul./dez. 2019.

\begin{tabular}{|c|c|c|c|c|c|c|}
\hline 101 & Maria Adamoli & $\begin{array}{l}\text { O valor da Filosofia } \\
\text { nas Empresas }\end{array}$ & $\begin{array}{l}\text { Saber Humano: Revista } \\
\text { Científica da Faculdade } \\
\text { Antonio Meneghetti }\end{array}$ & 24466298 & $\begin{array}{l}\text { Caderno Especial de } \\
\text { Ontopsicologia - } \\
\text { Iniciação Científica do } \\
\text { Curso de Bacharelado em } \\
\text { Ontopsicologia, p. } 157170\end{array}$ & 2016 \\
\hline 102 & Mariana de Brito Araújo & $\begin{array}{l}\text { O uso da lógica e da } \\
\text { Ontopsicologia na } \\
\text { análise de uma } \\
\text { decisão judicial }\end{array}$ & $\begin{array}{l}\text { Saber Humano: Revista } \\
\text { Científica da Faculdade } \\
\text { Antonio Meneghetti }\end{array}$ & 24466298 & $\begin{array}{l}\text { Caderno Especial de } \\
\text { Ontopsicologia - } \\
\text { Iniciação Científica do } \\
\text { Curso de Bacharelado em } \\
\text { Ontopsicologia, p. } 180201\end{array}$ & 2016 \\
\hline 103 & Michael Fragomeni Penna & $\begin{array}{l}\text { Socialidade e } \\
\text { responsabilidade: } \\
\text { valores da Cultura } \\
\text { Humanista no } \\
\text { contexto da Orquestra } \\
\text { Jovem } \\
\text { Recanto Maestro }\end{array}$ & $\begin{array}{l}\text { Saber Humano: Revista } \\
\text { Científica da Faculdade } \\
\text { Antonio Meneghetti }\end{array}$ & 24466298 & $\begin{array}{l}\text { Caderno Especial de } \\
\text { Ontopsicologia - } \\
\text { Iniciação Científica do } \\
\text { Curso de Bacharelado em } \\
\text { Ontopsicologia, p. } 278287\end{array}$ & 2016 \\
\hline 104 & $\begin{array}{l}\text { Patrícia Gabriela Bilha } \\
\text { Salles }\end{array}$ & $\begin{array}{l}\text { Formação Humanista } \\
\text { Ontopsicológica de } \\
\text { Jovens }\end{array}$ & $\begin{array}{l}\text { Saber Humano: Revista } \\
\text { Científica da Faculdade } \\
\text { Antonio Meneghetti }\end{array}$ & 24466298 & $\begin{array}{l}\text { Caderno Especial de } \\
\text { Ontopsicologia - } \\
\text { Iniciação Científica do } \\
\text { Curso de Bacharelado em } \\
\text { Ontopsicologia, p. } 207217\end{array}$ & 2016 \\
\hline 105 & Rosane Maria Neves & Identidade e valores & Saber Humano: Revista & 24466298 & Caderno Especial de & 2016 \\
\hline
\end{tabular}


Saber Humano, ISSN 2446-6298, V. 9, n. 15, p. 186-423, jul./dez. 2019.

\begin{tabular}{|c|c|c|c|c|c|c|}
\hline & & $\begin{array}{l}\text { do Humanismo } \\
\text { Perene: critérios para } \\
\text { a exatidão do } \\
\text { operador social }\end{array}$ & $\begin{array}{l}\text { Científica da Faculdade Antonio } \\
\text { Meneghetti }\end{array}$ & & $\begin{array}{l}\text { Ontopsicologia - } \\
\text { Iniciação Científica do } \\
\text { Curso de Bacharelado em } \\
\text { Ontopsicologia, p. } 314331\end{array}$ & \\
\hline 106 & Rosângela Alves Nabarros & $\begin{array}{l}\text { Modelo de } \\
\text { treinamento das } \\
\text { Bottegas } \\
\text { Renascentistas } \\
\text { utilizado na empresa } \\
\text { para a formação de } \\
\text { jovens iniciantes no } \\
\text { trabalho }\end{array}$ & $\begin{array}{l}\text { Saber Humano: Revista } \\
\text { Científica da Faculdade } \\
\text { Antonio Meneghetti }\end{array}$ & 24466298 & $\begin{array}{l}\text { Caderno Especial de } \\
\text { Ontopsicologia - } \\
\text { Iniciação Científica do } \\
\text { Curso de Bacharelado em } \\
\text { Ontopsicologia, p. } 346359\end{array}$ & 2016 \\
\hline 107 & $\begin{array}{l}\text { Tereza Cristina Melo de } \\
\text { Brito Carvalho }\end{array}$ & $\begin{array}{l}\text { Desenvolvimento } \\
\text { Sustentável e o } \\
\text { Humanismo Perene }\end{array}$ & $\begin{array}{l}\text { Saber Humano: Revista } \\
\text { Científica da Faculdade } \\
\text { Antonio Meneghetti }\end{array}$ & 24466298 & $\begin{array}{l}\text { Caderno Especial de } \\
\text { Ontopsicologia - } \\
\text { Iniciação Científica do } \\
\text { Curso de Bacharelado em } \\
\text { Ontopsicologia, p. } 229249\end{array}$ & 2016 \\
\hline 108 & Vanessa Alves Nabarros & $\begin{array}{l}\text { Estética como ética: a } \\
\text { retomada do } \\
\text { Humanismo por meio } \\
\text { do belo }\end{array}$ & $\begin{array}{l}\text { Saber Humano: Revista } \\
\text { Científica da Faculdade } \\
\text { Antonio Meneghetti }\end{array}$ & 24466298 & $\begin{array}{l}\text { Caderno Especial de } \\
\text { Ontopsicologia - } \\
\text { Iniciação Científica do } \\
\text { Curso de Bacharelado em } \\
\text { Ontopsicologia, p. } 250259\end{array}$ & 2016 \\
\hline 109 & $\begin{array}{l}\text { Carmen Ivanete } \\
\text { D`Agostini Spanhol Noemi }\end{array}$ & $\begin{array}{l}\text { Método } \\
\text { Ontopsicológico: }\end{array}$ & $\begin{array}{l}\text { Saber Humano: Revista } \\
\text { Científica da Faculdade }\end{array}$ & 24466298 & V.5 n.7/p. 53-69 & 2015 \\
\hline
\end{tabular}


Saber Humano, ISSN 2446-6298, V. 9, n. 15, p. 186-423, jul./dez. 2019.

\begin{tabular}{|l|l|l|l|l|l|}
\hline Boer & contribuições à & Antonio Meneghetti & & \\
\hline
\end{tabular}

\begin{tabular}{|c|c|c|c|c|c|c|}
\hline & & $\begin{array}{l}\text { formação continuada } \\
\text { na perspectiva de } \\
\text { professores do ensino } \\
\text { superior }\end{array}$ & & & & \\
\hline 110 & $\begin{array}{l}\text { Adriane Maria Moro } \\
\text { Mendes } \\
\text { Elisandro Elias Ubatuba }\end{array}$ & $\begin{array}{l}\text { Quem é o jovem } \\
\text { empreendedor que } \\
\text { estuda } \\
\text { Ontopsicologia }\end{array}$ & $\begin{array}{l}\text { Saber Humano: Revista } \\
\text { Científica da Faculdade } \\
\text { Antonio Meneghetti }\end{array}$ & 24466298 & V.5 n.7/p. 7-27 & 2015 \\
\hline 111 & $\begin{array}{l}\text { Viviane Elias Portela Estela } \\
\text { Maris Giordani }\end{array}$ & $\begin{array}{l}\text { Projeto flauta: } \\
\text { histórico, } \\
\text { fundamentos e } \\
\text { resultados }\end{array}$ & $\begin{array}{l}\text { Saber Humano: Revista } \\
\text { Científica da Faculdade } \\
\text { Antonio Meneghetti }\end{array}$ & 24466298 & V.5 n.7/p. $28-52$ & 2015 \\
\hline 112 & $\begin{array}{l}\text { João Francisco Dias Feltrin } \\
\text { Josemar Sidinei Soares }\end{array}$ & $\begin{array}{l}O \text { critério ético em } \\
\text { Aristóteles e } \\
\text { Meneghetti }\end{array}$ & $\begin{array}{l}\text { Saber Humano: Revista } \\
\text { Científica da Faculdade } \\
\text { Antonio Meneghetti }\end{array}$ & 24466298 & V.4 n.5/p. 36-54 & 2014 \\
\hline 113 & $\begin{array}{l}\text { Luísa Barcelos de Oliveira } \\
\text { Josiane Beatriz Piccin } \\
\text { Barbieri }\end{array}$ & $\begin{array}{l}\text { O nascimento do eu } \\
\text { na Psicoterapia de } \\
\text { Autenticação }\end{array}$ & $\begin{array}{l}\text { Saber Humano: Revista } \\
\text { Científica da Faculdade } \\
\text { Antonio Meneghetti }\end{array}$ & 24466298 & V.4 n.5/p. 55-66 & 2014 \\
\hline 114 & Alécio Vidor & $\begin{array}{l}\text { A objetividade da } \\
\text { subjetividade }\end{array}$ & $\begin{array}{l}\text { Saber Humano: Revista } \\
\text { Científica da Faculdade } \\
\text { Antonio Meneghetti }\end{array}$ & 24466298 & V.3 n.4/p. 37-45 & 2013 \\
\hline
\end{tabular}


Saber Humano, ISSN 2446-6298, V. 9, n. 15, p. 186-423, jul./dez. 2019.

\begin{tabular}{|c|c|c|c|c|c|c|}
\hline 115 & $\begin{array}{l}\text { Patrícia Wazlawick } \\
\text { Sandra Regina Concatto }\end{array}$ & $\begin{array}{l}\text { Arte e Cultura } \\
\text { Humanista como } \\
\text { premissas para a } \\
\text { educação e formação } \\
\text { humana }\end{array}$ & $\begin{array}{l}\text { Saber Humano: Revista } \\
\text { Científica da Faculdade } \\
\text { Antonio Meneghetti }\end{array}$ & 24466298 & V.3 n.4/p. 14-31 & 2013 \\
\hline 116 & Patrícia Wazlawick & L'uomo è in grado di & Revista Nuova Ontopsicologia & & V.1/p. 88-101 & 2013 \\
\hline 117 & $\begin{array}{l}\text { Érico de Lima Azevedo } \\
\text { Josiane Barbieri }\end{array}$ & $\begin{array}{l}\text { Por que } \\
\text { Ontopsicologia? }\end{array}$ & $\begin{array}{l}\text { Saber Humano: Revista } \\
\text { Científica da Faculdade } \\
\text { Antonio Meneghetti }\end{array}$ & 24466298 & V.3 n.4/p. 8-13 & 2013 \\
\hline 119 & Ângelo Accorsi Moreira & $\begin{array}{l}\text { Considerações sobre a } \\
\text { Psicotea: abertura de } \\
\text { um novo olhar sobre o } \\
\text { teatro e sua função no } \\
\text { desenvolvimento do } \\
\text { ser humano }\end{array}$ & $\begin{array}{l}\text { Saber Humano: Revista } \\
\text { Científica da Faculdade } \\
\text { Antonio Meneghetti }\end{array}$ & 24466298 & V.2 n.3/p. $46-59$ & 2012 \\
\hline
\end{tabular}


Saber Humano, ISSN 2446-6298, V. 9, n. 15, p. 186-423, jul./dez. 2019.

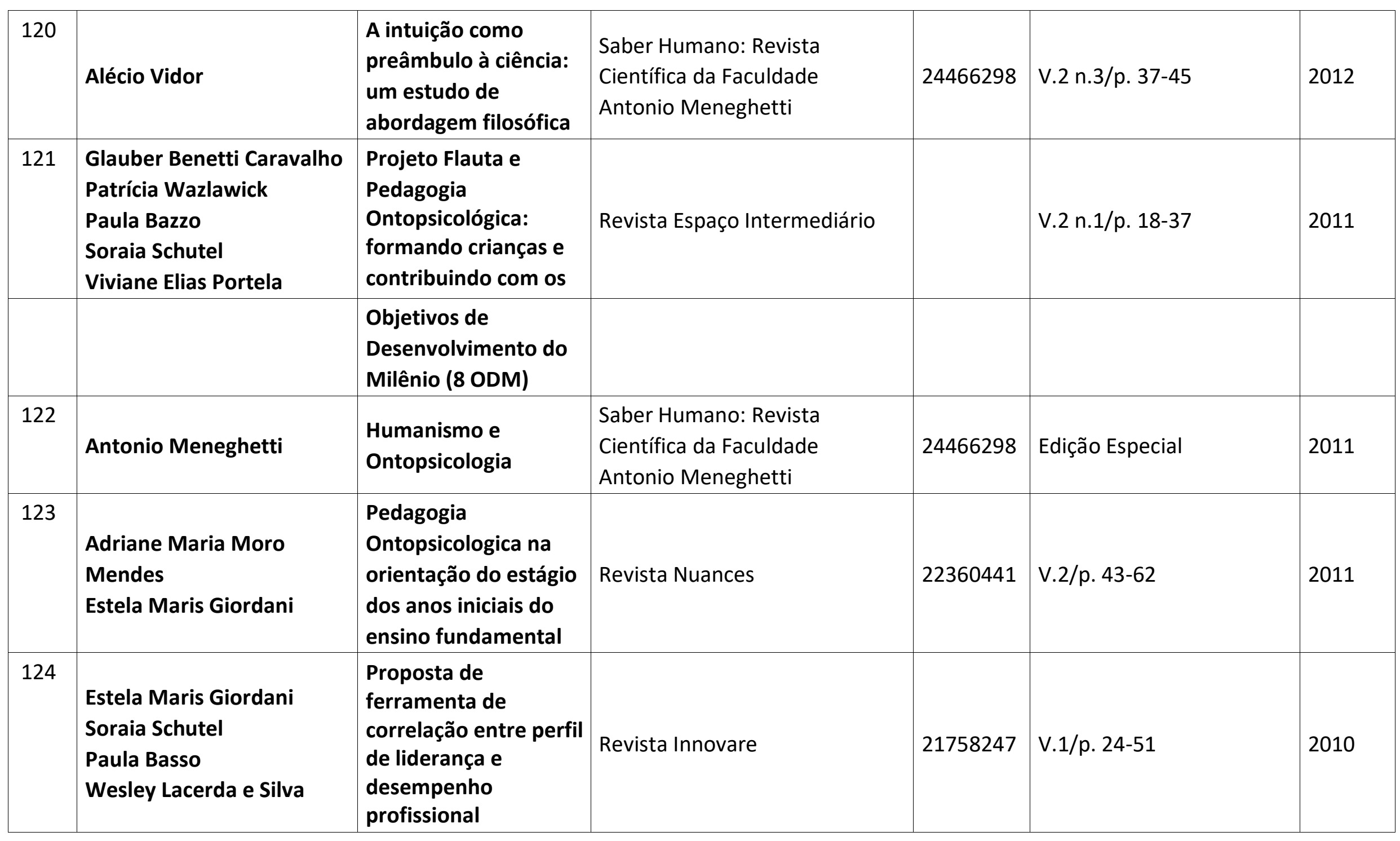




\begin{tabular}{|l|l|l|l|l|l|l|}
\hline 125 & Alécio Vidor & $\begin{array}{l}\text { Ser pessoa e ser } \\
\text { empresário }\end{array}$ & Revista Perspectiva da URI & 01012908 & V.62 \\
\hline
\end{tabular}

\section{TRABALHOS APRESENTADOS E PUBLICADOS EM ANAIS DE CONGRESSOS NACIONAIS E INTERNACIONAIS}

\begin{tabular}{|c|l|l|l|l|l|}
\hline № & \multicolumn{1}{|c|}{ Autor } & \multicolumn{1}{|c|}{ Título do Artigo } & \multicolumn{1}{c|}{ Congresso } & \multicolumn{1}{c|}{ ISBN } & \multicolumn{1}{c|}{ Páginas } \\
\hline 1 & $\begin{array}{l}\text { Ricardo Schaefer } \\
\text { Patrícia Wazlawick }\end{array}$ & $\begin{array}{l}\text { Development of the } \\
\text { Enterpreneurial } \\
\text { Mindset and Behavior } \\
\text { by the Means of na } \\
\text { Entrepreneurial } \\
\text { Education }\end{array}$ & $\begin{array}{l}\text { XVI European Congress of } \\
\text { Psycology, 2019, Moscow, Russia }\end{array}$ & $\begin{array}{l}\text { Book of Abstracts } \\
\text { European } \\
\text { Federation of } \\
\text { Psychologist's } \\
\text { Associations } \\
\text { Lomonosov Moscow } \\
\text { State University, } \\
\text { Faculty of } \\
\text { Psychology. } \\
\text { Moscow: Moscow } \\
\text { University Press }\end{array}$ \\
\hline
\end{tabular}


Saber Humano, ISSN 2446-6298, V. 9, n. 15, p. 186-423, jul./dez. 2019.

\begin{tabular}{|c|l|l|l|l|}
\hline 2 & $\begin{array}{l}\text { Bruno Fleck da Silva } \\
\text { Tommy Akira Goto } \\
\text { Patrícia Wazlawick }\end{array}$ & $\begin{array}{l}\text { A ontologia do mjundo } \\
\text { da vida e o nexo } \\
\text { ontológico: por uma } \\
\text { cultura científica } \\
\text { ontohumanista }\end{array}$ & $\begin{array}{l}\text { I Colóquio Internacional } \\
\text { Fenomenologia \& Cultura, } \\
\text { Covilhã, Portugal }\end{array}$ & $\begin{array}{l}\text { Vária / } \\
\text { Apresentação, } \\
\text { Programa, } \\
\text { Convidados, } \\
\text { Resumos, Notas do I } \\
\text { Colóquio } \\
\text { Internacional } \\
\text { Fenomenologia \& } \\
\text { Cultura. Covilhã, } \\
\text { Portugal: Editora da } \\
\text { Universidade da }\end{array}$ \\
\hline
\end{tabular}

\begin{tabular}{|c|c|c|c|c|c|}
\hline & & & & Beira Interior & \\
\hline 3 & $\begin{array}{l}\text { Annalisa Cangelosi } \\
\text { Fernanda Goulart Martins } \\
\text { Juliane Neves Fiorezi }\end{array}$ & $\begin{array}{l}\text { Relato de uma } \\
\text { experiência pedagógica: } \\
\text { a tríade ser-saber-fazer } \\
\text { aplicada à prática de } \\
\text { ensino-aprendizagem }\end{array}$ & 71a Reunião Anual da SBPC & No prelo & 2019 \\
\hline 4 & $\begin{array}{l}\text { Patrícia Wazlawick } \\
\text { Ricardo Schaefer } \\
\text { Victoria Dmitrieva } \\
\text { Tatiana Vereitnova } \\
\text { Elena Volkova }\end{array}$ & $\begin{array}{l}\text { Socialização Positiva de } \\
\text { jovens em condições de } \\
\text { transitividade social e } \\
\text { econômica: aplicação } \\
\text { prática da Pedagogia } \\
\text { Ontopsicológica }\end{array}$ & 71aㅡ Reunião Anual da SBPC & No prelo & 2019 \\
\hline
\end{tabular}


Saber Humano, ISSN 2446-6298, V. 9, n. 15, p. 186-423, jul./dez. 2019.

\begin{tabular}{|c|l|l|l|l|l|}
\hline 5 & Almir Foletto & $\begin{array}{l}\text { Responsabilidade e o } \\
\text { dever da pessoa }\end{array}$ & $\begin{array}{l}\text { III Congresso Uma Nova } \\
\text { Pedagogia para a Sociedade } \\
\text { Futura }\end{array}$ & $978-85-68901-15-1$ & p. 8-9 \\
\hline 6 & Victoria Dmitrieva & $\begin{array}{l}\text { O critério fundamental } \\
\text { da pedagogia }\end{array}$ & $\begin{array}{l}\text { III Congresso Uma Nova } \\
\text { Pedagogia para a Sociedade } \\
\text { Futura }\end{array}$ & $978-85-68901-15-1$ & p. 10-11 \\
\hline 7 & Helena Biasotto & $\begin{array}{l}\text { A formação superior do } \\
\text { jovem }\end{array}$ & $\begin{array}{l}\text { III Congresso Uma Nova } \\
\text { Pedagogia para a Sociedade } \\
\text { Futura }\end{array}$ & $978-85-68901-15-1$ & p. 12-13 \\
\hline 8 & Helena Biasotto & $\begin{array}{l}\text { A formação superior na } \\
\text { Antonio Meneghetti } \\
\text { Faculdade: } \\
\text { contribuição e } \\
\text { resultados sobre a }\end{array}$ & $\begin{array}{l}\text { III Congresso Uma Nova } \\
\text { Pedagogia para a Sociedade } \\
\text { Futura }\end{array}$ & $978-85-68901-15-1$ & p. 17-22 \\
\hline
\end{tabular}

\begin{tabular}{|c|l|l|l|l|l|}
\hline & $\begin{array}{l}\text { autóctise histórica dos } \\
\text { egressos }\end{array}$ & & & \\
\hline 9 & Rasa Balte Balciuniene & $\begin{array}{l}\text { The problem of } \\
\text { creativity: what images } \\
\text { do young people } \\
\text { choose? }\end{array}$ & $\begin{array}{l}\text { III Congresso Uma Nova } \\
\text { Pedagogia para a Sociedade } \\
\text { Futura }\end{array}$ & $978-85-68901-15-1$ & p. 23-27 \\
\hline
\end{tabular}


Saber Humano, ISSN 2446-6298, V. 9, n. 15, p. 186-423, jul./dez. 2019.

\begin{tabular}{|c|c|c|c|c|c|c|}
\hline 10 & $\begin{array}{l}\text { Karine Cristina Scherer } \\
\text { Patrícia Wazlawick }\end{array}$ & $\begin{array}{l}\text { O desenvolvimento da } \\
\text { Forma Mentis dos } \\
\text { alunos de } \\
\text { administração } \\
\text { fundamentada em } \\
\text { valores humanistas }\end{array}$ & $\begin{array}{l}\text { III Congresso Uma Nova } \\
\text { Pedagogia para a Sociedade } \\
\text { Futura }\end{array}$ & $978-85-68901-15-1$ & p. 47-51 & 2018 \\
\hline 11 & Marisa Elisabete da Silva & $\begin{array}{l}\text { Experiências } \\
\text { profissionais com a } \\
\text { Pedagogia } \\
\text { Ontopsicológica na } \\
\text { Educação Infantil }\end{array}$ & $\begin{array}{l}\text { III Congresso Uma Nova } \\
\text { Pedagogia para a Sociedade } \\
\text { Futura }\end{array}$ & $978-85-68901-15-1$ & p. 61-67 & 2018 \\
\hline 12 & $\begin{array}{l}\text { Arianna Alejandra } \\
\text { Gutierrez } \\
\text { Julian Pastor Ramos }\end{array}$ & $\begin{array}{l}\text { Encontro entre o "EI } \\
\text { Sistema" e a Pedagogía } \\
\text { Ontopsicologica }\end{array}$ & $\begin{array}{l}\text { III Congresso Uma Nova } \\
\text { Pedagogia para a Sociedade } \\
\text { Futura }\end{array}$ & $978-85-68901-15-1$ & p. 68-76 & 2018 \\
\hline 13 & Mireila Vieira Fagundes & $\begin{array}{l}\text { O crescimento através } \\
\text { do protagonismo no } \\
\text { trabalho }\end{array}$ & $\begin{array}{l}\text { Ill Congresso Uma Nova } \\
\text { Pedagogia para a Sociedade } \\
\text { Futura }\end{array}$ & $978-85-68901-15-1$ & p. $77-80$ & 2018 \\
\hline 14 & Patrícia Wazlawick & $\begin{array}{l}\text { Jovens no mundo: } \\
\text { atividades de formação } \\
\text { internacional do } \\
\text { Bacharelado em }\end{array}$ & $\begin{array}{l}\text { III Congresso Uma Nova } \\
\text { Pedagogia para a Sociedade } \\
\text { Futura }\end{array}$ & $978-85-68901-15-1$ & p. $215-238$ & 2018 \\
\hline
\end{tabular}

\begin{tabular}{|l|l|l|l|l|}
\hline & $\begin{array}{l}\text { Ontopsicologia da } \\
\text { Faculdade Antonio } \\
\text { Meneghetti }\end{array}$ & & & \\
\hline
\end{tabular}


Saber Humano, ISSN 2446-6298, V. 9, n. 15, p. 186-423, jul./dez. 2019.

\begin{tabular}{|c|c|c|c|c|c|c|}
\hline 15 & Patrícia Wazlawick & $\begin{array}{l}\text { Jovens \& ODS: ações e } \\
\text { resultados para a } \\
\text { cidadania global no } \\
\text { contexto social local da } \\
\text { 4a Colônia de } \\
\text { Imigração Italiana no } \\
\text { Rio Grande do Sul }\end{array}$ & $\begin{array}{l}\text { III Congresso Uma Nova } \\
\text { Pedagogia para a Sociedade } \\
\text { Futura }\end{array}$ & $978-85-68901-15-1$ & p. 204-214 & 2018 \\
\hline 16 & $\begin{array}{l}\text { Monique de Oliveira } \\
\text { Gularte } \\
\text { Márcia Regina Marchezan }\end{array}$ & $\begin{array}{l}\text { Projeto Mais Árvores e } \\
\text { Menos Poluição }\end{array}$ & $\begin{array}{l}\text { III Congresso Uma Nova } \\
\text { Pedagogia para a Sociedade } \\
\text { Futura }\end{array}$ & $978-85-68901-15-1$ & p. $81-87$ & 2018 \\
\hline 17 & Jean Missio Marzari & $\begin{array}{l}\text { Aulas Atitude } \\
\text { Empreendedora: } \\
\text { Jovem e Tecnologia }\end{array}$ & $\begin{array}{l}\text { III Congresso Uma Nova } \\
\text { Pedagogia para a Sociedade } \\
\text { Futura }\end{array}$ & $978-85-68901-15-1$ & p. $88-90$ & 2018 \\
\hline 18 & $\begin{array}{l}\text { William André Mazzardo } \\
\text { Dias } \\
\text { Jaciane Pretzel } \\
\text { Sheila Fernanda Wendt } \\
\text { Marlise llóis Flores }\end{array}$ & $\begin{array}{l}\text { O papel do líder na } \\
\text { gestão da equipe: o } \\
\text { desafio de motivar e } \\
\text { manter-se motivado }\end{array}$ & $\begin{array}{l}\text { III Congresso Uma Nova } \\
\text { Pedagogia para a Sociedade } \\
\text { Futura }\end{array}$ & $978-85-68901-15-1$ & p. $249-253$ & 2018 \\
\hline 19 & Rosane Leal da Silva & $\begin{array}{l}\text { Premissas para o êxito } \\
\text { do teletrabalho: a visão } \\
\text { do líder e o } \\
\text { protagonismo } \\
\text { responsável do } \\
\text { trabalhador }\end{array}$ & $\begin{array}{l}\text { III Congresso Uma Nova } \\
\text { Pedagogia para a Sociedade } \\
\text { Futura }\end{array}$ & 978-85-68901-15-1 & p. $271-278$ & 2018 \\
\hline 20 & José Luiz Richetti & O trabalho e seu valor & III Congresso Uma Nova & $978-85-68901-15-1$ & p. $262-270$ & 2018 \\
\hline
\end{tabular}


Saber Humano, ISSN 2446-6298, V. 9, n. 15, p. 186-423, jul./dez. 2019.

\begin{tabular}{|c|c|c|c|c|c|c|}
\hline & & ontológico & $\begin{array}{l}\text { Pedagogia para a Sociedade } \\
\text { Futura }\end{array}$ & & & \\
\hline 21 & Lygia de Almeida Marques & $\begin{array}{l}\text { A Arquitetura como } \\
\text { ambiente humano na } \\
\text { puberdade: lugar de } \\
\text { pedagogia para formar } \\
\text { o homem-pessoa na } \\
\text { função social }\end{array}$ & $\begin{array}{l}\text { III Congresso Uma Nova } \\
\text { Pedagogia para a Sociedade } \\
\text { Futura }\end{array}$ & $978-85-68901-15-1$ & p. $290-299$ & 2018 \\
\hline 22 & Claudiane Weber & $\begin{array}{l}\text { As imagens das mídias } \\
\text { sociais e o seu uso na } \\
\text { vida cotidiana: } \\
\text { responsabilidade e } \\
\text { dever da pessoa }\end{array}$ & $\begin{array}{l}\text { III Congresso Uma Nova } \\
\text { Pedagogia para a Sociedade } \\
\text { Futura }\end{array}$ & $978-85-68901-15-1$ & p. $317-325$ & 2018 \\
\hline 23 & Rosane Maria Neves & $\begin{array}{l}\text { Administração de si } \\
\text { com proporção } \\
\text { estética }\end{array}$ & $\begin{array}{l}\text { III Congresso Uma Nova } \\
\text { Pedagogia para a Sociedade } \\
\text { Futura }\end{array}$ & $978-85-68901-15-1$ & p. $326-337$ & 2018 \\
\hline 24 & $\begin{array}{l}\text { Luiz Henrique Dutra } \\
\text { Tamiris Alessandra } \\
\text { Gervasoni }\end{array}$ & $\begin{array}{l}\text { Direitos humanos em } \\
\text { perspectiva crítica e a } \\
\text { responsabilidade do } \\
\text { indivíduo na } \\
\text { concretização de } \\
\text { direitos humanos para } \\
\text { transformação de uma } \\
\text { nova sociedade }\end{array}$ & $\begin{array}{l}\text { III Congresso Uma Nova } \\
\text { Pedagogia para a Sociedade } \\
\text { Futura }\end{array}$ & $978-85-68901-15-1$ & p. $342-348$ & 2018 \\
\hline 25 & Viviane Machado Carllosso & $\begin{array}{l}\text { Ensaio reflexivo sobre a } \\
\text { Felicidade }\end{array}$ & $\begin{array}{l}\text { III Congresso Uma Nova } \\
\text { Pedagogia para a Sociedade }\end{array}$ & $978-85-68901-15-1$ & p. 349-353 & 2018 \\
\hline
\end{tabular}


Saber Humano, ISSN 2446-6298, V. 9, n. 15, p. 186-423, jul./dez. 2019.

\begin{tabular}{|l|l|l|l|l|l|}
\hline & & & Futura & & \\
\hline 26 & Patricia Michelotti & Escola da Vida: o início & Ill Congresso Uma Nova & $978-85-68901-15-1$ & p. 354-362 \\
\hline
\end{tabular}

\begin{tabular}{|c|c|c|c|c|c|c|}
\hline & & $\begin{array}{l}\text { de uma trajetória de } \\
\text { valor }\end{array}$ & $\begin{array}{l}\text { Pedagogia para a Sociedade } \\
\text { Futura }\end{array}$ & & & \\
\hline 27 & Ana Marli Bulegon & $\begin{array}{l}\text { Influência da } \\
\text { participação dos } \\
\text { estudantes, no jogo de } \\
\text { papéis, segundo a } \\
\text { Psicotea, para a } \\
\text { aprendizagem dos } \\
\text { conceitos de } \\
\text { matemática financeira }\end{array}$ & $\begin{array}{l}\text { Ill Congresso Uma Nova } \\
\text { Pedagogia para a Sociedade } \\
\text { Futura }\end{array}$ & $978-85-68901-15-1$ & p. $372-380$ & 2018 \\
\hline 28 & Liane Martins Bernardes & $\begin{array}{l}\text { O ser esclarecido em } \\
\text { busca de sua } \\
\text { autonomia }\end{array}$ & $\begin{array}{l}\text { III Congresso Uma Nova } \\
\text { Pedagogia para a Sociedade } \\
\text { Futura }\end{array}$ & $978-85-68901-15-1$ & p. $430-436$ & 2018 \\
\hline 29 & Darla Vargas & $\begin{array}{l}\text { O trabalho infantil: } \\
\text { exploração ou estímulo } \\
\text { à autonomia }\end{array}$ & $\begin{array}{l}\text { III Congresso Uma Nova } \\
\text { Pedagogia para a Sociedade } \\
\text { Futura }\end{array}$ & $978-85-68901-15-1$ & p. $437-442$ & 2018 \\
\hline 30 & José Alfredo Nedel Filho & $\begin{array}{l}\text { O potencial do cérebro } \\
\text { visceral }\end{array}$ & $\begin{array}{l}\text { III Congresso Uma Nova } \\
\text { Pedagogia para a Sociedade } \\
\text { Futura }\end{array}$ & 978-85-68901-15-1 & p. $411-4720$ & 2018 \\
\hline
\end{tabular}


Saber Humano, ISSN 2446-6298, V. 9, n. 15, p. 186-423, jul./dez. 2019.

\begin{tabular}{|l|l|l|l|l|l|l|}
\hline 31 & Vera Lúcia Rodegheri & $\begin{array}{l}\text { O Residence } \\
\text { Ontopsicológico de } \\
\text { Autenticação: } \\
\text { formação da pessoa e } \\
\text { do líder }\end{array}$ & $\begin{array}{l}\text { III Congresso Uma Nova } \\
\text { Pedagogia para a Sociedade } \\
\text { Futura }\end{array}$ & $978-85-68901-15-1$ & p. 421-429 & 2018 \\
\hline 32 & $\begin{array}{l}\text { Estela Maris Giordani } \\
\text { Elisiana Maria Cassol } \\
\text { Tanscheitt } \\
\text { Darla Vargas }\end{array}$ & $\begin{array}{l}\text { Pedagogia } \\
\text { Ontopsicológica nas } \\
\text { oficinas de } \\
\text { aprendizagens do }\end{array}$ & $\begin{array}{l}\text { Pedagogia para a Sociedade } \\
\text { Futura }\end{array}$ & $978-85-68901-15-1$ & p. 443-451 & 2018 \\
\hline
\end{tabular}

\begin{tabular}{|c|c|c|c|c|c|c|}
\hline & & Projeto CriAre & & & & \\
\hline 33 & $\begin{array}{l}\text { Tatiane Peixoto Isaia } \\
\text { Fátima Osmar Burin } \\
\text { Jacieli Vedovato Dalla Nora } \\
\text { Glauber Beneti Carvalho } \\
\text { Ângelo Accorsi Moreira }\end{array}$ & $\begin{array}{l}\text { A Metodologia da } \\
\text { Impare Educação: a } \\
\text { utilização do Ambiente } \\
\text { Virtual de } \\
\text { Aprendizagem em prol } \\
\text { da formação docente } \\
\text { continuada para a } \\
\text { plena implementação } \\
\text { da Base Nacional } \\
\text { Comum Curricular }\end{array}$ & $\begin{array}{l}\text { III Congresso Uma Nova } \\
\text { Pedagogia para a Sociedade } \\
\text { Futura }\end{array}$ & $978-85-68901-15-1$ & p. 525-535 & 2018 \\
\hline 34 & $\begin{array}{l}\text { Adriana dos Reis Emygdio } \\
\text { da Silva }\end{array}$ & $\begin{array}{l}\text { Projeto Ontoletras: a } \\
\text { leitura como pedagogia } \\
\text { de autenticação para } \\
\text { jovens de } 18 \text { a } 24 \text { anos }\end{array}$ & $\begin{array}{l}\text { III Congresso Uma Nova } \\
\text { Pedagogia para a Sociedade } \\
\text { Futura }\end{array}$ & $978-85-68901-15-1$ & p. $452-459$ & 2018 \\
\hline
\end{tabular}


Saber Humano, ISSN 2446-6298, V. 9, n. 15, p. 186-423, jul./dez. 2019.

\begin{tabular}{|c|c|c|c|c|c|c|}
\hline 35 & Glauciane Gonçalves & $\begin{array}{l}\text { Protagonismo } \\
\text { responsável ao } \\
\text { trabalho pelo método } \\
\text { ontopsicológico }\end{array}$ & $\begin{array}{l}\text { III Congresso Uma Nova } \\
\text { Pedagogia para a Sociedade } \\
\text { Futura }\end{array}$ & $978-85-68901-15-1$ & p. $460-466$ & 2018 \\
\hline 36 & Consuelo Campos & $\begin{array}{l}\text { Uma experiência de } \\
\text { formação para o uso do } \\
\text { critério organísmico no } \\
\text { jovem }\end{array}$ & $\begin{array}{l}\text { III Congresso Uma Nova } \\
\text { Pedagogia para a Sociedade } \\
\text { Futura }\end{array}$ & $978-85-68901-15-1$ & p. 489-499 & 2018 \\
\hline \multirow[t]{2}{*}{37} & $\begin{array}{l}\text { Juliana Fick } \\
\text { Ana Carolina Marzzari } \\
\text { Délis Stona } \\
\text { Annalisa Cangelosi }\end{array}$ & $\begin{array}{l}\text { A importância de uma } \\
\text { viagem pedagógica } \\
\text { internacional: Primeira } \\
\text { Semana Acadêmica }\end{array}$ & $\begin{array}{l}\text { III Congresso Uma Nova } \\
\text { Pedagogia para a Sociedade } \\
\text { Futura }\end{array}$ & $978-85-68901-15-1$ & p. $518-524$ & 2018 \\
\hline & & $\begin{array}{l}\text { Internacional do } \\
\text { Bacharelado em } \\
\text { Ontopsicologia da } \\
\text { Antonio Meneghetti } \\
\text { Faculdade }\end{array}$ & & & & \\
\hline 38 & Mariana Brito Araújo & $\begin{array}{l}\text { Aproximação } \\
\text { Pedagógica à } \\
\text { Ontopsicologia - Um } \\
\text { exemplo - Mateus e o } \\
\text { Anjo de Caravaggio }\end{array}$ & $\begin{array}{l}\text { III Congresso Uma Nova } \\
\text { Pedagogia para a Sociedade } \\
\text { Futura }\end{array}$ & $978-85-68901-15-1$ & p. $536-543$ & 2018 \\
\hline
\end{tabular}


Saber Humano, ISSN 2446-6298, V. 9, n. 15, p. 186-423, jul./dez. 2019.

\begin{tabular}{|c|c|c|c|c|c|c|}
\hline 39 & Bruno Fleck da Silva & $\begin{array}{l}\text { Aspectos filosóficos de } \\
\text { uma pedagogia da } \\
\text { autenticidade operante } \\
\text { em Antonio } \\
\text { Meneghetti }\end{array}$ & $\begin{array}{l}\text { III Congresso Uma Nova } \\
\text { Pedagogia para a Sociedade } \\
\text { Futura }\end{array}$ & $978-85-68901-15-1$ & p. $544-550$ & 2018 \\
\hline 40 & Lygia de Almeida Marques & $\begin{array}{l}\text { Contribuições da Escola } \\
\text { Ontopsicológica ao } \\
\text { processo de projeto de } \\
\text { Arquitetura de } \\
\text { Interiores }\end{array}$ & $\begin{array}{l}\text { III Congresso Uma Nova } \\
\text { Pedagogia para a Sociedade } \\
\text { Futura }\end{array}$ & $978-85-68901-15-1$ & p. $551-565$ & 2018 \\
\hline 41 & Karen Machado Duarte & $\begin{array}{l}\text { Marco jurídico do } \\
\text { direito à educação e a } \\
\text { pedagogia à luz da } \\
\text { ciência ontopsicológica: } \\
\text { o papel do } \\
\text { protagonismo } \\
\text { responsável }\end{array}$ & $\begin{array}{l}\text { III Congresso Uma Nova } \\
\text { Pedagogia para a Sociedade } \\
\text { Futura }\end{array}$ & $978-85-68901-15-1$ & p. $602-607$ & 2018 \\
\hline \multirow[t]{2}{*}{42} & Liliane de Araujo Mancebo & Mundo Feminino: 0 & III Congresso Uma Nova & $978-85-68901-15-1$ & p. $617-624$ & 2018 \\
\hline & & $\begin{array}{l}\text { desafio de viver para } \\
\text { ser o próprio valor }\end{array}$ & $\begin{array}{l}\text { Pedagogia para a Sociedade } \\
\text { Futura }\end{array}$ & & & \\
\hline 43 & $\begin{array}{l}\text { Helena Biasotto } \\
\text { Tainara Groff Schumacher }\end{array}$ & $\begin{array}{l}\text { O acompanhamento } \\
\text { dos egressos e a } \\
\text { regulação recente do } \\
\text { Ensino Superior no } \\
\text { Brasil }\end{array}$ & $\begin{array}{l}\text { III Congresso Uma Nova } \\
\text { Pedagogia para a Sociedade } \\
\text { Futura }\end{array}$ & $978-85-68901-15-1$ & p. $625-631$ & 2018 \\
\hline
\end{tabular}


Saber Humano, ISSN 2446-6298, V. 9, n. 15, p. 186-423, jul./dez. 2019.

\begin{tabular}{|c|c|c|c|c|c|c|}
\hline 44 & Ricardo Henrique Klüsener & $\begin{array}{l}\text { Projeto OIKOS: hortas e } \\
\text { a humanização de } \\
\text { patios escolares na } \\
\text { Quarta Colônia - RS }\end{array}$ & $\begin{array}{l}\text { III Congresso Uma Nova } \\
\text { Pedagogia para a Sociedade } \\
\text { Futura }\end{array}$ & $978-85-68901-15-1$ & p. 632-639 & 2018 \\
\hline 45 & Egídio Antônio Lasta & $\begin{array}{l}\text { Repensando o } \\
\text { Educador }\end{array}$ & $\begin{array}{l}\text { III Congresso Uma Nova } \\
\text { Pedagogia para a Sociedade } \\
\text { Futura }\end{array}$ & $978-85-68901-15-1$ & p. $640-646$ & 2018 \\
\hline 46 & Cleoci Werle Rockenbach & $\begin{array}{l}\text { São Francisco de Assis: } \\
\text { um exemplo dos } \\
\text { valores perenes que } \\
\text { tornam o homem mais } \\
\text { humano }\end{array}$ & $\begin{array}{l}\text { III Congresso Uma Nova } \\
\text { Pedagogia para a Sociedade } \\
\text { Futura }\end{array}$ & $978-85-68901-15-1$ & p. 647-654 & 2018 \\
\hline 47 & $\begin{array}{l}\text { Samuel Augusto Carminatti } \\
\text { Vitor Francisco Dalla Corte }\end{array}$ & $\begin{array}{l}\text { Sentido do Trabalho } \\
\text { para Jovens e a Cultura } \\
\text { Humanista como } \\
\text { pressupostos para } \\
\text { Responsabilidade e } \\
\text { Estilo de Vida }\end{array}$ & $\begin{array}{l}\text { III Congresso Uma Nova } \\
\text { Pedagogia para a Sociedade } \\
\text { Futura }\end{array}$ & $978-85-68901-15-1$ & p. $655-664$ & 2018 \\
\hline 48 & $\begin{array}{l}\text { Raquel de Melo Ferreira } \\
\text { Ricardo Henrique Klüsener } \\
\text { Tainara Bruna Friedrich }\end{array}$ & $\begin{array}{l}\text { Aprendendo sobre } \\
\text { reciclagem através do } \\
\text { lúdico }\end{array}$ & $\begin{array}{l}\text { III Congresso Uma Nova } \\
\text { Pedagogia para a Sociedade } \\
\text { Futura }\end{array}$ & $978-85-68901-15-1$ & p. $104-111$ & 2018 \\
\hline 49 & Estevão de Souza Silva & $\begin{array}{l}\text { As escolhas de } \\
\text { formação pessoal e } \\
\text { profissional de um } \\
\text { jovem protagonista } \\
\text { responsável }\end{array}$ & $\begin{array}{l}\text { III Congresso Uma Nova } \\
\text { Pedagogia para a Sociedade } \\
\text { Futura }\end{array}$ & $978-85-68901-15-1$ & p. $173-178$ & 2018 \\
\hline
\end{tabular}


Saber Humano, ISSN 2446-6298, V. 9, n. 15, p. 186-423, jul./dez. 2019.

\begin{tabular}{|c|c|c|c|c|c|c|}
\hline 50 & $\begin{array}{l}\text { Karine Cristina Scherer } \\
\text { Eliane A. Galvão dos Santos }\end{array}$ & $\begin{array}{l}\text { Formação de } \\
\text { professores do ensino } \\
\text { superior: ser, saber e } \\
\text { fazer }\end{array}$ & $\begin{array}{l}\text { III Congresso Uma Nova } \\
\text { Pedagogia para a Sociedade } \\
\text { Futura }\end{array}$ & $978-85-68901-15-1$ & p. $185-190$ & 2018 \\
\hline 51 & Liliane de Araujo Mancebo & $\begin{array}{l}\text { Oficinas Criativas: a arte } \\
\text { como ponte entre o ser } \\
\text { humano e a vida }\end{array}$ & $\begin{array}{l}\text { III Congresso Uma Nova } \\
\text { Pedagogia para a Sociedade } \\
\text { Futura }\end{array}$ & $978-85-68901-15-1$ & p. $142-149$ & 2018 \\
\hline 52 & $\begin{array}{l}\text { Priscila Valduga Dinarte } \\
\text { Roberta de Oliveira Sutel } \\
\text { Débora da Silva Doarte }\end{array}$ & $\begin{array}{l}\text { A efetividade do } \\
\text { Direito à educação } \\
\text { como promoção do } \\
\text { protagonismo do } \\
\text { educando frente aos } \\
\text { desafios do século XXI }\end{array}$ & $\begin{array}{l}\text { III Congresso Uma Nova } \\
\text { Pedagogia para a Sociedade } \\
\text { Futura }\end{array}$ & $978-85-68901-15-1$ & p. $98-103$ & 2018 \\
\hline 53 & $\begin{array}{l}\text { Fátima Osmari Burin } \\
\text { Ângelo Accorsi Moreira } \\
\text { Jaciele Dalla Nora } \\
\text { Tatiane Peixoto Isaia } \\
\text { Glauber Benetti Carvalho }\end{array}$ & $\begin{array}{l}\text { Ludicidade e prática } \\
\text { docente: impactos da } \\
\text { metodologia impare na } \\
\text { educação infantil }\end{array}$ & $\begin{array}{l}\text { III Congresso Uma Nova } \\
\text { Pedagogia para a Sociedade } \\
\text { Futura }\end{array}$ & $978-85-68901-15-1$ & p. 594-601 & 2018 \\
\hline 54 & $\begin{array}{l}\text { Martina Bopp Rubin Mário } \\
\text { Fernando Mello }\end{array}$ & $\begin{array}{l}\text { A importância da } \\
\text { educação } \\
\text { empreendedora para a } \\
\text { criação de empresas } \\
\text { sociais e }\end{array}$ & $\begin{array}{l}\text { III Congresso Uma Nova } \\
\text { Pedagogia para a Sociedade } \\
\text { Futura }\end{array}$ & $978-85-68901-15-1$ & p. $164-172$ & 2018 \\
\hline & & $\begin{array}{l}\text { desenvolvimento de } \\
\text { líderes sustentáveis }\end{array}$ & & & & \\
\hline
\end{tabular}


Saber Humano, ISSN 2446-6298, V. 9, n. 15, p. 186-423, jul./dez. 2019.

\begin{tabular}{|c|c|c|c|c|c|c|}
\hline 55 & $\begin{array}{l}\text { Carmen Ivanete D'Agostini } \\
\text { Spanhol } \\
\text { Fernando Duarte Martins de } \\
\text { Oliveira }\end{array}$ & $\begin{array}{l}\text { Experiência do próprio } \\
\text { negócio como } \\
\text { protagonismo } \\
\text { responsável ao trabalho }\end{array}$ & $\begin{array}{l}\text { III Congresso Uma Nova } \\
\text { Pedagogia para a Sociedade } \\
\text { Futura }\end{array}$ & $978-85-68901-15-1$ & p. $179-184$ & 2018 \\
\hline 56 & $\begin{array}{l}\text { Stefani Cristina Bülow } \\
\text { Arlete Salante }\end{array}$ & $\begin{array}{l}\text { Caminhos terapêuticos } \\
\text { para inclusão }\end{array}$ & $\begin{array}{l}\text { III Congresso Uma Nova } \\
\text { Pedagogia para a Sociedade } \\
\text { Futura }\end{array}$ & $978-85-68901-15-1$ & p. $112-119$ & 2018 \\
\hline 57 & $\begin{array}{l}\text { Ana Carolina Marzzari Eloisa } \\
\text { Vieira Ribeiro }\end{array}$ & $\begin{array}{l}\text { O jovem e a sua } \\
\text { segunda vida baseada } \\
\text { em estereótipos e o } \\
\text { diferencial da } \\
\text { Pedagogia } \\
\text { Ontopsicológica }\end{array}$ & $\begin{array}{l}\text { III Congresso Uma Nova } \\
\text { Pedagogia para a Sociedade } \\
\text { Futura }\end{array}$ & $978-85-68901-15-1$ & p. $127-133$ & 2018 \\
\hline 58 & $\begin{array}{l}\text { Pedro Henrique Hermes } \\
\text { Débora Franciele Pfüller }\end{array}$ & $\begin{array}{l}\text { A crise da academia e } \\
\text { da prática forense: } \\
\text { pressupostos de } \\
\text { Ontopsicologia para a } \\
\text { formação do novo } \\
\text { jurista brasileiro }\end{array}$ & $\begin{array}{l}\text { III Congresso Uma Nova } \\
\text { Pedagogia para a Sociedade } \\
\text { Futura }\end{array}$ & $978-85-68901-15-1$ & p. 91-97 & 2018 \\
\hline 59 & $\begin{array}{l}\text { Soila Maria Ferreira } \\
\text { Schroder } \\
\text { Elsa Maria Schirmann Gass } \\
\text { Paula Vicentina Ferreira } \\
\text { Machado }\end{array}$ & $\begin{array}{l}\text { Projeto Intersetorial de } \\
\text { ações para pessoas com } \\
\text { autismo sob a ótica da } \\
\text { Ontopsicologia }\end{array}$ & $\begin{array}{l}\text { III Congresso Uma Nova } \\
\text { Pedagogia para a Sociedade } \\
\text { Futura }\end{array}$ & $978-85-68901-15-1$ & p. $150-155$ & 2018 \\
\hline 60 & Mateus Marzzari & Líder: um protagonista & III Congresso Uma Nova & $978-85-68901-15-1$ & p. $749-751$ & 2018 \\
\hline
\end{tabular}


Saber Humano, ISSN 2446-6298, V. 9, n. 15, p. 186-423, jul./dez. 2019.

\begin{tabular}{|c|c|c|c|c|c|c|}
\hline & Ana Carolina Marzzari & com projeto vencedor & $\begin{array}{l}\text { Pedagogia para a Sociedade } \\
\text { Futura }\end{array}$ & & & \\
\hline 61 & Paula Savegnago Rossato & $\begin{array}{l}\text { A Pedagogia } \\
\text { Ontopsicologica e a } \\
\text { construção de saberes } \\
\text { geográficos nos anos } \\
\text { inicias do Ensino } \\
\text { Fundamental }\end{array}$ & $\begin{array}{l}\text { Ill Congresso Uma Nova } \\
\text { Pedagogia para a Sociedade } \\
\text { Futura }\end{array}$ & $978-85-68901-15-1$ & p. 769-771 & 2018 \\
\hline 62 & $\begin{array}{l}\text { Eloísa Vieira Ribeiro Ana } \\
\text { Carolina Marzzari }\end{array}$ & $\begin{array}{l}\text { Campo Semântico em } \\
\text { rede na rede: os } \\
\text { contributos da Ciência } \\
\text { Ontopsicológica }\end{array}$ & $\begin{array}{l}\text { III Congresso Uma Nova } \\
\text { Pedagogia para a Sociedade } \\
\text { Futura }\end{array}$ & $978-85-68901-15-1$ & p. $786-790$ & 2018 \\
\hline 63 & $\begin{array}{l}\text { Diana Milene Goltz } \\
\text { Katiele Daiana da Silva } \\
\text { Rehbein } \\
\text { Djulia Graciela Achterberg }\end{array}$ & $\begin{array}{l}\text { Core Business por } \\
\text { Antonio Meneghetti: o } \\
\text { coração ôntico } \\
\text { managerial }\end{array}$ & $\begin{array}{l}\text { III Congresso Uma Nova } \\
\text { Pedagogia para a Sociedade } \\
\text { Futura }\end{array}$ & $978-85-68901-15-1$ & p. 794-798 & 2018 \\
\hline 64 & $\begin{array}{l}\text { Gerson Jonas Schirmer } \\
\text { Marisa Dal Ongaro }\end{array}$ & $\begin{array}{l}\text { A Ontopsicologia e as } \\
\text { aulas de Graduação na } \\
\text { atualidade: aplicações } \\
\text { em aulas da UFSM, } \\
\text { Campus Cachoeira do } \\
\text { Sul-RS }\end{array}$ & $\begin{array}{l}\text { III Congresso Uma Nova } \\
\text { Pedagogia para a Sociedade } \\
\text { Futura }\end{array}$ & $978-85-68901-15-1$ & p. $843-846$ & 2018 \\
\hline
\end{tabular}


Saber Humano, ISSN 2446-6298, V. 9, n. 15, p. 186-423, jul./dez. 2019.

\begin{tabular}{|c|c|c|c|c|c|c|}
\hline 65 & Nicolas Lara do Amaral & $\begin{array}{l}\text { Colisão entre a } \\
\text { liberdade de expressão } \\
\text { e os direitos da } \\
\text { personalidade em } \\
\text { tempos de internet: o } \\
\text { indivíduo como }\end{array}$ & $\begin{array}{l}\text { III Congresso Uma Nova } \\
\text { Pedagogia para a Sociedade } \\
\text { Futura }\end{array}$ & $978-85-68901-15-1$ & p. $669-673$ & 2018 \\
\hline & & protagonista & & & & \\
\hline 66 & $\begin{array}{l}\text { Noá Oliveira Bittencourt } \\
\text { Vanessa Miolo } \\
\text { Camila Flores } \\
\text { Mariana Bizunin }\end{array}$ & $\begin{array}{l}\text { O desenvolvimento do } \\
\text { protagonismo } \\
\text { responsável à vida dos } \\
\text { alunos da Antonio } \\
\text { Meneghetti Faculdade }\end{array}$ & $\begin{array}{l}\text { III Congresso Uma Nova } \\
\text { Pedagogia para a Sociedade } \\
\text { Futura }\end{array}$ & $978-85-68901-15-1$ & p. $680-683$ & 2018 \\
\hline 67 & $\begin{array}{l}\text { Pedro Henrique Hermes } \\
\text { Débora Franciele Pfüller }\end{array}$ & $\begin{array}{l}\text { Projeto pequenos } \\
\text { cidadãos: cidadania e } \\
\text { protagonismo } \\
\text { responsável em } \\
\text { crianças do Ensino } \\
\text { Fundamental }\end{array}$ & $\begin{array}{l}\text { III Congresso Uma Nova } \\
\text { Pedagogia para a Sociedade } \\
\text { Futura }\end{array}$ & $978-85-68901-15-1$ & p. $684-686$ & 2018 \\
\hline 68 & Fábio Sarturi Prass & $\begin{array}{l}\text { Análise da } \\
\text { aprendizagem baseada } \\
\text { em problemas no } \\
\text { ensino da tecnologia da } \\
\text { informação com o } \\
\text { auxílio da } \\
\text { Ontopsicologia }\end{array}$ & $\begin{array}{l}\text { III Congresso Uma Nova } \\
\text { Pedagogia para a Sociedade } \\
\text { Futura }\end{array}$ & 978-85-68901-15-1 & p. $718-723$ & 2018 \\
\hline
\end{tabular}




\begin{tabular}{|c|c|c|c|c|c|c|}
\hline 69 & $\begin{array}{l}\text { Danielle de Souza Saad } \\
\text { Jussara Foletto Marcos } \\
\text { Vinicios Machado }\end{array}$ & $\begin{array}{l}\text { A sustentabilidade } \\
\text { centrada no trabalho do } \\
\text { indivíduo }\end{array}$ & $\begin{array}{l}\text { III Congresso Uma Nova } \\
\text { Pedagogia para a Sociedade } \\
\text { Futura }\end{array}$ & $978-85-68901-15-1$ & p. $726-728$ & 2018 \\
\hline 70 & Patrícia Gabriela Bilha Salles & $\begin{array}{l}\text { Da busca da identidade } \\
\text { à ação do projeto de } \\
\text { vida: minha arte é } \\
\text { costurar }\end{array}$ & $\begin{array}{l}\text { III Congresso Uma Nova } \\
\text { Pedagogia para a Sociedade } \\
\text { Futura }\end{array}$ & $978-85-68901-15-1$ & p. $729-731$ & 2018 \\
\hline 71 & $\begin{array}{l}\text { Jéssica Taís Abich } \\
\text { Janine Coelho Ouriques }\end{array}$ & $\begin{array}{l}\text { História e } \\
\text { desenvolvimento do }\end{array}$ & $\begin{array}{l}\text { III Congresso Uma Nova } \\
\text { Pedagogia para a Sociedade }\end{array}$ & $978-85-68901-15-1$ & p. $735-740$ & 2018 \\
\hline & & $\begin{array}{l}\text { Projeto Saber Fazer } \\
\text { uma Escola Viva }\end{array}$ & Futura & & & \\
\hline 72 & Estela Maris Giordani & $\begin{array}{l}\text { A responsabilidade do } \\
\text { político como } \\
\text { pedagogo na sociedade }\end{array}$ & $\begin{array}{l}\text { III Congresso Uma Nova } \\
\text { Pedagogia para a Sociedade } \\
\text { Futura }\end{array}$ & $978-85-68901-15-1$ & p. $772-777$ & 2018 \\
\hline 73 & \begin{tabular}{|l|} 
Vanice Hentges \\
Paula Savegnago Rossato \\
Daniela dos Santos Morales \\
Estela Maris Giordani
\end{tabular} & $\begin{array}{l}\text { Colônia de Férias e } \\
\text { diversão inteligente }\end{array}$ & $\begin{array}{l}\text { III Congresso Uma Nova } \\
\text { Pedagogia para a Sociedade } \\
\text { Futura }\end{array}$ & $978-85-68901-15-1$ & p. $791-793$ & 2018 \\
\hline 74 & $\begin{array}{l}\text { Samara Morais Nejelski } \\
\text { Arlete Salante }\end{array}$ & O uso do tempo livre & $\begin{array}{l}\text { III Congresso Uma Nova } \\
\text { Pedagogia para a Sociedade } \\
\text { Futura }\end{array}$ & $978-85-68901-15-1$ & p. $813-815$ & 2018 \\
\hline 75 & $\begin{array}{l}\text { Bianca Rodrigues } \\
\text { Eloisa Vieira Ribeiro }\end{array}$ & $\begin{array}{l}\text { Projeto Jovem \& } \\
\text { Tecnologia ajuda no } \\
\text { desenvolvimento de }\end{array}$ & $\begin{array}{l}\text { III Congresso Uma Nova } \\
\text { Pedagogia para a Sociedade } \\
\text { Futura }\end{array}$ & $978-85-68901-15-1$ & p. 816-819 & 2018 \\
\hline
\end{tabular}


Saber Humano, ISSN 2446-6298, V. 9, n. 15, p. 186-423, jul./dez. 2019.

\begin{tabular}{|c|c|c|c|c|c|c|}
\hline & & crianças e jovens & & & & \\
\hline 76 & $\begin{array}{l}\text { Katiele Daiana da Silva } \\
\text { Rehbein } \\
\text { Diana Milene Goltz } \\
\text { Djulia Graciela Achterberg }\end{array}$ & $\begin{array}{l}\text { Realidade } \\
\text { contemporânea: os } \\
\text { jovens e a regressão } \\
\text { ontológica }\end{array}$ & $\begin{array}{l}\text { III Congresso Uma Nova } \\
\text { Pedagogia para a Sociedade } \\
\text { Futura }\end{array}$ & $978-85-68901-15-1$ & p. $826-830$ & 2018 \\
\hline 77 & Michael Fragomeni Penna & $\begin{array}{l}\text { Responsabilidade de ser } \\
\text { pessoa no peak } \\
\text { expierence da } \\
\text { experiência musical }\end{array}$ & $\begin{array}{l}\text { III Congresso Uma Nova } \\
\text { Pedagogia para a Sociedade } \\
\text { Futura }\end{array}$ & $978-85-68901-15-1$ & p. $835-837$ & 2018 \\
\hline 78 & $\begin{array}{l}\text { Juliana Fick } \\
\text { Ana Carolina Marzzari Délis } \\
\text { Stona }\end{array}$ & $\begin{array}{l}\text { Nas raízes do novo } \\
\text { Humanismo }\end{array}$ & $\begin{array}{l}\text { III Congresso Uma Nova } \\
\text { Pedagogia para a Sociedade } \\
\text { Futura }\end{array}$ & $978-85-68901-15-1$ & p. $864-866$ & 2018 \\
\hline
\end{tabular}

\begin{tabular}{|c|c|c|c|c|c|c|}
\hline & Annalisa Cangelosi & & & & & \\
\hline 79 & $\begin{array}{l}\text { Endyra Paulla Santos da } \\
\text { Rocha }\end{array}$ & $\begin{array}{l}\text { "Eu no projeto": } \\
\text { Comitê Maestria }\end{array}$ & $\begin{array}{l}\text { III Congresso Uma Nova } \\
\text { Pedagogia para a Sociedade } \\
\text { Futura }\end{array}$ & $978-85-68901-15-1$ & p. $946-949$ & 2018 \\
\hline 80 & Débora Franciele Pfüller & $\begin{array}{l}\text { "Eu no projeto": } \\
\text { Pequenos cidadãos }\end{array}$ & $\begin{array}{l}\text { III Congresso Uma Nova } \\
\text { Pedagogia para a Sociedade } \\
\text { Futura }\end{array}$ & $978-85-68901-15-1$ & p. $950-953$ & 2018 \\
\hline
\end{tabular}


Saber Humano, ISSN 2446-6298, V. 9, n. 15, p. 186-423, jul./dez. 2019.

\begin{tabular}{|c|c|c|c|c|c|c|}
\hline 81 & $\begin{array}{l}\text { Guilherme Muller Sagrilo } \\
\text { Rodrigues }\end{array}$ & $\begin{array}{l}\text { Desenvolvimento } \\
\text { integral através dos } \\
\text { projetos sociais da } \\
\text { Fundação Antonio } \\
\text { Meneghetti }\end{array}$ & $\begin{array}{l}\text { III Congresso Uma Nova } \\
\text { Pedagogia para a Sociedade } \\
\text { Futura }\end{array}$ & 978-85-68901-15-1 & p. $959-962$ & 2018 \\
\hline 82 & Murilo Azevedo Rosa & $\begin{array}{l}\text { "Eu no projeto": } \\
\text { Projeto Casa dos } \\
\text { Estudantes }\end{array}$ & $\begin{array}{l}\text { III Congresso Uma Nova } \\
\text { Pedagogia para a Sociedade } \\
\text { Futura }\end{array}$ & $978-85-68901-15-1$ & p. $963-964$ & 2018 \\
\hline 83 & Fernanda da Silva Pedroso & $\begin{array}{l}\text { "Eu no projeto": } \\
\text { Recanto Maestro }\end{array}$ & $\begin{array}{l}\text { III Congresso Uma Nova } \\
\text { Pedagogia para a Sociedade } \\
\text { Futura }\end{array}$ & $978-85-68901-15-1$ & p. $965-969$ & 2018 \\
\hline 84 & Maicon Boeck Pfeifer & $\begin{array}{l}\text { Os seis pilares de } \\
\text { formação: residence } \\
\text { ontopsicológico como } \\
\text { transformação para a } \\
\text { sociedade futura }\end{array}$ & $\begin{array}{l}\text { III Congresso Uma Nova } \\
\text { Pedagogia para a Sociedade } \\
\text { Futura }\end{array}$ & 978-85-68901-15-1 & p. $970-974$ & 2018 \\
\hline 85 & André Menezes da Silva & $\begin{array}{l}\text { Primeira Semana } \\
\text { Acadêmica } \\
\text { Internacional do Curso } \\
\text { Bacharelado em } \\
\text { Ontopsicologia: }\end{array}$ & $\begin{array}{l}\text { III Congresso Uma Nova } \\
\text { Pedagogia para a Sociedade } \\
\text { Futura }\end{array}$ & $978-85-68901-15-1$ & p. $975-978$ & 2018 \\
\hline
\end{tabular}

\begin{tabular}{|l|l|l|l|l|}
\hline & $\begin{array}{l}\text { percepção da } \\
\text { participação como } \\
\text { estudante }\end{array}$ & & & \\
\hline
\end{tabular}




\begin{tabular}{|c|c|c|c|c|c|c|}
\hline 86 & $\begin{array}{l}\text { Débora da Silva Doarte } \\
\text { Roberta de Oliveira Sutel }\end{array}$ & $\begin{array}{l}\text { O jovem protagonista } \\
\text { responsável, autor de } \\
\text { suas conquistas e } \\
\text { contribuidor para o } \\
\text { desenvolvimento de } \\
\text { uma sociedade } \\
\text { sustentável }\end{array}$ & $\begin{array}{l}\text { III Congresso Uma Nova } \\
\text { Pedagogia para a Sociedade } \\
\text { Futura }\end{array}$ & 978-85-68901-15-1 & p. $979-981$ & 2018 \\
\hline \multicolumn{7}{|c|}{ ANAIS DO SYMPOSIUM INTERNACIONAL PEDAGOGIA CONTEMPORÂNEA: } \\
\hline \multicolumn{7}{|c|}{ RESPONSABILIDADE E FORMAÇÃO DO JOVEM PARA A SOCIEDADE DO FUTURO } \\
\hline & \multicolumn{6}{|c|}{ SEDE DA UNESCO } \\
\hline & \multicolumn{6}{|c|}{ PARIS, FRANÇA, OUTUBRO 2017} \\
\hline 1 & Horácio Chikota & $\begin{array}{l}\text { Aumento do déficit de } \\
\text { atenção e da } \\
\text { hiperatividade nas } \\
\text { 2crianças e nos }\end{array}$ & $\begin{array}{l}\text { Anais do Simposyum Internacional } \\
\text { Pedagogia Contemporânea: } \\
\text { Responsabilidade e Formação do }\end{array}$ & 978-85-68901-10-6 & p. $45-52$ & 2017 \\
\hline
\end{tabular}


Saber Humano, ISSN 2446-6298, V. 9, n. 15, p. 186-423, jul./dez. 2019.

\begin{tabular}{|c|c|c|c|c|c|c|}
\hline & & $\begin{array}{l}\text { adolescentes, sob o } \\
\text { viés médico e } \\
\text { ontopsicológico }\end{array}$ & $\begin{array}{l}\text { Jovem para a Sociedade do } \\
\text { Futuro. } \\
\text { Realizado pela Fundação Antonio } \\
\text { Meneghetti e Faculdade Antonio } \\
\text { Meneghetti na Sede da UNESCO, } \\
\text { em Paris, França, } 6 \text { de setembro } \\
\text { de } 2017 \text {. }\end{array}$ & & & \\
\hline 2 & Rafael Padilha dos Santos & $\begin{array}{l}\text { A potência do telefone } \\
\text { móvel, sob o viés } \\
\text { ontológico, } \\
\text { ontopsicológico e social } \\
\text { (da pessoa e da } \\
\text { sociedade) }\end{array}$ & $\begin{array}{l}\text { Anais do Simposyum Internacional } \\
\text { Pedagogia Contemporânea: } \\
\text { Responsabilidade e Formação do } \\
\text { Jovem para a Sociedade do } \\
\text { Futuro. } \\
\text { Realizado pela Fundação Antonio } \\
\text { Meneghetti e Faculdade Antonio } \\
\text { Meneghetti na Sede da UNESCO, } \\
\text { em Paris, França, } 6 \text { de setembro } \\
\text { de } 2017 \text {. }\end{array}$ & $978-85-68901-10-6$ & p. $53-58$ & 2017 \\
\hline 3 & Estela Maris Giordani & $\begin{array}{l}\text { Pedagogia } \\
\text { ontopsicológica para } \\
\text { pais e educadores }\end{array}$ & $\begin{array}{l}\text { Anais do Simposyum Internacional } \\
\text { Pedagogia Contemporânea: } \\
\text { Responsabilidade e Formação do } \\
\text { Jovem para a Sociedade do } \\
\text { Futuro. } \\
\text { Realizado pela Fundação Antonio } \\
\text { Meneghetti e Faculdade Antonio } \\
\text { Meneghetti na Sede da UNESCO, } \\
\text { em Paris, França, } 6 \text { de setembro }\end{array}$ & $978-85-68901-10-6$ & p. $59-66$ & 2017 \\
\hline
\end{tabular}


Saber Humano, ISSN 2446-6298, V. 9, n. 15, p. 186-423, jul./dez. 2019.

\begin{tabular}{|c|c|c|c|c|c|c|}
\hline & & & de 2017. & & & \\
\hline 4 & Alécio Vidor & $\begin{array}{l}\text { A gratificação na } \\
\text { educação }\end{array}$ & $\begin{array}{l}\text { Anais do Simposyum Internacional } \\
\text { Pedagogia Contemporânea: } \\
\text { Responsabilidade e Formação do } \\
\text { Jovem para a Sociedade do } \\
\text { Futuro. } \\
\text { Realizado pela Fundação Antonio } \\
\text { Meneghetti e Faculdade Antonio } \\
\text { Meneghetti na Sede da UNESCO, } \\
\text { em Paris, França, } 6 \text { de setembro } \\
\text { de } 2017 .\end{array}$ & $978-85-68901-10-6$ & p. $67-68$ & 2017 \\
\hline 5 & Josemar Sidinei Soares & $\begin{array}{l}\text { Juventude: um } \\
\text { momento para ser } \\
\text { preciso }\end{array}$ & $\begin{array}{l}\text { Anais do Simposyum Internacional } \\
\text { Pedagogia Contemporânea: } \\
\text { Responsabilidade e Formação do } \\
\text { Jovem para a Sociedade do } \\
\text { Futuro. } \\
\text { Realizado pela Fundação Antonio } \\
\text { Meneghetti e Faculdade Antonio } \\
\text { Meneghetti na Sede da UNESCO, } \\
\text { em Paris, França, } 6 \text { de setembro } \\
\text { de } 2017 .\end{array}$ & $978-85-68901-10-6$ & p. $69-74$ & 2017 \\
\hline 6 & Patrícia Wazlawick & $\begin{array}{l}\text { A vida e o mundo } \\
\text { dentro de uma fiction }\end{array}$ & $\begin{array}{l}\text { Anais do Simposyum Internacional } \\
\text { Pedagogia Contemporânea: } \\
\text { Responsabilidade e Formação do } \\
\text { Jovem para a Sociedade do }\end{array}$ & $978-85-68901-10-6$ & p. $75-82$ & 2017 \\
\hline
\end{tabular}


Saber Humano, ISSN 2446-6298, V. 9, n. 15, p. 186-423, jul./dez. 2019.

\begin{tabular}{|c|c|c|c|c|c|c|}
\hline & & & $\begin{array}{l}\text { Futuro. } \\
\text { Realizado pela Fundação Antonio } \\
\text { Meneghetti e Faculdade Antonio } \\
\text { Meneghetti na Sede da UNESCO, } \\
\text { em Paris, França, } 6 \text { de setembro } \\
\text { de } 2017 .\end{array}$ & & & \\
\hline 7 & Patrícia Wazlawick & $\begin{array}{l}\text { Fazer a Pedagogia } \\
\text { Ontopsicológica }\end{array}$ & $\begin{array}{l}\text { Anais do Simposyum Internacional } \\
\text { Pedagogia Contemporânea: } \\
\text { Responsabilidade e Formação do } \\
\text { Jovem para a Sociedade do } \\
\text { Futuro. } \\
\text { Realizado pela Fundação Antonio } \\
\text { Meneghetti e Faculdade Antonio } \\
\text { Meneghetti na Sede da UNESCO, } \\
\text { em Paris, França, } 6 \text { de setembro } \\
\text { de } 2017 \text {. }\end{array}$ & $978-85-68901-10-6$ & p. $83-90$ & 2017 \\
\hline
\end{tabular}


Saber Humano, ISSN 2446-6298, V. 9, n. 15, p. 186-423, jul./dez. 2019.

\begin{tabular}{|c|c|c|c|c|c|c|}
\hline 8 & Clarissa Miranda & $\begin{array}{l}\text { Um plano global para o } \\
\text { progresso sustentável }\end{array}$ & $\begin{array}{l}\text { Anais do Simposyum } \\
\text { Internacional Pedagogia } \\
\text { Contemporânea: } \\
\text { Responsabilidade e Formação do } \\
\text { Jovem para a Sociedade do } \\
\text { Futuro. } \\
\text { Realizado pela Fundação Antonio } \\
\text { Meneghetti e Faculdade Antonio } \\
\text { Meneghetti na Sede da UNESCO, } \\
\text { em Paris, França, } 6 \text { de setembro } \\
\text { de } 2017 \text {. }\end{array}$ & $978-85-68901-10-6$ & p. 91-104 & 2017 \\
\hline 9 & Clarissa Mazon Miranda & $\begin{array}{l}\text { Os Objetivos de } \\
\text { Desenvolvimento } \\
\text { Sustentável aplicados } \\
\text { no projeto Recanto } \\
\text { Maestro: uma } \\
\text { bemsucedida } \\
\text { experiência brasileira } \\
\text { voltada para a } \\
\text { formação humanista }\end{array}$ & $\begin{array}{l}\text { Anais do Simposyum } \\
\text { Internacional Pedagogia } \\
\text { Contemporânea: } \\
\text { Responsabilidade e Formação do } \\
\text { Jovem para a Sociedade do } \\
\text { Futuro. } \\
\text { Realizado pela Fundação Antonio } \\
\text { Meneghetti e Faculdade Antonio } \\
\text { Meneghetti na Sede da UNESCO, } \\
\text { em Paris, França, } 6 \text { de setembro } \\
\text { de } 2017 \text {. }\end{array}$ & $978-85-68901-10-6$ & p. $105-112$ & 2017 \\
\hline
\end{tabular}


Saber Humano, ISSN 2446-6298, V. 9, n. 15, p. 186-423, jul./dez. 2019.

\begin{tabular}{|c|c|c|c|c|c|c|}
\hline 10 & Juliane Neves Fiorezi & $\begin{array}{l}\text { Um novo humanismo } \\
\text { do trabalho }\end{array}$ & $\begin{array}{l}\text { Anais do Simposyum } \\
\text { Internacional Pedagogia } \\
\text { Contemporânea: } \\
\text { Responsabilidade e Formação do } \\
\text { Jovem para a Sociedade do } \\
\text { Futuro. } \\
\text { Realizado pela Fundação Antonio } \\
\text { Meneghetti e Faculdade Antonio } \\
\text { Meneghetti na Sede da UNESCO, } \\
\text { em Paris, França, } 6 \text { de setembro } \\
\text { de } 2017 \text {. }\end{array}$ & $978-85-68901-10-6$ & p. $113-118$ & 2017 \\
\hline 11 & Ari Fernando Foletto & $\begin{array}{l}\text { Empresário e jovem: a } \\
\text { recíproca relação de } \\
\text { vantagem }\end{array}$ & $\begin{array}{l}\text { Anais do Simposyum } \\
\text { Internacional Pedagogia } \\
\text { Contemporânea: } \\
\text { Responsabilidade e Formação do } \\
\text { 1Jovem para a Sociedade do } \\
\text { Futuro. }\end{array}$ & $978-85-68901-10-6$ & p. $119-124$ & 2017 \\
\hline
\end{tabular}

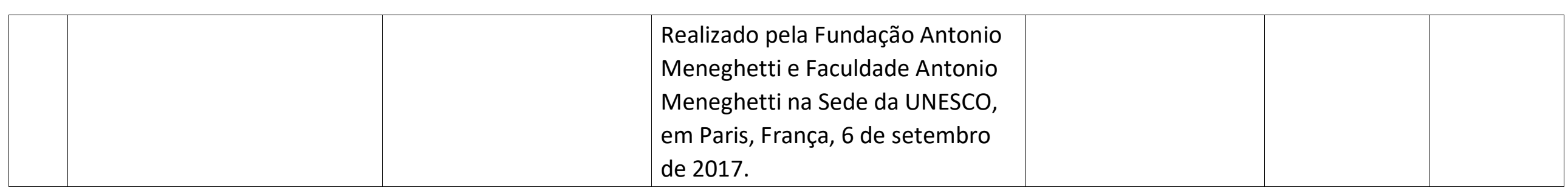


Saber Humano, ISSN 2446-6298, V. 9, n. 15, p. 186-423, jul./dez. 2019.

\begin{tabular}{|c|c|c|c|c|c|c|}
\hline 12 & Edna da Silva & $\begin{array}{l}\text { Formação do jovem e } \\
\text { atitude ao sucesso }\end{array}$ & $\begin{array}{l}\text { Anais do Simposyum } \\
\text { Internacional Pedagogia } \\
\text { Contemporânea: } \\
\text { Responsabilidade e Formação do } \\
\text { Jovem para a Sociedade do } \\
\text { Futuro. } \\
\text { Realizado pela Fundação Antonio } \\
\text { Meneghetti e Faculdade Antonio } \\
\text { Meneghetti na Sede da UNESCO, } \\
\text { em Paris, França, } 6 \text { de setembro } \\
\text { de } 2017 .\end{array}$ & $978-85-68901-10-6$ & p. $125-132$ & 2017 \\
\hline 13 & Wesley Lacerda e Silva & $\begin{array}{l}\text { A dialética do mérito e } \\
\text { a dinâmica do capaz }\end{array}$ & $\begin{array}{l}\text { Anais do Simposyum } \\
\text { Internacional Pedagogia } \\
\text { Contemporânea: } \\
\text { Responsabilidade e Formação do } \\
\text { Jovem para a Sociedade do } \\
\text { Futuro. } \\
\text { Realizado pela Fundação Antonio } \\
\text { Meneghetti e Faculdade Antonio } \\
\text { Meneghetti na Sede da UNESCO, } \\
\text { em Paris, França, } 6 \text { de setembro } \\
\text { de } 2017 .\end{array}$ & $978-85-68901-10-6$ & p. $133-140$ & 2017 \\
\hline 14 & Roberto Argenta & Formação como & Anais do Simposyum & $978-85-68901-10-6$ & p. $141-146$ & 2017 \\
\hline
\end{tabular}


Saber Humano, ISSN 2446-6298, V. 9, n. 15, p. 186-423, jul./dez. 2019.

\begin{tabular}{|c|c|c|c|c|c|c|}
\hline & & garantia de sucesso & $\begin{array}{l}\text { Internacional Pedagogia } \\
\text { Contemporânea: } \\
\text { Responsabilidade e Formação do } \\
\text { Jovem para a Sociedade do } \\
\text { Futuro. } \\
\text { Realizado pela Fundação Antonio } \\
\text { Meneghetti e Faculdade Antonio } \\
\text { Meneghetti na Sede da UNESCO, } \\
\text { em Paris, França, } 6 \text { de setembro } \\
\text { de } 2017 .\end{array}$ & & & \\
\hline 15 & Any Regina Rothmann & $\begin{array}{l}\text { Formação para a vida e } \\
\text { para a sociedade: } \\
\text { diretivas práticas de } \\
\text { evidência concreta }\end{array}$ & $\begin{array}{l}\text { Anais do Simposyum } \\
\text { Internacional Pedagogia } \\
\text { Contemporânea: } \\
\text { Responsabilidade e Formação do } \\
\text { Jovem para a Sociedade do } \\
\text { Futuro. } \\
\text { Realizado pela Fundação Antonio } \\
\text { Meneghetti e Faculdade Antonio } \\
\text { Meneghetti na Sede da UNESCO, } \\
\text { em Paris, França, } 6 \text { de setembro } \\
\text { de } 2017 .\end{array}$ & $978-85-68901-10-6$ & p. $147-156$ & 2017 \\
\hline 16 & Wilian Mauri Friedrich Neu & $\begin{array}{l}\text { A crise do humano: } 0 \\
\text { jovem como } \\
\text { combustível ou } \\
\text { solução? }\end{array}$ & $\begin{array}{l}\text { Anais do Simposyum } \\
\text { Internacional Pedagogia } \\
\text { Contemporânea: } \\
\text { Responsabilidade e Formação do } \\
\text { Jovem para a Sociedade do } \\
\text { Futuro. } \\
\text { Realizado pela Fundação Antonio }\end{array}$ & $978-85-68901-10-6$ & p. $157-162$ & 2017 \\
\hline
\end{tabular}


Saber Humano, ISSN 2446-6298, V. 9, n. 15, p. 186-423, jul./dez. 2019.

\begin{tabular}{|c|c|c|c|c|c|c|}
\hline & & & $\begin{array}{l}\text { Meneghetti e Faculdade Antonio } \\
\text { Meneghetti na Sede da UNESCO, } \\
\text { em Paris, França, } 6 \text { de setembro } \\
\text { de } 2017 \text {. }\end{array}$ & & & \\
\hline 17 & Augusto Roberto Gehrke & $\begin{array}{l}\text { Juventude "fora de } \\
\text { fase" }\end{array}$ & $\begin{array}{l}\text { Anais do Simposyum } \\
\text { Internacional Pedagogia } \\
\text { Contemporânea: } \\
\text { Responsabilidade e Formação do } \\
\text { Jovem para a Sociedade do } \\
\text { Futuro. } \\
\text { Realizado pela Fundação Antonio } \\
\text { Meneghetti e Faculdade Antonio } \\
\text { Meneghetti na Sede da UNESCO, } \\
\text { em Paris, França, } 6 \text { de setembro } \\
\text { de } 2017 \text {. }\end{array}$ & $978-85-68901-10-6$ & p. $163-168$ & 2017 \\
\hline 18 & $\begin{array}{l}\text { Natália dos Santos } \\
\text { Conceição }\end{array}$ & $\begin{array}{l}\text { A recuperação da } \\
\text { informação-base da } \\
\text { vida }\end{array}$ & $\begin{array}{l}\text { Anais do Simposyum } \\
\text { Internacional Pedagogia } \\
\text { Contemporânea: } \\
\text { Responsabilidade e Formação do } \\
\text { Jovem para a Sociedade do } \\
\text { Futuro. } \\
\text { Realizado pela Fundação Antonio } \\
\text { Meneghetti e Faculdade Antonio } \\
\text { Meneghetti na Sede da UNESCO, } \\
\text { em Paris, França, } 6 \text { de setembro } \\
\text { de } 2017 \text {. }\end{array}$ & $978-85-68901-10-6$ & p. $169-174$ & 2017 \\
\hline
\end{tabular}


Saber Humano, ISSN 2446-6298, V. 9, n. 15, p. 186-423, jul./dez. 2019.

\begin{tabular}{|c|c|c|c|c|c|c|}
\hline 19 & Mireila Vieira Fagundes & $\begin{array}{l}\text { Da construção de si } \\
\text { mesmo à contribuição }\end{array}$ & $\begin{array}{l}\text { Anais do Simposyum } \\
\text { Internacional Pedagogia }\end{array}$ & $978-85-68901-10-6$ & p. $175-180$ & 2017 \\
\hline & & com a sociedade & $\begin{array}{l}\text { Contemporânea: } \\
\text { Responsabilidade e Formação do } \\
\text { Jovem para a Sociedade do } \\
\text { Futuro. } \\
\text { Realizado pela Fundação Antonio } \\
\text { Meneghetti e Faculdade Antonio } \\
\text { Meneghetti na Sede da UNESCO, } \\
\text { em Paris, França, } 6 \text { de setembro } \\
\text { de } 2017 .\end{array}$ & & & \\
\hline 20 & Ricardo Schaefer & $\begin{array}{l}\text { "Responder" às } \\
\text { ocasiões da escola, da } \\
\text { sociedade, da vida }\end{array}$ & $\begin{array}{l}\text { Anais do Simposyum } \\
\text { Internacional Pedagogia } \\
\text { Contemporânea: } \\
\text { Responsabilidade e Formação do } \\
\text { Jovem para a Sociedade do } \\
\text { Futuro. } \\
\text { Realizado pela Fundação Antonio } \\
\text { Meneghetti e Faculdade Antonio } \\
\text { Meneghetti na Sede da UNESCO, } \\
\text { em Paris, França, } 6 \text { de setembro } \\
\text { de } 2017 \text {. }\end{array}$ & $978-85-68901-10-6$ & p. $181-186$ & 2017 \\
\hline
\end{tabular}




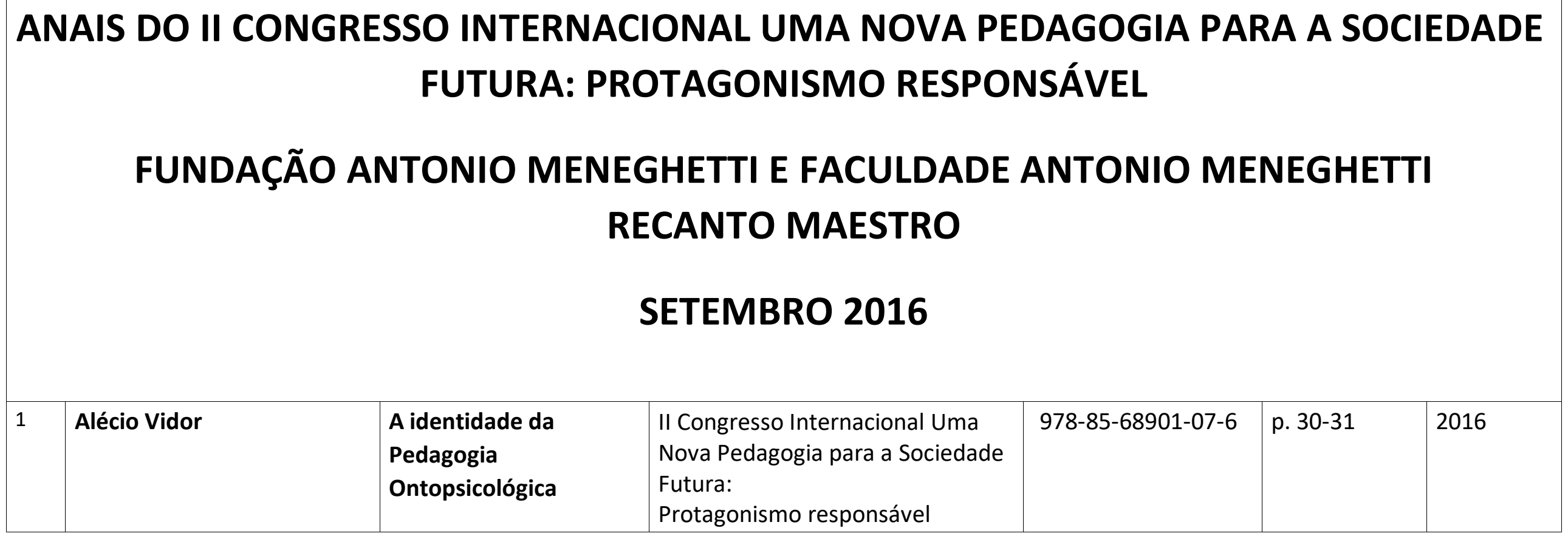


Saber Humano, ISSN 2446-6298, V. 9, n. 15, p. 186-423, jul./dez. 2019.

\begin{tabular}{|c|c|c|c|c|c|c|}
\hline 2 & $\begin{array}{l}\text { Eloy Demarchi Teixeira } \\
\text { Patrícia Wazlawick }\end{array}$ & $\begin{array}{l}\text { A relação entre } \\
\text { responsabilidade, } \\
\text { autonomia e } \\
\text { abordagem profunda ao } \\
\text { estudo: um estudo com } \\
\text { ingressantes } \\
\text { universitários da } \\
\text { Antonio Meneghetti } \\
\text { Faculdade }\end{array}$ & $\begin{array}{l}\text { II Congresso Internacional Uma } \\
\text { Nova Pedagogia para a Sociedade } \\
\text { Futura: } \\
\text { Protagonismo responsável }\end{array}$ & $978-85-68901-07-6$ & p. $111-124$ & 2016 \\
\hline \multirow[t]{2}{*}{3} & Janine Coelho Ouriques & Casa dos Estudantes da & II Congresso Internacional Uma & $978-85-68901-07-6$ & p. $133-146$ & 2016 \\
\hline & $\begin{array}{l}\text { Ariel Ramos } \\
\text { Luana Ramos } \\
\text { Patrícia Grabiela Bilha } \\
\text { Salles } \\
\text { André Menezes da Silva }\end{array}$ & $\begin{array}{l}\text { AMF - uma proposta } \\
\text { de gestão para a } \\
\text { construção da } \\
\text { cidadania: pedagogia } \\
\text { do fazer }\end{array}$ & $\begin{array}{l}\text { Nova Pedagogia para a Sociedade } \\
\text { Futura: } \\
\text { Protagonismo responsável }\end{array}$ & & & \\
\hline 4 & $\begin{array}{l}\text { Patrícia Gabriela Bilha } \\
\text { Salles } \\
\text { Janine Coelho Ouriques }\end{array}$ & $\begin{array}{l}\text { O caminho para a } \\
\text { identidade }\end{array}$ & $\begin{array}{l}\text { II Congresso Internacional Uma } \\
\text { Nova Pedagogia para a Sociedade } \\
\text { Futura: } \\
\text { Protagonismo responsável }\end{array}$ & $978-85-68901-07-6$ & p. $154-158$ & 2016 \\
\hline 5 & $\begin{array}{l}\text { Shaiane Bitencourt } \\
\text { Estela Maris Giordani } \\
\text { Gabriela Mombelli }\end{array}$ & $\begin{array}{l}\text { Aprendizado da } \\
\text { Pedagogia } \\
\text { Ontopsicológica na } \\
\text { educação de pais e } \\
\text { professores }\end{array}$ & $\begin{array}{l}\text { II Congresso Internacional Uma } \\
\text { Nova Pedagogia para a Sociedade } \\
\text { Futura: } \\
\text { Protagonismo responsável }\end{array}$ & $978-85-68901-07-6$ & p. $147-153$ & 2016 \\
\hline
\end{tabular}


Saber Humano, ISSN 2446-6298, V. 9, n. 15, p. 186-423, jul./dez. 2019.

\begin{tabular}{|c|c|c|c|c|c|c|}
\hline 6 & $\begin{array}{l}\text { Carmen Ivanete D'Agostini } \\
\text { Spanhol }\end{array}$ & $\begin{array}{l}\text { Formação continuada } \\
\text { em Ontopsicologia: } \\
\text { significados e sentidos }\end{array}$ & $\begin{array}{l}\text { II Congresso Internacional Uma } \\
\text { Nova Pedagogia para a Sociedade } \\
\text { Futura: } \\
\text { Protagonismo responsável }\end{array}$ & $978-85-68901-07-6$ & p. $168-177$ & 2016 \\
\hline 7 & Délis Stona & $\begin{array}{l}\text { A importância da } \\
\text { formação humanista } \\
\text { para o jovem } \\
\text { contemporâneo }\end{array}$ & $\begin{array}{l}\text { II Congresso Internacional Uma } \\
\text { Nova Pedagogia para a Sociedade } \\
\text { Futura: } \\
\text { Protagonismo responsável }\end{array}$ & $978-85-68901-07-6$ & p. $187-192$ & 2016 \\
\hline 8 & $\begin{array}{l}\text { Estela Maris Giordani } \\
\text { Gabriela Mombelli }\end{array}$ & $\begin{array}{l}\text { Pedagogia } \\
\text { Ontopsicológica na } \\
\text { prática de orientação } \\
\text { de estágio em anos } \\
\text { iniciais }\end{array}$ & $\begin{array}{l}\text { II Congresso Internacional Uma } \\
\text { Nova Pedagogia para a Sociedade } \\
\text { Futura: } \\
\text { Protagonismo responsável }\end{array}$ & $978-85-68901-07-6$ & p. $193-206$ & 2016 \\
\hline \multirow[t]{2}{*}{9} & Gabriel de Souza Carrara & Os jovens e o nexo & II Congresso Internacional Uma & $978-85-68901-07-6$ & p. $217-223$ & 2016 \\
\hline & & ontológico & $\begin{array}{l}\text { Nova Pedagogia para a Sociedade } \\
\text { Futura: } \\
\text { Protagonismo responsável }\end{array}$ & & & \\
\hline 10 & $\begin{array}{l}\text { Ângelo Accorsi Moreira } \\
\text { Glauber Benetti Carvalho } \\
\text { Fátima Osmari Burin } \\
\text { Viviane Elias Portela }\end{array}$ & $\begin{array}{l}\text { Metodologia IMPARE } \\
\text { como meio para o } \\
\text { desenvolvimento do } \\
\text { profissionalismo } \\
\text { docente }\end{array}$ & $\begin{array}{l}\text { II Congresso Internacional Uma } \\
\text { Nova Pedagogia para a Sociedade } \\
\text { Futura: } \\
\text { Protagonismo responsável }\end{array}$ & $978-85-68901-07-6$ & p. $224-232$ & 2016 \\
\hline
\end{tabular}


Saber Humano, ISSN 2446-6298, V. 9, n. 15, p. 186-423, jul./dez. 2019.

\begin{tabular}{|c|c|c|c|c|c|c|}
\hline 11 & $\begin{array}{l}\text { Glauber Benetti Carvalho } \\
\text { Ângelo Accorsi Moreira } \\
\text { Tatiane Peixoto Isaía }\end{array}$ & $\begin{array}{l}\text { IMPARE ducação e a } \\
\text { Metodologia Sensibile: } \\
\text { a formação humanista } \\
\text { por meio da educação } \\
\text { musical }\end{array}$ & $\begin{array}{l}\text { II Congresso Internacional Uma } \\
\text { Nova Pedagogia para a Sociedade } \\
\text { Futura: } \\
\text { Protagonismo responsável }\end{array}$ & $978-85-68901-07-6$ & p. $233-242$ & 2016 \\
\hline 12 & Gustavo dos Santos Oliveira & $\begin{array}{l}\text { A autenticidade do } \\
\text { adulto-mãe como } \\
\text { pressuposto da } \\
\text { aplicação de uma } \\
\text { pedagogia funcional }\end{array}$ & $\begin{array}{l}\text { II Congresso Internacional Uma } \\
\text { Nova Pedagogia para a Sociedade } \\
\text { Futura: } \\
\text { Protagonismo responsável }\end{array}$ & $978-85-68901-07-6$ & p. $243-252$ & 2016 \\
\hline 13 & Gustavo Henrique Florêncio & $\begin{array}{l}\text { Relação entre } \\
\text { Inteligências: } \\
\text { Formação de Jovem no } \\
\text { Centro Internacional de } \\
\text { Arte e Cultura } \\
\text { Humanista Recanto } \\
\text { Maestro }\end{array}$ & $\begin{array}{l}\text { II Congresso Internacional Uma } \\
\text { Nova Pedagogia para a Sociedade } \\
\text { Futura: } \\
\text { Protagonismo responsável }\end{array}$ & $978-85-68901-07-6$ & p. $253-262$ & 2016 \\
\hline \multirow[t]{2}{*}{14} & Helena Biasotto & $\begin{array}{l}\text { O contexto do mercado } \\
\text { de trabalho } \\
\text { contemporâneo: }\end{array}$ & $\begin{array}{l}\text { II Congresso Internacional Uma } \\
\text { Nova Pedagogia para a Sociedade } \\
\text { Futura: }\end{array}$ & $978-85-68901-07-6$ & p. 263-274 & 2016 \\
\hline & & $\begin{array}{l}\text { contribuição da } \\
\text { Metodologia } \\
\text { Ontopsicológica para a } \\
\text { formação da } \\
\text { competência de jovens }\end{array}$ & Protagonismo responsável & & & \\
\hline
\end{tabular}




\begin{tabular}{|c|c|c|c|c|c|c|}
\hline 15 & $\begin{array}{l}\text { Josiane Aparecida Martim } \\
\text { Estela Maris Giordani } \\
\text { Márcia Cristiane Rambo }\end{array}$ & \begin{tabular}{|l|} 
Pedagogia \\
Ontopsicológica na \\
prática educativa do \\
pedagogo em formação
\end{tabular} & $\begin{array}{l}\text { II Congresso Internacional Uma } \\
\text { Nova Pedagogia para a Sociedade } \\
\text { Futura: } \\
\text { Protagonismo responsável }\end{array}$ & $978-85-68901-07-6$ & p. $275-287$ & 2016 \\
\hline 16 & $\begin{array}{l}\text { Júlio Cezar Scheid Jane } \\
\text { de Fátima Foliatti } \\
\text { Scheid }\end{array}$ & $\begin{array}{l}\text { Estratégias de práticas } \\
\text { para a promoção } \\
\text { sustentável: enfoque } \\
\text { no protagonismo do } \\
\text { líder }\end{array}$ & $\begin{array}{l}\text { II Congresso Internacional Uma } \\
\text { Nova Pedagogia para a Sociedade } \\
\text { Futura: } \\
\text { Protagonismo responsável }\end{array}$ & $978-85-68901-07-6$ & p. 298-311 & 2016 \\
\hline 17 & Mami Ueno & $\begin{array}{l}\text { Valores humanos, o } \\
\text { saber prático e a } \\
\text { educação: estudo } \\
\text { comparado entre } \\
\text { Brasil, Itália e Japão }\end{array}$ & $\begin{array}{l}\text { II Congresso Internacional Uma } \\
\text { Nova Pedagogia para a Sociedade } \\
\text { Futura: } \\
\text { Protagonismo responsável }\end{array}$ & $978-85-68901-07-6$ & p. $319-335$ & 2016 \\
\hline 18 & Marcela Anton & $\begin{array}{l}\text { Como desenvolver } \\
\text { relações funcionais a } \\
\text { partir da díade }\end{array}$ & $\begin{array}{l}\text { II Congresso Internacional Uma } \\
\text { Nova Pedagogia para a Sociedade } \\
\text { Futura: } \\
\text { Protagonismo responsável }\end{array}$ & $978-85-68901-07-6$ & p. $336-345$ & 2016 \\
\hline 19 & $\begin{array}{l}\text { Márcia Regina Marchezan } \\
\text { Ricardo Schaefer } \\
\text { Eloisa Vieira Ribeiro } \\
\text { Angélica Zitzmann }\end{array}$ & $\begin{array}{l}\text { Formação pessoal e } \\
\text { profissional do NEL: } \\
\text { protagonismo } \\
\text { responsável }\end{array}$ & $\begin{array}{l}\text { II Congresso Internacional Uma } \\
\text { Nova Pedagogia para a Sociedade } \\
\text { Futura: } \\
\text { Protagonismo responsável }\end{array}$ & $978-85-68901-07-6$ & p. $346-352$ & 2016 \\
\hline
\end{tabular}

Elenilton Kohls 
Saber Humano, ISSN 2446-6298, V. 9, n. 15, p. 186-423, jul./dez. 2019.

\begin{tabular}{|c|c|c|c|c|c|c|}
\hline 20 & $\begin{array}{l}\text { Nadege Moreira Pereira } \\
\text { Estela Maris Giordani }\end{array}$ & $\begin{array}{l}\text { Aprendizagens da } \\
\text { Pedagogia } \\
\text { Ontopsicológica } \\
\text { durante o estágio do } \\
\text { ensino fundamental }\end{array}$ & $\begin{array}{l}\text { Il Congresso Internacional Uma } \\
\text { Nova Pedagogia para a Sociedade } \\
\text { Futura: } \\
\text { Protagonismo responsável }\end{array}$ & $978-85-68901-07-6$ & p. $353-363$ & 2016 \\
\hline 21 & $\begin{array}{l}\text { Alexander Ostrovskiy } \\
\text { Tatiana Vereitnova Namdi } \\
\text { Namdi }\end{array}$ & $\begin{array}{l}0 \text { aconselhamento } \\
\text { psicológico de } \\
\text { empreendedores: } \\
\text { abordagens modernas }\end{array}$ & $\begin{array}{l}\text { Il Congresso Internacional Uma } \\
\text { Nova Pedagogia para a Sociedade } \\
\text { Futura: } \\
\text { Protagonismo responsável }\end{array}$ & $978-85-68901-07-6$ & p. 364-369 & 2016 \\
\hline 22 & $\begin{array}{l}\text { Patrícia Wazlawick } \\
\text { Eloy Demarchi Teixeira }\end{array}$ & $\begin{array}{l}\text { Cultura Humanista e } \\
\text { protagonismo } \\
\text { responsável: os valores } \\
\text { do humanismo } \\
\text { histórico perene para a } \\
\text { educação } \\
\text { contemporânea }\end{array}$ & $\begin{array}{l}\text { Il Congresso Internacional Uma } \\
\text { Nova Pedagogia para a Sociedade } \\
\text { Futura: } \\
\text { Protagonismo responsável }\end{array}$ & $978-85-68901-07-6$ & p. $370-381$ & 2016 \\
\hline 23 & Priscila Valduga Dinarte & $\begin{array}{l}\text { Direito à educação e } \\
\text { novas tecnologias: a } \\
\text { necessária formação } \\
\text { para a cidadania }\end{array}$ & $\begin{array}{l}\text { II Congresso Internacional Uma } \\
\text { Nova Pedagogia para a Sociedade } \\
\text { Futura: } \\
\text { Protagonismo responsável }\end{array}$ & $978-85-68901-07-6$ & p. 382-391 & 2016 \\
\hline 24 & Rosane Leal da Silva & $\begin{array}{l}\text { Os desafios à educação } \\
\text { na era digital: do } \\
\text { paradigma da } \\
\text { reprodução ao } \\
\text { desenvolvimento da } \\
\text { autonomia do } \\
\text { educando }\end{array}$ & $\begin{array}{l}\text { Il Congresso Internacional Uma } \\
\text { Nova Pedagogia para a Sociedade } \\
\text { Futura: } \\
\text { Protagonismo responsável }\end{array}$ & $978-85-68901-07-6$ & p. $392-400$ & 2016 \\
\hline
\end{tabular}




\begin{tabular}{|c|c|c|c|c|c|c|}
\hline 25 & $\begin{array}{l}\text { Vanice Hentges } \\
\text { Ana Marli Bulegon }\end{array}$ & $\begin{array}{l}\text { Programação de } \\
\text { softwares no ensino } \\
\text { fundamental e suas } \\
\text { contribuições no } \\
\text { desenvolvimento do } \\
\text { pensamento } \\
\text { lógicomatemático: uso } \\
\text { do } \\
\text { Scratch }\end{array}$ & $\begin{array}{l}\text { II Congresso Internacional Uma } \\
\text { Nova Pedagogia para a Sociedade } \\
\text { Futura: } \\
\text { Protagonismo responsável }\end{array}$ & $978-85-68901-07-6$ & p. $401-412$ & 2016 \\
\hline 26 & $\begin{array}{l}\text { Tatiana Vereitnova } \\
\text { Daria Sklemina } \\
\text { Dana Namdi }\end{array}$ & $\begin{array}{l}\text { Bem-estar psicológico } \\
\text { como base para a } \\
\text { eficiência pessoal: } \\
\text { abordagem } \\
\text { ontopsicológica }\end{array}$ & $\begin{array}{l}\text { II Congresso Internacional Uma } \\
\text { Nova Pedagogia para a Sociedade } \\
\text { Futura: } \\
\text { Protagonismo responsável }\end{array}$ & $978-85-68901-07-6$ & p. $413-419$ & 2016 \\
\hline 27 & $\begin{array}{l}\text { Viviane Thaís de Araújo } \\
\text { Luzia A. de C. M. Longo }\end{array}$ & $\begin{array}{l}\text { Parceria de valor: uma } \\
\text { jornada de crescimento } \\
\text { mútuo e transformação } \\
\text { social }\end{array}$ & $\begin{array}{l}\text { II Congresso Internacional Uma } \\
\text { Nova Pedagogia para a Sociedade } \\
\text { Futura: } \\
\text { Protagonismo responsável }\end{array}$ & $978-85-68901-07-6$ & p. $420-428$ & 2016 \\
\hline 28 & $\begin{array}{l}\text { Walter Akio Goya } \\
\text { Tereza Cristina Melo de } \\
\text { Brito Carvalho } \\
\text { Ana Maria Domingues Luz } \\
\text { Araci Martins Musolino }\end{array}$ & $\begin{array}{l}\text { Projeto Eco-Eletro: } \\
\text { segurança, renda e } \\
\text { Realização Pessoal } \\
\text { Através da Destinação } \\
\text { Adequada de REEEs }\end{array}$ & $\begin{array}{l}\text { II Congresso Internacional Uma } \\
\text { Nova Pedagogia para a Sociedade } \\
\text { Futura: } \\
\text { Protagonismo responsável }\end{array}$ & $978-85-68901-07-6$ & p. $429-437$ & 2016 \\
\hline
\end{tabular}


Saber Humano, ISSN 2446-6298, V. 9, n. 15, p. 186-423, jul./dez. 2019.

\begin{tabular}{|c|c|c|c|c|c|c|}
\hline 29 & Wilian Mauri Friedrich Neu & $\begin{array}{l}\text { Protagonismo e } \\
\text { responsabilidade na } \\
\text { formação no jovem }\end{array}$ & $\begin{array}{l}\text { Il Congresso Internacional Uma } \\
\text { Nova Pedagogia para a Sociedade } \\
\text { Futura: } \\
\text { Protagonismo responsável }\end{array}$ & $978-85-68901-07-6$ & p. $438-445$ & 2016 \\
\hline \multirow[t]{2}{*}{30} & Ana Paula Coelho Tonolli & $\begin{array}{l}\text { A responsabilidade do } \\
\text { educador na }\end{array}$ & $\begin{array}{l}\text { Il Congresso Internacional Uma } \\
\text { Nova Pedagogia para a }\end{array}$ & $978-85-68901-07-6$ & p. $459-465$ & 2016 \\
\hline & & $\begin{array}{l}\text { construção de uma } \\
\text { sociedade responsável: } \\
\text { da realização de si } \\
\text { mesmo a atuação como } \\
\text { função social - a } \\
\text { contribuição da } \\
\text { autenticação } \\
\text { ontopsicológica }\end{array}$ & $\begin{array}{l}\text { Sociedade Futura: } \\
\text { Protagonismo responsável }\end{array}$ & & & \\
\hline 31 & Adelaide dos Santos Dias & $\begin{array}{l}\text { Aprofundamento } \\
\text { teórico sobre as } \\
\text { imagens oníricas e a } \\
\text { correlação com os } \\
\text { valores do em si } \\
\text { organísmico e os } \\
\text { valores sistêmicosociais }\end{array}$ & $\begin{array}{l}\text { Il Congresso Internacional Uma } \\
\text { Nova Pedagogia para a Sociedade } \\
\text { Futura: } \\
\text { Protagonismo responsável }\end{array}$ & $978-85-68901-07-6$ & p. $446-451$ & 2016 \\
\hline
\end{tabular}


Saber Humano, ISSN 2446-6298, V. 9, n. 15, p. 186-423, jul./dez. 2019.

\begin{tabular}{|c|c|c|c|c|c|c|}
\hline 32 & $\begin{array}{l}\text { Ana Paula Mariana } \\
\text { Pregardier }\end{array}$ & $\begin{array}{l}\text { Método lúdicovivencial } \\
\text { de formação de hábitos } \\
\text { financeiros e a } \\
\text { abordagem da } \\
\text { Pedagogia } \\
\text { Ontopsicológica }\end{array}$ & $\begin{array}{l}\text { II Congresso Internacional Uma } \\
\text { Nova Pedagogia para a Sociedade } \\
\text { Futura: } \\
\text { Protagonismo responsável }\end{array}$ & $978-85-68901-07-6$ & p. $466-475$ & 2016 \\
\hline 33 & $\begin{array}{l}\text { Ana Valéria Silva Gonçalves } \\
\text { Estela Maris Giordani }\end{array}$ & $\begin{array}{l}\text { A Pedagogia } \\
\text { Ontopsicológica na } \\
\text { mediação nos processos } \\
\text { de divórcio: como ficam } \\
\text { os filhos? }\end{array}$ & $\begin{array}{l}\text { II Congresso Internacional Uma } \\
\text { Nova Pedagogia para a Sociedade } \\
\text { Futura: } \\
\text { Protagonismo responsável }\end{array}$ & $978-85-68901-07-6$ & p. $476-489$ & 2016 \\
\hline \multirow[t]{2}{*}{34} & Arlete Salante & Gênero e Humanismo & II Congresso Internacional Uma & $978-85-68901-07-6$ & p. $490-497$ & 2016 \\
\hline & & $\begin{array}{l}\text { na formação de alunas } \\
\text { de Psicologia }\end{array}$ & $\begin{array}{l}\text { Nova Pedagogia para a Sociedade } \\
\text { Futura: } \\
\text { Protagonismo responsável }\end{array}$ & & & \\
\hline 35 & Bernardina Amantino & Liderar com estilo & $\begin{array}{l}\text { II Congresso Internacional Uma } \\
\text { Nova Pedagogia para a Sociedade } \\
\text { Futura: } \\
\text { Protagonismo responsável }\end{array}$ & $978-85-68901-07-6$ & p. $498-503$ & 2016 \\
\hline 36 & Cleoci Werle Rockenbach & $\begin{array}{l}\text { O estímulo ao } \\
\text { protagonismo } \\
\text { responsável na política } \\
\text { de assistência social }\end{array}$ & $\begin{array}{l}\text { II Congresso Internacional Uma } \\
\text { Nova Pedagogia para a Sociedade } \\
\text { Futura: } \\
\text { Protagonismo responsável }\end{array}$ & $978-85-68901-07-6$ & p. 504-509 & 2016 \\
\hline
\end{tabular}




\begin{tabular}{|c|c|c|c|c|c|c|}
\hline 37 & $\begin{array}{l}\text { Eloísa Vieira Ribeiro } \\
\text { Jacieli Vedovato Dalla Nora }\end{array}$ & $\begin{array}{l}\text { O crescimento do } \\
\text { jovem através da } \\
\text { Pedagogia } \\
\text { Ontopsicológica }\end{array}$ & $\begin{array}{l}\text { II Congresso Internacional Uma } \\
\text { Nova Pedagogia para a Sociedade } \\
\text { Futura: } \\
\text { Protagonismo responsável }\end{array}$ & $978-85-68901-07-6$ & p. $515-523$ & 2016 \\
\hline 38 & $\begin{array}{l}\text { Fernando Duarte Martins } \\
\text { de Oliveira }\end{array}$ & $\begin{array}{l}\text { Educação Marcial: a } \\
\text { contribuição da escola } \\
\text { de artes marciais no } \\
\text { processo formativo do } \\
\text { jovem protagonista } \\
\text { responsável }\end{array}$ & $\begin{array}{l}\text { II Congresso Internacional Uma } \\
\text { Nova Pedagogia para a Sociedade } \\
\text { Futura: } \\
\text { Protagonismo responsável }\end{array}$ & $978-85-68901-07-6$ & p. 524-531 & 2016 \\
\hline 39 & $\begin{array}{l}\text { Gabriela Mombelli } \\
\text { Fernando Belgravo Kohaut } \\
\text { da Silva } \\
\text { Estela Maris Giordani }\end{array}$ & $\begin{array}{l}\text { Princípios da } \\
\text { Pedagogia } \\
\text { Ontopsicológica na } \\
\text { educação de um filho }\end{array}$ & $\begin{array}{l}\text { II Congresso Internacional Uma } \\
\text { Nova Pedagogia para a Sociedade } \\
\text { Futura: } \\
\text { Protagonismo responsável }\end{array}$ & $978-85-68901-07-6$ & $535-546$ & 2016 \\
\hline 40 & Ivo Canisio Mallmann & $\begin{array}{l}\text { Pedagogia da ação } \\
\text { prática na empresa }\end{array}$ & $\begin{array}{l}\text { II Congresso Internacional Uma } \\
\text { Nova Pedagogia para a Sociedade } \\
\text { Futura: }\end{array}$ & $978-85-68901-07-6$ & p. $555-563$ & 2016 \\
\hline & & & Protagonismo responsável & & & \\
\hline 41 & $\begin{array}{l}\text { Maria Alice Schuch } \\
\text { http://lattes.cnpq.br/57682 } \\
02542112018\end{array}$ & $\begin{array}{l}\text { A mulher professora e } \\
\text { a professora mulher: } \\
\text { um estudo acerca da } \\
\text { responsabilidade } \\
\text { docente }\end{array}$ & $\begin{array}{l}\text { II Congresso Internacional Uma } \\
\text { Nova Pedagogia para a Sociedade } \\
\text { Futura: } \\
\text { Protagonismo responsável }\end{array}$ & $978-85-68901-07-6$ & p. $580-587$ & 2016 \\
\hline
\end{tabular}


Saber Humano, ISSN 2446-6298, V. 9, n. 15, p. 186-423, jul./dez. 2019.

\begin{tabular}{|c|c|c|c|c|c|c|}
\hline 42 & Patrícia Wazlawick & $\begin{array}{l}\text { Pedagogia } \\
\text { ontopsicológica, } \\
\text { desenvolvimento da } \\
\text { personalidade e } \\
\text { formação de jovens na } \\
\text { universidade }\end{array}$ & $\begin{array}{l}\text { II Congresso Internacional Uma } \\
\text { Nova Pedagogia para a Sociedade } \\
\text { Futura: } \\
\text { Protagonismo responsável }\end{array}$ & $978-85-68901-07-6$ & p. $600-615$ & 2016 \\
\hline 43 & Rosane Maria Neves & $\begin{array}{l}\text { Empreendedorismo e } \\
\text { criatividade em ação: } \\
\text { trajetória exitosa na } \\
\text { formação do jovem } \\
\text { "protagonista } \\
\text { responsável" }\end{array}$ & $\begin{array}{l}\text { II Congresso Internacional Uma } \\
\text { Nova Pedagogia para a Sociedade } \\
\text { Futura: } \\
\text { Protagonismo responsável }\end{array}$ & $978-85-68901-07-6$ & p. $621-642$ & 2016 \\
\hline 44 & $\begin{array}{l}\text { Talita Moser } \\
\text { Elenice Guimarães }\end{array}$ & $\begin{array}{l}\text { Educação para ser: um } \\
\text { relato pessoal }\end{array}$ & $\begin{array}{l}\text { II Congresso Internacional Uma } \\
\text { Nova Pedagogia para a Sociedade } \\
\text { Futura: } \\
\text { Protagonismo responsável }\end{array}$ & $978-85-68901-07-6$ & p. $647-652$ & 2016 \\
\hline 45 & Tiago de Moraes Kasper & $\begin{array}{l}\text { A responsabilidade do } \\
\text { indivíduo na obtenção } \\
\text { da autonomia pessoal e } \\
\text { na construção de uma } \\
\text { sociedade baseada em } \\
\text { valores }\end{array}$ & $\begin{array}{l}\text { II Congresso Internacional Uma } \\
\text { Nova Pedagogia para a Sociedade } \\
\text { Futura: } \\
\text { Protagonismo responsável }\end{array}$ & $978-85-68901-07-6$ & p. $661-666$ & 2016 \\
\hline & & humanistas & & & & \\
\hline
\end{tabular}




\begin{tabular}{|c|c|c|c|c|c|c|}
\hline 46 & $\begin{array}{l}\text { Alana Azevedo } \\
\text { Ezequiel Losekann Drews }\end{array}$ & $\begin{array}{l}\text { O diferencial } \\
\text { profissional do jovem } \\
\text { universitário que } \\
\text { estuda na Faculdade } \\
\text { Antonio Meneghetti } \\
\text { (AMF) }\end{array}$ & $\begin{array}{l}\text { Il Congresso Internacional Uma } \\
\text { Nova Pedagogia para a Sociedade } \\
\text { Futura: } \\
\text { Protagonismo responsável }\end{array}$ & $978-85-68901-07-6$ & p. $667-670$ & 2016 \\
\hline 47 & Bernadina Amantino & $\begin{array}{l}\text { Empresa: oportunidade } \\
\text { para o jovem fazer, } \\
\text { saber e ser }\end{array}$ & $\begin{array}{l}\text { II Congresso Internacional Uma } \\
\text { Nova Pedagogia para a Sociedade } \\
\text { Futura: } \\
\text { Protagonismo responsável }\end{array}$ & $978-85-68901-07-6$ & p. $676-678$ & 2016 \\
\hline 48 & $\begin{array}{l}\text { Dionatas Ferreira de } \\
\text { Oliveira } \\
\text { Hyago Azzolim Aguirre }\end{array}$ & $\begin{array}{l}\text { Tecnologia da } \\
\text { informação entre } \\
\text { crianças e adolescentes }\end{array}$ & $\begin{array}{l}\text { II Congresso Internacional Uma } \\
\text { Nova Pedagogia para a Sociedade } \\
\text { Futura: } \\
\text { Protagonismo responsável }\end{array}$ & $978-85-68901-07-6$ & p. $679-683$ & 2016 \\
\hline 49 & Djovani Pozzobon & $\begin{array}{l}\text { Educação e critério } \\
\text { ético do ser humano: a } \\
\text { Pedagogia } \\
\text { Ontopsicológica } \\
\text { aplicada na formação } \\
\text { profissional do jovem } \\
\text { do curso de direito }\end{array}$ & $\begin{array}{l}\text { II Congresso Internacional Uma } \\
\text { Nova Pedagogia para a Sociedade } \\
\text { Futura: } \\
\text { Protagonismo responsável }\end{array}$ & $978-85-68901-07-6$ & p. $684-696$ & 2016 \\
\hline 50 & Flávia Lourenço da Silva & Egoísmo sadio & $\begin{array}{l}\text { II Congresso Internacional Uma } \\
\text { Nova Pedagogia para a Sociedade } \\
\text { Futura: Protagonismo responsável }\end{array}$ & $978-85-68901-07-6$ & p. $701-705$ & 2016 \\
\hline 51 & $\begin{array}{l}\text { Gabrielle Viegas Foletto } \\
\text { Adriane Mendes }\end{array}$ & $\begin{array}{l}\text { Proposta de um guia } \\
\text { para a escolha dos }\end{array}$ & $\begin{array}{l}\text { II Congresso Internacional Uma } \\
\text { Nova Pedagogia para a Sociedade }\end{array}$ & $978-85-68901-07-6$ & p. $713-719$ & 2016 \\
\hline
\end{tabular}


Saber Humano, ISSN 2446-6298, V. 9, n. 15, p. 186-423, jul./dez. 2019.

\begin{tabular}{|c|c|c|c|c|c|c|}
\hline & & $\begin{array}{l}\text { colaboradores do líder } \\
\text { baseado nos oito } \\
\text { critérios para escolha } \\
\text { dos colaboradores } \\
\text { explicitados pela FOIL }\end{array}$ & Futura: Protagonismo responsável & & & \\
\hline 52 & Gustavo Fronza de Prá & $\begin{array}{l}\text { Breve aceno sobre } \\
\text { jovem e existência }\end{array}$ & $\begin{array}{l}\text { Il Congresso Internacional Uma } \\
\text { Nova Pedagogia para a Sociedade } \\
\text { Futura: Protagonismo responsável }\end{array}$ & $978-85-68901-07-6$ & p. $720-723$ & 2016 \\
\hline 53 & Henrique Marafiga Martins & $\begin{array}{l}\text { Metodologia } \\
\text { educacional por projeto }\end{array}$ & $\begin{array}{l}\text { Il Congresso Internacional Uma } \\
\text { Nova Pedagogia para a Sociedade } \\
\text { Futura: Protagonismo responsável }\end{array}$ & $978-85-68901-07-6$ & p. $724-729$ & 2016 \\
\hline 54 & Karin Jorgensen Milano & $\begin{array}{l}\text { A filosofia como base } \\
\text { para o conhecimento } \\
\text { do ser humano }\end{array}$ & $\begin{array}{l}\text { Il Congresso Internacional Uma } \\
\text { Nova Pedagogia para a Sociedade } \\
\text { Futura: Protagonismo responsável }\end{array}$ & $978-85-68901-07-6$ & p. $730-733$ & 2016 \\
\hline 55 & $\begin{array}{l}\text { Luis Paulo Nery Silveira } \\
\text { Jardel Felipe Knirsch }\end{array}$ & $\begin{array}{l}\text { Como a programação } \\
\text { pode auxiliar no } \\
\text { desenvolvimento do } \\
\text { raciocínio lógico em } \\
\text { crianças, adolescentes } \\
\text { e jovens }\end{array}$ & $\begin{array}{l}\text { Il Congresso Internacional Uma } \\
\text { Nova Pedagogia para a Sociedade } \\
\text { Futura: Protagonismo responsável }\end{array}$ & $978-85-68901-07-6$ & p. $734-737$ & 2016 \\
\hline 56 & $\begin{array}{l}\text { Luiza de Fátima das Neves } \\
\text { Fiorezi }\end{array}$ & $\begin{array}{l}\text { Paradigmas } \\
\text { pedagógicos na } \\
\text { consolidação da } \\
\text { autonomia }\end{array}$ & $\begin{array}{l}\text { Il Congresso Internacional Uma } \\
\text { Nova Pedagogia para a Sociedade } \\
\text { Futura: Protagonismo responsável }\end{array}$ & $978-85-68901-07-6$ & p. $742-746$ & 2016 \\
\hline
\end{tabular}


Saber Humano, ISSN 2446-6298, V. 9, n. 15, p. 186-423, jul./dez. 2019.

\begin{tabular}{|c|c|c|c|c|c|c|}
\hline 57 & Natália dos Santos & A formação do jovem: & II Congresso Internacional Uma & $978-85-68901-07-6$ & p. 761-766 & 2016 \\
\hline & Conceição & $\begin{array}{l}\text { relação entre os } \\
\text { principais estereótipos } \\
\text { e a responsabilidade } \\
\text { pessoal }\end{array}$ & $\begin{array}{l}\text { Nova Pedagogia para a Sociedade } \\
\text { Futura: Protagonismo responsável }\end{array}$ & & & \\
\hline 58 & Patrícia Wazlawick & $\begin{array}{l}\text { Pedagogia } \\
\text { Ontopsicológica e os } \\
\text { sete pontos do } \\
\text { crescimento: uma } \\
\text { apresentação }\end{array}$ & $\begin{array}{l}\text { II Congresso Internacional Uma } \\
\text { Nova Pedagogia para a Sociedade } \\
\text { Futura: Protagonismo responsável }\end{array}$ & $978-85-68901-07-6$ & p. $767-774$ & 2016 \\
\hline 59 & $\begin{array}{l}\text { Rhuan Matheus Drescher } \\
\text { Letícia Silva Machado } \\
\text { Hercules Affonso Karkow }\end{array}$ & $\begin{array}{l}\text { Aplicação da formação } \\
\text { empreendedora e } \\
\text { liderança nas escolas }\end{array}$ & $\begin{array}{l}\text { II Congresso Internacional Uma } \\
\text { Nova Pedagogia para a Sociedade } \\
\text { Futura: Protagonismo responsável }\end{array}$ & $978-85-68901-07-6$ & p. $775-777$ & 2016 \\
\hline 60 & Ricardo Rechden Barcellos & $\begin{array}{l}\text { O aprendizado da } \\
\text { análise ontopsicológica } \\
\text { da pessoa e intervenção }\end{array}$ & $\begin{array}{l}\text { II Congresso Internacional Uma } \\
\text { Nova Pedagogia para a Sociedade } \\
\text { Futura: Protagonismo responsável }\end{array}$ & $978-85-68901-07-6$ & p. 778-784 & 2016 \\
\hline 61 & $\begin{array}{l}\text { Rosana Niederauer } \\
\text { Marques } \\
\text { Xavéle Braatz Petermann } \\
\text { Everton Lüdke }\end{array}$ & $\begin{array}{l}\text { Promoção da saúde na } \\
\text { construção de conceitos } \\
\text { e formação da } \\
\text { consciência do primeiro } \\
\text { ano de vida até a } \\
\text { entrada na escola }\end{array}$ & $\begin{array}{l}\text { II Congresso Internacional Uma } \\
\text { Nova Pedagogia para a Sociedade } \\
\text { Futura: Protagonismo responsável }\end{array}$ & $978-85-68901-07-6$ & p. $785-789$ & 2016 \\
\hline
\end{tabular}




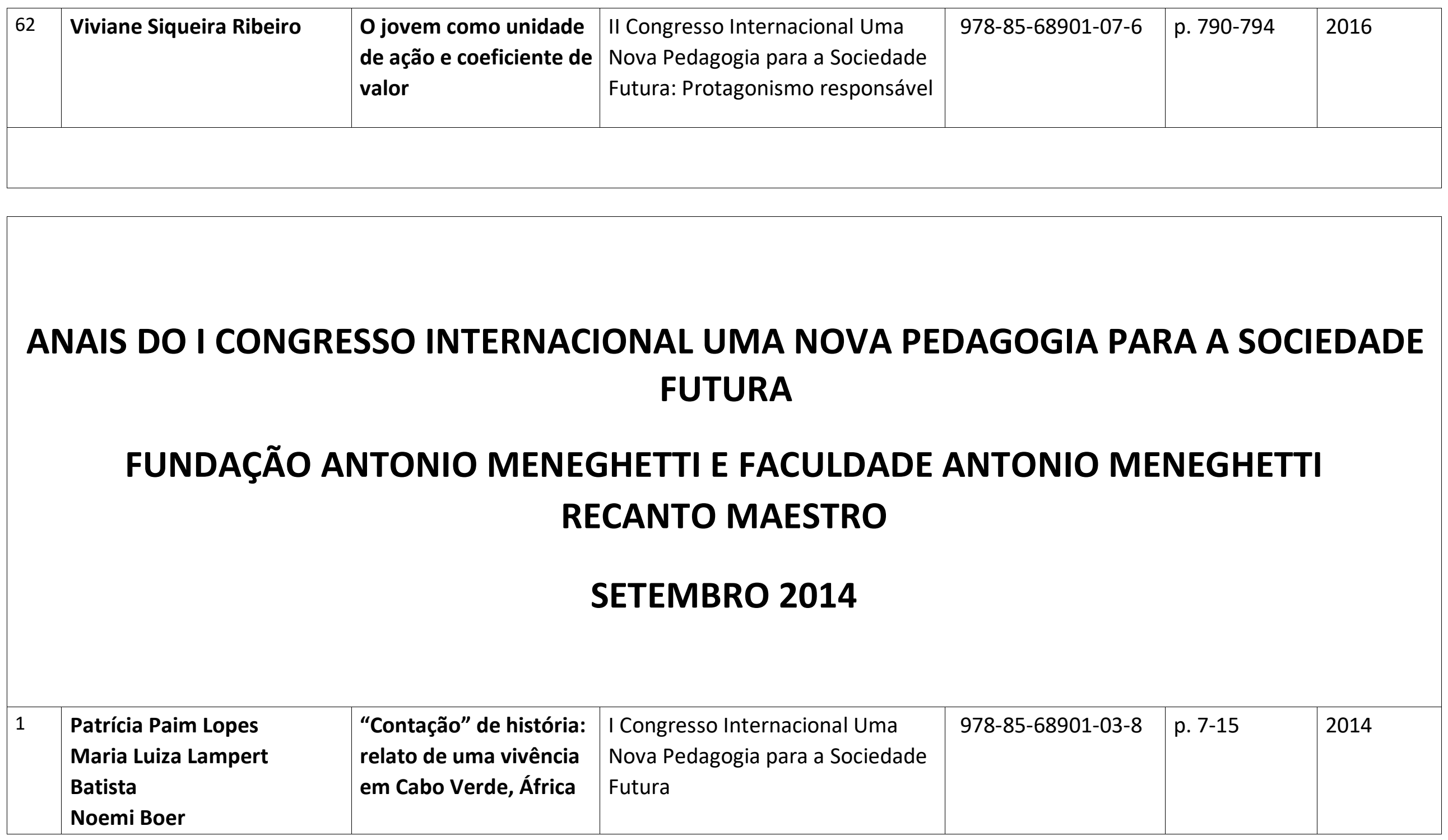




\begin{tabular}{|l|l|l|l|l|l|}
\hline 2 & $\begin{array}{l}\text { Vera Lúcia Rodegheri Estela } \\
\text { Maris Giordani }\end{array}$ & $\begin{array}{l}\text { O contexto da crise das } \\
\text { ciências e proposta da } \\
\text { Ontopsicologia aplicada } \\
\text { à Pedagogia no Centro } \\
\text { Internacional de Arte e } \\
\text { Cultura Humanista }\end{array}$ & $\begin{array}{l}\text { I Congresso Internacional Uma } \\
\text { Nova Pedagogia para a Sociedade }\end{array}$ & $978-85-68901-03-8$ & p. 16-28 \\
\hline
\end{tabular}

\begin{tabular}{|c|c|c|c|c|c|c|}
\hline & & Recanto Maestro & & & & \\
\hline 3 & $\begin{array}{l}\text { Karoline da Silva Guedes de } \\
\text { Freitas } \\
\text { Kellen Machado dos Santos } \\
\text { Padilha } \\
\text { Estela Maris Giordani }\end{array}$ & $\begin{array}{l}\text { O curso de Licenciatura } \\
\text { em Pedagogia para } \\
\text { quem não quer exercer } \\
\text { a profissão professor }\end{array}$ & $\begin{array}{l}\text { I Congresso Internacional Uma } \\
\text { Nova Pedagogia para a Sociedade } \\
\text { Futura }\end{array}$ & $978-85-68901-03-8$ & p. $29-43$ & 2014 \\
\hline 4 & $\begin{array}{l}\text { Ana Carolina Marzzari } \\
\text { Norton Soares } \\
\text { Joana Gabriela } \\
\text { Fabiane Bachinski } \\
\text { Ana Rubia Burin } \\
\text { Maéli Mattos } \\
\text { Patricia Wazlawick } \\
\text { Vera Rodegheri }\end{array}$ & $\begin{array}{l}\text { A Humanidade } \\
\text { buscando a civilização }\end{array}$ & $\begin{array}{l}\text { I Congresso Internacional Uma } \\
\text { Nova Pedagogia para a Sociedade } \\
\text { Futura }\end{array}$ & $978-85-68901-03-8$ & p. $44-48$ & 2014 \\
\hline 5 & $\begin{array}{l}\text { Josiane Barbieri Rachel } \\
\text { Eckert }\end{array}$ & $\begin{array}{l}\text { Relação do jovem com } \\
\text { o Humanismo }\end{array}$ & $\begin{array}{l}\text { I Congresso Internacional Uma } \\
\text { Nova Pedagogia para a Sociedade } \\
\text { Futura }\end{array}$ & $978-85-68901-03-8$ & p. $59-65$ & 2014 \\
\hline
\end{tabular}


Saber Humano, ISSN 2446-6298, V. 9, n. 15, p. 186-423, jul./dez. 2019.

\begin{tabular}{|c|c|c|c|c|c|c|}
\hline 6 & $\begin{array}{l}\text { Hivi de Jesus Souto Koppe } \\
\text { Noemi Boer }\end{array}$ & $\begin{array}{l}\text { Pedagogia ambiental: } \\
\text { concepções de } \\
\text { estudantes }\end{array}$ & $\begin{array}{l}\text { I Congresso Internacional Uma } \\
\text { Nova Pedagogia para a Sociedade } \\
\text { Futura }\end{array}$ & $978-85-68901-03-8$ & p. $66-75$ & 2014 \\
\hline 7 & $\begin{array}{l}\text { Gabriely Muniz Siqueira } \\
\text { Estela Maris Giordani }\end{array}$ & $\begin{array}{l}\text { Pedagogia } \\
\text { Ontopsicológica e } \\
\text { dificuldades de } \\
\text { adaptação na educação } \\
\text { infantil }\end{array}$ & $\begin{array}{l}\text { I Congresso Internacional Uma } \\
\text { Nova Pedagogia para a Sociedade } \\
\text { Futura }\end{array}$ & $978-85-68901-03-8$ & p. 76-96 & 2014 \\
\hline 8 & $\begin{array}{l}\text { Eduardo Panta Weber Estela } \\
\text { Maris Giordani }\end{array}$ & $\begin{array}{l}\text { Uma reflexão sobre a } \\
\text { arquitetura nos } \\
\text { espaços da educação }\end{array}$ & $\begin{array}{l}\text { I Congresso Internacional Uma } \\
\text { Nova Pedagogia para a Sociedade } \\
\text { Futura }\end{array}$ & $978-85-68901-03-8$ & p. $97-111$ & 2014 \\
\hline 9 & $\begin{array}{l}\text { Ana Marli Bulegon Helena } \\
\text { Biasotto }\end{array}$ & $\begin{array}{l}\text { Contribuições da } \\
\text { Psicotea para o ensino e } \\
\text { a aprendizagem de } \\
\text { conceitos de } \\
\text { Matemática }\end{array}$ & $\begin{array}{l}\text { I Congresso Internacional Uma } \\
\text { Nova Pedagogia para a Sociedade } \\
\text { Futura }\end{array}$ & $978-85-68901-03-8$ & p. $112-122$ & 2014 \\
\hline 10 & $\begin{array}{l}\text { Bruna Marquetti } \\
\text { Dallepiane } \\
\text { Estela Maris Giordani }\end{array}$ & $\begin{array}{l}\text { A Pedagogia } \\
\text { Ontopsicológica } \\
\text { aplicada ao Projeto } \\
\text { "Orquestra Juvenil } \\
\text { Recanto Maestro" }\end{array}$ & $\begin{array}{l}\text { I Congresso Internacional Uma } \\
\text { Nova Pedagogia para a Sociedade } \\
\text { Futura }\end{array}$ & $978-85-68901-03-8$ & p. $123-139$ & 2014 \\
\hline
\end{tabular}


Saber Humano, ISSN 2446-6298, V. 9, n. 15, p. 186-423, jul./dez. 2019.

\begin{tabular}{|c|c|c|c|c|c|c|}
\hline 11 & $\begin{array}{l}\text { Patrícia Wazlawick } \\
\text { Wesley Lacerda e Silva }\end{array}$ & $\begin{array}{l}\text { Resultados da } \\
\text { Pedagogia } \\
\text { Ontopsicológica } \\
\text { aplicada na formação } \\
\text { pessoal e profissional } \\
\text { de jovens no ensino } \\
\text { superior universitário }\end{array}$ & $\begin{array}{l}\text { I Congresso Internacional Uma } \\
\text { Nova Pedagogia para a Sociedade } \\
\text { Futura }\end{array}$ & $978-85-68901-03-8$ & p. $140-158$ & 2014 \\
\hline 12 & $\begin{array}{l}\text { Estela Maris Giordani } \\
\text { Jaqueline de Gaspari } \\
\text { Daniele Barros Vargas } \\
\text { Furtado }\end{array}$ & $\begin{array}{l}\text { Formação do pedagogo } \\
\text { no estágio curricular de } \\
\text { ensino fundamental: } \\
\text { aplicação da Pedagogia } \\
\text { Ontopsicológica }\end{array}$ & $\begin{array}{l}\text { I Congresso Internacional Uma } \\
\text { Nova Pedagogia para a Sociedade } \\
\text { Futura }\end{array}$ & $978-85-68901-03-8$ & p. $159-169$ & 2014 \\
\hline 13 & Claudiane Weber & $\begin{array}{l}\text { As particularidades da } \\
\text { atitude à vida no } \\
\text { campo: Jovens Sul } \\
\text { Brasileiros }\end{array}$ & $\begin{array}{l}\text { I Congresso Internacional Uma } \\
\text { Nova Pedagogia para a Sociedade } \\
\text { Futura }\end{array}$ & $978-85-68901-03-8$ & p. $170-178$ & 2014 \\
\hline 14 & Karoline da Silva Guedes de & Teoria e a prática: & I Congresso Internacional Uma & $978-85-68901-03-8$ & p. $179-188$ & 2014 \\
\hline
\end{tabular}

\begin{tabular}{|l|l|l|l|l|}
\hline $\begin{array}{l}\text { Freitas } \\
\text { Kellen Machado dos Sa } \\
\text { Padilha } \\
\text { Estela Maris Giordani }\end{array}$ & $\begin{array}{l}\text { elementos de Pedagogia } \\
\text { Ontopsicológica } \\
\text { aprendidas nas } \\
\text { orientações de estágio }\end{array}$ & $\begin{array}{l}\text { Nova Pedagogia para a Sociedade } \\
\text { Futura }\end{array}$ & \\
\hline
\end{tabular}


Saber Humano, ISSN 2446-6298, V. 9, n. 15, p. 186-423, jul./dez. 2019.

\begin{tabular}{|c|c|c|c|c|c|c|}
\hline 15 & $\begin{array}{l}\text { Lilian Werner Philippi d } \\
\text { Silva }\end{array}$ & $\begin{array}{l}\text { Considerações sobre a } \\
\text { aplicação da Pedagogia } \\
\text { Ontopsicológica a } \\
\text { jovens: um relato de } \\
\text { experiência }\end{array}$ & $\begin{array}{l}\text { I Congresso Internacional Uma } \\
\text { Nova Pedagogia para a Sociedade } \\
\text { Futura }\end{array}$ & $978-85-68901-03-8$ & p. $199-200$ & 2014 \\
\hline 16 & Arlete Salante & $\begin{array}{l}\text { Gerações Y e Z: o } \\
\text { desafio na gestão de } \\
\text { pessoas }\end{array}$ & $\begin{array}{l}\text { I Congresso Internacional Uma } \\
\text { Nova Pedagogia para a Sociedade } \\
\text { Futura }\end{array}$ & $978-85-68901-03-8$ & p. $201-210$ & 2014 \\
\hline 17 & $\begin{array}{l}\text { Patrícia Rossato } \\
\text { Estela Maris Giordani }\end{array}$ & $\begin{array}{l}\text { Pedagogia } \\
\text { Ontopsicológica: } \\
\text { educação ao saber } \\
\text { servir no Atelier Escola } \\
\text { Viva }\end{array}$ & $\begin{array}{l}\text { I Congresso Internacional Uma } \\
\text { Nova Pedagogia para a Sociedade } \\
\text { Futura }\end{array}$ & $978-85-68901-03-8$ & p. $211-224$ & 2014 \\
\hline 18 & Nádia Isabel de Souza & $\begin{array}{l}\text { A contribuição do } \\
\text { Projeto OIKOS para o } \\
\text { alcance do } 7^{\circ} \text { ODM no } \\
\text { Recanto Maestro-RS }\end{array}$ & $\begin{array}{l}\text { I Congresso Internacional } \\
\text { Responsabilidade e Reciprocidade }\end{array}$ & $978-85-68901-03-8$ & p. 1-8 & 2011 \\
\hline 19 & $\begin{array}{l}\text { Ana Maris Petry, } \\
\qquad \text { Gal } \\
\text { Rockenbach de Oliveira, } \\
\text { Ricardo } \\
\text { Schaefer }\end{array}$ & $\begin{array}{l}\text { A forma mentis de uma } \\
\text { sociedade sustentável: } \\
\text { uma proposta de } \\
\text { formação de jovens }\end{array}$ & $\begin{array}{l}\text { I Congresso Internacional Uma } \\
\text { Nova Pedagogia para a Sociedade } \\
\text { Futura }\end{array}$ & $978-85-68901-03-8$ & p. $17-27$ & 2011 \\
\hline
\end{tabular}

\begin{tabular}{|l|l|l|l|l|l|l|}
\hline 20 & Ana Claudia Valentin & A formação & I Congresso Internacional Uma & $978-85-68901-03-8$ & p. 28-39 & 2011 \\
\hline
\end{tabular}


Saber Humano, ISSN 2446-6298, V. 9, n. 15, p. 186-423, jul./dez. 2019.

\begin{tabular}{|c|c|c|c|c|c|c|}
\hline & Montenegro & $\begin{array}{l}\text { ontopsicológica de } \\
\text { jovens e a mentalidade } \\
\text { sustentável }\end{array}$ & $\begin{array}{l}\text { Nova Pedagogia para a Sociedade } \\
\text { Futura }\end{array}$ & & & \\
\hline 21 & $\begin{array}{l}\text { Estela } \quad \text { Maris } \\
\text { Giordani }\end{array}$ & $\begin{array}{l}\text { A Pedagogia } \\
\text { Ontopsicológica na } \\
\text { formação do aluno } \\
\text { como um ser } \\
\text { responsável de sua } \\
\text { aprendizagem }\end{array}$ & $\begin{array}{l}\text { I Congresso Internacional Uma } \\
\text { Nova Pedagogia para a Sociedade } \\
\text { Futura }\end{array}$ & $978-85-68901-03-8$ & p. $40-46$ & 2011 \\
\hline 22 & $\begin{array}{l}\text { Véra Lúcia Guedes } \\
\text { Simon, } \\
\text { Andrea Pereira Lock, } \\
\text { Angelise Vieira Mendes, } \\
\text { Noemi Boer }\end{array}$ & $\begin{array}{l}\text { Educação ambiental e } \\
\text { sustentabilidade: } \\
\text { atividades e } \\
\text { intervenções do } \\
\text { PROMFEA }\end{array}$ & $\begin{array}{l}\text { I Congresso Internacional Uma } \\
\text { Nova Pedagogia para a Sociedade } \\
\text { Futura }\end{array}$ & $978-85-68901-03-8$ & p. $56-64$ & 2011 \\
\hline 23 & $\begin{array}{l}\text { José Reinado } \\
\text { Ferreira } \\
\text { Carvalho, Renata Quemel } \\
\text { Pires, } \\
\text { Taís Cristina Sousa de } \\
\text { Jesus }\end{array}$ & $\begin{array}{l}\text { Gestão Ambiental } \\
\text { aplicado ao Setor } \\
\text { Madeireiro: um estudo } \\
\text { de caso na empresa } \\
\text { Rondobel }\end{array}$ & $\begin{array}{l}\text { I Congresso Internacional Uma } \\
\text { Nova Pedagogia para a Sociedade } \\
\text { Futura }\end{array}$ & $978-85-68901-03-8$ & p. $65-72$ & 2011 \\
\hline 24 & Eduardo João Moro & O mercado que separa & I Congresso Internacional Uma & $978-85-68901-03-8$ & p. $73-81$ & 2011 \\
\hline
\end{tabular}


Saber Humano, ISSN 2446-6298, V. 9, n. 15, p. 186-423, jul./dez. 2019.

\begin{tabular}{|c|c|c|c|c|c|c|}
\hline & & $\begin{array}{l}\text { Agricultura Orgânica e } \\
\text { Agroecologica }\end{array}$ & $\begin{array}{l}\text { Nova Pedagogia para a Sociedade } \\
\text { Futura }\end{array}$ & & & \\
\hline 25 & Ana Petry, Joana de Jesus & $\begin{array}{l}\text { Projeto Formação do } \\
\text { Líder Autêntico }\end{array}$ & $\begin{array}{l}\text { I Congresso Internacional Uma } \\
\text { Nova Pedagogia para a Sociedade } \\
\text { Futura }\end{array}$ & $978-85-68901-03-8$ & p. $82-89$ & 2011 \\
\hline 26 & $\begin{array}{l}\text { Mauro Matias Ruiz, } \\
\text { André } \\
\text { Kohl }\end{array}$ & $\begin{array}{l}\text { Responsabilidade e } \\
\text { reciprocidade no }\end{array}$ & $\begin{array}{l}\text { I Congresso Internacional Uma } \\
\text { Nova Pedagogia para a Sociedade }\end{array}$ & $978-85-68901-03-8$ & p. $90-95$ & 2011 \\
\hline
\end{tabular}

\begin{tabular}{|c|c|c|c|c|c|c|}
\hline & & $\begin{array}{l}\text { âmbito empresarial: a } \\
\text { empresa como agente } \\
\text { de transformação social }\end{array}$ & Futura & & & \\
\hline 26 & $\begin{array}{l}\text { Ana Marli Bulegon, } \\
\text { Patrícia Wazlawick, } \\
\text { Soraia Schutel, Helena } \\
\text { Biasotto, } \\
\text { Josele Delazeri, } \\
\text { Ana Cláudia Valentin } \\
\text { Montenegro, } \\
\text { Gisiani Ferreira Alberti, } \\
\text { Patrícia Rossato, } \\
\text { Sabrina Garcia Hoppe, } \\
\text { Marco Antonio Poll Junio ; } \\
\text { Paula Silva Bazzo }\end{array}$ & $\begin{array}{l}\text { Responsabilidade social } \\
\text { \& sustentabilidade: } \\
\text { contribuições da } \\
\text { pesquisa “Dados } \\
\text { sócioeconômicos da } \\
\text { Região da Quarta } \\
\text { Colônia de Imigração } \\
\text { Italiana do Rio Grande } \\
\text { do Sul” no } \\
\text { desenvolvimento } \\
\text { regional }\end{array}$ & $\begin{array}{l}\text { I Congresso Internacional Uma } \\
\text { Nova Pedagogia para a Sociedade } \\
\text { Futura }\end{array}$ & $978-85-68901-03-8$ & p. $96-104$ & 2011 \\
\hline
\end{tabular}


Saber Humano, ISSN 2446-6298, V. 9, n. 15, p. 186-423, jul./dez. 2019.

\begin{tabular}{|c|c|c|c|c|c|c|}
\hline 27 & Carolina Schuskel Mirand & $\begin{array}{l}\text { Valores humanistas } \\
\text { aplicados à publicidade } \\
\text { como garantia da } \\
\text { sustentabilidade na } \\
\text { comunicação }\end{array}$ & $\begin{array}{l}\text { I Congresso Internacional Uma } \\
\text { Nova Pedagogia para a Sociedade } \\
\text { Futura }\end{array}$ & $978-85-68901-03-8$ & p. $105-114$ & 2011 \\
\hline 28 & $\begin{array}{l}\text { Viviane Portela, } \\
\text { Glauber Benetti Carvalho, } \\
\text { Patrícia Wazlawick, } \\
\text { Soraia Schutel, } \\
\text { Estela Maris Giordani }\end{array}$ & $\begin{array}{l}\text { A pesquisa-formação } \\
\text { de professores e a } \\
\text { replicabilidade do } \\
\text { Projeto Flauta a partir } \\
\text { do curso de formação } \\
\text { profissional continuada } \\
\text { em música }\end{array}$ & $\begin{array}{l}\text { I Congresso Internacional Uma } \\
\text { Nova Pedagogia para a Sociedade } \\
\text { Futura }\end{array}$ & $978-85-68901-03-8$ & p.126-134 & 2011 \\
\hline & & $\begin{array}{l}\text { da Faculdade Antonio } \\
\text { Meneghetti }\end{array}$ & & & & \\
\hline 29 & $\begin{array}{l}\text { Anete } \\
\text { Giordani, } \\
\text { Carmen Ivanete D'Agostini } \\
\text { Spanhol, } \\
\text { Fábio de } \\
\text { Oliveira } \\
\text { Rodrigues, } \\
\text { Juliane } \\
\text { Fiorezi, Neves } \\
\text { Luciana dos }\end{array}$ & $\begin{array}{l}\text { Espaço Cidadão } \\
\text { Musical: participação } \\
\text { empresarial no apoio ao } \\
\text { desenvolvimento sócio- } \\
\text { cultural }\end{array}$ & $\begin{array}{l}\text { I Congresso Internacional } \\
\text { Responsabilidade e Reciprocidade }\end{array}$ & $978-85-68901-03-8$ & p. $162-171$ & 2011 \\
\hline
\end{tabular}


Saber Humano, ISSN 2446-6298, V. 9, n. 15, p. 186-423, jul./dez. 2019.

\begin{tabular}{|c|c|c|c|c|c|c|}
\hline & Santos & & & & & \\
\hline 30 & $\begin{array}{l}\text { Amanda Duarte, } \\
\text { Ana Maris Petry, } \\
\text { Josiane Barbieri, } \\
\text { Luísa } \\
\text { Oliveira }\end{array}$ & $\begin{array}{l}\text { Responsabilidade e } \\
\text { Reciprocidade colocadas } \\
\text { em prática }\end{array}$ & $\begin{array}{l}\text { I Congresso Internacional } \\
\text { Responsabilidade e Reciprocidade }\end{array}$ & $978-85-68901-03-8$ & p. $192-201$ & 2011 \\
\hline 31 & $\begin{array}{ll}\text { Vânia } & \text { Maria } \\
\text { Marques } & \\
\text { Portela, } & \\
\text { Estela } & \text { Maris } \\
\text { Giordani } & \end{array}$ & $\begin{array}{l}\text { Docência universitária: } \\
\text { desenvolvendo } \\
\text { competências } \\
\text { linguísticas em leitura(s) } \\
\text { e produção textual } \\
\text { científica }\end{array}$ & $\begin{array}{l}\text { I Congresso Internacional } \\
\text { Responsabilidade e Reciprocidade }\end{array}$ & $978-85-68901-03-8$ & p. $219-227$ & 2011 \\
\hline 32 & $\begin{array}{ll}\text { Erlei } & \text { Roldano } \\
\text { Melgarej } & \end{array}$ & $\begin{array}{l}\text { Economia criativa: } \\
\text { alternativa para o } \\
\text { desenvolvimento } \\
\text { sustentável econômico } \\
\text { e social para os países } \\
\text { em desenvolvimento }\end{array}$ & $\begin{array}{l}\text { I Congresso Internacional } \\
\text { Responsabilidade e Reciprocidade }\end{array}$ & $978-85-68901-03-8$ & p. $228-238$ & 2011 \\
\hline 33 & $\begin{array}{l}\text { José Luiz Rodrigueslho, } \\
\text { Fi } \\
\text { Everton Costa Pasqu ılin }\end{array}$ & $\begin{array}{l}\text { Gestão do } \\
\text { conhecimento }\end{array}$ & $\begin{array}{l}\text { I Congresso Internacional } \\
\text { Responsabilidade e Reciprocidade }\end{array}$ & $978-85-68901-03-8$ & p. $239-244$ & 2011 \\
\hline
\end{tabular}


Saber Humano, ISSN 2446-6298, V. 9, n. 15, p. 186-423, jul./dez. 2019.

\begin{tabular}{|c|c|c|c|c|c|c|}
\hline & & sustentável & & & & \\
\hline 34 & $\begin{array}{l}\text { Estela Maris Giordani, } \\
\text { Camila Ribeiro Menotti, } \\
\text { Adriane Maria Moro } \\
\text { Mendes }\end{array}$ & $\begin{array}{l}\text { O humano e a } \\
\text { tecnologia: Rousseau, } \\
\text { Heidegger e } \\
\text { Meneghetti }\end{array}$ & $\begin{array}{l}\text { I Congresso Internacional } \\
\text { Responsabilidade e Reciprocidade }\end{array}$ & $978-85-68901-03-8$ & p. $245-253$ & 2011 \\
\hline 35 & $\begin{array}{l}\text { Lilian Werner Philippi da } \\
\text { Silva }\end{array}$ & $\begin{array}{l}\text { Sustentabilidade e } \\
\text { recursos hídricos: a } \\
\text { experiência da } \\
\text { Lavanderia } \\
\text { Acquachiara }\end{array}$ & $\begin{array}{l}\text { I Congresso Internacional } \\
\text { Responsabilidade e Reciprocidade }\end{array}$ & $978-85-68901-03-8$ & p. $285-293$ & 2011 \\
\hline 36 & $\begin{array}{l}\text { Cristiano Bittencourt dos } \\
\text { Santos, } \\
\text { Noemi Boer }\end{array}$ & $\begin{array}{l}\text { Educação e } \\
\text { Sustentabilidade } \\
\text { Ambiental: relato de um } \\
\text { case escolar }\end{array}$ & $\begin{array}{l}\text { I Congresso Internacional } \\
\text { Responsabilidade e Reciprocidade }\end{array}$ & $978-85-68901-03-8$ & p. $294-301$ & 2011 \\
\hline 37 & $\begin{array}{l}\text { Paula Silva Bazzo, Gabriela } \\
\text { Rockenbach de Oliveira, } \\
\text { Soraia Schutel, } \\
\text { Ricardo Schaefer }\end{array}$ & $\begin{array}{l}\text { A “Identidade Jovem" } \\
\text { para os Objetivos do } \\
\text { Milênio }\end{array}$ & $\begin{array}{l}\text { I Congresso Internacional } \\
\text { Responsabilidade e Reciprocidade }\end{array}$ & $978-85-68901-03-8$ & p. $302-311$ & 2011 \\
\hline 38 & $\begin{array}{l}\text { Diori Lovatto Ricaldi, } \\
\text { Almir Foletto, } \\
\text { Paulo Costabeber,Marce } \\
\text { Fraga }\end{array}$ & $\begin{array}{l}\text { Desenvolvimento local, } \\
\text { integrado e sustentável } \\
\text { do meio rural e do } \\
\text { homem do campo }\end{array}$ & $\begin{array}{l}\text { I Congresso Internacional } \\
\text { Responsabilidade e Reciprocidade }\end{array}$ & $978-85-68901-03-8$ & p. $321-326$ & 2011 \\
\hline 39 & Marcel Lemos Gomes de & Formação & I Congresso Internacional & $978-85-68901-03-8$ & p. $327-337$ & 2011 \\
\hline
\end{tabular}


Saber Humano, ISSN 2446-6298, V. 9, n. 15, p. 186-423, jul./dez. 2019.

\begin{tabular}{|l|l|l|} 
Fraga & $\begin{array}{l}\text { ontopsicológica do } \\
\text { administrador es } \\
\text { princípios do Pacto } \\
\text { Global: considerações }\end{array}$
\end{tabular} \mid

\begin{tabular}{|c|c|c|c|c|c|c|}
\hline & & $\begin{array}{l}\text { acerca das práticas da } \\
\text { Faculdade Antonio } \\
\text { Meneghetti }\end{array}$ & & & & \\
\hline 40 & $\begin{array}{l}\text { Vera Lúcia Rodegheri, } \\
\text { Estela Maris } \\
\text { Giordani, } \\
\text { Joana de } \\
\text { Jesus, } \\
\text { Vicente Medeiros }\end{array}$ & $\begin{array}{l}\text { Ontopsicologia e } \\
\text { aprendizagem entre } \\
\text { líderes: a autenticidade } \\
\text { e a reciprocidade para } \\
\text { responsabilidade social }\end{array}$ & $\begin{array}{l}\text { I Congresso Internacional } \\
\text { Responsabilidade e Reciprocidade }\end{array}$ & $978-85-68901-03-8$ & p. $338-345$ & 2011 \\
\hline 41 & $\begin{array}{l}\text { Josiane Barbieri, } \\
\text { Maria Alice Schuch, } \\
\text { Maria Tereza Andreola, } \\
\text { Regina Panceri }\end{array}$ & $\begin{array}{l}\text { Projeto Mulher do } \\
\text { Milênio: } \\
\text { responsabilizando a } \\
\text { mulher pela conquista } \\
\text { de autonomia e } \\
\text { reciprocidade }\end{array}$ & $\begin{array}{l}\text { I Congresso Internacional } \\
\text { Responsabilidade e Reciprocidade }\end{array}$ & $978-85-68901-03-8$ & p. $346-353$ & 2011 \\
\hline 42 & $\begin{array}{l}\text { Adriane Maria Moro } \\
\text { Mendes, } \\
\text { Estela Maris Giordani }\end{array}$ & $\begin{array}{l}\text { A ação social como } \\
\text { ferramenta de } \\
\text { desenvolvimento da }\end{array}$ & $\begin{array}{l}\text { I Congresso Internacional } \\
\text { Responsabilidade e Reciprocidade }\end{array}$ & $978-85-68901-03-8$ & p. $354-360$ & 2011 \\
\hline
\end{tabular}


Saber Humano, ISSN 2446-6298, V. 9, n. 15, p. 186-423, jul./dez. 2019.

\begin{tabular}{|c|c|c|c|c|c|c|}
\hline & & $\begin{array}{l}\text { responsabilidade } \\
\text { profissional dos } \\
\text { estudantes de } \\
\text { graduação }\end{array}$ & & & & \\
\hline 43 & Érico de Lima Azevedo & $\begin{array}{l}\text { A Ontopsicologia como } \\
\text { resposta eficiente à } \\
\text { "Crise das ciências" de } \\
\text { Edmund Husserl: qual } \\
\text { reciprocidade cabe às } \\
\text { ciências? }\end{array}$ & $\begin{array}{l}\text { I Congresso Internacional } \\
\text { Responsabilidade e Reciprocidade }\end{array}$ & $978-85-68901-03-8$ & p. $361-369$ & 2011 \\
\hline 44 & $\begin{array}{l}\text { Clarissa Miranda, } \\
\text { Ricardo Schaefer, } \\
\text { Vicente } \\
\text { Medeiros }\end{array}$ & $\begin{array}{l}\text { Autenticidade e } \\
\text { responsabilidade: } \\
\text { premissas para um } \\
\text { jornalismo promotor de } \\
\text { valores sociais }\end{array}$ & $\begin{array}{l}\text { I Congresso Internacional } \\
\text { Responsabilidade e Reciprocidade }\end{array}$ & $978-85-68901-03-8$ & p. $378-388$ & 2011 \\
\hline 45 & $\begin{array}{l}\text { Carmen Ivanete D'Agostini } \\
\text { Spanhol, } \\
\text { Juliane } \\
\text { Fiorezi, } \\
\text { Luciana } \\
\text { Santos }\end{array}$ & $\begin{array}{l}\text { Autossustento: fruto de } \\
\text { escolhas existências }\end{array}$ & $\begin{array}{l}\text { I Congresso Internacional } \\
\text { Responsabilidade e Reciprocidade }\end{array}$ & $978-85-68901-03-8$ & p. 389-397 & 2011 \\
\hline 46 & Patrícia Wazlawick & Declaração Universal & I Congresso Internacional & $978-85-68901-03-8$ & p. $398-412$ & 2011 \\
\hline
\end{tabular}


Saber Humano, ISSN 2446-6298, V. 9, n. 15, p. 186-423, jul./dez. 2019.

\begin{tabular}{|c|c|c|c|c|c|c|}
\hline & & $\begin{array}{l}\text { dos Direitos do } \\
\text { Homem: considerações } \\
\text { à luz da dialética de } \\
\text { responsabilidade e } \\
\text { reciprocidade } \\
\text { fundamentada na } \\
\text { Ontopsicologia }\end{array}$ & Responsabilidade e Reciprocidade & & & \\
\hline 47 & $\begin{array}{l}\text { Carmen Ivanete D'Agostini } \\
\text { Spanhol }\end{array}$ & $\begin{array}{l}\text { Educar para autonomia } \\
\text { e responsabilização }\end{array}$ & $\begin{array}{l}\text { I Congresso Internacional } \\
\text { Responsabilidade e Reciprocidade }\end{array}$ & $978-85-68901-03-8$ & p. $413-425$ & 2011 \\
\hline 48 & $\begin{array}{l}\text { leda Fatima da Silva } \\
\text { Brandeburski, } \\
\text { Estela Maris } \\
\text { Giordani }\end{array}$ & $\begin{array}{l}\text { Formação continuada } \\
\text { de docentes: o } \\
\text { ressignificar das práticas } \\
\text { pedagógicas como } \\
\text { processo existencial }\end{array}$ & $\begin{array}{l}\text { I Congresso Internacional } \\
\text { Responsabilidade e Reciprocidade }\end{array}$ & $978-85-68901-03-8$ & p. $426-433$ & 2011 \\
\hline 49 & $\begin{array}{l}\text { Soraia } \\
\text { Schutel }\end{array}$ & $\begin{array}{l}\text { O homem parentético } \\
\text { de Guerreiro Ramos e a } \\
\text { prática sustentável }\end{array}$ & $\begin{array}{l}\text { I Congresso Internacional } \\
\text { Responsabilidade e Reciprocidade }\end{array}$ & $978-85-68901-03-8$ & p. $443-455$ & 2011 \\
\hline 50 & $\begin{array}{l}\text { Vicente Reis Medeiros, } \\
\text { Ana Claudia Valentini } \\
\text { Montenegro }\end{array}$ & $\begin{array}{l}\text { O humanismo, a } \\
\text { comunicação } \\
\text { empresarial e a }\end{array}$ & $\begin{array}{l}\text { I Congresso Internacional } \\
\text { Responsabilidade e Reciprocidade }\end{array}$ & $978-85-68901-03-8$ & p. $446-455$ & 2011 \\
\hline
\end{tabular}


Saber Humano, ISSN 2446-6298, V. 9, n. 15, p. 186-423, jul./dez. 2019.

\begin{tabular}{|c|c|c|c|c|c|c|}
\hline & & $\begin{array}{l}\text { responsabilidade do } \\
\text { assessor de } \\
\text { comunicação }\end{array}$ & & & & \\
\hline 51 & $\begin{array}{l}\text { Jander Fernandes Martin 5, } \\
\text { Estela Maris Giordani }\end{array}$ & $\begin{array}{l}\text { O Trabalho Didático nas } \\
\text { Sociedades Antigas }\end{array}$ & $\begin{array}{l}\text { I Congresso Internacional } \\
\text { Responsabilidade e Reciprocidade }\end{array}$ & $978-85-68901-03-8$ & p. $456-462$ & 2011 \\
\hline 52 & $\begin{array}{l}\text { Maria Alice Schuch } \\
\text { http://lattes.cnpq. }{ }^{\text {r/ } / 576} 32 \\
02542112018\end{array}$ & $\begin{array}{l}\text { Percepção da mulher } \\
\text { sobre sua } \\
\text { responsabilidade }\end{array}$ & $\begin{array}{l}\text { I Congresso Internacional } \\
\text { Responsabilidade e Reciprocidade }\end{array}$ & $978-85-68901-03-8$ & p. $463-469$ & 2011 \\
\hline 53 & $\begin{array}{l}\text { Tailana } \\
\text { Lüdtke, } \\
\text { Patrícia Wazlawick }\end{array}$ & $\begin{array}{l}\text { Os sentidos de } \\
\text { responsabilidade e } \\
\text { reciprocidade }\end{array}$ & $\begin{array}{l}\text { I Congresso Internacional } \\
\text { Responsabilidade e Reciprocidade }\end{array}$ & $978-85-68901-03-8$ & p. $470-479$ & 2011 \\
\hline 54 & $\begin{array}{l}\text { Ana } \quad \text { Marli } \\
\text { Bulegon, } \\
\text { Viviane Teresinha Biacchi } \\
\text { Brust, } \\
\text { Estela } \quad \text { Maris } \\
\text { Giordani, } \\
\text { Erlei } \\
\text { Melgarejo, } \\
\text { Josele Nara } \\
\text { de }\end{array}$ & $\begin{array}{l}\text { A Ciência } \\
\text { Ontopsicológica e sua } \\
\text { influência na prática } \\
\text { pedagógica de } \\
\text { professores } \\
\text { universitários }\end{array}$ & $\begin{array}{l}\text { I Congresso Internacional } \\
\text { Responsabilidade e Reciprocidade }\end{array}$ & $978-85-68901-03-8$ & p. $480-484$ & 2011 \\
\hline
\end{tabular}


Saber Humano, ISSN 2446-6298, V. 9, n. 15, p. 186-423, jul./dez. 2019.

\begin{tabular}{|l|l|l|l|l|l|} 
& Danielle de Souza Saad & & \\
\hline 55 & $\begin{array}{l}\text { Claudiane } \\
\text { Weber }\end{array}$ & $\begin{array}{l}\text { As bibliotecas e o aporte } \\
\text { para o desenvolvimento } \\
\text { sustentável }\end{array}$ & Responsabilidade e Reciprocidade & $978-85-68901-03-8$ & p. 491-496 \\
\hline
\end{tabular}

\begin{tabular}{|c|c|c|c|c|c|c|}
\hline 56 & $\begin{array}{l}\text { Nádia Isabel de Souza, } \\
\text { Soraia Schutel }\end{array}$ & $\begin{array}{l}\text { As sete dimensões da } \\
\text { sustentabilidade para a } \\
\text { organização saudável }\end{array}$ & $\begin{array}{l}\text { I Congresso Internacional } \\
\text { Responsabilidade e Reciprocidade }\end{array}$ & $978-85-68901-03-8$ & p. $497-500$ & 2011 \\
\hline 57 & $\begin{array}{l}\text { Noemi Boer, } \\
\text { Bruno de Oliveira } \\
\text { Fernandes }\end{array}$ & $\begin{array}{l}\text { Descarte de } \\
\text { medicamentos: um } \\
\text { modelo de logística } \\
\text { reversa }\end{array}$ & $\begin{array}{l}\text { I Congresso Internacional } \\
\text { Responsabilidade e Reciprocidade }\end{array}$ & $978-85-68901-03-8$ & p. $504-507$ & 2011 \\
\hline 58 & $\begin{array}{l}\text { Bruna Marquetti } \\
\text { Dallepiane, } \\
\text { Soraia } \\
\text { Schutel, } \\
\text { Nádia Isabel de Souza }\end{array}$ & $\begin{array}{l}\text { Instrumento de } \\
\text { verificação da } \\
\text { sustentabilidade em } \\
\text { realidades microssociais } \\
\text { a partir da metodologia } \\
\text { ontopsicológica }\end{array}$ & $\begin{array}{l}\text { I Congresso Internacional } \\
\text { Responsabilidade e Reciprocidade }\end{array}$ & $978-85-68901-03-8$ & p. $515-517$ & 2011 \\
\hline 59 & Helena Biasotto & Reciprocidade, & I Congresso Internacional & $978-85-68901-03-8$ & p. 527-531 & 2011 \\
\hline
\end{tabular}


Saber Humano, ISSN 2446-6298, V. 9, n. 15, p. 186-423, jul./dez. 2019.

\begin{tabular}{|c|c|c|c|c|c|c|}
\hline & & $\begin{array}{l}\text { responsabilidade e a } \\
\text { cultura do valor }\end{array}$ & Responsabilidade e Reciprocidade & & & \\
\hline 60 & Gabrielle Viegas Foletto & $\begin{array}{l}\text { Responsabilidade e } \\
\text { reciprocidade: contrato } \\
\text { natural }\end{array}$ & $\begin{array}{l}\text { I Congresso Internacional } \\
\text { Responsabilidade e Reciprocidade }\end{array}$ & $978-85-68901-03-8$ & p. $536-538$ & 2011 \\
\hline 61 & $\begin{array}{l}\text { Daniela Limana Crestani, } \\
\text { Sueli Bianchin } \\
\text { Fachini, } \\
\text { Ana Luisa Pontelli,Josel } 2 \\
\text { Nara Delazeri de Oliveira }\end{array}$ & $\begin{array}{l}\text { Responsabilidade } \\
\text { socioambiental: } \\
\text { proposta de coleta } \\
\text { seletiva em uma Fábrica } \\
\text { de Tapetes }\end{array}$ & $\begin{array}{l}\text { I Congresso Internacional } \\
\text { Responsabilidade e Reciprocidade }\end{array}$ & $978-85-68901-03-8$ & p. $543-545$ & 2011 \\
\hline 62 & Giselle Kossatz Lopes & A compreensão da & I Congresso Internacional & $978-85-68901-03-8$ & p. $554-558$ & 2011 \\
\hline
\end{tabular}

\begin{tabular}{|c|c|c|c|c|c|c|}
\hline & & $\begin{array}{l}\text { psicologia do cliente } \\
\text { como fator do trabalho } \\
\text { eficaz do designer }\end{array}$ & Responsabilidade e Reciprocidade & & & \\
\hline 63 & Maria Lúcia Teixeira Carrara & $\begin{array}{l}\text { Pesquisa e } \\
\text { desenvolvimento de um } \\
\text { produto sustentável: } \\
\text { Lilium } \\
\text { Recanto }\end{array}$ & $\begin{array}{l}\text { I Congresso Internacional } \\
\text { Responsabilidade e Reciprocidade }\end{array}$ & $978-85-68901-03-8$ & p. $578-581$ & 2011 \\
\hline 64 & Maria Luiza Bazzo & $\begin{array}{l}\text { Diagnóstico molelular } \\
\text { rápido da tuberculose: } \\
\text { uma abordagem } \\
\text { integrada de pesquisa, } \\
\text { ensino e extensão }\end{array}$ & $\begin{array}{l}\text { I Congresso Internacional } \\
\text { Responsabilidade e Reciprocidade }\end{array}$ & $978-85-68901-03-8$ & p. 586-589 & 2011 \\
\hline
\end{tabular}


Saber Humano, ISSN 2446-6298, V. 9, n. 15, p. 186-423, jul./dez. 2019.

\begin{tabular}{|c|c|c|c|c|c|c|}
\hline 65 & Nádia Isabel de Souza & $\begin{array}{l}\text { Empregados e } \\
\text { empregadores: uma } \\
\text { relação corresponsável } \\
\text { para a sustentabilidade } \\
\text { econômico-social }\end{array}$ & $\begin{array}{l}\text { I Congresso Internacional } \\
\text { Responsabilidade e Reciprocidade }\end{array}$ & $978-85-68901-03-8$ & p. $590-5922$ & 2011 \\
\hline 66 & $\begin{array}{l}\text { Maria Lúcia de Souza } \\
\text { Carrara, Maria Luiza } \\
\text { Andreola }\end{array}$ & $\begin{array}{l}\text { Estética funcional com } \\
\text { base na Ecobiologia e } \\
\text { na Sustentabilidade }\end{array}$ & $\begin{array}{l}\text { I Congresso Internacional } \\
\text { Responsabilidade e Reciprocidade }\end{array}$ & $978-85-68901-03-8$ & p. 503-596 & 2011 \\
\hline 67 & $\begin{array}{l}\text { Janine Coelho Ouriques, } \\
\text { Rosane Maria Neves }\end{array}$ & $\begin{array}{l}\text { A complexidade do } \\
\text { conceito de promoção } \\
\text { da saúde humana e a } \\
\text { sua relação com a } \\
\text { responsabilidade } \\
\text { pessoal e a ajuda }\end{array}$ & $\begin{array}{l}\text { I Congresso Internacional } \\
\text { Responsabilidade e Reciprocidade }\end{array}$ & $978-85-68901-03-8$ & p. $597-600$ & 2011 \\
\hline
\end{tabular}

\begin{tabular}{|c|c|c|c|c|c|c|}
\hline & & recíproca & & & & \\
\hline 68 & Alécio Vidor & Ciência e Filosofia & $\begin{array}{l}\text { I Congresso Internacional } \\
\text { Responsabilidade e Reciprocidade }\end{array}$ & 978-85-68901-03-8 & p. $601-604$ & 2011 \\
\hline
\end{tabular}


Saber Humano, ISSN 2446-6298, V. 9, n. 15, p. 186-423, jul./dez. 2019.

\begin{tabular}{|c|c|c|c|c|c|c|}
\hline 69 & Márcio Vieira dos Santos & $\begin{array}{l}\text { Contrato: principal } \\
\text { ferramenta } \\
\text { interdisciplinar } \\
\text { reguladora da } \\
\text { materialização do } \\
\text { projeto do indivíduo } \\
\text { frente à sociedade, } \\
\text { garantindo o } \\
\text { desenvolvimento } \\
\text { humanista de um } \\
\text { ambiente complexo }\end{array}$ & $\begin{array}{l}\text { I Congresso Internacional } \\
\text { Responsabilidade e Reciprocidade }\end{array}$ & $978-85-68901-03-8$ & p. $605-608$ & 2011 \\
\hline 70 & $\begin{array}{l}\text { Rosana Niederauer } \\
\text { Marques, Estela Maris } \\
\text { Giordani, Deisi Sangoi } \\
\text { Freitas }\end{array}$ & $\begin{array}{l}\text { Formação pedagógica } \\
\text { do docente de estágio } \\
\text { curricular } \\
\text { supervisionado do } \\
\text { Curso de Fisioterapia } \\
\text { como fator de } \\
\text { responsabilidade social }\end{array}$ & $\begin{array}{l}\text { I Congresso Internacional } \\
\text { Responsabilidade e Reciprocidade }\end{array}$ & $978-85-68901-03-8$ & p. $609-612$ & 2011 \\
\hline 71 & Daniel Sombio & $\begin{array}{l}\text { O critério de } \\
\text { funcionalidade humana } \\
\text { aplicado no Direito }\end{array}$ & $\begin{array}{l}\text { I Congresso Internacional } \\
\text { Responsabilidade e Reciprocidade }\end{array}$ & $978-85-68901-03-8$ & p. 613-616 & 2011 \\
\hline 72 & $\begin{array}{l}\text { Ágatha Depiné, João } \\
\text { Henrique Celant, Josemar } \\
\text { Soares }\end{array}$ & $\begin{array}{l}\text { O critério ético como } \\
\text { ponto de compreensão } \\
\text { da relação entre o }\end{array}$ & $\begin{array}{l}\text { I Congresso Internacional } \\
\text { Responsabilidade e Reciprocidade }\end{array}$ & $978-85-68901-03-8$ & p. $617-620$ & 2011 \\
\hline
\end{tabular}


Saber Humano, ISSN 2446-6298, V. 9, n. 15, p. 186-423, jul./dez. 2019.

\begin{tabular}{|c|c|c|c|c|c|c|}
\hline & & $\begin{array}{l}\text { homem e o ambiente } \\
\text { diante da crise da } \\
\text { PósModernidade }\end{array}$ & & & & \\
\hline 73 & $\begin{array}{l}\text { Ademar Silva Júnior, } \\
\text { Clodoaldo Martins de } \\
\text { Oliveira Júnior }\end{array}$ & $\begin{array}{l}\text { Projeto Vida Nova: } \\
\text { Ressocialização de } \\
\text { apenados do Centro } \\
\text { Penal da Gameleira em } \\
\text { Campo Grande-MS }\end{array}$ & $\begin{array}{l}\text { I Congresso Internacional } \\
\text { Responsabilidade e Reciprocidade }\end{array}$ & $978-85-68901-03-8$ & p. $621-624$ & 2011 \\
\hline 74 & Cleoci Rockenbach & $\begin{array}{l}\text { Responsabilidade } \\
\text { versus assistencialismo } \\
\text { em projetos sociais: } \\
\text { uma experiência de } \\
\text { resgate da dignidade } \\
\text { humana }\end{array}$ & $\begin{array}{l}\text { I Congresso Internacional } \\
\text { Responsabilidade e Reciprocidade }\end{array}$ & $978-85-68901-03-8$ & p. $625-631$ & 2011 \\
\hline 75 & $\begin{array}{l}\text { Carolina Brandolff Stivanin, } \\
\text { Patrícia Wazlawick }\end{array}$ & $\begin{array}{l}\text { "Saber amar o próprio } \\
\text { jogo": a importância da } \\
\text { atividade esportiva } \\
\text { para a formação } \\
\text { integral do jovem líder }\end{array}$ & $\begin{array}{l}\text { I Congresso Internacional } \\
\text { Responsabilidade e Reciprocidade }\end{array}$ & $978-85-68901-03-8$ & p. $632-635$ & 2011 \\
\hline 76 & Sabrina Garcia Hoppe & $\begin{array}{l}\text { A arte de saber } \\
\text { negociar }\end{array}$ & $\begin{array}{l}\text { I Congresso Internacional } \\
\text { Responsabilidade e Reciprocidade }\end{array}$ & $978-85-68901-03-8$ & p. $632-634$ & 2011 \\
\hline 77 & $\begin{array}{l}\text { Luiz Alberto Aude, João Luiz } \\
\text { Portela }\end{array}$ & $\begin{array}{l}\text { A importância dos } \\
\text { Cursos de Extensão } \\
\text { realizados pela } \\
\text { Faculdade Antonio } \\
\text { Meneghetti e Grupo } \\
\text { Meta }\end{array}$ & $\begin{array}{l}\text { I Congresso Internacional } \\
\text { Responsabilidade e Reciprocidade }\end{array}$ & $978-85-68901-03-8$ & p. $639-642$ & 2011 \\
\hline
\end{tabular}




\section{ATOS DO CONGRESSO INTERNACIONAL BUSINESS INTUITION \\ RIGA, LETÔNIA, 2004}

\begin{tabular}{|c|c|c|c|c|c|c|}
\hline № & AUTOR & TíTULO & PUBLICAÇÃO & ISSN & PÁGINAS & ANO \\
\hline 1 & Alena Antonova & $\begin{array}{l}\text { Duas abordagens } \\
\text { decisionais no campo } \\
\text { legal }\end{array}$ & Atos do Congresso Business Intuition & $978-85-89941-05-1$ & p. $79-83$ & 2007 \\
\hline 2 & Barbara Bernabei & $\begin{array}{l}\text { Capacidade analítica de } \\
\text { supervisão } \\
\text { delegatário }\end{array}$ & Atos do Congresso Business Intuition & $978-85-89941-05-1$ & p. $84-89$ & 2007 \\
\hline 3 & Pamela Bernabei & Intuição e Racionalidade & Atos do Congresso Business Intuition & $978-85-89941-05-1$ & p. $90-97$ & 2007 \\
\hline 4 & Pamela Bernabei & $\begin{array}{l}\text { FOIL Management e } \\
\text { Business Intuition }\end{array}$ & Atos do Congresso Business Intuition & $978-85-89941-05-1$ & p. $98-104$ & 2007 \\
\hline
\end{tabular}


Saber Humano, ISSN 2446-6298, V. 9, n. 15, p. 186-423, jul./dez. 2019.

\begin{tabular}{|c|c|c|c|c|c|c|}
\hline 5 & Pamela Bernabei & $\begin{array}{l}\text { Problemáticas, análises e } \\
\text { diretivas no processo de } \\
\text { colaboração do líder } \\
\text { (Colaboração, díade, } \\
\text { delegação, transfert, } \\
\text { sabotagem, incremento) }\end{array}$ & Atos do Congresso Business Intuition & $978-85-89941-05-1$ & p. $105-120$ & 2007 \\
\hline 6 & Helena Biasotto & $\begin{array}{l}\text { O fenômeno } \\
\text { fundamental do } \\
\text { desenvolvimento } \\
\text { econômico }\end{array}$ & Atos do Congresso Business Intuition & $978-85-89941-05-1$ & p. $121-125$ & 2007 \\
\hline 7 & Sergio Bodriti & $\begin{array}{l}\text { Intuição, animais e } \\
\text { business }\end{array}$ & Atos do Congresso Business Intuition & $978-85-89941-05-1$ & p. $126-129$ & 2007 \\
\hline 8 & Marcelo Bruognolo & $\begin{array}{l}\text { Atualização FOIL Sobre o } \\
\text { balanço das } \\
\text { competências }\end{array}$ & Atos do Congresso Business Intuition & $978-85-89941-05-1$ & p. $130-134$ & 2007 \\
\hline 9 & Marcelo Bruognolo & $\begin{array}{l}\text { A Ontopsicologia como } \\
\text { instrumento de } \\
\text { integração entre as } \\
\text { diferenciações culturais } \\
\text { da globalização }\end{array}$ & Atos do Congresso Business Intuition & $978-85-89941-05-1$ & p. $135-138$ & 2007 \\
\hline
\end{tabular}


Saber Humano, ISSN 2446-6298, V. 9, n. 15, p. 186-423, jul./dez. 2019.

\begin{tabular}{|c|c|c|c|c|c|c|}
\hline 10 & Manuel Campus & $\begin{array}{l}\text { Business na Arte e } \\
\text { Personalidade do Artista }\end{array}$ & Atos do Congresso Business Intuition & $978-85-89941-05-1$ & p. $139-149$ & 2007 \\
\hline 11 & $\begin{array}{l}\text { Maria Consuelo } \\
\text { Campus }\end{array}$ & $\begin{array}{l}\text { C.T.O Intuição } \\
\text { Ontopsicológica }\end{array}$ & Atos do Congresso Business Intuition & $978-85-89941-05-1$ & p. $150-155$ & 2007 \\
\hline 12 & Annalisa Cangelosi & $\begin{array}{l}\text { Auto-Sabotagem: o } \\
\text { principal obstáculo na } \\
\text { vida de um jovem }\end{array}$ & Atos do Congresso Business Intuition & $978-85-89941-05-1$ & p. $156-159$ & 2007 \\
\hline \multirow[t]{2}{*}{13} & Analisa Cangelosi & A Melolística como meio & Atos do Congresso Business Intuition & $978-85-89941-05-1$ & p. $160-166$ & 2007 \\
\hline & & $\begin{array}{l}\text { orgânico para } \\
\text { aproximar-se da intuição }\end{array}$ & & & & \\
\hline 14 & Franco Ceccarelli & $\begin{array}{l}\text { A saúde como business } \\
\text { para além dos } \\
\text { mecanismos da } \\
\text { autosabotagem }\end{array}$ & Atos do Congresso Business Intuition & $978-85-89941-05-1$ & p. $167-173$ & 2007 \\
\hline 15 & Cristina Cecconi & $\begin{array}{l}\text { Intuição: entre a loucura } \\
\text { e a história }\end{array}$ & Atos do Congresso Business Intuition & $978-85-89941-05-1$ & p. $174-178$ & 2007 \\
\hline 16 & Horácio Chikota & $\begin{array}{l}\text { O Líder, o miricismo } \\
\text { cotidiano, a vantagem e a } \\
\text { auto-sabotagem }\end{array}$ & Atos do Congresso Business Intuition & $978-85-89941-05-1$ & p. $179-183$ & 2007 \\
\hline
\end{tabular}


Saber Humano, ISSN 2446-6298, V. 9, n. 15, p. 186-423, jul./dez. 2019.

\begin{tabular}{|c|c|c|c|c|c|c|}
\hline 17 & Lorenzo Cristiano & $\begin{array}{l}\text { Na mudança de } \\
\text { mercados e regras, a } \\
\text { intuição é hoje } \\
\text { indispensável: como se } \\
\text { abre e, quando a } \\
\text { perdemos, o que fazer }\end{array}$ & Atos do Congresso Business Intuition & 978-85-89941-05-1 & p. $184-191$ & 2007 \\
\hline 18 & Carla Di Bernardo & $\begin{array}{l}\text { A intuição ponderável } \\
\text { economicamente }\end{array}$ & Atos do Congresso Business Intuition & 978-85-89941-05-1 & p. 192-195 & 2007 \\
\hline 19 & Daniela Di Pietro & $\begin{array}{l}\text { O jovem entre } \\
\text { contestação, } \\
\text { desemprego e liderança }\end{array}$ & Atos do Congresso Business Intuition & 978-85-89941-05-1 & p. 196-204 & 2007 \\
\hline
\end{tabular}

\begin{tabular}{|c|c|c|c|c|c|c|}
\hline & & evolutiva & & & & \\
\hline 20 & Victoria Dimitrieva & $\begin{array}{l}\text { A auto-sabotagem como } \\
\text { infração da ética interior } \\
\text { do líder }\end{array}$ & Atos do Congresso Business Intuition & $978-85-89941-05-1$ & p. 205-209 & 2007 \\
\hline 21 & Anna Fedorova & $\begin{array}{l}\text { Jovens especialistas no } \\
\text { mercado de trabalho e } \\
\text { no business: problema de } \\
\text { autogestão }\end{array}$ & Atos do Congresso Business Intuition & $978-85-89941-05-1$ & p. $210-213$ & 2007 \\
\hline
\end{tabular}


Saber Humano, ISSN 2446-6298, V. 9, n. 15, p. 186-423, jul./dez. 2019.

\begin{tabular}{|c|c|c|c|c|c|c|}
\hline 22 & Natalya Fedoryshyn & $\begin{array}{l}\text { O uso funcional dos } \\
\text { memes na rádio }\end{array}$ & Atos do Congresso Business Intuition & 978-85-89941-05-1 & p. 214- 217 & 2007 \\
\hline 23 & Antonella Ferraro & $\begin{array}{l}\text { Inovação no Marketing } \\
\text { Mix }\end{array}$ & Atos do Congresso Business Intuition & 978-85-89941-05-1 & p. $218-221$ & 2007 \\
\hline 24 & Alessandro Filippetti & $\begin{array}{l}\text { Da franchising à } \\
\text { autonomia comercial }\end{array}$ & Atos do Congresso Business Intuition & 978-85-89941-05-1 & p. $222-225$ & 2007 \\
\hline 25 & Franca Fizio & $\begin{array}{l}\text { Obstetrícia e } \\
\text { Ontopsicologia }\end{array}$ & Atos do Congresso Business Intuition & 978-85-89941-05-1 & p. 226-232 & 2007 \\
\hline 26 & Tatyana Frolova & $\begin{array}{l}\text { Intuição na tomada de } \\
\text { uma decisão de business }\end{array}$ & Atos do Congresso Business Intuition & 978-85-89941-05-1 & p. $233-238$ & 2007 \\
\hline 27 & Giuseppe Fusco & $\begin{array}{l}\text { O corpo como radar de } \\
\text { conhecimento: um } \\
\text { instrumento para o } \\
\text { business }\end{array}$ & Atos do Congresso Business Intuition & 978-85-89941-05-1 & p. $239-242$ & 2007 \\
\hline 28 & Karin Gambaracci & Jovens e estilo de vida & Atos do Congresso Business Intuition & 978-85-89941-05-1 & p. $243-245$ & 2007 \\
\hline 29 & Estela Maris Giordani & $\begin{array}{l}\text { A formação pessoal e a } \\
\text { congruência nos } \\
\text { professores } \\
\text { universitários }\end{array}$ & Atos do Congresso Business Intuition & 978-85-89941-05-1 & p. $246-251$ & 2007 \\
\hline
\end{tabular}


Saber Humano, ISSN 2446-6298, V. 9, n. 15, p. 186-423, jul./dez. 2019.

\begin{tabular}{|c|c|c|c|c|c|c|}
\hline 30 & Elvio Gramignano & $\begin{array}{l}\text { Caso prático de um CEO } \\
\text { com conhecimento FOIL }\end{array}$ & Atos do Congresso Business Intuition & 978-85-89941-05-1 & p. $252-258$ & 2007 \\
\hline 31 & Elvio Gramignano & $\begin{array}{l}\text { O Plano de Marketing } \\
\text { como instrumento para } \\
\text { transformar a intuição } \\
\text { em ação }\end{array}$ & Atos do Congresso Business Intuition & 978-85-89941-05-1 & p. $259-261$ & 2007 \\
\hline 32 & Elvio Gramignano & Experiência FOIL & Atos do Congresso Business Intuition & 978-85-89941-05-1 & p. $262-267$ & 2007 \\
\hline 33 & Natalia Grishina & $\begin{array}{l}\text { A intuição como fator } \\
\text { elementar do processo } \\
\text { cognitivo e decisional }\end{array}$ & Atos do Congresso Business Intuition & 978-85-89941-05-1 & p. $268-272$ & 2007 \\
\hline 34 & Larisa Gusseva & $\begin{array}{l}\text { Tudo se resolve a partir } \\
\text { das pessoas }\end{array}$ & Atos do Congresso Business Intuition & 978-85-89941-05-1 & p. $273-276$ & 2007 \\
\hline 35 & Svetlana Ipatyeva & $\begin{array}{l}\text { Autenticação e estudo na } \\
\text { FOIL como garantia da } \\
\text { exatidão para o consultor } \\
\text { anticrise }\end{array}$ & Atos do Congresso Business Intuition & 978-85-89941-05-1 & p. $277-279$ & 2007 \\
\hline 36 & Vladimir Kalyuga & Cultura Corporativa & Atos do Congresso Business Intuition & 978-85-89941-05-1 & p. $280-284$ & 2007 \\
\hline
\end{tabular}


Saber Humano, ISSN 2446-6298, V. 9, n. 15, p. 186-423, jul./dez. 2019.

\begin{tabular}{|c|c|c|c|c|c|c|}
\hline 37 & Viktor Khanin & $\begin{array}{l}\text { Trabalho aprofundado } \\
\text { sobre as motivações } \\
\text { inconscientes dos } \\
\text { participantes de um } \\
\text { grupo de estudo como } \\
\text { condição necessária na } \\
\text { introdução para o } \\
\text { business }\end{array}$ & Atos do Congresso Business Intuition & 978-85-89941-05-1 & p. $285-289$ & 2007 \\
\hline 38 & $\begin{array}{l}\text { Veronika } \\
\text { Kozhevnikova }\end{array}$ & $\begin{array}{l}\text { O meme que se pode } \\
\text { dispor a serviço do } \\
\text { business }\end{array}$ & Atos do Congresso Business Intuition & 978-85-89941-05-1 & p. $290-294$ & 2007 \\
\hline 39 & Emanuela La Rosa & $\begin{array}{l}\text { O superego legal como } \\
\text { obstáculo à intuição do } \\
\text { profissional }\end{array}$ & Atos do Congresso Business Intuition & 978-85-89941-05-1 & p. $295-300$ & 2007 \\
\hline 40 & Tatiana Lisitskaya & $\begin{array}{l}\text { A criação da Galeria } \\
\text { “OntoArte” como } \\
\text { realização global da } \\
\text { personalidade }\end{array}$ & Atos do Congresso Business Intuition & 978-85-89941-05-1 & p.301-304 & 2007 \\
\hline 41 & Oscar Livrerio & $\begin{array}{l}\text { Informação, lógica e } \\
\text { intuição }\end{array}$ & Atos do Congresso Business Intuition & 978-85-89941-05-1 & p. $305-312$ & 2007 \\
\hline 42 & Elena Makusheva & $\begin{array}{l}\text { Os centros para } \\
\text { aquisição de experiência }\end{array}$ & Atos do Congresso Business Intuition & 978-85-89941-05-1 & p. $313-315$ & 2007 \\
\hline
\end{tabular}


Saber Humano, ISSN 2446-6298, V. 9, n. 15, p. 186-423, jul./dez. 2019.

\begin{tabular}{|c|c|c|c|c|c|c|}
\hline 43 & Oxana Milyanchikova & $\begin{array}{l}\text { A globalização é o ponto } \\
\text { de responsabilidade dos } \\
\text { Líderes }\end{array}$ & Atos do Congresso Business Intuition & 978-85-89941-05-1 & p. $316-322$ & 2007 \\
\hline 44 & Luca Morotti & $\begin{array}{l}\text { Marudo: história e } \\
\text { experiência de uma } \\
\text { intuição }\end{array}$ & Atos do Congresso Business Intuition & 978-85-89941-05-1 & p. $323-327$ & 2007 \\
\hline 45 & Alexander Ostrovskiy & $\begin{array}{l}\text { Chantagem legal do } \\
\text { empresário por parte do } \\
\text { cliente }\end{array}$ & Atos do Congresso Business Intuition & 978-85-89941-05-1 & p. $328-330$ & 2007 \\
\hline 46 & Gabriella Palumbo & $\begin{array}{l}\text { O insight do líder e a } \\
\text { intuição: um critério }\end{array}$ & Atos do Congresso Business Intuition & 978-85-89941-05-1 & p. 331-336 & 2007 \\
\hline 47 & Régia Panceri & $\begin{array}{l}\text { A intuição do líder na } \\
\text { empresa }\end{array}$ & Atos do Congresso Business Intuition & 978-85-89941-05-1 & p. $337-340$ & 2007 \\
\hline 48 & Igor Parubskiy & $\begin{array}{l}\text { Formação das estratégias } \\
\text { de vendas e análise dos } \\
\text { modelos } \\
\text { comportamentais do } \\
\text { público-alvo }\end{array}$ & Atos do Congresso Business Intuition & 978-85-89941-05-1 & p. $341-344$ & 2007 \\
\hline 49 & Ana Petry & $\begin{array}{l}\text { Intuição e mitos } \\
\text { brasileiros }\end{array}$ & Atos do Congresso Business Intuition & 978-85-89941-05-1 & p. $345-348$ & 2007 \\
\hline
\end{tabular}


Saber Humano, ISSN 2446-6298, V. 9, n. 15, p. 186-423, jul./dez. 2019.

\begin{tabular}{|c|c|c|c|c|c|c|}
\hline 50 & Pieroni Fausto & $\begin{array}{l}\text { O critério dos clientes na } \\
\text { formação profissionais }\end{array}$ & Atos do Congresso Business Intuition & $978-85-89941-05-1$ & p. $349-353$ & 2007 \\
\hline 51 & Paolo Saibeni & $\begin{array}{l}\text { Do Marketing de Massa } \\
\text { ao Marketing Holístico }\end{array}$ & Atos do Congresso Business Intuition & $978-85-89941-05-1$ & p. $354-360$ & 2007 \\
\hline 52 & Soraia Schutel & $\begin{array}{l}\text { Como entrar na } \\
\text { estratégia do business }\end{array}$ & Atos do Congresso Business Intuition & $978-85-89941-05-1$ & p. $361-367$ & 2007 \\
\hline 53 & Lucio Silvestri & $\begin{array}{l}\text { Relação funcional com a } \\
\text { Administração Pública }\end{array}$ & Atos do Congresso Business Intuition & $978-85-89941-05-1$ & p. $368-370$ & 2007 \\
\hline 54 & Alexey Suhan & $\begin{array}{l}\text { A Memética e a } \\
\text { Psicologia Social, ou } \\
\text { então, como tomar e } \\
\text { manter o poder usando a } \\
\text { mídia }\end{array}$ & Atos do Congresso Business Intuition & $978-85-89941-05-1$ & p. $371-376$ & 2007 \\
\hline 55 & Larisa Tsvetkova & $\begin{array}{l}\text { Orientações Estratégicas } \\
\text { de desenvolvimento da } \\
\text { Faculdade de Psicologia } \\
\text { da Universidade Estatal } \\
\text { de São Petesburgo }\end{array}$ & Atos do Congresso Business Intuition & 978-85-89941-05-1 & p. $377-381$ & 2007 \\
\hline
\end{tabular}


Saber Humano, ISSN 2446-6298, V. 9, n. 15, p. 186-423, jul./dez. 2019.

\begin{tabular}{|c|c|c|c|c|c|c|}
\hline 56 & Elena Us & $\begin{array}{l}\text { Intuição: visão da ação } \\
\text { ou imagem da } \\
\text { consciência }\end{array}$ & Atos do Congresso Business Intuition & $978-85-89941-05-1$ & p. $382-387$ & 2007 \\
\hline 57 & Elena Us & $\begin{array}{l}\text { Os conceitos da intuição } \\
\text { na Filosofia e a intuição } \\
\text { prática na Ontopsicologia }\end{array}$ & Atos do Congresso Business Intuition & $978-85-89941-05-1$ & p. 388-393 & 2007 \\
\hline 58 & Alécio Vidor & $\begin{array}{l}\text { O resgate do Eu real } \\
\text { como fonte da intuição } \\
\text { científica }\end{array}$ & Atos do Congresso Business Intuition & $978-85-89941-05-1$ & p. 399-402 & 2007 \\
\hline 59 & Tatyana Vinokourova & $\begin{array}{l}\text { Princípio da escolha dos } \\
\text { empregados }\end{array}$ & Atos do Congresso Business Intuition & $978-85-89941-05-1$ & p. $403-408$ & 2007 \\
\hline 60 & Ekaterina Yudina & Intuição e Memética & Atos do Congresso Business Intuition & $978-85-89941-05-1$ & p. $409-412$ & 2007 \\
\hline
\end{tabular}




\section{TRABALHOS DE INICIAÇÃO CIENTÍFICA FINALIZADOS E AINDA NÃO} PUBLICADOS

\section{MOSTRAS DE INICIAÇÃO CIENTÍFICA DO CURSO DE BACHARELADO EM ONTOPSICOLOGIA}

\section{FACULDADE ANTONIO MENEGHETTI}

\begin{tabular}{|c|l|l|l|c|}
\hline No & \multicolumn{1}{|c|}{ Autor } & \multicolumn{1}{|c|}{ Título do Artigo } & \multicolumn{1}{c|}{ Curso } & Ano \\
\hline 1 & Celso Esperdião & $\begin{array}{l}\text { A importância do } \\
\text { tempo livre }\end{array}$ & Curso de Bacharelado em Ontopsicologia & 2018 \\
\hline 2 & Diogo Lauter & $\begin{array}{l}\text { Os jovens e a } \\
\text { tecnologia }\end{array}$ & Curso de Bacharelado em Ontopsicologia & 2018 \\
\hline
\end{tabular}


Saber Humano, ISSN 2446-6298, V. 9, n. 15, p. 186-423, jul./dez. 2019.

\begin{tabular}{|c|l|l|l|c|}
\hline 3 & Keity Fernandes & $\begin{array}{l}\text { Formação da } \\
\text { personalidade através } \\
\text { dos estereótipos } \\
\text { aprendidos na infância }\end{array}$ & Curso de Bacharelado em Ontopsicologia & 2018 \\
\hline 4 & Pâmela Bortoluzi & $\begin{array}{l}\text { Moda e estética como } \\
\text { estilo de vida }\end{array}$ & Curso de Bacharelado em Ontopsicologia & 2018 \\
\hline
\end{tabular}

\begin{tabular}{|c|l|l|l|c|}
\hline 5 & Sabrina Raminelli Hall & $\begin{array}{l}\text { Contemplando águas } \\
\text { profundas: breves } \\
\text { acenos sobre o } \\
\text { inconsciente }\end{array}$ & Curso de Bacharelado em Ontopsicologia & 2018 \\
\hline 6 & Vinícius Camargo & $\begin{array}{l}\text { Dança: uma arte ou um } \\
\text { problema? }\end{array}$ & Curso de Bacharelado em Ontopsicologia & 2018 \\
\hline 7 & $\begin{array}{l}\text { Gustavo Henrique } \\
\text { Florêncio }\end{array}$ & $\begin{array}{l}\text { Ontopsicologia e vida } \\
\text { cotidiana }\end{array}$ & $\begin{array}{l}\text { Curso de Bacharelado em Ontopsicologia } \\
2018\end{array}$ & 2018 \\
\hline 8 & Ivo Canísio Mallmann & $\begin{array}{l}\text { Heisenberg } \\
\text { (transcrição e tradução } \\
\text { de vídeo originalmente } \\
\text { em } \\
\text { língua alemã) }\end{array}$ & Curso de Bacharelado em Ontopsicologia & \\
\hline
\end{tabular}


Saber Humano, ISSN 2446-6298, V. 9, n. 15, p. 186-423, jul./dez. 2019.

\begin{tabular}{|c|c|c|c|c|}
\hline 9 & $\begin{array}{l}\text { Luiz Victor Azevedo } \\
\text { Gazzanéo }\end{array}$ & $\begin{array}{l}\text { O paradoxo entre o } \\
\text { problema crítico do } \\
\text { conhecimento }\end{array}$ & Curso de Bacharelado em Ontopsicologia & 2018 \\
\hline 10 & $\begin{array}{l}\text { Natália dos Santos } \\
\text { Conceição }\end{array}$ & $\begin{array}{l}\text { Metanoia: a identidade } \\
\text { ôntica no } \\
\text { projeto de vida }\end{array}$ & Curso de Bacharelado em Ontopsicologia & 2018 \\
\hline 11 & $\begin{array}{l}\text { Ricardo Rechden } \\
\text { Barcellos }\end{array}$ & Metanoia & Curso de Bacharelado em Ontopsicologia & 2018 \\
\hline 12 & Gustavo Fronza de Prá & Conhecimento que & Curso de Bacharelado em Ontopsicologia & 2018 \\
\hline
\end{tabular}

\begin{tabular}{|c|l|l|l|l|}
\hline & $\begin{array}{l}\text { porta a práxis da } \\
\text { autorrealização }\end{array}$ & \\
\hline 13 & Breno Prado da Silva & $\begin{array}{l}\text { Fundamentação } \\
\text { PréSocrática da } \\
\text { Ontopsicologia }\end{array}$ & Curso de Bacharelado em Ontopsicologia \\
\hline 14 & Everaldo Vieira & $\begin{array}{l}\text { Aceno sobre os } \\
\text { estereótipos dos } \\
\text { jovens na ótica } \\
\text { ontopsicológica }\end{array}$ & Curso de Bacharelado em Ontopsicologia & 2018 \\
\hline
\end{tabular}


Saber Humano, ISSN 2446-6298, V. 9, n. 15, p. 186-423, jul./dez. 2019.

\begin{tabular}{|c|l|l|l|c|}
\hline 15 & Felipe Carpes Irala & $\begin{array}{l}\text { O modo como o jovem } \\
\text { enfrenta a frustrações }\end{array}$ & Curso de Bacharelado em Ontopsicologia & 2018 \\
\hline 16 & Juliana Fick & $\begin{array}{l}\text { A psicologia feminina } \\
\text { como possibilidade de } \\
\text { conhecimento integral } \\
\text { à mulher }\end{array}$ & $\begin{array}{l}\text { Curso de Bacharelado em Ontopsicologia } \\
2018\end{array}$ & 2018 \\
\hline 17 & Karine Pereira Veleda & $\begin{array}{l}\text { Os vícios mais } \\
\text { difundidos entre os } \\
\text { jovens }\end{array}$ & Curso de Bacharelado em Ontopsicologia & 2018 \\
\hline 18 & $\begin{array}{l}\text { Maria Clara Mahlke } \\
\text { Ranoff }\end{array}$ & $\begin{array}{l}\text { Os sonhos na } \\
\text { Ontopsicologia: } \\
\text { aspectos e conceitos }\end{array}$ & Curso de Bacharelado em Ontopsicologia & \\
\hline
\end{tabular}

\begin{tabular}{|l|l|l|l|c|}
\hline & & $\begin{array}{l}\text { definidos na Ciência } \\
\text { de Antonio Meneghetti }\end{array}$ & & \\
\hline 19 & Raquel Gomes & $\begin{array}{l}\text { A importância do sono } \\
\text { segundo a } \\
\text { Ontopsicologia }\end{array}$ & Curso de Bacharelado em Ontopsicologia & 2018 \\
\hline 20 & Shayani Guaresi & O Líder Protagonista & Curso de Bacharelado em Ontopsicologia & 2018 \\
\hline
\end{tabular}


Saber Humano, ISSN 2446-6298, V. 9, n. 15, p. 186-423, jul./dez. 2019.

\begin{tabular}{|c|c|c|c|c|}
\hline 21 & $\begin{array}{l}\text { Fernando Duarte } \\
\text { Martins de Oliveira }\end{array}$ & $\begin{array}{l}\text { Pré-requisitos } \\
\text { conceituais à } \\
\text { compreensão do texto } \\
\text { Espicularidade e } \\
\text { Organísmico: o que são } \\
\text { relé, célula } \\
\text { fotoelétrica, monitor e } \\
\text { efeito estroboscópico }\end{array}$ & Curso de Bacharelado em Ontopsicologia & 2018 \\
\hline 22 & $\begin{array}{l}\text { Gustavo Henrique } \\
\text { Florêncio }\end{array}$ & $\begin{array}{l}\text { A formação da } \\
\text { personalidade do } \\
\text { profissional de } \\
\text { Ontopsicologia }\end{array}$ & Curso de Bacharelado em Ontopsicologia & 2018 \\
\hline 23 & Ivo Canísio Mallmann & $\begin{array}{l}\text { Alguns aspectos da } \\
\text { fronteira entre a } \\
\text { Mecânica Quântica e a } \\
\text { Ontopsicologia }\end{array}$ & Curso de Bacharelado em Ontopsicologia & 2018 \\
\hline
\end{tabular}

\begin{tabular}{|c|l|l|l|l|}
\hline 24 & $\begin{array}{l}\text { Luiz Victor Azevedo } \\
\text { Gazzanéo }\end{array}$ & $\begin{array}{l}\text { Considerações sobre a } \\
\text { relação entre } \\
\text { Ontopsicologia e } \\
\text { Língua }\end{array}$ & Curso de Bacharelado em Ontopsicologia & 2018 \\
\hline 25 & $\begin{array}{l}\text { Natália dos Santos } \\
\text { Conceição }\end{array}$ & Da díade à metanoia & Curso de Bacharelado em Ontopsicologia & 2018 \\
\hline
\end{tabular}


Saber Humano, ISSN 2446-6298, V. 9, n. 15, p. 186-423, jul./dez. 2019.

\begin{tabular}{|c|c|c|c|c|}
\hline 26 & $\begin{array}{l}\text { Ricardo Rechden } \\
\text { Barcellos }\end{array}$ & $\begin{array}{l}\text { Mecanismos de } \\
\text { Defesa: um Estudo } \\
\text { Ontopsicológico }\end{array}$ & Curso de Bacharelado em Ontopsicologia & 2018 \\
\hline 27 & Délis Stona & $\begin{array}{l}\text { Ontopsicologia e } \\
\text { Psicologia: a função } \\
\text { principal que distingue } \\
\text { essas duas grandes } \\
\text { Ciências }\end{array}$ & Curso de Bacharelado em Ontopsicologia & 2017 \\
\hline 28 & Marcela Anton & $\begin{array}{l}\text { Indivíduo x sociedade: } \\
\text { o homem como } \\
\text { partícipe de valor para } \\
\text { a contribuição no } \\
\text { social }\end{array}$ & Curso de Bacharelado em Ontopsicologia & 2017 \\
\hline 29 & Ricardo Schaefer & $\begin{array}{l}\text { Em direção a novos } \\
\text { paradigmas da ciência: } \\
\text { a contribuição da }\end{array}$ & Curso de Bacharelado em Ontopsicologia & 2017 \\
\hline
\end{tabular}

\begin{tabular}{|l|l|l|l|l|}
\hline & & $\begin{array}{l}\text { Ciência } \\
\text { Ontopscológica }\end{array}$ & \\
\hline 30 & Belino Oliveira & Análise Onírica & Curso de Bacharelado em Ontopsicologia & 2016 \\
\hline
\end{tabular}




\begin{tabular}{|c|c|c|c|c|}
\hline 31 & Eunice Escosteguy & $\begin{array}{l}\text { Constante H: eidos de } \\
\text { Platão e Santo } \\
\text { Agostinho }\end{array}$ & Curso de Bacharelado em Ontopsicologia & 2016 \\
\hline 32 & Marcela Anton & $\begin{array}{l}\text { Como desenvolver } \\
\text { relações funcionais a } \\
\text { partir da díade }\end{array}$ & Curso de Bacharelado em Ontopsicologia & 2016 \\
\hline 33 & Marcelo Girarde & $\begin{array}{l}\text { Utilização do conceito } \\
\text { de univocidade para } \\
\text { validar a cientificidade } \\
\text { de uma análise }\end{array}$ & Curso de Bacharelado em Ontopsicologia & 2016 \\
\hline 34 & $\begin{array}{l}\text { Márcio Vieira dos } \\
\text { Santos }\end{array}$ & Do Ser; Do Em Si ôntico & Curso de Bacharelado em Ontopsicologia & 2016 \\
\hline 35 & Patrícia Rossato & O que é intuição & Curso de Bacharelado em Ontopsicologia & 2016 \\
\hline 36 & Rodrigo Sales Barbosa & $\begin{array}{l}\text { A metodologia } \\
\text { ontopsicológica como } \\
\text { instrumento de } \\
\text { exatidão no processo } \\
\text { legislativo }\end{array}$ & Curso de Bacharelado em Ontopsicologia & 2016 \\
\hline
\end{tabular}




\begin{tabular}{|c|c|c|c|c|c|}
\hline № & Nome do Aluno & Título do TCC & $\begin{array}{c}\text { Prof.(a) } \\
\text { Orientador(a) }\end{array}$ & $\begin{array}{c}\text { Prof.(a) } \\
\text { Membro Banca }\end{array}$ & $\begin{array}{c}\text { Prof.(a) } \\
\text { Membro Banca }\end{array}$ \\
\hline 1 & Carmen Ivanete d'Agostini Spanhol & $\begin{array}{l}\text { Fazer-se pessoa: a evolução pessoal de } \\
\text { mulheres de meia idade acadêmicas } \\
\text { do Bacharelado em Ontopsicologia }\end{array}$ & $\begin{array}{c}\text { Profa Dra Noemi } \\
\text { Boer }\end{array}$ & $\begin{array}{l}\text { Profa Ms. Maria } \\
\text { Tereza Andreola }\end{array}$ & $\begin{array}{c}\text { Profa Dra } \\
\text { Claudiane Weber }\end{array}$ \\
\hline 2 & Maria Adamoli & $\begin{array}{l}\text { Atravessamentos familiares e } \\
\text { socioculturais na formação da visão de } \\
\text { si: um estudo de natureza } \\
\text { (auto)biográfica }\end{array}$ & $\begin{array}{c}\text { Profa Dra Noemi } \\
\text { Boer }\end{array}$ & $\begin{array}{l}\text { Profa Ms. Maria } \\
\text { Tereza Andreola }\end{array}$ & $\begin{array}{l}\text { Profa Ms. } \\
\text { Juliane Neves } \\
\text { Fiorezi }\end{array}$ \\
\hline 3 & Maria Ragalzi Ferraz & $\begin{array}{l}\text { Jovens, ambição e escolha da carreira } \\
\text { profissional: um estudo introdutório } \\
\text { interdisciplinar entre Psicologia, } \\
\text { Educação e Ontopsicologia }\end{array}$ & $\begin{array}{l}\text { Profa Dra } \\
\text { Patrícia } \\
\text { Wazlawick }\end{array}$ & $\begin{array}{l}\text { Profa Ms. Maria } \\
\text { Tereza Andreola }\end{array}$ & $\begin{array}{c}\text { Prof. Esp. } \\
\text { Mestrando } \\
\text { Bruno Fleck da } \\
\text { Silva }\end{array}$ \\
\hline 4 & $\begin{array}{l}\text { Tereza Cristina Melo de Brito } \\
\text { Carvalho }\end{array}$ & Transformação Digital e a Liderança & $\begin{array}{c}\text { Profa Dra } \\
\text { Claudiane Weber }\end{array}$ & $\begin{array}{c}\text { Prof. Ms. } \\
\text { Wesley Lacerda } \\
\text { e Silva }\end{array}$ & $\begin{array}{l}\text { Prof. Dr. Felipe } \\
\text { Becker Nunes }\end{array}$ \\
\hline 5 & Andréa Ferreira Gomes & A presença de mulheres nos espaços & Profa $\mathrm{Dr}^{\mathrm{a}}$ & Profa Dra Helena & Prof. Esp. \\
\hline & & $\begin{array}{l}\text { de poder e decisão: e o desejo de fazer } \\
\text { a diferença }\end{array}$ & Carmen Spanhol & Biasotto & $\begin{array}{l}\text { Mestrando } \\
\text { Bruno Fleck da } \\
\text { Silva }\end{array}$ \\
\hline
\end{tabular}


Saber Humano, ISSN 2446-6298, V. 9, n. 15, p. 186-423, jul./dez. 2019.

\begin{tabular}{|c|c|c|c|c|c|}
\hline 6 & Claudia Maria Vicentini & $\begin{array}{l}\text { O impacto do jardim e o contato com a } \\
\text { terra como ponto de retomada e } \\
\text { reforço da autoestima }\end{array}$ & $\begin{array}{c}\text { Profa Dra } \\
\text { Claudiane Weber }\end{array}$ & $\begin{array}{l}\text { Prof. Esp. Almir } \\
\text { Francisco Foletto }\end{array}$ & $\begin{array}{l}\text { Profa } \\
\text { Ms./Doutoranda } \\
\text { Fernanda } \\
\text { Martins }\end{array}$ \\
\hline 7 & Ricardo Schaefer & $\begin{array}{l}\text { Empreender como uma forma de ser, } \\
\text { saber e fazer }\end{array}$ & $\begin{array}{l}\text { Profa Dra } \\
\text { Patrícia } \\
\text { Wazlawick }\end{array}$ & $\begin{array}{c}\text { Profa Dra Noemi } \\
\text { Boer }\end{array}$ & $\begin{array}{l}\text { Prof. Dr. } \\
\text { Armando João } \\
\text { Dalla Costa }\end{array}$ \\
\hline 8 & Rosane Maria Neves & $\begin{array}{l}\text { Proporção Estética aplicada: proposta } \\
\text { funcional de aprendizagem empresarial }\end{array}$ & $\begin{array}{c}\text { Profa Dra } \\
\text { Claudiane Weber }\end{array}$ & $\begin{array}{c}\text { Profa Dra Helena } \\
\text { Biasotto }\end{array}$ & $\begin{array}{l}\text { Prof. Esp. Almir } \\
\text { Francisco Foletto }\end{array}$ \\
\hline 9 & Rosângela Alves Nabarros & $\begin{array}{l}\text { A educação empresarial no processo de } \\
\text { formação de gestoras }\end{array}$ & $\begin{array}{l}\text { Prof. Ms. } \\
\text { Wesley Lacerda } \\
\text { e Silva }\end{array}$ & $\begin{array}{c}\text { Profa Dra Helena } \\
\text { Biasotto }\end{array}$ & $\begin{array}{l}\text { Prof. Esp. Almir } \\
\text { Francisco Foletto }\end{array}$ \\
\hline 10 & Patrícia Gabriela Bilha Salles & $\begin{array}{l}\text { Vestindo a luza da alma: minha arte é } \\
\text { costurar }\end{array}$ & $\begin{array}{l}\text { Prof. Dr. } \\
\text { Josemar Sidinei } \\
\text { Soares }\end{array}$ & $\begin{array}{c}\text { Profa Ms. Janine } \\
\text { Ouriques }\end{array}$ & $\begin{array}{c}\text { Profa Ms. } \\
\text { Carolina } \\
\text { Schuskel } \\
\text { Miranda } \\
\text { Profa Esp. Any } \\
\text { Regina } \\
\text { Rothmann }\end{array}$ \\
\hline 11 & Mariana de Brito Araújo & $\begin{array}{l}\text { Roma, fonte do Humanismo Clássico: } \\
\text { do Direito às Belas Artes }\end{array}$ & $\begin{array}{l}\text { Prof. Dr. Josemar } \\
\text { Sidinei }\end{array}$ & $\begin{array}{l}\text { Prof. Ms. Lúcio } \\
\text { André Müller }\end{array}$ & $\begin{array}{l}\text { Prof. Esp. } \\
\text { Mestrando }\end{array}$ \\
\hline
\end{tabular}


Saber Humano, ISSN 2446-6298, V. 9, n. 15, p. 186-423, jul./dez. 2019.

\begin{tabular}{|c|c|c|c|c|c|}
\hline & & & Soares & Lorenzon & $\begin{array}{l}\text { Bruno Fleck da } \\
\text { Silva }\end{array}$ \\
\hline 12 & Hans Egon Horstmann & $\begin{array}{l}\text { Metafísica da Física: a relação crítica } \\
\text { entre o problema crítico do } \\
\text { conhecimento e a Ontopsicologia }\end{array}$ & $\begin{array}{l}\text { Profa Dra } \\
\text { Patrícia } \\
\text { Wazlawick }\end{array}$ & $\begin{array}{l}\text { Prof. Dr. Alécio } \\
\text { Vidor }\end{array}$ & $\begin{array}{l}\text { Prof. Dr. } \\
\text { Gilberto Orengo } \\
\text { Moreira }\end{array}$ \\
\hline 13 & Ademar Silva Júnior & $\begin{array}{l}\text { O conceito de Ecobiologia segundo a } \\
\text { Ontopsicologia aplicado à busca pela } \\
\text { identidade de um local: o case do } \\
\text { Espaço Valmar }\end{array}$ & $\begin{array}{l}\text { Profa Dra } \\
\text { Clarissa Mazon } \\
\text { Miranda }\end{array}$ & $\begin{array}{c}\text { Profa Dra } \\
\text { Claudiane Weber }\end{array}$ & $\begin{array}{l}\text { Prof. Esp. Almir } \\
\text { Francisco Foletto }\end{array}$ \\
\hline 14 & Adalberto Panzan Júnior & $\begin{array}{l}\text { Do nascimento do Eu à Psicologia da } \\
\text { Vitória: caso prático }\end{array}$ & $\begin{array}{l}\text { Profa Ms. Maria } \\
\text { Tereza Andreola }\end{array}$ & $\begin{array}{l}\text { Prof. Dr. Érico de } \\
\text { Lima } \\
\text { Azevedo }\end{array}$ & - \\
\hline 15 & Marcelo Pfleger & $\begin{array}{l}\text { A “primogenitura da alma” em } \\
\text { conquista: o processo de } \\
\text { conscientização da estrutura da } \\
\text { remoção individual }\end{array}$ & $\begin{array}{l}\text { Profa Ms. Maria } \\
\text { Tereza Andreola }\end{array}$ & $\begin{array}{l}\text { Prof. Dr. Érico de } \\
\text { Lima } \\
\text { Azevedo }\end{array}$ & $\begin{array}{l}\text { Profa Dra } \\
\text { Patrícia } \\
\text { Wazlawick }\end{array}$ \\
\hline 16 & Amauri Paulo Cervo & $\begin{array}{c}\text { Algumas considerações sobre a } \\
\text { linguagem não-verbal e sua possível } \\
\text { utilização na Ciência Jurídica }\end{array}$ & $\begin{array}{l}\text { Prof. Dr. Ricardo } \\
\text { Schaefer }\end{array}$ & $\begin{array}{c}\text { Prof. Dr. } \\
\text { Josemar Sidinei } \\
\text { Soares }\end{array}$ & $\begin{array}{l}\text { Prof. Dr. Rafael } \\
\text { Padilha dos } \\
\text { Santos }\end{array}$ \\
\hline 17 & Eunice Escosteguy & Informação ôntica: finalmente a Archè & $\begin{array}{l}\text { Prof. Dr. } \\
\text { Josemar Sidinei } \\
\text { Soares }\end{array}$ & $\begin{array}{c}\text { Prof. Esp. } \\
\text { Mestrando } \\
\text { Bruno Fleck da } \\
\text { Silva }\end{array}$ & $\begin{array}{l}\text { Prof. Ms. Egídio } \\
\text { Lasta }\end{array}$ \\
\hline
\end{tabular}


Saber Humano, ISSN 2446-6298, V. 9, n. 15, p. 186-423, jul./dez. 2019.

\begin{tabular}{|c|c|c|c|c|c|}
\hline 18 & Alessandra Heinz & Formar-se terapeuta: um estudo da & Profa & Prof. Esp. & Prof. Dr. \\
\hline & & $\begin{array}{c}\text { obra de Parmênides em busca dos } \\
\text { pressupostos para a formação do } \\
\text { Ontoterapeuta }\end{array}$ & $\begin{array}{l}\text { Ms./Doutoranda } \\
\text { Fernanda } \\
\text { Martins }\end{array}$ & $\begin{array}{l}\text { Mestrando } \\
\text { Bruno Fleck da } \\
\text { Silva }\end{array}$ & $\begin{array}{l}\text { Josemar Sidinei } \\
\text { Soares }\end{array}$ \\
\hline 19 & Carla Sewald Vieira & $\begin{array}{l}\text { Critério Organísmico: medida guia da } \\
\text { Ciência Ontopsicológica }\end{array}$ & $\begin{array}{l}\text { Profa } \\
\text { Ms./Doutoranda } \\
\text { Fernanda } \\
\text { Martins }\end{array}$ & $\begin{array}{l}\text { Prof. Dr. Horácio } \\
\text { Chikota }\end{array}$ & $\begin{array}{l}\text { Prof. Dr. Tommy } \\
\text { Akira Goto }\end{array}$ \\
\hline 20 & Délis Stona & $\begin{array}{c}\text { Vivenciando as características do Em Si } \\
\text { ôntico: o exemplo da Jornada da Vida e } \\
\text { do Weekend Life }\end{array}$ & $\begin{array}{l}\text { Profa Dra } \\
\text { Annalisa } \\
\text { Cangelosi }\end{array}$ & $\begin{array}{l}\text { Profa } \\
\text { Ms./Doutoranda } \\
\text { Fernanda } \\
\text { Martins }\end{array}$ & $\begin{array}{l}\text { Profa Dra } \\
\text { Patrícia } \\
\text { Wazlawick }\end{array}$ \\
\hline 21 & Gustavo dos Santos Oliveira & $\begin{array}{l}\text { Direito e Ontopsicologia: a análise da } \\
\text { aplicação do critério autopoiético } \\
\text { ôntico-humanista em decisão proferida } \\
\text { no Supremo Tribunal Federal }\end{array}$ & $\begin{array}{l}\text { Prof. Ms. } \\
\text { Matheus Renard } \\
\text { Machado }\end{array}$ & $\begin{array}{c}\text { Profa Dra } \\
\text { Rosane Leal da } \\
\text { Silva }\end{array}$ & $\begin{array}{l}\text { Profa Dra } \\
\text { Annalisa } \\
\text { Cangelosi }\end{array}$ \\
\hline 22 & Michael Fragomeni Penna & $\begin{array}{l}\text { Contribuição da Ciência } \\
\text { Ontopsicológica na metodologia } \\
\text { aplicada pela Orquestra Jovem } \\
\text { Recanto Maestro }\end{array}$ & $\begin{array}{l}\text { Profa Dra } \\
\text { Annalisa } \\
\text { Cangelosi }\end{array}$ & $\begin{array}{c}\text { Prof } \mathbf{a} \\
\text { Ms./Doutoranda } \\
\text { Fernanda } \\
\text { Martins }\end{array}$ & $\begin{array}{c}\text { Prof. Ms. Claudio } \\
\text { Carrara }\end{array}$ \\
\hline
\end{tabular}


Saber Humano, ISSN 2446-6298, V. 9, n. 15, p. 186-423, jul./dez. 2019.

\begin{tabular}{|c|c|c|c|c|c|}
\hline 23 & Vanessa Alves Nabarros & $\begin{array}{c}\text { Da formação acadêmica à formação } \\
\text { para a vida: o Bacharelado em } \\
\text { Ontopsicologia }\end{array}$ & $\begin{array}{l}\text { Profa } \\
\text { Ms./Doutoranda } \\
\text { Fernanda } \\
\text { Martins }\end{array}$ & $\begin{array}{l}\text { Profa Dra } \\
\text { Patrícia } \\
\text { Wazlawick }\end{array}$ & $\begin{array}{l}\text { Profa Dra } \\
\text { Annalisa } \\
\text { Cangelosi }\end{array}$ \\
\hline
\end{tabular}

\begin{tabular}{|c|c|c|c|c|}
\hline 24 & José Alfredo Nedel Filho & O cérebro visceral & $\begin{array}{c}\text { Prof. Dr. Horácio } \\
\text { Chikota }\end{array}$ & $\begin{array}{c}\text { Prof. Esp. Almir } \\
\text { Francisco Foletto }\end{array}$ \\
\hline $\begin{array}{c}\text { Profa Ms. } \\
\text { Juliane Neves } \\
\text { Fiorezi }\end{array}$ \\
\hline
\end{tabular}

